\title{
The Cultural Identity and Education of University Students in Selected East-Central Countries
}

A Polish-Czech Comparative Study

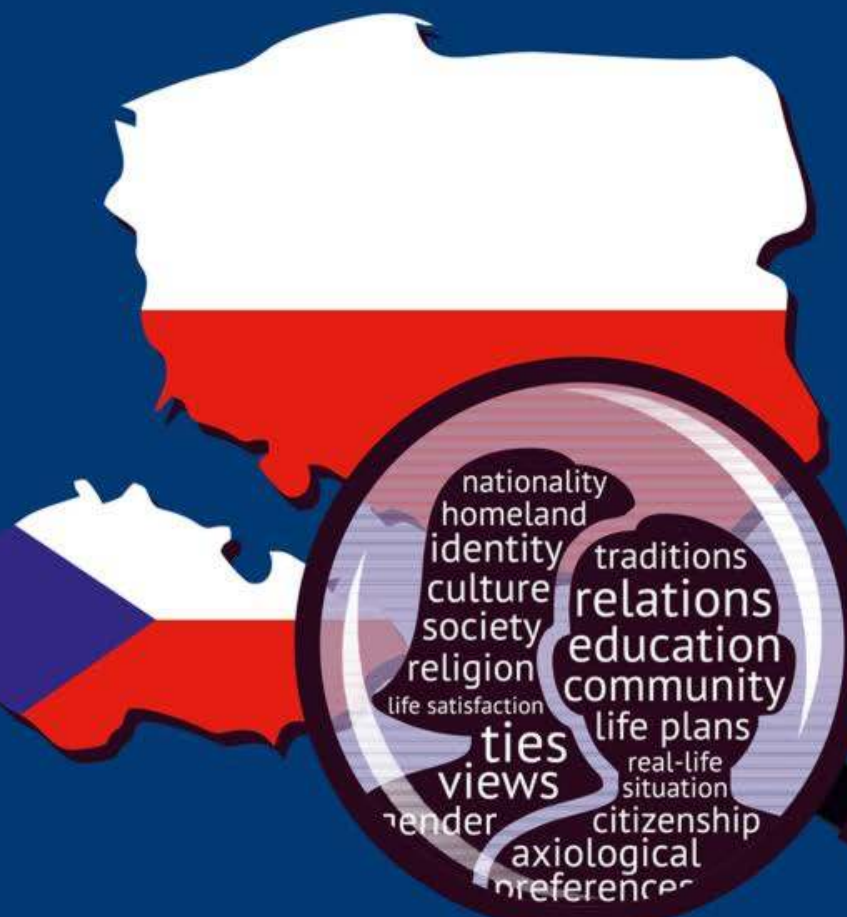


Open-Access-Publikation im Sinne der CC-Lizenz BY 4.0

(c) 2021, Vandenhoeck \& Ruprecht GmbH \& Co. KG, Göttingen ISBN Print: 9783847112549 - ISBN E-Lib: 9783737012546 
Ewa Ogrodzka-Mazur / Anna Szafrańska / Josef Malach / Milan Chmura

\section{The Cultural Identity and Education of University Students in Selected East-Central Countries}

A Polish-Czech Comparative Study

With 61 figures

V\&R unipress 
Republic of Poland

Bibliographic information published by the Deutsche Nationalbibliothek

The Deutsche Nationalbibliothek lists this publication in the Deutsche Nationalbibliografie; detailed bibliographic data are available online: https://dnb.de.

Funded by the "Excellent Science" program of the Minister of Science and Higher Education, agreement no. DNM/SP/465558/2020. The research grant was carried out at the University of Silesia in Katowice.

( 2 2021, Vandenhoeck \& Ruprecht GmbH \& Co. KG, Theaterstraße 13, 37073 Göttingen, Germany This publication is licensed under a Creative Commons Attribution 4.0 International license, at DOI 10.14220/9783737012546. For a copy of this license go to https://creativecommons.org/licenses/ by/4.0/.

Any use in cases other than those permitted by this license requires the prior written permission from the publisher.

Cover image: ๑ Anton Dragomiletskii

Reviewers: Sixto Cubo Delgado, William S. New

Translation: Agata Cienciała

Vandenhoeck \& Ruprecht Verlage | www.vandenhoeck-ruprecht-verlage.com

ISBN 978-3-7370-1254-6 


\section{Contents}

Preface $\ldots \ldots \ldots \ldots \ldots \ldots \ldots \ldots \ldots \ldots$

Introduction. The Polish-Czech borderland in a situation of social and cultural changes - the characteristics of the environment and the surveyed groups . . . . . . . . . . . . . .

Theoretical and methodological assumptions of the research . . . . . .

Chapter 1 . The cultural identity of young university adults - individual and community resources in building the social capital of the borderland . . . . . . . . . . . . . . . . 37

1.1. Cultural identity - the essence and scope of the notion . . . . . 37

1.2. Emerging adulthood - identity forming in the period of early

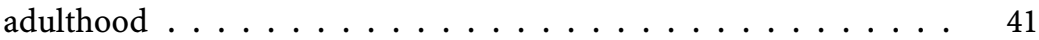

1.3. The dilemmas of constructing individual cultural identity in the

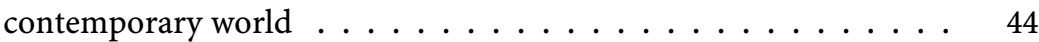

1.4. Identity in the educational perspective . . . . . . . . . 48

1.5. Identity behaviours manifested by university students from the Polish-Czech borderland - research results . . . . . . . . . 50

1.5.1. Axiological preferences . . . . . . . . . . . . 51

1.5.2. Feeling of identity and national identifications - towards a multidimensional identity . . . . . . . . . . . 55

1.5.3. Feeling of association with selected social groups . . . . . 61

1.5.4. One's own life situation and satisfaction from it versus the

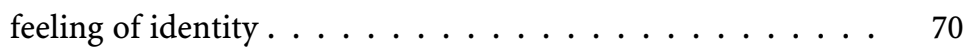

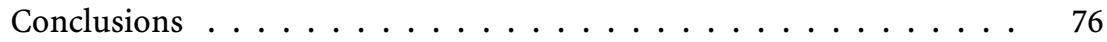


Chapter 2. A difficult history - what about the present day? Borderland relationships in the declarations of surveyed university students . . . . . 79

2.1. A neighbour as the other or our own? The relationship between Poles and Czechs in the region $\ldots \ldots \ldots \ldots$. . . . . 81

2.2. Learning from the neighbour in the declarations of Polish and Czech students . . . . . . . . . . . . . . . . . . 89

2.3. The perception of mixed marriages . . . . . . . . . . . . . . 98

Conclusions ......................... 103

Chapter 3. Pathways to higher education and its value . . . . . . . . . 107

3.1. Theory and practice for a future career . . . . . . . . . . . . . 111

3.1.1. The thoretical knowledge students acquire during their studies . . . . . . . . . . . . . . . . . . . . 115

3.1.2. Practical skills acquired by students during their university studies . . . . . . . . . . . . . . . . . . . . . 117

3.1.3. The interrelations of theory and practice in individual

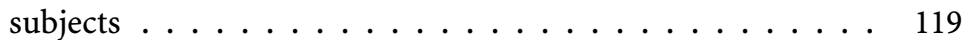

3.2. Value of higher education . . . . . . . . . . . . . . . . . . . . . . . . . . . . 123

3.3. People at university . . . . . . . . . . . . . . . . . . . . . . . . . . . . 128

3.3.1. The relationship of academic staff and students . . . . . . . 137

3.3.2. Quality of the student's life . . . . . . . . . . . . . 139

3.4. The conditions and process of university studies . . . . . . . . 142

3.4.1. The study environment created by the university . . . . . . 145

3.4.2. Quality of education . . . . . . . . . . . . . . 147

3.4.3. The approaches and methods used by teachers in the course of examination and evaluation of students . . . . . . . . . 149

3.4.4. The overall influence of the university on students' comprehensive development . . . . . . . . . . 152

Conclusions . . . . . . . . . . . . . . . . . . . 155

Chapter 4. University students studying and working abroad, their field of study and the university . . . . . . . . . . . . . . . 157

4.1. University students studying and working abroad . . . . . . . . . 160

4.2. University students studying and working abroad - descriptive and hypotheses testing results . . . . . . . . . . . . 163

4.2.1. University students studying abroad . . . . . . . . . . . . . . . . 164

4.2.2. University students working abroad . . . . . . . . . . . . . . 165

4.2.3. Students' willingness to study abroad . . . . . . . . . 166

4.2.4. Students' willingness to work abroad . . . . . . . . . . . . 167

4.3. The feeling of citizenship - correlation analysis . . . . . . . . 167 
4.4. Teachers' professional qualities and prospects . . . . . . . . . 171

4.5. Students' professional qualities and prospects - descriptive and hypotheses testing results . . . . . . . . . . . . 177 4.5.1. The suitability of the acquired education for the profession . 177 4.5.2. Opportunities for students' development after their studies . 178 4.5.3. Assessment of the students' own professional qualities . . . . 180 4.5.4. Prospects for getting a job in accordance with students' acquired education . . . . . . . . . . . . 182

4.5.5. The status of an individual with education in the studied field . . . . . . . . . . . . . . . . . . . . . . . . . 183

4.6. Students' feeling of bonds with the academic community at their university - a correlation analysis . . . . . . . . . . . . . . 184

4.7. The image of the university and the attractiveness of the study field

4.7.1. The image of the university and the attractiveness of the study field - descriptive and hypotheses testing results . . . 188

4.7.2. The image of the university and the attractiveness of the study field - correlation analysis . . . . . . . . . . 191

Conclusions

Ending

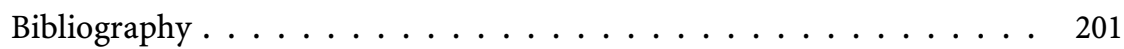

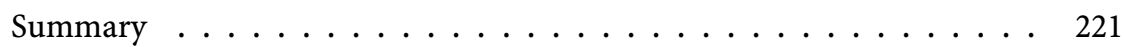

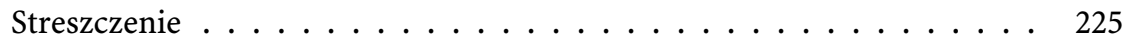

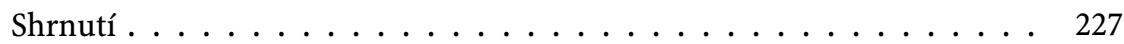

Biographical notes ... . . . . . . . . . . . . . 229

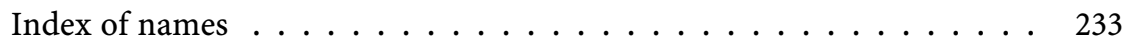

Index of subjects $\ldots \ldots \ldots \ldots 237$ 
Open-Access-Publikation im Sinne der CC-Lizenz BY 4.0

(c) 2021, Vandenhoeck \& Ruprecht GmbH \& Co. KG, Göttingen ISBN Print: 9783847112549 - ISBN E-Lib: 9783737012546 


\section{Preface}

The idea to write a joint book dedicated to university students was born during a one-month scholarly stay at Curtin University in Perth, Western Australia, at the end of 2017. The student and academic community in this relatively remote corner of the world and the staff of the Polish and Czech universities met on several formal and informal occasions, which manifested many clear signs of a multicultural environment - an environment of cooperation, the respecting of differences, and granting the same rights and having the same requirements for each student. The direct experiences of the diverse and enriching environment of the Australian university enhanced the germinating idea of examining students and their views on their life, surroundings and academic environment in the border regions of Poland and the Czech Republic, where the authors' universities are based.

The issue of the identity of young people living in borderlands is topical due to the decomposing tendencies in the populations of most European countries, as well as an apparent disappointment with "European" politics. From this point of view, the appeal of populism, protection of national interests, the ignoring of divergent views, disregarding others and closing oneself within one's own borders, is anathema to the broader European project. A more attractive attitude is to get to know each other better, to explore what we have in common and what makes us unique and different from others. The authors of this book promote an alternative way of living together and make efforts to find unity within the diversity of opinions and ways of experiencing the social and academic environment of young Polish and Czech university students living in a place where two national cultures meet.

The topic of higher education and work of current students at home and abroad is studied in the context of European education and recent trends in the development of teaching and learning strategies and technologies. Contemporary university students are given many opportunities to visit foreign universities and familiarise themselves with other students and educational systems. They are also regularly asked by the authorities of their universities to 
conduct an evaluation of their education. It is therefore possible to assume that they have developed their own assessment competences, enabling them to assess their academic education and its effects on their further career and personal life in a quite qualified way.

This comparative study is the first in a series that will be developed in the future on the borderlands of other Central European countries.

The research in both countries was carried out with the use of one questionnaire in two national versions. The construction of its items, the interpretation of the obtained data and their comparison, as well as the search for the interrelationships between the obtained research findings and others were based on several theoretical concepts: an axiological concept of culture, the theory of transformation of individual experiences, the theory of cultural identity, the theory of identity behaviours, and the theory of intergroup contact and mutual intergroup differentiation. Other applied theoretical concepts comprised the constructivist perspective, the model of qualitative comparison of academic education, curriculum design and development theory and the higher education theory.

The first chapter, entitled "The Cultural Identity of University Students Individual and Community Resources in the Building of Social Capital in the Borderland", focuses on describing the issues of the shaping of the cultural identity of university students and their axiological preferences. It offers a new perspective on how to connect young adults from different social groups by shaping their multidimensional identity.

The second chapter, entitled "A Difficult History - What about the Present Day? Borderland Relations in the Declarations of the Surveyed University Students" provides some analyses of the attitudes of young Poles and Czechs living in a geographically close area towards their neighbours and neighbourhoods, and their views on how one nation can learn from another. Young university students' views on nationally mixed marriages are also noteworthy.

In the third chapter "Pathways to Higher Education and Its Value", the following issues are examined: the effects of the university curriculum, the value of higher education, the cooperation of people in the university environment, the perception of the quality of the learning environment, and the assessment of educational quality and of the study environment.

The fourth chapter "University Students Studying and Working Abroad" comprises an analysis of the respondents' links to the foreign labour market and their possible study experience abroad, as well as a presentation of students' future intentions in both directions. It also provides a comparison of students' answers to questions about the attractiveness of their field of study and its contribution to establishing professional prospects. 
This book can be useful for professionals interested in the issues of national identity in the changing political, economic, cultural and technological conditions in which university students live and study. Similarly, some inquisitive residents of the Polish and Czech borderland can discover what young people on the other side of the border think about their identity, how they evaluate many social phenomena, how they experience their university studies and assess their prospective usefulness. It can be assumed with certainty that the students themselves, not only those from the universities where the interview was conducted but also others in this region in both countries, will be interested in the lives of their colleagues from both sides of the Olza River.

The authors would like to thank the authorities of their faculties, the Faculty of Art and Educational Science (based in Cieszyn) of the University of Silesia in Katowice and the Faculty of Education of the University of Ostrava in Ostrava, Czech Republic for their administrative and financial support needed to complete this book successfully. Deep gratitude should also be expressed for the three statisticians who processed the data - Wojciech Mazur, Agnieszka GajdzicaPeppard and Tomáš Barot, as well as to Andrzej Szczurek and Tatiana Havlásková for administering the online questionnaire.

The authors would also like to thank their families for understanding and supporting the work on the book while others were enjoying their summer holidays. The translator deserves due respect as well for their interpretation of a demanding text from Polish and Czech into English. 
Open-Access-Publikation im Sinne der CC-Lizenz BY 4.0

(c) 2021, Vandenhoeck \& Ruprecht GmbH \& Co. KG, Göttingen ISBN Print: 9783847112549 - ISBN E-Lib: 9783737012546 


\section{Introduction.}

\section{The Polish-Czech borderland in a situation of social and cultural changes - the characteristics of the environment and the surveyed groups}

The issues of borderland communities, especially of the Polish-Czech borderland, have been examined in many works. The studies have been published by the Social Team for Research into Borderland Culture and Education at the Faculty of Arts and Educational Science in Cieszyn ${ }^{1}$ - a unit of the University of Silesia in Katowice, as well as by the academic staff of the Faculty of Education at the University of Ostrava ${ }^{2}$. The works constitute a report showing the important political and social transformations taking place in Poland and the Czech Republic. The origin of these changes, initiated in 1989 - when both countries became democratic states, based on a free market economy and political and cultural pluralism - can be sought as early as the post-war years. The introduction of the socialist system (aspiring to communism) after World War II in both countries, which was based on authoritarian foundations, was contradictory to earlier systems and social norms. Many events which had taken place before 1989 were crucial for the changes in the following years.

The Republic of Poland and the Czech Republic are situated in Central and Eastern Europe. The binding political system in both states is parliamentary democracy. Despite the different sizes of territory and population, both countries

1 Until now, 80 books have been published in the series "Edukacja Międzykulturowa [Intercultural Education]", prepared by the University of Silesia, in particular the Social Team for Research on Borderland Education and Culture, the Department and Chair of General Pedagogy at the Faculty of Art and Educational Science in Cieszyn. The research was supervised by Tadeusz Lewowicki. The works focus on, e.g. the axiological dimension of socialization and education in family and at school; its association with the development and formation of the identity of children, youth and adults; nationally and/or religiously mixed marriages; the continuity and change of the transmission of language, tradition and cultural heritage across generations; intercultural dialogue and the transformations of contemporary family and school, determined by integration and globalization processes.

2 For many years, the Faculty of Education of the University of Ostrava has had the Center for Studies on European Identity. The Center's research is focused on the Silesian history in the context of Central European social and cultural history; on Czech-Polish relations; on religious and ethnic communities in the region and on the historical consciousness and ethnic and national stereotypes among school youth. More information https://pdf.osu.eu/csei. 
show a lot of similarity, mostly due to their close location and similar history, resulting from their geo-political conditions and common history - both societies have undergone similar historical and life experiences (from the period of partitions, through World War I and II, to imposing the socialist system and the supremacy of the USSR).

Poland and the Czech Republic have regained full political independence as a result of intensive political, socio-economic and cultural changes which have taken place since 1989. In Poland, this was brought about by the "round table" agreements, while in the Czech Republic - by the "velvet revolution". The multilayered transformation which took place then also triggered some changes in thinking about the role and function of culture, education, and school of that time. The reforms undertaken in both countries, also in the field of higher education, are reflected in the current social and cultural condition of the young generation, as well as in their aims, values and aspirations.

In the context of Grzegorz Babiński's hypothetical typology (2001, p. 77), the Polish-Czech borderland, which is the subject matter of this study, is an example of an old borderland. Its characteristic features are:

- a particular territory which can be spatially delineated;

- a history resulting from long social and cultural processes;

- mutual permeating of cultures;

- a lack of sharp divisions and boundaries between communities;

- a drifting apart from the majority's cultural domination towards the acceptance of subordinated cultures and more and more distinct cultural equality;

- the important significance of religious diversity;

- a floating economic and social diversification.

As a result of a long process of infiltration and the overlapping of different cultures, a specific type of community and its particular culture has come into being in this borderland (Chlebowczyk, 1983; Panic, 2015). Yet, its current characteristics are: the lack of sharp divisions and borderlines between communities; significant cultural, linguistic, ethnic and religious diversity; gradual acceptance of cultures and rather horizontal than vertical intercultural relations.

As stated by Babiński (2002, p. 15), "most of the current borderlands have generally lost their 'status' of a place where various - different and/or competing - centres of domination clash. Nowadays, they are a place of diffusion of cultures rather than of their domination, a place of transition rather than of rivalry or confrontation of various centres. Therefore, it is much more difficult now not only to demarcate the border areas themselves but also to indicate the most important borderlines between cultural differences and divisions. It is considered that this results from the changing relationships within the triad: politics (state) - culture - ethnic identities." This important assertion enables 
one to focus on the phenomena and problems which are directly and/or indirectly associated with the education of university students currently living in the borderland environment.

The functioning of university students in the borderland is associated with their natural experience of belonging to a particular social (e.g. national or cultural) group. This also enables self-identification, which constitutes the foundation for differentiating between Me-Us and Others-Them. The outer (attributing the membership) and/or inner (self-identifying) nature of identification, formed at many differently hierarchized platforms, shapes this cohort's feeling of identity (Lewowicki, 2009, pp. 249-261).

The research results of the studies conducted so far (Lewowicki, OgrodzkaMazur and Szczurek-Boruta, 2009; Lewowicki, Ogrodzka-Mazur and SzczurekBoruta, 2011; Kyuchukov, Lewowicki and Ogrodzka-Mazur, 2015; Lewowicki, Ogrodzka-Mazur, Chojnacka-Synaszko and Klajmon-Lech, 2018) on the feeling of identity among the communities of the Polish-Czech borderland in Cieszyn Silesia indicate that currently both the traditional (constant) elements and some new phenomena or processes take place. They are conditioned by the complexity and diversity of various (historical, sociocultural, cultural, personal and economic) determinants, which more accurately define the rapidly shaping identity of the younger generation. As the researchers who explore the development of the feeling of identity notice, in late childhood and adolescence - most of the individual's important and highly emotionally tinted experiences are associated both with tasks and self-image. It is the feeling of identity, shaping itself in this period, which enables a person to constantly aim at improving self-recognition and self-definition - at forming the individual personal and social identity. The functioning of youth in the family, school, peer and the broader surroundings in the diversified cultural environment, becomes a source of their various identity experiences - a feeling of unity, of separateness, and of continuity.

This process is determined by the specificity of the borderlands and one of the main assumptions in this process is that the way of shaping a person's feeling of individual and social identity leads through identification with a small community - the family, local or regional one. The values, symbols, ethnic patterns of culture, passed down by these communities, generate positive bonds in the process of institutional and non-institutional education. The borderland becomes a certain cultural space in which young people can broaden their knowledge of the problems and diversity of their local environment, the country, Europe, and the world. At the same time, they can take active part in a sociocultural life and experience specific social unity. First of all, this unity means the acceptance of common values and institutions. Secondly, it is based on a shared respect for socially prevailing behaviour patterns and methods of social control. Thirdly, this unity is treated as a form of social capital built on mutual social trust, 
supported by social relations. Fourthly, it is built on the feeling of belonging to particular communities and on their members' sharing a common cultural identity (Vasta, 2007; Grzymała-Kazłowska, 2013, pp. 31-52; Lompart, 2010). These distinguished dimensions show the crucial significance of identity and social relations for the inner integration of borderland communities, which might lead to so called "social anchoring". What takes place through this anchoring is socialization, understood by Mirosawa Marody and Anna GizaPoleszczuk (2004) as the process of including the individual into the network of relationships which form particular communities. The authors distinguish between the natural identity, typical of people living in traditional communities, the role identity - typical of the modern society in which people are linked through associations, and the contemporary Ego identity. This Ego identity dominates in the individualized post-modern society, in which individuals present themselves as autonomous but, at the same time, reflective creatures, aiming at preserving continuity and reliability and driven by the need of self-fulfilment.

The university students currently living in the Polish-Czech borderland are a new generation, and are markedly different from their earlier peers. This specificity and unlikeness has its sources in the sociocultural, political and economic situation of Poland, Europe and the world, which also constitutes an important reference point (Ogrodzka-Mazur, 2013, pp. 106-127). In the middle of accelerated globalization and transformation processes, the traditional order of values has been disturbed - the more accepted values now are those which refer to particular human, social or economic situations. The observation of social life indicates the relation between the contemporary cultural crisis and the crisis of orientation and the ability to evaluate which the young experience. Their world of values is largely rooted in the new culture, which has an impact on their lifestyle. Modern youth do not share any longer a common ideology, axiology, or communication code which they used to have in the post-war or post-communist years. They are a generation of growing diversity of attitudes and evaluative assessments - a specifically lost, reflective generation, who is focused on their own existence.

The processes of transformations in Poland, the Czech Republic and other countries of Central and Eastern Europe encouraged us in 2018 to undertake comparative team studies on the cultural identity and education of university students. The research comprised 330 university students - 164 in Poland (Cieszyn) and 166 in the Czech Republic (Ostrava). The sample is representative for pedagogy students educated at the University of Silesia and the University of Ostrava. 
The Faculty of Arts and Educational Science (earlier Cieszyn Branch) ${ }^{3}$ has been a part of the University of Silesia since 1971 and has undergone various transformations over these 47 years. During the last three decades, the units of the Faculty (institutes, departments and chairs) have elaborated upon some major research currents in their studies, and focused on the social, educational and cultural processes occurring in the Polish borderlands, especially the PolishCzech one. Due to its geographical location, the Faculty has acted in compliance with the European research space. The scientific activity of the Faculty is mostly associated with interdisciplinary research into the Polish-Czech borderland in Cieszyn Silesia. These studies deal with history, culture, education, intercultural education, and transfrontier collaboration.

Current scientific studies continue the previously conducted research, and also refer to the didactic activity aimed at educating students of the Faculty. The studies comprise the following areas:

- multisided borderland research (with particular regard to Polish-Czech and Polish-Slovak borderlands), exploring cultural, educational, religious and ethnic issues;

- anthropological issues of religion and folk culture (the sociocultural problems of the modern town, Poles in a multi-ethnic environment);

- the broadly understood areas of education and socialization (contemporary cultural education, the popularization of culture, family and school in the face of the reality and challenges of the $21^{\text {st }}$ century, school and pre-school didactics in regard to quality of teaching, the education and socialization of the disabled, language behaviour patterns in school and non-school environments, ICT education, including distance learning);

- the dilemmas of the modern philosophy of education; existential and axiological dimensions of truth, good and beauty.

Particularly intensive collaboration takes place between the Faculty and the University of Ostrava in the Czech Republic. This results from the close distance between Cieszyn and Ostrava (about $50 \mathrm{~km}$ ) and the hardly noticeable state border. The contacts between university teachers and students have a regular daily character. This collaboration involves the exchange of scientific and didactic experiences during research internships, cyclic didactic and training trips within the Erasmus+ programme and scientific conferences organized on both sides of the border. Moreover, the researchers from the University of Ostrava and

3 https://us.edu.pl/wydzial/wsne/ (access: 1.09.2020). 
the University of Silesia are partners in various international (also transfrontier) projects ${ }^{4}$.

The history of the Faculty of Education at the University of Ostrava ${ }^{5}$ dates back to 1953, but the status of an independent Faculty of Education was granted to it in 1964. An academic research centre was created soon thereafter and university teachers started to participate in the scientific and cultural life of the local and international environment. The University of Ostrava was founded in 1991 - the Faculty of Education, as the oldest independent, autonomous unit, became one of its three founding faculties. The other two were the faculty of natural sciences and the philological one. Currently, the Faculty of Education is one of the six faculties of the University of Ostrava (the other units are the faculties of arts, fine arts, social studies, science, and medicine). The Faculty of Education in Ostrava is an important research centre, which focuses on social and humanistic issues in the field of preparing teachers of all types and levels. The Faculty of Education consists of 14 chairs of various profiles and 4 research centres. Their researchers explore various subjects in compliance with the specificity of the academic units. This comprises the following areas of interest: - studies on Europeanness, European and regional identity, European political development in the pluralistic society; research into the history of Silesia and Polish-Czech relations; studies on religious and ethnic communities in the region, as well as on historical awareness and ethnic and national stereotypes among school youth (Centre for European Identity Studies);

- familiarization with the musical culture of the region of Ostrava and Austrian (Czech) Silesia in former centuries and in the recent past (Centre for Regional Studies on Music Culture);

- pedagogical and andragogical didactics in the context of preparing future teachers for their professional activity with the use of traditional and digital didactic means;

- educating learners with special educational needs, with various disabilities and disorders;

4 Among other projects, there are such joint undertakings as: International Research Network for the study and development of new tools and methods for advanced pedagogical science in the field of ICT instruments, e-learning and intercultural competences, financed by the European Commission under the $7^{\text {th }}$ Framework Programme, within the Marie Curie Actions International Research Staff Exchange Scheme, Grant Agreement No: PIRSES-GA-2013-612536, implemented: 1.01.2014-31.12.2017, http://www.irnet.us.edu.pl (access: 31.01.2019); High school teacher competence in change, financed by the International Visegrad Fund, project No 21720008, implemented: 01.01.2018-31.12.2018, http://histecc.kubg.edu.ua/en/ (access: 31.01.2019).

5 https://pdf.osu.cz (access: 1.09.2020). 
- pedagogical diagnosis and evaluation of the educational process; educational courses, theory and ideology, philosophy of education; comparative pedagogy and intercultural education;

- providing educational and psychological services for children and youth in schools, families and other social and educational environments.

In the academic year 2018/19, 518 students undertook both full-time and parttime studies in the course entitled pedagogy at the Faculty of Ethnology and Education of the University of Silesia. The required representative sample size was specified with the help of the sample size calculator. For the size of population, the following was assumed: fraction size 0.5 , confidence interval $85 \%$, maximum error 0.5 (the $9 \%$ error is still acceptable for concluding in social sciences, the estimation results are valid). As Dorota Węziak-Białowolska claims, concluding with a $15 \%$ error constitutes the lower limit for nonacceptance (2013). The representative size for Polish students was 148 people.

In the academic year 2018/2019, 2240 students were educated at the Faculty of Education in Ostrava. The research was conducted with the use of a questionnaire survey sent to students' by e-mail. The sample consisted of 166 respondents who had fulfilled the questionnaire. These were full-time and part-time students educated in various pedagogical courses both with and without teaching qualifications. The sample was representative with the assumption of a maximal error of $8 \%$.

The nationality composition was slightly different. This results from the fact that 2 respondents in Poland indicated their Czech nationality (students from Zaolzie) and 1 declared another (Ukrainian) nationality, whereas in the Czech Republic 2 students declared a different nationality than the Czech one. Altogether, 161 students declared Polish nationality (48.9 \%), 165 Czech nationality $(50.2 \%)$, and $3(0.9 \%)$ another nationality (cf. Figure 1 and 2$)$. One person did not declare their nationality at all.

The percentage of women in all groups of respondents was higher than of men. In total, the research involved 279 women $(84.5 \%)$ and 51 men $(15.5 \%)$. The group of Polish students was much more dominated by women - 159 female respondents $(97 \%)$ and only 5 men $(3 \%)$. The Czech group consisted of a relatively smaller percentage of women - 120 (72.3\%); while there were 46 male respondents $(27.7 \%)$ (cf. Figure 3 ).

Both in Poland and the Czech Republic, the binding system of higher education consists of two academic degrees - Bachelor (I degree) and Master (II degree) studies. The research involved 233 students (70.8 \%) of I degree and 96 students $(29.2 \%)$ of II degree. In the group from Poland, there were more II degree students than in the Czech one. The detailed data are provided in Figure 4. 


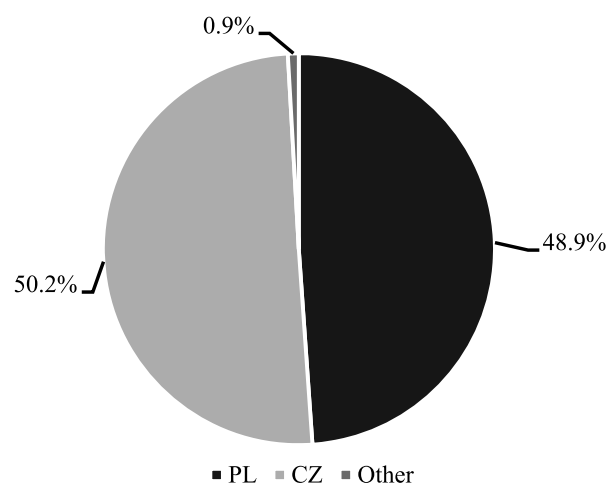

Figure 1. Surveyed students in regard to their declared nationality. Source: the authors' own research.

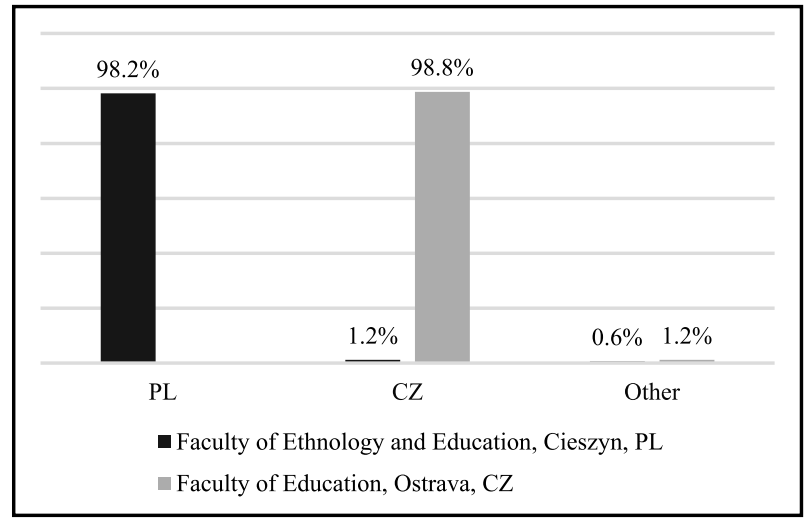

Figure 2. Surveyed students from PL and CZ in regard to their declared nationality. Source: the authors' own research.

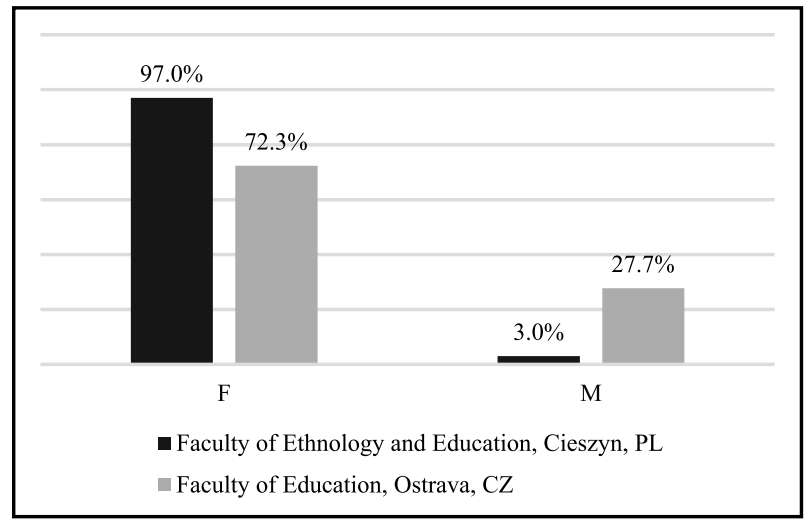

Figure 3. Surveyed students from PL and CZ in regard to sex. Source: the authors' own research. 


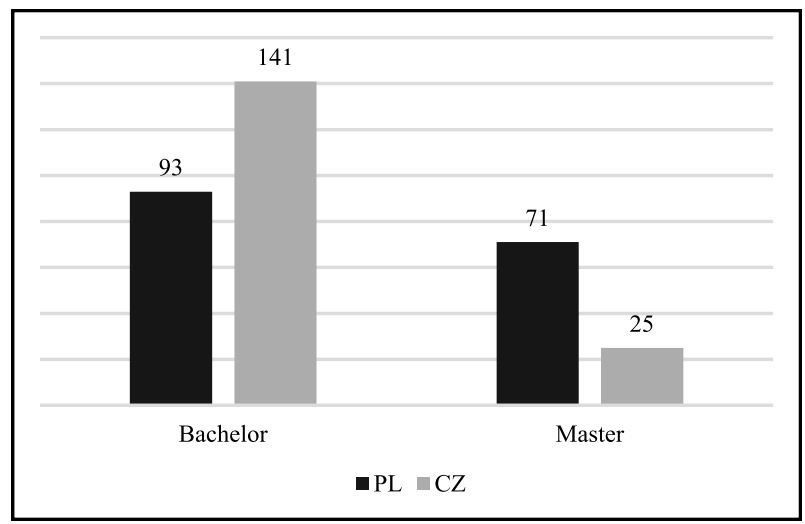

Figure 4. Surveyed students from PL and CZ in regard to the degree of university studies. Source: the authors' own research.

The declarations concerning the year of studies were submitted by 323 respondents. The largest number of students were the first year students of I degree (B.A.) studies. This concerns students from both countries - respectively 93 from $\mathrm{CZ}$ and 49 from PL. The second largest group are the second year students of II degree (M.A.) studies. A similar number represents the second year students of I degree - 59 respondents ( 32 from $\mathrm{CZ}$ and 27 from PL). The third year B.A. students as well as the first year M.A. students are represented by much smaller numbers (cf. Table 1).

Table 1. Students from PL and CZ in regard to the year of studies

\begin{tabular}{cccccccc}
\hline & & & I degree & \multicolumn{4}{c}{ II degree } \\
& & 1 & 2 & 3 & 1 & 2 & Total \\
\hline \multirow{2}{*}{ Students from PL } & Number & 49 & 27 & 13 & 26 & 42 & 157 \\
& $\%$ & 31.2 & 17.2 & 8.3 & 16.6 & 26.8 & 10 \\
Students from CZ & Number & 93 & 32 & 16 & 6 & 19 & 166 \\
& $\%$ & 56 & 19.3 & 9.6 & 3.6 & 11.4 & 100 \\
Total & Number & 142 & 59 & 29 & 32 & 61 & 323 \\
& $\%$ & 44 & 18.3 & 9.0 & 9.9 & 18.9 & 100 \\
\hline
\end{tabular}

Source: the authors' own research.

In Poland, the respondents were learners studying in both the full- and part-time system. Part-time studies are conducted on the weekends and are fee-paid. Most of the respondents were full-time students - 121 (73.8\%). 41 respondents ( $25 \%)$ declared they were part-time students.

The research sample of the Czech students is comprised of students of both full-time and combined studies. Full-time studies are a typical form of higher education requiring the attendance of students at classes, primarily in seminars and practical classes. Although the lectures are voluntary, students attend them 
frequently. The physical presence at seminars is compulsory. It is possible to complete distance education without physical attendance mainly via information and communication technologies, MOODLE-based educational courses, etc. The Act on Higher Education also recognises the third possible form of education, combined studies, a mixture of full-time and distant forms. Lessons take place once a week in an afternoon block or once a fortnight in a day-long block. Various institutions organise three-day-long blocks once a month. The combined studies are more demanding in terms of home preparation and require more self-learning.

Students keep contact with their teachers primarily through e-mail. Students also use scripts, digital MOODLE-based courses and other supportive materials and means. As for the number of subjects and credits, students are required to complete all subjects of their study plans and acquire the same amount of credits as full-time students. (111/1998 Act on Higher Education). The Czech students were not questioned about the form of their studies. 1088 (48 \%) of students from (out of 2240) the Pedagogical Faculty of the University of Ostrava are enrolled in the combined form. Therefore, it is possible to estimate that they are significantly represented in the research sample.

The respondents from Poland are students of the course pedagogy and they represent 6 specializations (cf. Figure 5). The biggest number -82 students $(50.3 \%)$ represent Integrated pre- and early school education (IPaESE). 31 students (19\%) represent Care and educational pedagogy with pedagogical therapy (CaEPwPT), 27 (16.6 \%) - Care and educational pedagogy with family assistance (CaEPwFA), 15 (9.2\%) - Integrated early school education with pedagogical therapy (IESEwPT), 5 (3.1\%) - Resocialization with intercultural education (RwIE), and 3 students (1.8\%) - Pre-school education with early developmental support (PSEwEDS).

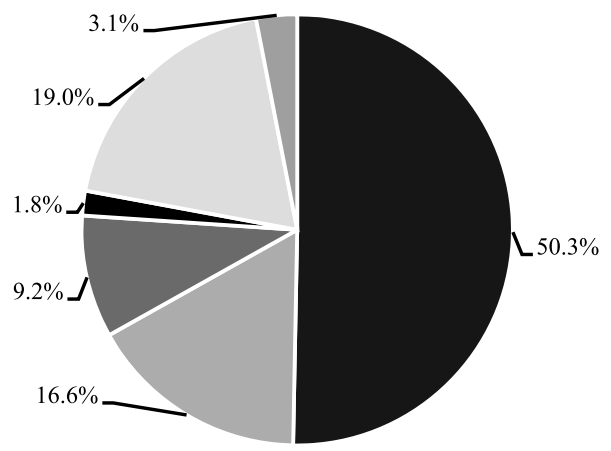

- IPaESE $=$ CaEPwFA $=$ IESEwPT - PSEwEDS $\approx$ CaEPwPT $\approx$ RwIE

Figure 5. Surveyed students from PL in regard to their specializations within the course Pedagogy. Source: the authors' own research. 
The surveyed Czech students can be divided into five groups. The first comprises 19 respondents $(11.4 \%)$ studying a teaching specialization and preparing for work at ISCED ${ }^{6} 0$ level - pre-school education and at ISCED 1 level - early school education. The second group consists of 87 respondents $(52.4 \%)$ studying a teaching specialization as well but preparing for work at ISCED 2 level - lower secondary education and at ISCED 3 - upper secondary education. The third group comprises 41 respondents $(24.6 \%)$ who are studying pedagogy without teaching qualifications (social pedagogy, andragogy and special education). The fourth group is composed of 9 students (5.5\%) of non-school recreation. The fifth group consists of 10 respondents $(6.1 \%)$ who, in their questionnaire, did not provide any information regarding which specialization they were studying.

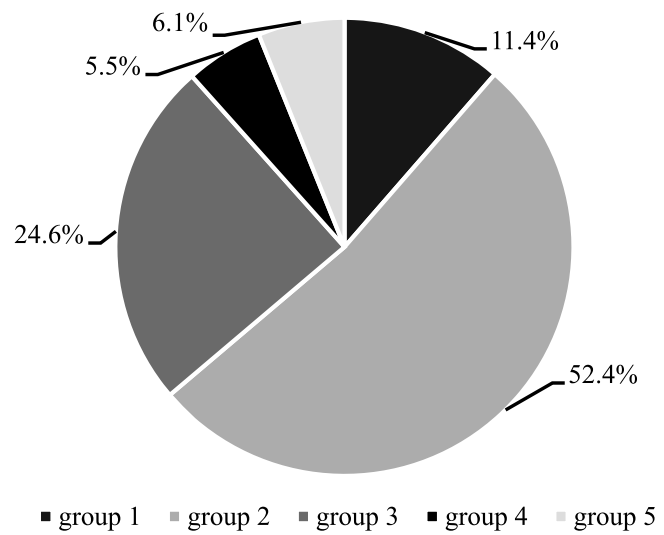

Figure 6. Surveyed students from $\mathrm{CZ}$ with the division into specializations within the pedagogy course. Source: the authors' own research.

The respondents were mostly aged 19-22 - such an age was indicated by 170 students (51.7\%). A similar number of respondents were aged 23-26-80 $(24.3 \%)$ and 27 years and older - 79 (24\%). Among students from Poland, there are much fewer people belonging to the oldest age group (cf. Figure 6 and 7).

In Polish and Czech pedagogy, there have not been many studies on the social, cultural and educational functioning of academic youth in a culturally diversified environment. The existing knowledge in this field, presented mostly within comparative pedagogy, is usually limited to presenting expert opinions on the state and situation of higher education in a particular country and the solutions applied there.

The analysis of identity behaviours presented by university students from the Polish-Czech borderland and of their learning potentialities will provide a

6 The International Standard Classification of Education (ISCED 2011, UNESCO); http://uis.une sco.org/en/isced-mappings. 


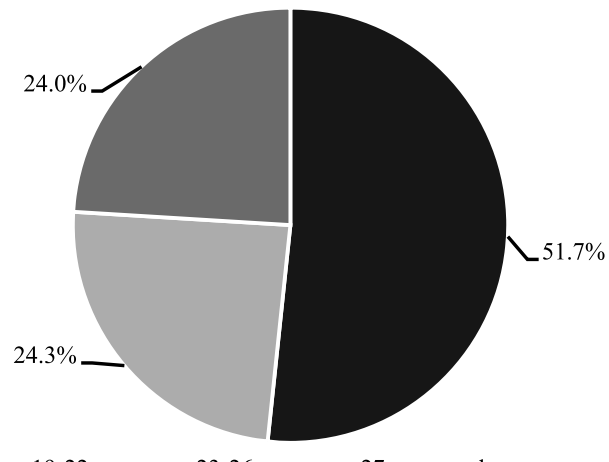

- 19-22 years $-23-26$ years -27 years and more

Figure 7. Surveyed students in regard to age groups. Source: the authors' own research.

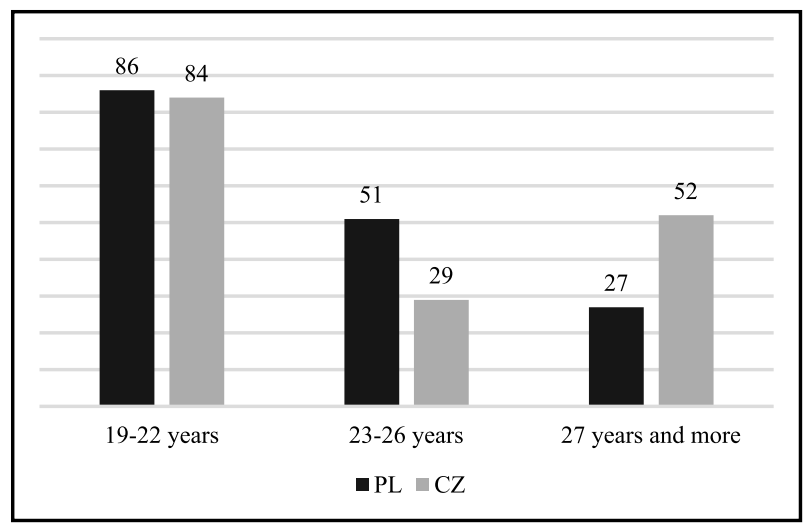

Figure 8. Surveyed students from PL and CZ in regard to age groups. Source: the authors' own research.

chance for mutual recognition, understanding and the enrichment of both cultures - along with providing a chance for cultural sensitization. Due to the applied culturalization attitudes, this will also enhance the participation in the culture of the neighbouring country and the shortening of cultural distance. Such studies are also associated with a reflection upon the way in which a contemporary human understands cultural dimensions, the role they play in human life and the scope in which they shape the individual's own and their social/ cultural identity. 


\section{Theoretical and methodological assumptions of the research}

In the pedagogical analysis of the undertaken issues concerning the cultural identity and education of young adults learning in a culturally diversified environment, some theoretical conceptualizations were applied related to Ward $\mathrm{H}$. Goodenough's (1) axiological concept of culture as a set of values. The concept was applied in its phenomenal order (the material manifestation of culture in the created products, behaviour patterns - also language-related ones - and social events) and ideational order (what people learn as members of culture, the standards which constitute the directly unobservable ideational order - the appropriate culture). In this sense, culture is not a material phenomenon, it does not consist of things, people, behaviours or feelings. It is rather a kind of organization of all these components. It is a form of what people keep in their mind, of their models of perceiving, associating and interpreting the world. Culture is a set of certain cognitive standards which regulate the way of individual participation in culture. They enable the interpretation of the senses of cultural activities and objects as well as allow for encompassing - with human thought - the reality which a particular society distinguishes notionally (Goodenough and Harris, 2006, pp. 13-20).

What was also referred to in the research was Ewa Ogrodzka-Mazur's (2) concept of borderland as a cultural category which comprises the sphere of the transformation of an individual's experiences. These experiences are characterized by:

- openness - understood as experiencing the Self (feeling of subjectivity) from the perspective of Otherness in the situation of daily co-existence among the representatives of other cultures;

- complexity - understood as accepting the consent for functioning and coexistence of ambivalent valuing orientations (judgements) which do not contradict each other as alternatives;

- polyphonity - as experiencing the dialogic, multidimensional relationship in the situation of contact with otherness; 
- being in culture (multiculturalism) - as experiencing the limits of one's own self-effectiveness and potentialities in making choices in the sphere of values and valuing (2007, p. 65).

The cultural identity of university students was specified in the context of Pawel Boski's (3) theory of cultural identity based on values and practices in the conditions of bi- and multicultural socialization. Cultural identity is approached here as "a relational notion which is the degree of convergence in the value between the individual Self and a positive cultural prototype or between the descriptive - for one's own culture - or its evaluative aspect" (Boski, 2009, p. 552; Boski, 2008a, pp. 165-205; Boski, 2008b, pp. 97-145). In the case of functioning on the edge of two cultures, what occurs is the identity with both these cultural systems and the integration of both components. In the author's research, two levels of each cultural system were distinguished - the symbolic and the axiological (values and practices), as well as a level comprising the following elements: (a) cultural knowledge, (b) language competences, (c) affective bonds, (d) the feeling of unlikeness and difficulty, (e) bicultural identity (preservation and acquisition), (f) one's own life situation and the satisfaction of it (Boski, 2009, pp. 548-564). Referring to the suggested model in pedagogical analyses assumes the possibility of cultural transmission in the conditions of an intentional learning process (i.e. in the family, school, peer group, local environment) and some experiences in the social discourse of a particular country. In comparison to the traditional concepts of enculturation, this also constitutes (Berry, 1994, pp. 253-257; Wysocka, 2003, pp. 74-79) the most complex construct which explores integration in its five senses: integration as a positive valuing of biculturalism; integration as bilingual/bicultural competence; integration as a "functional specialization"; integration as a new quality in which the components have been merged; and integration as psychological autonomy towards both initial cultures (Boski, 2009, pp. 542-547).

Another significant perspective in the search for some regularities which determine identity shaping in the changing environment of cultural diversity is Tadeusz Lewowicki's (4) theory of identity behaviours. This theory has made it possible to provide a holistic but simultaneously comparative approach to the processes and phenomena taking place in multicultural environments. In this theory, six fields (elements) of identity are distinguished: the first comprises history and identification with a particular territory and social group; the second is indicated by the unlikeness of culture, language, transmission of tradition, and the knowledge of the spiritual and material output of a particular community; the third is associated with a specific historical genealogy and some particular features of the group(s) and the stereotypes which function within it; the fourth concerns the economic condition and the group's living standards; the fifth is 
connected with its needs, life aims, and axiological preferences; and the sixth takes into account the political, ideological, social and economic context. All these fields of identity are important determinants of identity behaviours (Lewowicki, 1995a, pp. 51-63; Lewowicki 1995b, pp. 13-26).

What was also applied in the theoretical assumptions was (5) the theory of intergroup contact and mutual intergroup differentiation, which come from the contact hypothesis. In compliance with its broadened model (cf. Figure 9) the assumption was made that the effects $(\mathrm{C})$ of the intergroup contact between Polish and Czech students was a function ( $\mathrm{f}$ ) of a person $(\mathrm{P})$, a situation $(\mathrm{S})$ and a social context (SC): C = f (P + S + SC) (Stephan and Stephan, 1999, pp. 70-97; Hewstone, 1999, pp. 267-282).

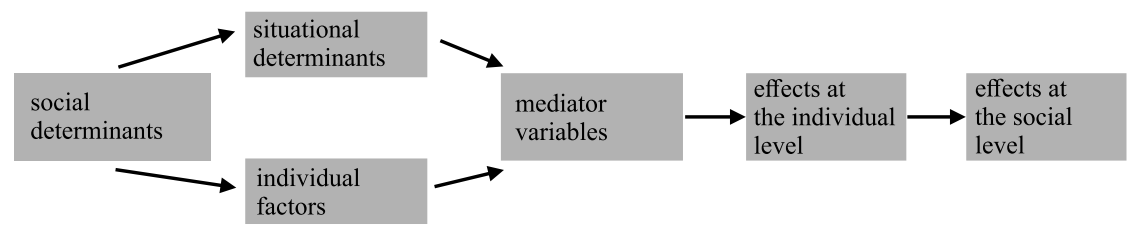

Figure 9. The casual model of the contact hypothesis. Source: Stephan and Stephan, 1999, p. 80.

Due to the sociocultural specificity of both investigated environments, the following components of the suggested model are distinguished:

- in the social context:

- the structure of groups (students' age, sex, course and year of studies, residence place, nationality, religion),

- the social and cultural determinants of the relationship between the contacting groups,

- the current relations between these groups,

- the course of culturalization and socialization processes in both groups;

- in the situational context:

- the surroundings in which the contact takes place,

- the character of the interaction,

- the composition of the groups,

- the tasks fulfilled by its members;

- within individual factors:

- demographic variables,

- personality traits,

- stereotypes, prejudices and other beliefs;

- within mediator variables:

- cognitive processes,

- emotional processes,

- behavioural processes; 
- within the effects on the individual level:

- beliefs (particularly stereotypes and prejudices),

- emotional reactions,

- behaviour;

- within the effects on the social level:

- changes in publicly manifested attitudes (especially in regard to stereotypes and prejudices),

- changes of social norms in groups.

The significance and usefulness of the presented model in the conducted pedagogical studies may firstly be specified in regard to the interactions among all factors which indicate all the existing casual relations. Secondly, the model suggests the existence (within each category) of several variables which might influence every situation in the intergroup contact. Thirdly, the model points to some factors which can be taken into consideration in an attempt to improve intergroup relations (Stephan and Stephan, 1999, pp. 81-83).

In the undertaken research, the (6) constructivist perspective was also applied, which consisted in emphasizing learners' activeness in the educational process and the resulting construction of their own educational reality. Students actively construct their knowledge instead of acquiring it as the knowledge provided by teachers - people are not recorders of information but constructors of their own knowledge (Bruner, 1996; Lunenburg, 1998, pp. 75-81). This way of understanding learning is rooted in the thought of John Dewey, Lev S. Vygotsky, George Kelly and in Jerome Bruner's theory of personal constructs, which treats knowledge as a form of intellectual representation, as the construction of the human mind (Shapiro, 1994, p. 3; Klus-Stańska, 2010; Gofron, 2013, pp. 159-173; Report, 2014). This approach seems particularly useful in the interpretation of university students' learning, which is understood as participation in constructing the social world and a common culture.

Due to the comparative character of the research, some references were made to Harold J. Noah's (7) model of qualitative comparison of academic education (Noah and Eckstein, 1988, pp. 165-192; Marshall, 2014). This referred to the case of Poland and the Czech Republic and took into account a description of the traditions and latest tendencies in higher education in both countries, namely, an analysis of university curricula, socio-economic and cultural contexts, some interpretations of the educational phenomena which might become change predictors, and statistical methods (Malach, Kostolánová, Chmura, OgrodzkaMazur and Szafrańska-Gajdzica, 2016, pp. 41-580).

Students, graduates and employers assess university studies by the degree of harmony between goals and content, as well as by the requirements of individual professions. 
"Our knowledge and understanding of student learning gleaned from the research literature indicates that the attention given to curriculum design and development (8), the planning of learning experiences and assessment of student learning, have a significant impact on students' approaches to learning" (Stefani, 2009).

Changes in the organisation of higher education, in all countries, are inevitably accompanied by changes in the goals and content of educational curricula, which should react to the advances in science, development of technology, as well as to the changes of sociocultural conditions. University studies focused on the acquiring of the qualifications required in different educational careers have reached the phase of stronger regulation on the part of decision-making authorities, both in terms of its professional profiling and the processes required for obtaining the implementation of accreditation by universities. According to the new legislation, it is possible to shift certain, so far centralised, powers to universities ${ }^{7}$.

National qualification frameworks for tertiary education, based on appropriate European frameworks, create a unified graduate's profile ${ }^{8}$ and provide information about the field of studies for potential employers throughout the European Union. Qualification frameworks may fulfil both communicative and regulative functions. All qualification frameworks have a communicative function, i. e. they contribute to the clarity of the qualification system, define system links among individual qualification levels and simplify their recognition and informal acceptation by the society and job marketplace by interpreting their implementation in the system. The communicative function is dominant in regional qualification frameworks. Several qualification frameworks also have a regulative function, i.e. define the learning results standard for individual qualification levels (Nantl, 2014).

In case a particular qualification system uses the concept of learning results, the qualification profile is operationalised via these results. Learning results are understood as the explicit expression of knowledge, skills and other competences a person must prove to receive qualification. By the nature of things, the results must be observable and assessable (Nantl, 2014). Thus, the novel "learning outcomes approach to curriculum design" (Stefani, 2009, CEDEFOP, 2016) was introduced. The curricular theory also calls for the further development of students' key, more recently transversal or transferable, competences elaborated in

7 After obtaining the institutional accreditation newly defined in The Higher Education Act. 8 European Qualification Framework - EQF is one of the European tools for clarity, transparency and comparability of educational system support. It eases orientation in qualification levels across Europe, simplifies study and work mobility, and supports lifelong learning. EQF recognizes eight qualification levels covering the entire scale of educational activities from primary school education up to the higher education. 
several geographically distinct frameworks 9 . Closely linked to the current job market, the catalogues of transversal key competences for employability are being prepared as well ${ }^{10}$.

The fact that the pedagogical professions, especially teaching, do not belong to the most attractive and/or desired professions, mainly due to low salaries, imposes higher demands on universities in attracting applicants for studies as well as in the implementation of curricula.

The creation of the research tool and further interpretation of the results was also related to the findings within the current higher education theory (9) (Biggs and Tang, 2011; Fry, Ketteridge and Marshall, 2009; Cleaver, Lintern and McLinden, 2014; Kasíková, 2015; Sajdak, 2013), which emphasizes the role of both subjects - the academic teacher and the engaged student. The requirements to develop university students through various methods and tools are introduced by the texts on university education (Sikorová et al. 2007; Rohlíková and Vejvodová, 2012; Slavík et al, 2012; Podlahová et al, 2012). Prusáková and Kariková (2011). Furthermore, Bajtoš (2013) and Ciechanowska (2009) emphasize that the success of studies largely depends on the independent work of a student, as well as on the autonomy of individuals manifested by the responsibility for their own development, their own choices, and the quality of learning and its effects. Bajtoš (2013) explored the problem of students' learning in terms of learning styles and approaches. The implementation of the European Credit Transfer and Accumulation System (ECTS) and the structuring of studies into two separate blocks brought about the possibility to organise one's entire studies or at least parts of them abroad and to recognise the education in all countries thanks to the application of the Framework for Qualifications of the European Higher Education Area (FQ-EHEA) (European Commission, 2015a; 2018). Structured studies were also introduced to the curricula focused on achieving the teaching qualification ${ }^{11}$. The development of digital technologies gradually leads to the preference of independent, personalised learning, making use of the potentialities in all various e-learning and social sites, which facilitates students' collaborative activities (Ogrodzka-Mazur, Szafrańska, Malach and Chmura, 2018a; Ogrodzka-Mazur,

9 The European Union formulated the concept of key competencies in the RECOMMENDATION OF THE EUROPEAN PARLIAMENT AND OF THE COUNCIL of $18^{\text {th }}$ December 2006 on key competences for lifelong learning (2006/962/ES) and the USA in the $21^{\text {st }}$ Century skills (The Mile Guide. Milestones for Improving Learning and Education. Partnership for $21^{\text {st }}$ Century skills, 2009). The materials of UNESCO: Transversal competencies in education and policy. Regional Synthesis report, Bangkok Office, 2015, introduces four competency domains: critical and innovative thinking, interpersonal skills, intrapersonal skills and global citizenships that are specified by several key characteristics.

10 Keystart to work, Project Erasmus+.

11 There is an exemption of the rule in both countries in unstructured five-year-long studies of primary education in the Czech Republic or kindergartens and primary education in Poland. 
Szafrańska, Malach and Chmura, 2018b; Ogrodzka-Mazur, Szafrańska, Malach and Chmura, 2017). University pedagogy, or andragogy ${ }^{12}$, is enriched by concepts of experiential learning and reflection (Kolb, 1984), transformative learning (Mezirow, 1997), deeper learning (Pellegrino, Hilton, 2012) and opened learning, mainly in connection with the application of MOOC in distance studies or blended-learning ${ }^{13}$. The recent trends are manifested more visibly in higher education than at other levels: technology-supported and distant learning, internationalisation, globalisation (international recognition of higher education, the application of the Bologna process, the establishment of foreign university branches, partnerships, joint degrees, or dual degrees study programmes); quality assurance and accountability (completing university studies, assuring the quality of learning, costs of education, indebtedness, cost compensation, and the responsibility of school management) (Wolff, 2015; Malach and Chmura, 2017).

Academic staff is the creator, the carrier and the keeper of academic culture. However, pedeutology, the science dealing with educational professions, has not paid due attention to this yet. Academic staff belongs to the group of the least researched professionals even though they fundamentally influence the quality of universities and their reputation - its categorisation or placement in any of the higher education rankings.

Turek et al. (2013) and Bajtoš (2013) differentiate the academic teacher's competences into the subject matter competence (in-depth knowledge of the subject), the scientific (ability to conduct scientific research), psychodidactic (ability to create suitable conditions for learning), communication, diagnostic, planning and organising, counselling, self-reflective and self-cultivating competences. Blašková, Blaško and Kucharčíková (2014) introduce a university teacher competence model consisting - apart from the previously mentioned also of moral-ethic, technical, scientific, didactic competences. Summan and Zitouni (2017) mention four sets of academic staff competences - professional, technological, humane and evaluative ones.

The recently organised project "High school teacher competence in change" (ID 21720008, 2017-2018), in which the authors of the book participated, of the Visegrad Fund of four countries (Ukraine, Poland, Czech Republic and Slovakia) contributed to the formation of the theory of academic culture. Three profiles of academic teachers integrating 14 professional competences were used - the professional, social \& personal, and academic (scientific) profile (Malach and Chmura, 2019). The higher education theory is enriched by the studies of Ke-

12 University students are considered adults from the point of view of andragogy (Fry, Kettridge, Marshall, 2009).

13 Other characteristics of the theoretical concepts: Bates, B. Learning theories simplified. Los Angeles: SAGE, 2019 or Bertrand, Y. Contemporary theories and practice in education. Madison: Atwood Publ. 2003. 
mény (2017), Bothwell (2018) and the European Commission's monitor ${ }^{14}$, stating that the "Demands on the higher education are rising, but inadequate attention is paid to the influence of the demands on academic staff."

In the authorial studies, four groups of problems were distinguished and formulated in the following scopes:

\section{Cultural identity and the manifested identity behaviours}

- What values do young university students recognize and to what extent does the culturally diversified environment determine their axiological preferences?

- What feeling of identity and national identifications are manifested by students in the examined multicultural environments from the angle of criterial identity attributes (knowledge of cultural symbols) and correlative ones (the behaviour which reflects normative assumptions and the values of a particular culture)?

- To what extent does the culturally diversified environment determine students' feeling of association with selected social groups?

- What is the relationship between one's own life situation, satisfaction with it, affective bonds, feeling of unlikeness or difficulty and the identity behaviours manifested by Polish and Czech university students?

\section{Intercultural competences}

- How do the respondents evaluate their intercultural competences and to what extent does one's place of residence determine their assessment?

- How do young university students evaluate the relationships between Poles and Czechs living in their region and to what extent does the place of studying determine their assessment?

- How do university students evaluate their attitude to Czechs/Poles?

- What symptoms of unwillingness or discrimination towards a person of a different nationality have the respondents directly experienced?

- What knowledge of their neighbours do students living in the borderland have?

- How do university students from both countries evaluate each other? What qualities, skills or activities do they consider beneficial and worth imitating in their own country?

- What - in the opinion of young university students - can Poles learn from Czechs and Czechs from Poles?

- What is the respondents' view on mixed marriages in their environment?

14 European Commission/EACEA/Eurydice, 2017. Modernisation of Higher Education in Europe: Academic Staff - 2017. Eurydice Report. Luxembourg: Publications Office of the European Union. 
- What problems and difficulties - in their opinion - can mixed marriages face and to what extent do the place of studying and the age determine their opinions?

\section{Quality of university studies}

- What is the difference between Polish and Czech students in the assessment of the quality of theoretical and practical training? Are the differences influenced by gender or year of study?

- What is the difference between Polish and Czech students in the estimation of higher education? Are the differences influenced by gender or year of study?

- What is the difference between Polish and Czech students in the evaluation of relationships among students and of students with academic staff? Are the differences influenced by gender or year of study?

- What is the difference between Polish and Czech students in the evaluation of conditions and processes of university studies? Are the differences influenced by gender or year of study?

- Is the student's evaluation of conditions and processes of university studies modified by the depth of relationships with the academic environment? Are the differences determined by gender or year of study?

IV. University students' studying and working abroad, their field of study and university

- What is the difference between Polish and Czech students in the number of students studying abroad or interested in studying abroad? Are the differences influenced by gender or year of study?

- What is the difference in the share of Polish and Czech students studying abroad and interested in studying abroad? Are the differences influenced by gender or year of study?

- Is the evaluation of some selected parameters of university studies influenced by the student's experience of studying abroad?

- What is the difference in the share of Polish and Czech students working before beginning their studies abroad or considering employment after finishing their studies abroad? Are the differences influenced by gender or year of study?

- Is the evaluation of some selected parameters of university studies influenced by the student's experience of working abroad?

- Is the reality or potentialities of studying abroad influenced by regional solidarity? Are the differences influenced by gender or year of study?

- To what extent are the ideas of Polish and Czech students' potentialities and possibilities concerning further professional development fulfilled by university studies? Are the differences influenced by gender or year of study? 
- How is the attractivity of the field of studies and the overall image of university assessed by Polish and Czech students? Are the differences influenced by gender or year of study?

In order to find answers to the formulated research problems, the quantitativequalitative approach was applied. In compliance with the dual context theory, the approach takes into account both the context of justification (through the causereason explanation of the examined pedagogical phenomena) and the context of discovery (through interpretation and understanding, completed with a phenomenological analysis of these phenomena) (Pietruska-Madej, 1995, pp. 65-76).

In accordance with the applied methodological standpoint, the research was conducted with the use of both quantitative and qualitative methods and particular research tools, elaborated on the basis of the research procedures recognized within these methods. Their choice and/or construction (in the case of the authors' tools) were determined by the applied theories and the research assumptions resulting from them. In the analysis of empirical materials, both the reducing and developing of data processing was applied. Moreover, the assumptions of the interpretative approach to the analysis of utterances were taken into consideration, in the context of understanding respondents' thoughts, critical reasoning, and theoretical understanding (Kvale, 2004, pp. 213-231; Miles and Huberman, 2000; Denzin and Lincoln, 2009). For a full description of this phenomena, the phenomenological approach was applied as well, which involved the transition from the individual textural-structural relations between the senses and the essence of respondents' experiences towards a synthesis - in the form of a universal description of cultural experiences, representing a group (groups) as a whole (Moustakas, 2001, pp. 147-149).

The authors' research was carried out with the use of (1) ethnographic observation, which comprised four stages:

- the first (descriptive observation) aimed at recognizing the research field and students' groups;

- the second (focused observation) involved the registering - in compliance with the elaborated observation guides - of all (verbal and non-verbal) behaviours of respondents in regard to their cultural experiences;

- the third (selective observation) made it possible to verify the formulated conclusions and to register (in a detailed way) the respondents' behaviours concerning the conditions of their life and learning, in which they acquire the norms, values and behaviour patterns binding the culture of their country;

- the fourth (self-observation) made use of the reflectiveness principle, according to which the researchers themselves were subjected to observation, as well as of the process of their own assimilation - of applying the cognitive 
perspective which dominates in a particular research area (Konarzewski, 2000, pp. 113-114).

The ethnographic observation was complemented with the qualitative (2) individual interview, which comprised questions that enabled the researchers (a) to acquire a full image of a university student's functioning in particular spheres of life, (b) to specify the feeling of identity (including the national one), (c) to diagnose the degree of identification with groups with which a student has contacts, (d) to specify the level of culturalization, taking into account the sphere of competence (knowledge and the understanding of behaviours) and the emotional sphere (the personal attitude to different events which a student observes and participates in as well as the evaluation of behaviour) (Chodynicka and Więckowska, 2005, pp. 370-394). Finally, (3) questionnaire studies and (4) document analysis, were also used in the research, mainly concerning the implemented university curricula, the students' exchange within Erasmus+ programme, and the functioning of students' scientific research teams.

The obtained empirical data were subjected to a quantitative and qualitative statistical analysis. It was conducted with the use of programmes comprised in the STATISTICA Advanced Package 10 PL (Luszniewicz and Słaby, 2008). In order to present the degree of diversification of the examined environments, the method was used via a hierarchical cluster analysis, and for specifying the relationship between conditional variables and the obtained research results the method of one-factor and multi-factor analyses ANOVA. In providing the characteristics of the examined groups, descriptive statistics were used as well. In the organization and analysis of qualitative data, the software of STATISTICA Advanced Package 10 PL made it possible to make and transcribe the notes during field studies, to encode the data (labelling - attributing semantic units to descriptive information), to categorize them, to analyse contents and preliminarily, elaborate various representations of data in the form of templates.

Without a doubt, contemporary academic youth, who live in a complicated and contradicting reality, must answer some crucial existential questions: Who am I? Where do I belong? Who can I be? This social group is in a special situation, as it is subjected to various socializing experiments of history, it experiences the phenomena of exclusion, freedom, disintegration and integration of identity. The identities and biographies of the young are shaped by macro-social and macro-economic tendencies.

The concern for the young Polish and Czech university students is also associated with an attempt at finding the answers to many other questions. Among them, the key one is how to help them in shaping their identity, in organizing their relationship with the world. Seeking an answer to this question is a never- 
ending story, because every answer generates new questions, broadens the research field and the range of hypotheses, the source of which can be found in theories and the practice of social life.

The discussion presented in our study does not fully reflect the social, educational and cultural determinants of the development of the young adult inhabitants of the Polish-Czech borderland. It allows us only to make an attempt at capturing, describing and interpreting the characteristic features and tendencies of the discussed problems, which - at the same time - are of crucial significance in undertaking particular educational activities in multicultural communities. 


\section{Chapter 1. \\ The cultural identity of young university adults - individual and community resources in building the social capital of the borderland}

\subsection{Cultural identity - the essence and scope of the notion}

The term identity has drawn the attention of many humanistic and cognitive psychologists, psychoanalysts, philosophers, sociologists, and educationalists, mostly representing various theoretical orientations. Therefore, a lot of doubt and controversy has been raised around the definition of identity. In the opinion of many authors, it usually refers to all the self-concepts which an individual has and which are ordered according to a subjective ranking (Witkowski, 1988; Melosik and Szkudlarek, 1998; Kwiatkowska, 1999; Gałdowa, 2000; Giddens, 2001; Jawłowska, 2001; Ogrodzka-Mazur, 2001; Żardecka-Nowak and Nowak, 2004; Bobrownicka, 2006; Bokszański, 2007; Mamzer 2007; Strelau and Doliński, 2008; Boski, 2009). However, the undertaken considerations are not aimed at a review and presentation of different definitions and theoretical standpoints in this field but at indicating such an understanding (understandings) of identity that can be useful in the conducted analyses concerning the shaping of an individual's cultural identity in early adulthood.

Referring to philosophical thinking about identity, including the concept suggested by Jürgen Habermas, a three-range epistemological foundation of the notion of identity can be applied. It comprises the following:

- identity in the range of Ego condition,

- identity in the range of self-concept in the world,

- identity in the range of activity competences (the possible contact with the world) (quoted in: Witkowski, 1988, p. 116; Habermas, 1993).

What takes part in such a complex process of crystallization of individual identity are the particular types of identification which express a person's way of referring to the environment:

- identification understood as the recognition of the surroundings (distinguishing and classification of objects within the eyeshot which constitute the background of the individual's behaviour), 
- identification understood as a reflexion of the environment's expectations (entering the required roles in a social reference group),

- identification understood as the process of creating the image of ideal Ego (Witkowski, 1988, pp. 117-122).

The theoretical remarks outlined above unambiguously indicate that the definition problems around the notion of identity are mostly associated with the existence of two different perspectives in viewing this notion - the individual (subjective, personal) and the social (external) perspective, as well as with the birth of two categories of identity questions:

- Who am I as a unique individual?

- Who am I as a social being, an element of the social world? (Jarymowicz, 1984, p. 59; Oleś, 2012a, pp. 115-127).

Alongside the advancement in the studies on the notion of one's own or personal identity, many attempts have been made to specify these terms in detail and in regard to different categories of the criteria in distinguishing one's own Ego. The following spheres might be distinguished, for example (Jarymowicz, 1984, pp. 54-55):

- Material Self: everything that the subject specifies as "mine" (body, clothes, family, house, country) - the sphere of material culture,

- Social Self: everything that is manifested in fulfilling social roles and is seen and assessed by the environment - the sphere of societal (social) culture,

- Spiritual Self: the own inner Self (mental traits and dispositions, feelings, aspirations) - the sphere of symbolic culture.

Thus, all the (composed of these denotations) representations of the own person, can be called "the identity". This is emphasized by Maria Jarymowicz, who claims that "the own identity means the subject's visions of the own person, more precisely - the visions of what is the most important, the most characteristic and specific for self-characterization" (Jarymowicz, 1989, p. 73; Jarymowicz, 2008).

Similar interrelations appear in the attempts to define the notion of social identity. In a few selected theoretical standpoints, it means: the way of defining oneself through belonging to different types of social groups (Nowicka, 1992, p. 155; Machaj, 2017, pp. 17-31); the whole set of social identifications which an individual uses for self-description (Miluska, 2006a, pp. 3-23); the set of selfdefinitions, made up of relevant rankings with the help of which an individual describes their own person - this occurs without differentiating between Me and Us and with the differentiation between Us and Other people (Bikont, 1988, p. 29; Miluska, 2006b, pp. 63-78). 
In this perspective, it can be claimed that an identity is associated with the identification of the person's subjectivity, which takes place through the identification with social groups - most frequently by comparing oneself to other members of the group and by emphasizing one's own personality. As a result, what comes into being is "a subjective map of the social world, in which the Ego is - to a smaller or bigger extent - differentiated from other social objects" (Jarymowicz, 1984, p. 64).

Although in many sociological and psychological approaches to identity the standpoint of symbolic interactionism is suggested, in Antonina Kłoskowska’s opinion, "the theories of symbolic interactionism and its adequate approaches to personality refer mostly or exclusively to the social (societal) culture occurring in informal relationships (the first system of culture). The specific formalism of symbolic interactionism and similar orientations cuts them off from the way to learn the real impact of symbols and values on a human being. Yet, the culture of values and symbols is an important factor and the object of directing the attitudes and of the reflective specification of the identity" (Kłoskowska, 1990, p. 178). A similar opinion is expressed by Zbigniew Bokszański, who claims that the ideological (culturalistic - the author's note) model of identity brings about drifting apart from the notion of interaction and the use of other notions, such as value, pattern of culture or ethos. "The concept of identity is understood here as a set of permanent properties which characterize the ways of self-perception formed among the members of a sufficiently sized group - the ways of perceiving oneself stem from the qualities of the social structure or of the entirely anthropologically understood culture of the discussed group" (1989, p. 34; Hogg and Vaughan, 2010, pp. 64-90). Therefore, the shaping of a person's individual dimension - the feeling of one's own coherence and separateness - is influenced by the processes of the subject's relating to the surrounding world. Such a sense applied to identity seems most useful for describing the individual (subjective) and the social sphere of the functioning of young adults in the conditions of cultural diversification.

Cultural identity, which according to many researchers is a specific form of social identity, is a relatively permanent individual or collective identification with particular cultural values (ideas, beliefs, views, attitudes, etc.). As Irena Wojnar aptly notices, "cultural identity has many faces and is expressed in a spontaneous identification with the local, regional, national and language community, with its characteristic moral and aesthetic values; in the way of internalizing the traditions, customs, patterns of life, in the feeling of bonds with the common history and its changes, in the face of the individual 'Me' within the collective 'Me', which consolidates its image" (Wojnar, 1998, pp. 132-133).

The dimensions of cultural identity distinguished here get a specific sense in the situation when individuals can choose and enrich their present cultural 
identity with some elements coming from other, often different, cultures. One such situation is living in a cultural borderland, which determines the multidimensional shaping of an individual's cultural identity in the field of this person's "experiencing the world" and "being in the world". This is manifested in:

- the openness in experiencing Me (the feeling of subjectivity) from the angle of otherness in the situation of daily coexistence with the representatives of other cultures;

- borderland complexity, understood as the acceptance of the functioning orientations and coexistence of ambivalent valuing orientations which do not oppose each other as alternatives;

- polyphonity as experiencing a dialogic multi-dimensional relationship in the situation of facing the otherness;

- being in the culture (multiculturalism) as experiencing the limits of one's selfeffectiveness and the possibilities of making choices in the sphere of values and valuing.

What also seems justified in the context of the discussed issues is focusing on the phenomenon of cultural distance, which might appear in the contact place of borderland cultures and may cause some particular changes in the development of an individual's cultural identity. In the already mentioned theoretical standpoint represented by Paweł Boski, it is emphasized that the cultural distance developing within an individual may impede the process of social identification and lead to biculturalism, to abandoning the original identity or to the acquisition of a negative identity (Boski, 1992, p. 103; Staś-Romanowska, 2004, pp. 4849).

Taking into account culturally diversified borderlands, three types of cultural identity can be distinguished:

- identification with two cultures (biculturalism, the borderland man),

- identification with the dominating culture (assimilation, accommodation, indifferent or negative identity in family socialization),

- identification with one's own minority group (separation, ethnocentrism, aiming at preserving the own identity),

- lack of identification with any of the groups representing particular cultures (marginalization) (Nikitorowicz, 2009, p. 379).

In the suggested approaches to cultural identity, two things have been assumed. Firstly, it is the existence of the external (independent from the individual) sphere of values, which - as a result of various incidental and intentional (inter)cultural contacts - is manifested in its experiencing, and secondly - the relatively permanent (individual and/or group) identification with these values. 


\subsection{Emerging adulthood - identity forming in the period of early adulthood}

Not long ago, it was still thought in social and humanistic sciences that achieving a more stable (in comparison to earlier developmental stages) identity was a characteristic feature of early adulthood (age 18-25). However, the newest studies (Brzezińska and Piotrowski, 2010, pp. 265-274; Oleś, 2012b; Klimstra, Luyckx, Branje, Teppers, Goossens and Meeus, 2013, pp. 1661-1673; Brzezińska and Syska, 2016) indicate that the intensive process of shaping and transforming the identity is continued after adolescence. Anyway, the optimal effect of the process of identity formation is its consolidation, which takes place particularly in adulthood. This is related to building a stable and coherent structure of $\mathrm{Me}$, which is a response to the requirements of the environment, the expectations of other people and one's own dreams and aspirations (Ziółkowska, 2005, p. 427). The information comprised in Figure 10 illustrates the most important determinants of identity consolidation in early adulthood and presents their significance in the process of consolidating identity. This consolidation is manifested in: a feeling of self-continuity in time and space, a feeling of identicality with the simultaneous feeling of uniqueness, an awareness of one's own strengths and limitations, an openness to and interest in the world without the fear of infringing upon the feeling of one's own safety, entering into close relationsships with other people without the fear of breaking the limits of one's own autonomy. What determines the individual's feeling of the quality of life is the undertaking of major tasks in this developmental stage in three basic dimensions: social interactions, educational and professional activity and forming one's own worldview.

The most recent psychological studies on the process of undertaking adult social roles and on the development of personality have been largely influenced by Jensen Arnett's theory of emerging adulthood, which was put forward nearly two decades ago. The stage of emerging adulthood occurs in the countries in which the knowledge-based economy dominates and in which the people aiming at satisfying social positions have to devote many years to gain education and experience and - therefore - they postpone adulthood tasks until they acquire an appropriate (in their opinion) social and professional position (quoted in: Piotrowski, 2010, p. 14; Arnett, 2000, pp. 470-479). Such a situation takes place in Poland and the Czech Republic, where many young people aged 18-30 (especially until 25) complete the consecutive levels of education (after graduating from secondary school) and collect their first experiences at work. This will bring effects not earlier than in later years. 


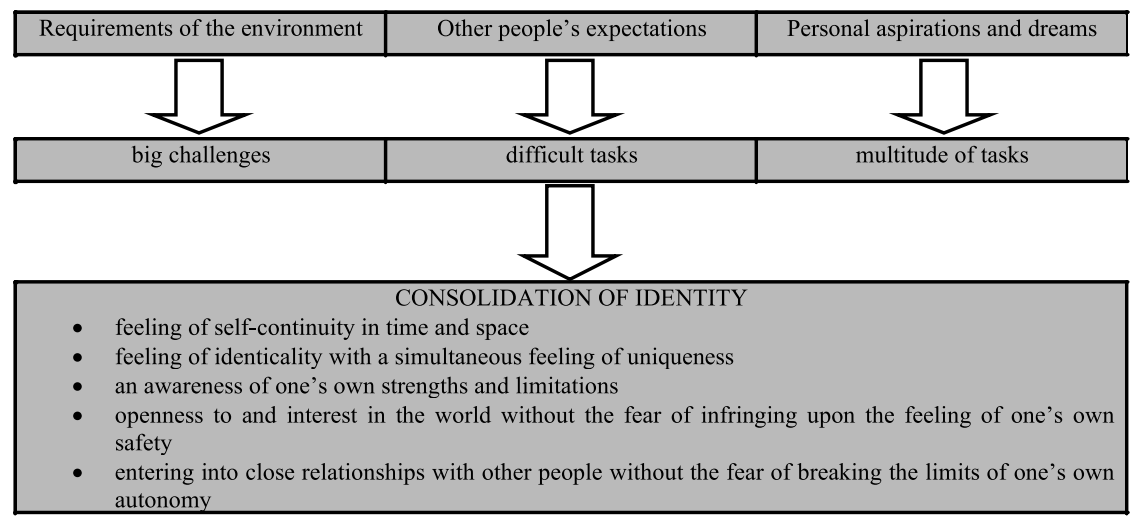

Figure 10. The factors determining the consolidation of identity in early childhood. Source: Ziółkowska, 2005, p. 428.

A characteristic feature of the period of emerging adulthood is substantial demographic differentiation and instability, which reflects young people's tendency to exploration and change. The changes, determined by a particular sociocultural, economic or political situation in a certain country/society, take place in the field of: (1) more frequent undertaking - after graduating from secondary school - of higher education, (2) the age of getting married, (3) the age of the first child's birth. The changes taking place with growing frequency decrease young people's motivation to engage in adult social roles and lead to postponing them (Piotrowski, 2010, pp. 15-16). The cases of Poland and the Czech Republic (cf. Table 2) point to the occurrence of similar social transformations which result in putting off the moment of entering into adulthood and in prolonging the time for shaping the basic competences, such as responsibility for one's own acts, the acquisition of autonomy, or building one's own open, flexible, but at the same time clear and stable - identity. In contrast to the beginning of the transformation period in the 1990s, currently - the number of Polish and Czech young adults who continue education at university has increased three times and constitutes $50 \%$ of the whole population at the age 1924. Similarly to most EU countries, they also get married for the first time later (women PL - 27.3 years, CZ - 29.1 years; men PL - 29.6 years, CZ - 31.8 years) and later decide to have children (PL -27.8 years; $C Z-28.2$ years). 
Table 2. Changes in the age of undertaking adulthood tasks - the case of Poland and the Czech Republic

\begin{tabular}{|c|c|c|}
\hline \multirow[t]{2}{*}{ Categories } & \multicolumn{2}{|c|}{$\begin{array}{c}\text { Characteristics of people in the period of emerging } \\
\text { adulthood }\end{array}$} \\
\hline & Poland & Czech Republic \\
\hline $\begin{array}{l}\text { Gross enrollment ratio in } \\
\text { higher education }\end{array}$ & $\begin{array}{r}12.9 \% \text { in } 1990 \\
40.7 \% \text { in } 2000 \\
53.8 \% \text { in } 2010 \\
46.6 \% \text { in } 2019, \\
(\text { men }-42 \% \text {; } \\
\text { women }-58 \%)\end{array}$ & $\begin{array}{r}16.2 \% \text { in } 1990 \\
28.4 \% \text { in } 2000 \\
38.7 \% \text { in } 2010 \\
34.9 \% \text { in } 2019 \text {, } \\
(\text { men }-42.7 \% \text {; } \\
\text { women }-57.3 \%)\end{array}$ \\
\hline $\begin{array}{l}\text { Percentage of university } \\
\text { students aged 20-29 (gross } \\
\text { enrollment ratio) }\end{array}$ & $\begin{array}{r}16 \% \text { in } 1995 \\
24 \% \text { in } 2000 \\
30 \% \text { in } 2010 \\
27.8 \% \text { in } 2019 \\
\end{array}$ & $\begin{array}{r}10 \% \text { in } 1995 \\
14 \% \text { in } 2000 \\
24 \% \text { in } 2010 \\
23.9 \% \text { in } 2019 \\
\end{array}$ \\
\hline $\begin{array}{l}\text { Percentage of young adults } \\
\text { in education according to } \\
\text { age groups: } 20-24 \text { years }\end{array}$ & $\begin{array}{r}3.1 \% \text { in } 2000 \\
12.8 \% \text { in } 2010 \\
12.8 \% \text { in } 2019\end{array}$ & $\begin{array}{r}3.5 \% \text { in } 2000 \\
7.6 \% \text { in } 2010 \\
10.6 \% \text { in } 2019\end{array}$ \\
\hline $\begin{array}{l}\text { Percentage of young adults } \\
\text { in education according to } \\
\text { age groups: } 25-34 \text { years }\end{array}$ & $\begin{array}{l}14.3 \% \text { in } 2000 \\
37.1 \% \text { in } 2010 \\
43.5 \% \text { in } 2019\end{array}$ & $\begin{array}{l}11.7 \% \text { in } 2000 \\
22.6 \% \text { in } 2010 \\
32.6 \% \text { in } 2019\end{array}$ \\
\hline $\begin{array}{l}\text { Average age of women } \\
\text { getting married for the } \\
\text { first time }\end{array}$ & $\begin{array}{l}22.2 \text { years in } 1990 \\
24.1 \text { years in } 2000 \\
26.1 \text { years in } 2010 \\
27.3 \text { years in } 2018\end{array}$ & $\begin{array}{l}21.6 \text { years in } 1990 \\
24.6 \text { years in } 2000 \\
27.9 \text { years in } 2010 \\
29.1 \text { years in } 2018\end{array}$ \\
\hline $\begin{array}{l}\text { Average age of men getting } \\
\text { married for the first time }\end{array}$ & $\begin{array}{l}24 \text { years in } 1990 \\
26.5 \text { years in } 2000 \\
28.4 \text { years in } 2010 \\
29.6 \text { years in } 2018\end{array}$ & $\begin{array}{l}24.3 \text { years in } 1990 \\
27.6 \text { years in } 2000 \\
30.8 \text { years in } 2010 \\
31.8 \text { years in } 2018\end{array}$ \\
\hline $\begin{array}{l}\text { Average age of the first } \\
\text { child's birth }\end{array}$ & $\begin{array}{r}22.7 \text { years in } 1990 \\
23.7 \text { years in } 2000 \\
26.6 \text { years in } 2010 \\
27.8 \text { years in } 2018 \\
\text { In the } 1990 \text { s, the period of } \\
\text { the highest female fertility } \\
\text { was } 20-24 \text { years, at the be- } \\
\text { ginning of the } 21^{\text {st }} \text { century - } \\
25-29 \text { years, currently - it is } \\
30-34 \text { years. }\end{array}$ & $\begin{array}{r}22.1 \text { years in } 1990 \\
25 \text { years in } 2000 \\
27.7 \text { years in } 2010 \\
28.2 \text { years in } 2018 \\
\text { In the } 1990 \text { s, the period of } \\
\text { the highest female fertility } \\
\text { was } 20-24 \text { years, at the be- } \\
\text { ginning of the } 21^{\text {st }} \text { century - } \\
25-29 \text { years, currently - it is } \\
30-34 \text { years. }\end{array}$ \\
\hline Total fertility rate & $\begin{array}{l}1.99 \text { in } 1990 \\
1.36 \text { in } 2000 \\
1.37 \text { in } 2010 \\
1.43 \text { in } 2018\end{array}$ & $\begin{array}{l}1.90 \text { in } 1990 \\
1.15 \text { in } 2000 \\
1.51 \text { in } 2010 \\
1.69 \text { in } 2018\end{array}$ \\
\hline
\end{tabular}

Source: own elaboration based on: Piotrowski, 2010, p. 16; Kwiek, 2014; OECD, 2018, p. 67; Rocznik Statystyczny Rzeczypospolitej Polskiej [Statistical Yearbook of the Republic of Poland], 2019, p. 347; Rocznik Statystyki Międzynarodowej [International Statistics Yearbook], 2019; Stańczak, 2018; Statistical Yearbook of the Czech Republic, 2019. 
Summarizing the discussion on the formation of identity in early, emerging adulthood, it seems worthy to focus on the main features of this identity:

- lack of a well-crystalized feeling of identity;

- need for experimenting with "multiple identities" (the ideal, real, expected one);

- need for experimenting with and within the job market and in the geographical space;

- undertaking risky behaviour associated with one's own life;

- large demand for psychological and institutional support (career counselling, personal coaching);

- making attempts at assessing one's own life experience in the supra-national, cross-border and intercultural dimension;

- openness to new experiences (Wysocka, 2013, p. 79).

All these phenomena determine young adults' taking on new social roles, finding ways of fulfilling them and of stabilizing their place in the world of adults.

\subsection{The dilemmas of constructing individual cultural identity in the contemporary world}

The current changes mean that the shaping of cultural identity becomes the constructing and arranging of its particular fragments into the whole in unceasing references and relationsships with Others - in confrontation with more and more culturally diversified societies. Thus, this process is never ending, dynamic, contextually changeable, largely aimed at the future, multidirectional, and supranational. According to Jerzy Nikitorowicz, it also requires the subject's creative effort, softening the tension and contradiction between permanent elements (the indigenous ones, inherited, anchored in the family and local community) and stable elements (the acquired ones, resulting from the interaction and participation in culture) (2003, p. 56; Nikitorowicz, 2005, pp. 60-103).

The individual's functioning in the intercultural environment is related (in a voluntary and/or coerced way) to the need for this person's constructive shaping of (inter)cultural identity. Both in the horizontal (diachronic - changeable) dimension and in the vertical one (layered in relation to each other, mostly on the basis of indigenous values), this identity can occur as the following types:

- ethnocentric (inherited) identity - which evaluates an alien, different culture through native cultural standards (values, lifestyles, personal and cultural patterns) and, at the same time, affirms one's own culture, which is considered as the model; 
- dispersed (multicultural) identity - which results from the confrontation of the inherited identity with the new changing cultural reality, as its consequence - the individual acquires the awareness of belonging to many sociocultural groups existing side by side;

- integrated (intercultural) identity - which combines the elements of the individual's personal system of values with the values of the culture of the group(s) to which this person belongs and in the life of which consciously and reflectively participates;

- virtual (culturally disoriented) identity - which comes into being usually as a result of a cross-generation break-up, the lack of (cross)cultural guides and interpreters, or the distance and rivalry between generations (Nikitorowicz, 2009, pp. 406-416; Nikitorowicz, 2013, pp. 29-49).

In this context, it is necessary to draw attention to two fundamental phenomena which form cultural identity today - globalization and multiculturalism. In the opinion of Marian Kempny, a sociologist, there are two major currents of reflection in the thinking about the current world and the effects of globalization. The first - economism - refers to the world of capitalism and economic transformations, the second - culturalism - focuses on cultural transformations. The current associated with capitalism is a natural and inevitable process resulting from modernization - the consolidation of the foundations of capitalist economy (2001, pp. 79-101; Kawiecka, 2010, pp. 26-33). Globalization processes in this sense would lead to the creation of a global society - to the homogenization of national states. The borders of national states would become bleared or diluted, which would bring about the rise of supranational organizational structures. The opposite current is the domain of the supporters of hybridization. "Copying certain models present in the Western culture is treated by them as a manifestation not of the subordination of local particularities to universal processes but of the domination of one particular form of social life over the others" (Gilarek, 2003, p. 62). Therefore, in this approach - the unification of societies will take place in the context of cultural spheres. For the representatives of this current, the factors that determine the dynamics of the new order of the world are cultural factors, which are autonomous, being independent from economy and politics.

However, there are some approaches which combine the elements of both economism and culturalism, presenting integration and fragmentation as two complementary processes. Globalization does not involve only the integration of societies into a kind of superpower, nor the rebirth of particularisms as the local reaction to global processes. The dynamics of the modern world results from the mutual influence of both processes, which act selectively in regard to the spheres of life within particular communities and to the regions in which they take place. This approach can be exemplified by Roland Robertson's concept of glocaliza- 
tion (1992, pp. 61-84), continued by Zygmunt Bauman (2007), the essence of which concerns the restructuring of the social world, based on the (different than so far) principles of restratification and self-reproducing hierarchy in a worldwide scale. This approach is also present in Wolfgang Welsch's new concept of culture, the so called transculturalism, which has been developed since the early 1990s (2004, pp. 31-34; Bartosiak, 2012, pp. 9-26; Paleczny, 2017, pp. 63-81). It assumes the functioning of two levels of transculturalism - "it exists not only at the macro level of the whole societies (building networks, the process of hybridization, versatility of cultural changes, lack of differentiation between the alien and the own) but also reaches the micro level of individual identity (many cultural sources, the necessity of various social roles, 'democratization' of inner pluralism, cultural versus national identity)” (Welsch, 2004, p. 34).

Globalization leads to undertaking the reflection upon shaping the new identity, called - in compliance with the process - global identity. The standpoints presented within social sciences concerning the forming of global identity stretch between two extremes of the same continuum. The views of the researchers who comment on the reality and predict possible changes are various as they result from their applying different assumptions. Yet, the fact itself of undertaking the issues of shaping a new type of identity or of constructing the global society makes the researchers - despite ideological differences - share a common belief that globalization processes influence contemporary societies. Thus, the question can be formulated as to whether a national state will be able to counteract the negative effects of globalization. As Tadeusz Szkołut indicates, some prognoses appear that a centralized national state as a product of the modern era will have to go away with this era. "Without a doubt, any national state, even a relatively strong one, is not able in today's world to keep economic, political and military self-sufficiency. [...] Will the predictions turn true that the individual's feeling of attachment to a particular national community will increasingly become less important for shaping this person's identity and that the future will belong to a new class of highly educated professionals, who while working in huge supranational corporations will not be linked to any national loyalty?" (2003, pp. 83-84; Szymański, 2016, pp. 11-24).

What is missing in specifying the direction in which modern societies should go are the references to the axionormative layer, without which the reality will become flattened and one-dimensional. Therefore, some new questions can be raised: Can an identity exist without values? How to construct an identity without the identification with some particular values and goals which provide an order to human existence? If it is assumed that values are indispensable for constructing the global identity, another issue emerges - the problem of multiculturalism, diversity, multidimensionality of cultures, which all permeate each other, as well as the multitude of attitudes, recognized values or ways of under- 
standing the world. Should globalization processes lead to the unification of values, which seems rather not feasible due to the heterogeneity of the world, or should this head for a certain type of mixing the values recognized by multicultural societies? Some practical recommendations and an attempt at formulating the assessment principles have been made by UNESCO, as an institution aimed at the cultural integration of the world. "The general and frequently repeated opinion on the creative nature of diversity and on the need for not only tolerance but also for the support of its development is associated with two basic rules: 1 ) the principle of recognizing the rights of all national and ethnic cultures to cherish their own values; 2 ) the belief in the universality of fundamental human features and aims, expressed in all cultures" (Kłoskowska, 2002, p. 159). These principles can only be followed when the existence of universal values is assumed with the simultaneous rejection of ethical relativism.

According to Antonina Kłoskowska, the openness of cultures, which - at the same time - does not mean a lack of acquired influences, is a sine qua non in the contemporary world. Only a friendly turn to other cultures, a really personal view on other societies and on the individuals who constitute them may lay the foundation for building a new intercultural space. However, this cannot mean an uncritical acceptance of all cultural influences. The acquisition of values promoted in other cultures ought to take place on the basis of openness supported by a well-wishing criticism with a simultaneous acceptance of and emphasis on the inalienable right of every person to freedom (2002, pp. 160-162; Dyczewski and Jurek, 2013). Due to the impossibility to inhibit the current globalization processes, this issue has been and still will be topical. Yet, what seems to be needed to prevent many conflict-raising tensions as the consequences of these processes is an idea which will indicate the rules of conduct. Universalism - open to all topics, questions and accusations - can become such a solution. "It should aim at a holistic, not fragmentary, approach. Still, this does not mean that universalism is hostile to diversity. The kind of wholeness which is appropriate for an open process of thinking tolerates and praises individuality, differences, and even opposite views. Above this - however, there should be a total unity and harmony, a fundamental set of principles accepted by all thinkers" (Andersen, 1997, p. 96).

In this context, another question can be formulated: Will the values and traditions constituting the identity of particular nations not be blurred in the process of constructing such a universal set of principles? In one of her works, Magdalena Grygierek puts forward an interesting thesis that a strong feeling of identity, resulting from the rooting in the native tradition, brings about openness which, in turn, leads to universalism. The author indicates that universalism and indigenousness are not antagonistic - what is more, they draw from their common experience, revealing in this way the wealth of human attitudes. "Authentic and living cultures give an opportunity of a better understanding of 
universal truths [...]. Aiming at universalism in the new reality is not a fad but a necessity. It offers a chance for peaceful and fruitful meeting with others. It is important not to resign from one's own traditions while heading for it. The rooting in the local, ethnic culture provides an opportunity to receive universal values and, at the same time, protects individuals from the diluting of their identity" (Grygierek, 2001, p. 232; Miluska, 2005, pp. 26-36; Śliwerski, 2008, pp. 55-74).

\subsection{Identity in the educational perspective}

The current associations of identity and education may be situated in three basic contexts - the social, cultural, and cognitive one and in the related ethical context, as the fourth. All of them are implemented in various family and educational situations. These situations, occurring both intentionally and accidentally, become a source of different values (their possible understandings) and they enhance the individual's development of the skill of assessing the acquired knowledge and experience.

The social and cultural contexts are characterized by:

- the relationship: individual - culture - education, which links the sphere of culture with values and personal self-development and which emphasizes the individual's freedom and self-definition (subjectivity);

- building the feeling of multidimensional cultural and intercultural identity in the individual (subjective) and social (external) perspective in the field of: a) the condition of Ego, b) the self-concept in the world, c) competences in activities (possible contacts with the world and relations with Others);

- sensitization to the Other and noticing the dissimilarity of people from other cultures, which, among other things, aims at "weakening" the consolidated negative stereotypes and prejudices and at their modification;

- intercultural communication and dialogue, which enables systematic language contacts with members of other communities and often creates natural situations of the simultaneous participation in two (and more) cultures and two (and more) linguistic systems;

- broadening the range of sociocultural integration with: (a) the integration of the common activities of educators and students, b) the integration of class groups, c) the integration of the individual's life environments (family home, peer group, school/university), and d) the integration of educational-cultural offers. 
The third - cognitive - context comprises:

- the motives for exploring the world and learning - intensive motivation to familiarize oneself with the surrounding world of people, things and phenomena, as well as to acquire (in the process of learning) social competences, which determine the functional effectiveness in social situations;

- constructing knowledge in the educational environment: learning through intercultural dialogue and contact, which necessitates a different approach to the process of the individual's acquisition of knowledge - the transition from monologue to dialogue education, which is associated with creating meanings;

- promoting the paradigms of "educating for development" and "coexistence", with the focus on basic and applied studies in the sphere of the so-called guided development of learners in culturally diversified environments;

- relating educational and intercultural studies to the latest currents in philosophy, psychology, sociology, cultural studies and other scientific disciplines.

The ethical dimension of the relationship between identity and education, which combines the above described social, cultural and cognitive contexts, may be situated within the value of responsibility. As Jacek Filek states, “[...] The contemporary world calls for responsibility. Yet, this cannot be the same as the so far existing negative responsibility which - while looking back - notices a certain performed evil, attributes it to a person and holds this person accountable for it. Here, it concerns the power of positive responsibility, which looks into the future and shows individuals the good attributed to them. The feeling of responsibility that is being born in this way has not got the nature of the feeling of guilt, but it is the power providing the feeling of one's own task, own dignity and significance" (2003, pp. 10-12; Rembierz, 2008, pp. 265-280; Dąbrowska and Kniejski, 2012, pp. 105-112).

The inspiration for seeking the interpretative framework of the current identity and educational processes comes with the views of Emmanuel Lévinas, the author of the "humanism of the Other", one of the most eminent thinkers of the $20^{\text {th }}$ century, whose way of thinking about responsibility constitutes the introduction to the philosophy of responsibility of the third millennium. In his considerations, Lévinas makes the criticism of European rationalism his starting point. This criticism is based on the following relationship: the recognizing subject $(\mathrm{Me})$ - the recognized object (You), but Lévinas suggests a new, ethical two-subject relationship Me-You, which enables the authentic "meeting" with another person and the dialogue with what is Other. In Lévinas's opinion, openness to the Other in such a sense requires a specification of the new vision of society, hence - new culture, with a simultaneous keeping of the principles of universalism (Lévinas, 2006, pp. 175-187; Gadacz, J. Migasiński, 2002). Therefore, the culture of transcendence is likely to become the basic cultural orientation in 
modern times, which links the sphere of culture with the values and self-development of a human being, who is responsible for the Other in the "face-to-face" relationship. Becoming aware of the specific cultural continuity with its interrelated responsibility for the Other and - on the other hand - of the current cultural changes due to globalization (both in the aspect of its progressive and regressive qualities, as well as of ambivalence, as a characteristic feature of this category), might result in counteracting the relativization of individual social identities and might lead to the openness of cultures and to building new intercultural (also educational) spaces (Kempny, 2000, pp. 9-11; Ogrodzka-Mazur, Grabowska, Szafrańska-Gajdzica and Kwadrans, 2016; Nikitorowicz, 2017).

Thus, in the contemporary reality, a particularly significant role is played by intercultural education, the starting point of which is the reconciliation of "homelands", a kind of responsible and creative shaping of the personal and social identity. This is viewed as a condition of the protection of an individual from being treated as an object and from getting lost in the world. No culture can function and defend itself through denying the right to existence of other cultures. As Zygmunt Bauman stresses, "if - in the conditions of liquid modernity education and learning are to be useful, they need to have a permanent character and to last for the whole life. It is hard to imagine any other model of education or learning. 'Forming' of the own 'me' or of the own identity must apply a form of unceasing and always unfinished reforming. [...] We need lifelong education so that we have no possibility to choose. We need it even more to save the conditions which make this choice possible and real" (Bauman, 2007, pp. 229, 235; Bauman, 2008, pp. 151-170).

\subsection{Identity behaviours manifested by university students from the Polish-Czech borderland - research results}

The characteristics of the identity behaviours manifested by the surveyed communities of Polish and Czech students were considered in the light of the Lewowicki's aforementioned theory of identity behaviours. This enabled a holistic and, at the same time, comparative approach to the processes and phenomena taking place in multicultural environments. The results of the conducted research into the feeling of identity seem to indicate that two types of elements in its image can be seen - the traditional (stable) elements and new phenomena and processes, influenced by the complexity and diversity of various determinants (historical, sociocultural, cultural-personal, economic), which accurately specify the intensively shaped identity of young learning adults. 


\subsubsection{Axiological preferences}

The surveyed community of university students from the Polish-Czech borderland (both now and in the early 1990s) has been observing the transformations occurring in Poland and the Czech Republic. The young learning adults who live in culturally diversified environments and often in mixed families perceive these phenomena from different angles. This is of crucial significance for shaping their cultural identity and the individual structure of their axiological reality.

The research results presented in this section show the image of values recognized by students as well as their attitude to the implementation of the declared values. Taking into account the outcomes of the earlier studies conducted in this field in the Polish-Czech borderland (Ogrodzka-Mazur and SzafrańskaGajdzica, 2016, pp. 8-21; Ogrodzka-Mazur, 2016, pp. 23-98; 2017, pp. 66-80) allows for presenting the relative dynamics of the change in the area of values recognized by contemporary academic youth, as well as for capturing certain mechanisms which determine this change.

In the current structure of values preferred by borderland university students, three subsystems can be distinguished. In the first and clearly dominating subsystem, the following values are located: the ones associated with family life (99 \%), with an exciting job and professional career (97.5\%), moral values and the ones concerning respectable life (94\%), knowledge and education (89\%) and problem-free, comfortable life (87.5\%). Family values are most highly ranked in the declarations of young adults, which points to the specific generational continuity - family is the most appreciated value, the basic educational environment and a place where values are passed down (cf. Figure 11).

So far - in the nationally and religiously diversified family communities in Cieszyn Silesia, the value of the person and family have been built into the consciousness of its members since childhood. What has guarded the transmission of those values are the behaviour norms pertaining to their daily lifestyle, which have been imprinted in consecutive generations and which have marked the feeling of responsibility for the family in the face of God and the community. Those values have resulted from faith, religiousness, and the conditions of life and work. In daily life, the behaviour patterns based on the Decalogue and the life experience of the elderly are preferred. Therefore, the specificity of these families' system of values has been influenced not only by their inner organization but also by the cultural space (shaped and used by generations) of the environment and family home, work, religious and cultural life, as well as the created feeling of regional and national identity (Lewowicki, Suchodolska, 2000; Ogrodzka-Mazur, 2011, pp. 15-71). All the surveyed Polish students and $98 \%$ of their Czech peers rank family values the highest and, in their individual responses, they declare the implementation of these values. 


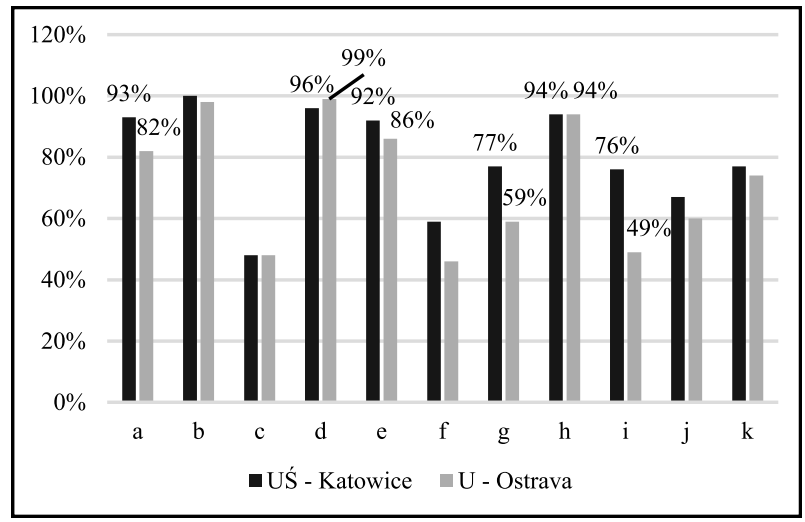

Figure 11. Values preferred by students from Poland and the Czech Republic (percentages). Legend: a - comfortable, problem-free life; b - life among family and friends; $c$ - popularity, fame, success; $\mathrm{d}$ - exciting job, professional career; e - knowledge, education, scientific achievements; f - high position, supervising people, decision making; $\mathrm{g}$ - fortune, high living standards; $\mathrm{h}$ - implementation of moral values, respectable life; $\mathrm{i}$ - social engagement, civil activity; $\mathrm{j}$ - participation in culture, artistic activity, creativity; $\mathrm{k}$ - life full of changes, adventures and attractions. Statistically significant differences confirmed in Mann-Whitney U Test are marked in black colour. Source: the authors' own research.

A high rank in the structure of the values preferred by students on both sides of the border was also given to work and a professional career. They are slightly higher ranked by students from the University of Ostrava (CR -99\%, PL - $96 \%$ ). Such high ranks of this group of values can confirm the proper fulfilment of developmental tasks in early adulthood. Starting a professional career largely determines the successful implementation of the further aims emerging in other periods of human life and leads to satisfaction and success in fulfilling the tasks in later life stages. Such appreciation of work and professional career is determined - in the opinion of $94 \%$ of respondents - by moral attitudes and a respectable life, as well as knowledge and education (PL - $92 \%, \mathrm{CZ}-86 \%$ ) values shaped mostly in the family environment and in the course of secondary socialization.

The subsystem of the most highly ranked values is completed with the respondents' very positive attitude to the fulfilment of a current and future comfortable, problem-free life ( $\mathrm{PL}-93 \%, \mathrm{CZ}-82 \%$ ), which is confirmed in their individual answers in the surveys. Being conscious of their potentialities and needs, academic youth is - from the sociological standpoint - the so-called generation Y, also referred to as "millennials", the "next generation", or "digital generation". They were born in the 1980s or 1990s and they value independence, leisure time and comfort very much. Among their characteristic features, there are: active use of media and digital technologies, a high level education and 
readiness for self-development, high assessment of their own skills, the belief in their own uniqueness, excessive expectations and a strong aversion to criticism (Laird, Harvey, Lancaster, 2015, pp. 87-100). The obtained research results are also similar to the set of values recognized by the young which was based on the studies conducted over a decade ago in seven European countries (Great Britain, Germany, Italy, the Netherlands, Poland, Greece, Sweden). This set comprised: tradition (recognition of the significance of family and parental authority), individuality (feeling of autonomy and independence), honesty (expressed in the attitude of friendship and loyalty to others), effort (attributing significance to ethics of work and aiming at success) and optimism (positive thinking as the key to success and a happy life $)^{15}$.

The second, less appreciated subsystem comprises the declarations which concern fulfilling a life full of changes, adventures and attractions (PL - $77 \%$, $\mathrm{CZ}-74 \%$ ), possessing and earning a fortune (PL - $77 \%, \mathrm{CZ}-59 \%$ ), social engagement and civil activity ( $\mathrm{PL}-76 \%, \mathrm{CZ}-49 \%)$, and participation in culture and artistic activity (PL - $67 \%, \mathrm{CZ}-60 \%)$.

The least importance is attributed by respondents to the values which constitute the third subsystem, related to high positions and supervising people (PL $59 \%, \mathrm{CZ}-46 \%)$ and to popularity, fame and success ( $\mathrm{PL}-48 \%, \mathrm{CZ}-48 \%)$.

The obtained research results (cf. Figure 12) indicate some differences in the values declared by young learning adults. Significantly more often than their peers from the University of Ostrava, the surveyed students from the University of Silesia declare higher ranks to the values associated with:

- comfortable, problem-free values (Mann-Whitney U test: $Z=3.09 ; p=0.002$ ),

- knowledge, education, scientific achievements $(Z=2.03 ; p=0.04)$,

- fortune, high living standards $(Z=3.74 ; p=0.0002)$,

- implementation of moral values and a respectable life $(Z=2.62 ; p=0.009)$,

- social engagement, civil activity $(Z=5.53 ; \mathrm{p}=0.00)$.

They attribute significantly lower significance to an exciting job and professional career $(\mathrm{Z}=-3.84 ; \mathrm{p}=0.0001)$.

Such a differentiated image of the values currently recognized by the generation of young learning adults suggests the changes which occur in their axiological awareness and are determined by their social sensitivity and the distinctness (which they feel) of the economic and cultural condition of either country. The values and life goals seem to be similar to the typical qualities of the image of values highly ranked by contemporary university youth with a distinct tendency towards focusing on the life for oneself and the increased significance of individual-private values, associated with work, professional career and self-

15 The studies "Youthopia", conducted in 2009 on the order of MTV Networks International. 


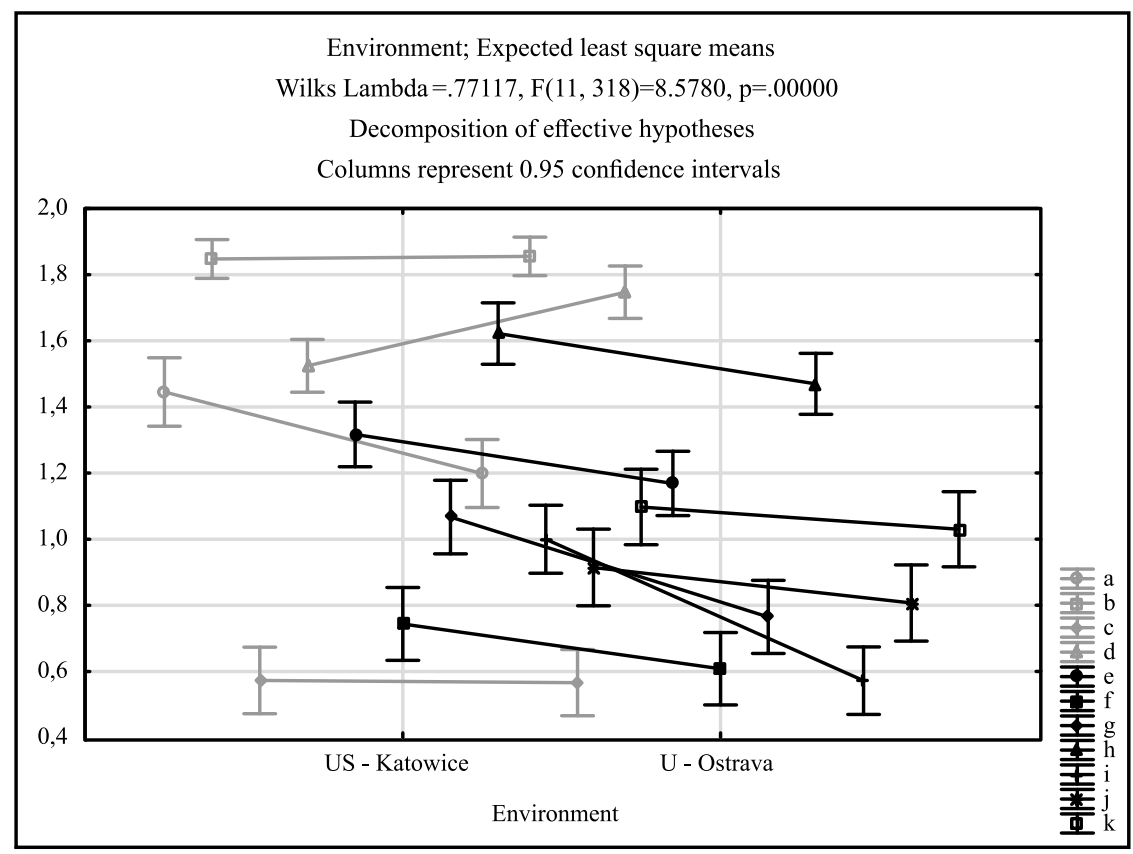

Figure 12. Values preferred by students from Poland and the Czech Republic (one-factor analysis ANOVA). Legend: a - comfortable, problem-free life; $b$ - life among family and friends; $c$ popularity, fame, success; d - exciting job, professional career; e - knowledge, education, scientific achievements; $\mathrm{f}$ - high position, supervising people, decision making; $\mathrm{g}$ - fortune, high living standards; $\mathrm{h}$ - implementation of moral values, respectable life; $\mathrm{i}$ - social engagement, civil activity; $\mathrm{j}$ - participation in culture, artistic activity, creativity; $\mathrm{k}$ - life full of changes, adventures and attractions. Source: the authors' own research.

fulfilment (Strózik, 2014, pp. 5-23; Felchner, Gal and Jakubczak-Krawczyńska, 2016, pp. 111; Langer and Siembida, 2018, pp. 402-410).

While making an attempt at interpreting the obtained research results, it can be stated that the axiological world of academic youth is already largely grounded on the new sociocultural reality, which differs from the culture of their parents and older generations.

The axiological orientations of young learning adults are aimed mostly at fulfilling family, professional, moral, and individual-private (autotelic) values, which enable them to live comfortably and focus on themselves. Social and cultural values, which are important determinants and regulators of behaviour, are of lesser significance for the whole surveyed group. Thus, what is manifested here is a clear tendency of young adults to fulfil selected private values in order to find the sense of their life and their own identity. Students at the threshold of adulthood approve of and manifest in their everyday behaviour the affirmation of pleasure providing values. This certainly results from the occurring socio- 
cultural changes and related processes, such as: European integration, globalization, easy access to goods of various types, a free market economy, as well as from the change in the style of family education. In the current socio-political conditions, liberalization of family education is developing much more extensively and intensively than in the times when the respondents' parents were young. Therefore, it seems right to agree with the apt opinion of Maria StaśRomanowska, according to whom: "among all the reference points possible in the human world, the most permanent values are those which exist in it. They constitute the most certain semantic horizon for the interpretation of events and subjective experiences, which can be specified by the conscious choices of goals and acts compliant with values - because, eventually, the human being is who they will become, owing to what they aim at" (2004, p. 58).

\subsubsection{Feeling of identity and national identifications - towards a multidimensional identity}

The declarations of the surveyed students (cf. Figure 13) from Poland concerning their feeling of identity constitute a similar (in percentages) local (91\%) - national (88 \%) - regional (87 \%) arrangement. To a slightly smaller extent, they also feel as Europeans $(80 \%)$ and citizens of the world $(71 \%)$. Thus, the young identify with their place of residence, country and region. The academic youth from the Czech part of the borderland define themselves in their identity declarations in a national (93\%) - local (89\%) - regional arrangement. Definitely fewer respondents feel citizens of the world (73.5) and as Europeans (63\%).

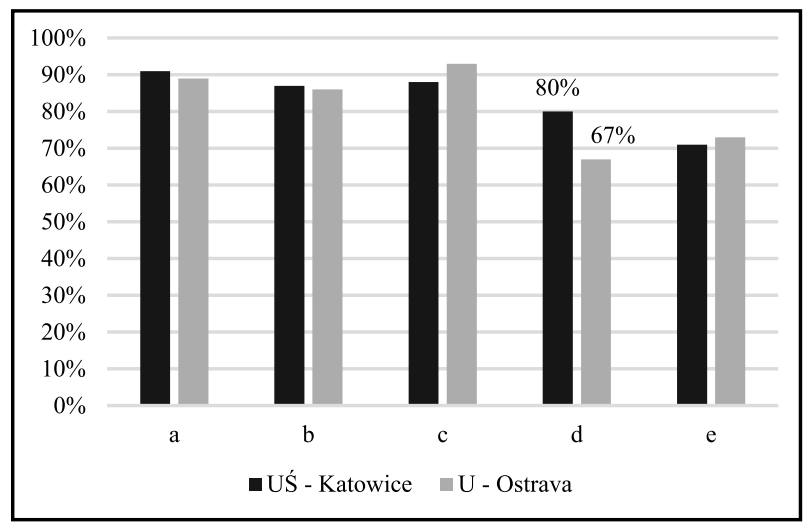

Figure 13. Feeling of identity declared by students from Poland and the Czech Republic (percentages). Legend: $\mathrm{a}$ - I feel a resident of my town/village; $\mathrm{b}$ - a resident of the region; $\mathrm{c}-\mathrm{a}$ citizen of Poland/Czech Republic; d - a European; e - a citizen of the world. Source: the authors' own research. 
The differences in the declared national identifications of particular groups of students indicate the currently observed tendency among the young to identify with various communities - national, local, regional, or more broadly - European or supra-European ones. At the same time, the construction by young learning adults of their own identity means drifting apart from the homogenous dimension towards the discovery and conscious choice of an enriched, multidimensional identity, which is most often determined by the processes of democratization of social life. As T. Lewowicki notices, "[...] in these conditions many young people can - with growing boldness and conviction - identify themselves simultaneously with Poland, the nearest region, and Europe. There is no need for radical choices, the awareness of bonds and communities is growing as well as the need to collaborate in various platforms and in various scopes of individual, social, national and supra-national matters. This results in shaping the multidimensional identity" (Lewowicki, pp. 254-255).

A detailed comparative analysis of the surveyed environments (cf. Figure 14) points both to insignificant differences and to similarities in students' feeling of identity.

The youth from the University of Silesia significantly more often declare the feeling of being a European than their peers from the University of Ostrava (Mann-Whitney $U$ test: $Z=3.85 ; p=0.0001$ ). It should be emphasized that in Poland, the integration efforts were particularly intensive in the 1990s. Cultural traditions, social aspirations, political campaigns and the evident tendencies to EU integration have turned out to be so strong and dominating that they still determine the thinking about individual fates as well as about the fortune of the society and state. This fortune is still associated with the European Union, which has been reflected in the multidimensional feeling of identity, as is shown among the respondents.

The evaluations of the feeling of identity declared by Polish respondents have made it possible to distinguish four characteristic clusters of evaluations, on the basis of which four identity profiles of the respondents can be distinguished (cf. Figure 15). The profiles based on the clusters of respondents' evaluations might reflect the way in which students perceive their own identity behaviours. The features of particular profiles are characterized in reference to:

- evaluations of cluster 1 (composed of the declarations of $36 \%$ of the respondents) - by a substantively significant underestimation of the feeling of being a European (Mann-Whitney U: $Z=-4.85 ; \mathrm{p}=0.000001$ ) and a citizen of the world $(Z=-6.26 ; p=0.00)$;

- evaluations of cluster 2 (45\% of respondents' declarations) - by a substantively significant overestimation in all evaluations of the feeling of identity; 


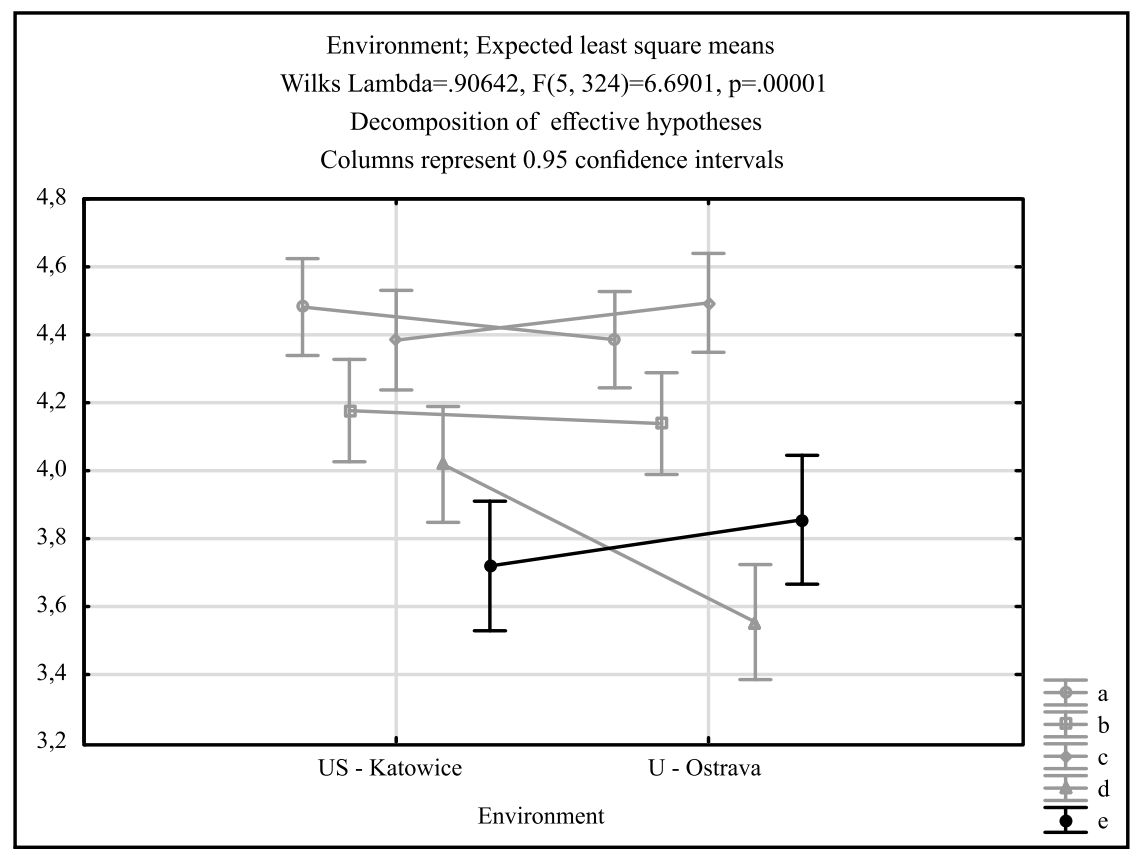

Figure 14. Feeling of identity declared by students from Poland and the Czech Republic (onefactor analysis ANOVA). Legend: $\mathrm{a}$ - I feel a resident of home town/village, $\mathrm{b}$ - a resident of the region, $\mathrm{c}-\mathrm{a}$ citizen of Poland/Czech Republic, $\mathrm{d}-\mathrm{a}$ European, $\mathrm{e}-\mathrm{a}$ citizen of the world. Source: the authors' own research.

- evaluations of cluster 3 (16\% of respondents' declarations) - by a substantively significant underestimation of the feeling of being a resident of one's town/village (Mann-Whitney $U: Z=-4.74 ; p=0.000002)$, one's region $(\mathrm{Z}=-4.22 ; \mathrm{p}=0.000024)$ and a citizen of Poland $(\mathrm{Z}=-5.16 ; \mathrm{p}=0.00)$;

- evaluations of cluster 4 ( $3 \%$ of respondents' declarations) - by a substantively significant overestimation in all evaluations of the feeling of identity, yet - due to a small size of the group, these results are not significant.

On the basis of two largest clusters, comprising the declarations of $81 \%$ of the surveyed students from Poland, it can be stated that their identity behaviours comprise the identification with a particular territory and social (family, peer, local) group, which takes place in the process of (primary and secondary) socialization and culturalization (the first field). Identity behaviours of young learning adults also refer to the fourth field, associated with the economic condition and living standards in the group's life, which determine the level of fulfilling their needs. The respondents' expectations are related both to the life in the residence country and to the life in other European and non-European 


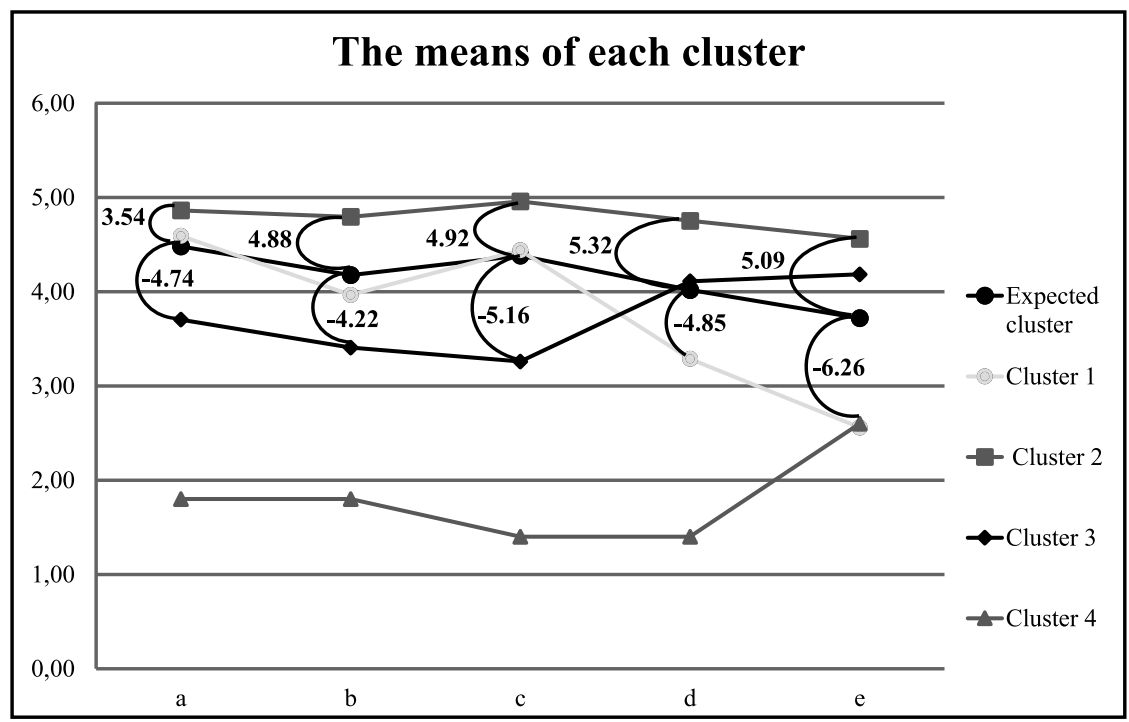

Figure 15. Identity profiles of students from Poland based on cluster analysis. Legend: a - I feel a resident of my town/village, b - a resident of the region, $\mathrm{c}-\mathrm{a}$ citizen of Poland/Czech Republic, $\mathrm{d}-\mathrm{a}$ European, e - a citizen of the world. Source: the authors' own research.

countries. In individual interviews, a large group of Polish students declared their intention to undertake professional work abroad or to continue education in studies at the level of the master's degree abroad. They are also interested in participation in the Erasmus+ programme and other forms of international academic exchange.

The evident tendency to shaping the European identity among young Poles, which is compliant with the spatial correlates of their cultural identity, indicates the need for not only the declared but also practical educational solutions (on the national, European and worldwide scale). They would enhance the formation of the individual and social dimension of intercultural identity. Such a solution is/ should be provided by an intercultural education, which - according to T. Lewowicki - "is aimed to prevent or, if needed, overcome isolation, stigmatization and self-stigmatization, difficulties in social integration and identity problems, which often co-occur with or result from multicultural education. In the theory and practice of intercultural education, there are no aspirations to dominate, weaken or eradicate any culture. Similarly, the multidimensional identity is not to pose danger to any of the dimensions (spheres) of identity - it should liberate from one-dimensional, as if monopolized, identity and enrich it" (2014, p. 29).

The evaluations of the feeling of identity declared by Czech students have made it possible also to distinguish four characteristic clusters of evaluations, on 
the basis of which four identity profiles of the respondents can be presented (cf. Figure 16). They are characterized in reference to:

- evaluations of cluster 1 (comprising $20 \%$ of respondents' declarations) - by a substantively significant overestimation of the feeling of being a resident of one's own town/village (Mann-Whitney $U$ test: $Z=2.95 ; p=0.003$ ) with a simultaneous underestimation of the feeling of being a citizen of the world $(\mathrm{Z}=-6.37 ; \mathrm{p}=0.00)$;

- evaluations of cluster 2 (41\% of the declarations) - by a substantive overestimation in all evaluations of the feeling of identity apart from the local dimension (being a resident of one's own town/village);

- evaluations of cluster 3 (19\% of the declarations) - by a substantive underestimation in all evaluations of the feeling of identity;

- evaluations of cluster 4 (20\% of the declarations) - by a substantively significant overestimation of the feeling of being a citizen of the world (MannWhitney $U$ test: $Z=2.96 ; p=0.003)$ and a simultaneous underestimation of the feeling of being a European $(Z=-5.15 ; p=0.00)$.

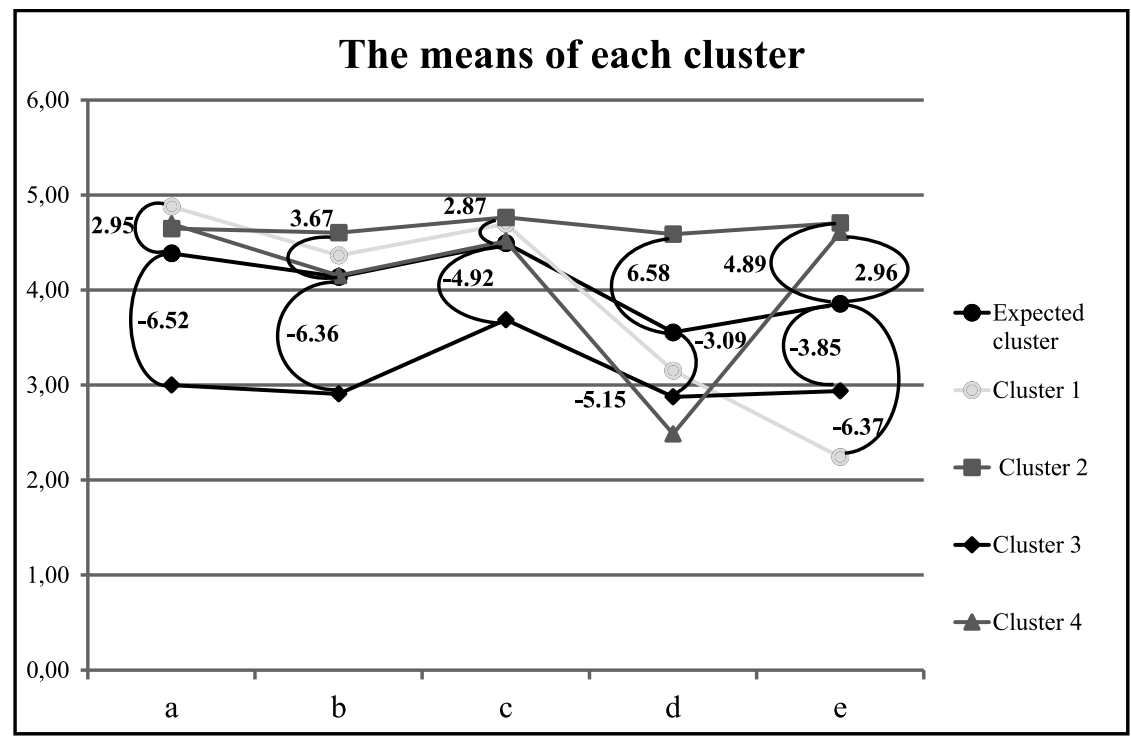

Figure 16. Identity profiles of students from the Czech Republic based on cluster analysis. Legend: $\mathrm{a}$ - I feel a resident of my town/village, $\mathrm{b}$ - a resident of the region, $\mathrm{c}$ - a citizen of Poland/ Czech Republic, d - a European, e - a citizen of the world. Source: the authors' own research.

The identity profile of Czech students, contrary to their Polish peers, has mostly a national dimension. What seems typical of this profile are clear preferences of the own ethnic group as regards identity, language and social contacts, as well as a balanced level of duties and rights. Students from Ostrava associate their life, 
career and educational plans with their homeland and the nearest region, which was confirmed in their statements in individual interviews. The vast majority of them are not interested in going abroad to find better conditions of work and life. At the same time, they emphasize the need for civil activity in the local environment. The dissimilarity in the image of national identifications of the respondents from the Czech part of the borderland results from its specificity determined by historical, sociocultural and economic conditions, which have been extensively explored in intercultural pedagogical studies for 30 years $^{16}$.

In the context of these results and in the situation of the ongoing processes of universalization, globalization and integration, the strong national identification of young learning adults is an indicator of both separateness and the bonds with the national community. National culture is the deepest foundation which protects the individual's sovereignty in the internal dimension. In compliance with the thought promoted in Lewowicki's theory of identity behaviours, achieving this separateness allows communities and individuals to fulfil their own goals and triggers some particular social activities of an individual or collective nature. Moreover, national identification should be viewed as a consecutive stage in rooting, which makes it possible to reach the borderlands of one's own culture with the motivation to open and familiarize oneself with other cultures. This stage of rooting is based on the family, local and regional heritage and becomes indispensable when the world becomes global (Szczurek-Boruta and Grabowska, 2009, pp. 21-64).

The current research results and their interpretation show that the fears appearing in the studies conducted in the 1990s and concerning the loss of national identity and of losing its primary status among other dimensions of identity have not been justified. However, the thesis has been confirmed which was formulated over two decades ago by Antonina Kłoskowska, a sociologist of culture. Focusing on the individual's experience pertaining to different aspects of a person's social identity, she drew attention to the phenomenon of the specific nationalization of social (Polish, European or world) reality. This nationalization was expressed in better visibility of national symbolics in the infrastructure of daily life (1996, pp. 27-38). What is more, it can be supposed that another significant experience in the analysed process was the division of Czechoslovakia into the Czech Republic and Slovakia, which took place after the Velvet Revolution. In such a situation, aiming at re-specifying the national identity in social awareness seems understandable. After many experiences which had not been favourable for this re-specification, the time came for unambiguous identification, resulting in a clearly seen increase in the number of people, especially the young, who highlighted their Czech identity. This phenomenon - the stage of regaining and

16 Cf. the information provided in Footnote 1 on p. 9. 
redefining the identity - can be explained in the sense of some mechanisms of social psychology and sociology. It is also compliant with the theory of identity behaviours (Lewowicki, 2009, pp. 255).

\subsubsection{Feeling of association with selected social groups}

What seems to be an important dimension of the individual's cultural identity is the declaration concerning the strength of the feeling of association with selected social groups in the life of which the person participates. In the survey, both Czech and Polish students expressed their opinions pertaining to the family, religious, ethnic, national, peer (academic) group, as well as the groups in which they fulfil their hobbies or spend leisure time and the groups of professionals with whom they work.

The obtained research results (cf. Figure 17) indicate that young learning adults educated in the Polish-Czech borderland feel most attached to the family environment (95\%), peer groups with which they feel bonds of common interests, passions and ways of spending leisure time (72\%) and groups of professionals (respectively $65 \%$ and $66 \%$ ). These declarations confirm their axiological preferences, in which family and work-related values were most highly ranked in both surveyed environments.

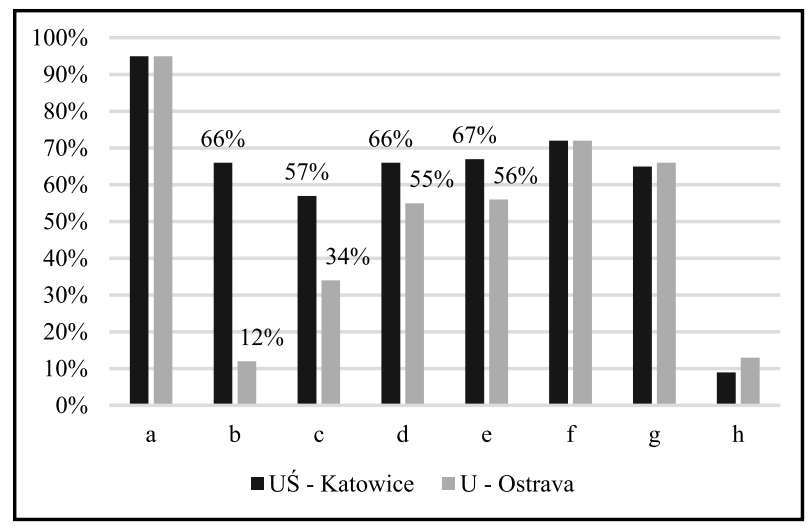

Figure 17. Strength of the feeling of association with selected social groups declared by students from Poland and the Czech Republic (percentages). Legend: a - I feel attached to family; b religious group; $\mathrm{c}$ - ethnic group; $\mathrm{d}$ - national group; e - academic community at my university; $\mathrm{f}$ - group sharing my interests or leisure time group; $\mathrm{g}$ - group of professionals; $\mathrm{h}$ - other people/ groups. Source: the authors' own research. 
Such a homogeneous image of the felt strength of respondents' bonds with these groups confirms substantial significance of family and social values in the life of young generations. It is worth noticing that these are - in the context of developmental tasks which a person fulfils in the course of life - the most important goals typical of early adulthood: starting a family, finding a related social group and starting professional work (Donnellan, Larsen-Rife and Conger, 2005, pp. 562-575; Malina, 2015, pp. 559-572).

A detailed statistical comparative analysis of the investigated environments (cf. Figure 18) indicates that Polish students substantively differ from their peers from the University of Ostrava, as they declare the strength of their association with:

- religious group (SS test: $\mathrm{F}(1.328)=207.02 ; \mathrm{p}=0.00)$,

- ethnic group (SS test: $\mathrm{F}(1.328)=29.48 ; \mathrm{p}=0.00)$,

- national group (SS test: $\mathrm{F}(1.328)=9.41 ; \mathrm{p}=0.002)$,

- academic community at their university (SS test: $F(1.328)=4.40 ; \mathrm{p}=0.04)$.

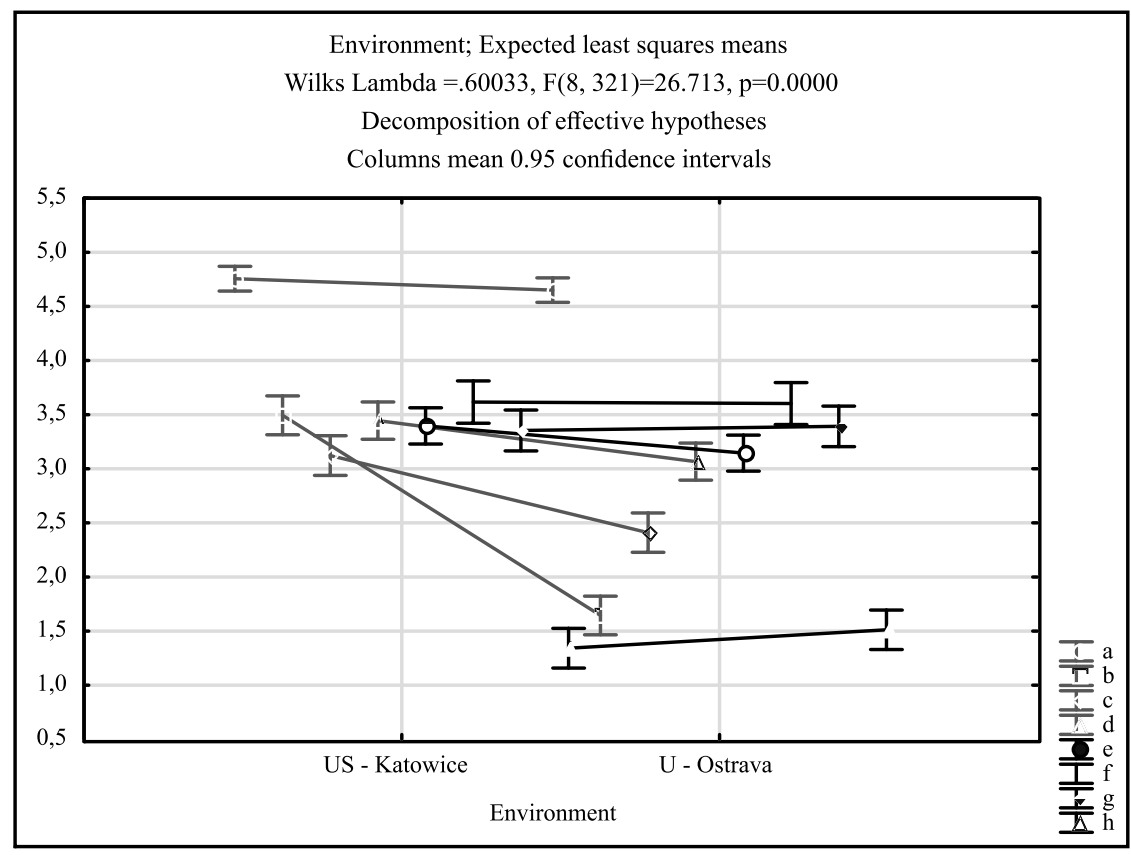

Figure 18. Strength of the feeling of association with selected social groups declared by students from Poland and the Czech Republic (one factor analysis ANOVA). Legend: a - I feel attached to family; b - religious group; $\mathrm{c}$ - ethnic group; $\mathrm{d}$ - national group; $\mathrm{e}$ - academic community at my university; f - group sharing my interests or leisure time group; $\mathrm{g}$ - group of professionals; $\mathrm{h}$ other people/groups. Source: authors' own research. 
Moreover, Polish academic youth substantively more often declare higher evaluations of their association with:

- family (Mann-Whitney U test: $Z=2.07 ; \mathrm{p}=0.039$ ),

- religious group (Mann-Whitney $U$ test: $Z=11.46 ; p=0.00$ ),

- ethnic group (Mann-Whitney $U$ test: $Z=5.18 ; p=0.00$ ),

- national group (Manna-Whitney $U$ test: $Z=2.73 ; p=0.006$ ),

- academic community at their university (Mann-Whitney $U$ test: $Z=2.29$; $\mathrm{p}=0.02)$.

Substantively big differences occur especially in the strength of the feeling of attachment to religious groups, with which $66 \%$ of Polish and $12 \%$ of Czech students identify. The attitude of younger generations to the issue of religion and denomination in the Polish-Czech borderland has been explored and interpreted in intercultural studies for many years. In her latest works, Aniela Różańska $(2015 ; 2019$, pp. 38-54) draws attention to an interesting phenomenon. Although for the last several decades secularization in the Czech Republic has been most visible among all the countries in Central Europe and, according to the newest studies conducted in 2017 within an international research project European Values Study (https://europeanvaluesstudy.eu/), the Czech Republic had the highest percentage of people not belonging to any religious organizations, in the perspective of post-secular Europe, (a) religiousness of the Czech society should be viewed in a different way. It is usually the subject of stereotypical conclusions, drawn mostly on the basis of the institutional aspects of secularization, such as the indicator of religious belonging or the manifestations of religious practices. The thesis presenting Czechs as the most atheized nation is an oversimplification, based on the stereotypical perception of religiousness and on insufficient knowledge concerning the specificity of the religiousness of modern European society, especially the Czech one. Due to the high level of privatization and individualization, as well as the lack of trust in traditional religious institutions, Czech religiousness is a much more complicated phenomenon, which cannot be subjected to unequivocal categorization. This has been confirmed by the latest studies on the religious awareness and attitudes to religion of the Czech society (Różańska, 2019, pp. 40-41).

What is more, individual responses of the surveyed youth from the University of Ostrava show that they search for the sense of life beyond the areas indicated by traditional religion, focusing mostly on their spirituality. In the opinion of Tomáš Halík, the dominating religion of Czechs is neither Catholicism nor atheism but the so-called "somethingism". In this way, he refers to people's belief in "something that exists above them", "a certain supreme power" and/or people's placing the subject of their faith in non-religious spheres (Halík and Dostatni 2011, p. 45). 
Despite the strong feeling of bonds with the religious group declared by Polish students, some significant transformations have taken place also in the image of Polish religiousness over the three last decades. Janusz Mariański, a researcher exploring this issue, notices that contemporary young people have a tendency to negate the traditional (religious and moral) values of the Catholic Church and to take over the values promoted by new ideological currents typical of postmodern and pluralistic societies. Moreover, the "creeping" secularization in youth environments seems to have become a social fact (2019, pp. 19-37).

Polish students' evaluations of the strength of the feeling of association with selected social groups have enabled the distinguishing of their four characteristic clusters (cf. Figure 19). They are characterized in reference to:

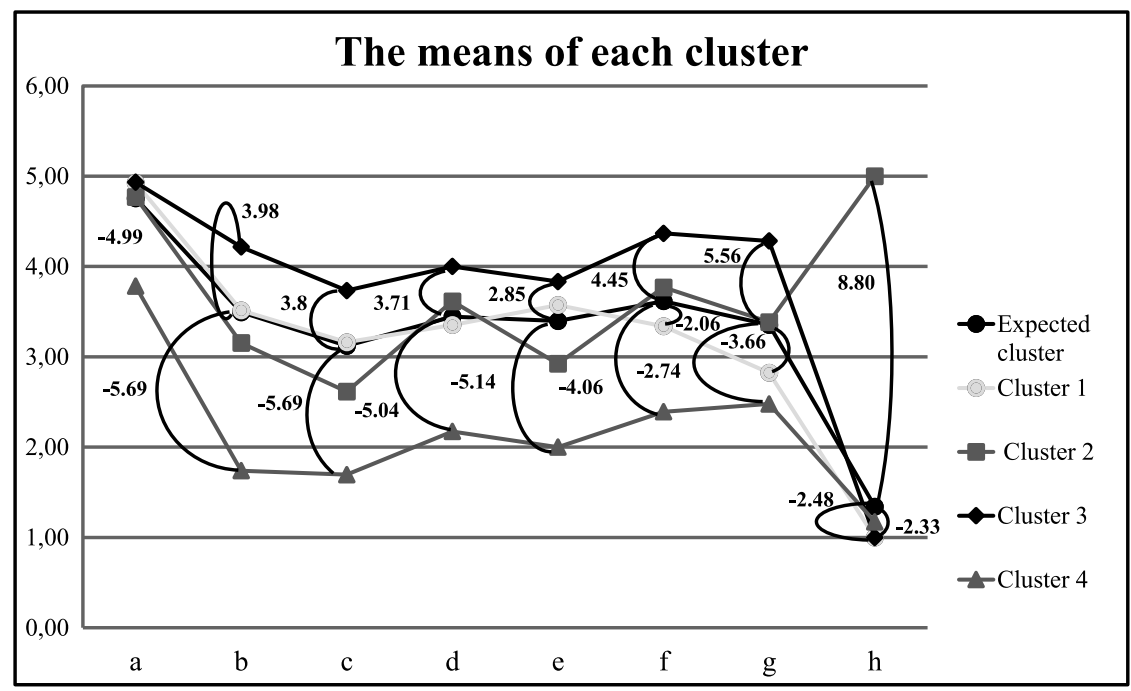

Figure 19. Polish students' profiles concerning the strength of the feeling of association with selected social groups. Legend: a - I feel attached to family; b - religious group; $\mathrm{c}$ - ethnic group; $\mathrm{d}$ - national group; $\mathrm{e}$ - academic community at my university; $\mathrm{f}$ - group sharing my interests or leisure time group; g - group of professionals; h - other people/groups. Source: authors' own research.

- evaluations of cluster 1 (comprising the declarations of $41 \%$ of the respondents) - by a substantively significant underestimation of the strength of feeling of attachment with the interests sharing group and/or leisure time group (Mann-Whitney $U$ test: $Z=-2.06 ; p=0.04$ ), group of professionals $(Z=$ -3.66; $\mathrm{p}=0.0003)$ and other people/groups $(\mathrm{Z}=-2.48 ; \mathrm{p}=0.01)$;

- evaluations of cluster 2 (the declarations of $8 \%$ of the respondents) - by a substantive overestimation of the strength of the feeling of attachment with other people/groups $(Z=8.80 ; \mathrm{p}=0.00)$; 
- evaluations of cluster 3 (the declarations of $37 \%$ of the respondents) - by a substantive overestimation of the strength of the feeling of attachment with all the selected groups, apart from the family one;

- evaluations of cluster 4 (the declarations of $14 \%$ of the respondents) - by a substantive underestimation of the strength of the feeling of attachment with all the selected social groups.

The two largest clusters $(1,3)$ comprising evaluations declared by $78 \%$ of the surveyed Polish students may reflect their actual attitude to the selected social groups. The strongest emotional bonds with family and the significance of family values in the life of young adults seem to be confirmed in their individual responses, in which they draw attention to the following issues:

- they want their children to be brought up in love and this value was the most highly ranked in their declarations. In their opinion, family home, consisting of parents and children, is a place providing the feeling of safety, love, happiness and shelter in difficult moments and situations;

- they feel responsible for shaping the system of values of their (also future) children, mostly for improving their moral structure that promotes the good and truth, as well as for developing their altruistic attitudes. In order to make these values felt, accepted and implemented, the following should have a high position in the family's system of values: concordant coexistence, passing down parental love, truthfulness and honesty;

- they attribute a high rank in the transmission of values to wisdom and knowledge (this refers especially to male respondents), therefore - they would like their children to acquire appropriate education which will enable them to have a decent life in the future. Women, current and future mothers, also focus on the transmission of religious values and on developing sensitivity and respect for other people's religious beliefs;

- another group highly ranked by the respondents comprises the values associated with a peaceful and affluent life in a family and with the preparation for fulfilling future social roles, also of a spouse, as regards both seeking an appropriate partner and passing down the principles of creating a happy marriage and family. The value of a successful marital life is more often indicated by women than men;

- the respondents attribute substantial significance to shaping the attitudes of respect for family and national traditions and to developing the skill of expressing one's beliefs and views, as well as of engaging in the sociocultural life of the region and the country. 
Despite a substantive overestimation in the strength of the feeling of association with all the selected groups apart from family, the surveyed students from the University of Silesia are aware of the need of being social individuals. While choosing other, additional groups, they most often indicated partners, friends, acquaintances, social networks, or sport clubs and teams - the environments in which they are active daily participants and in which they fulfil their present and future goals and life aspirations.

The evaluations, declared by students educated in the Czech Republic, of the strength of the feeling of attachment with selected social groups have made it possible to distinguish four clusters as well (cf. Figure 20). They are characterized in the reference to:

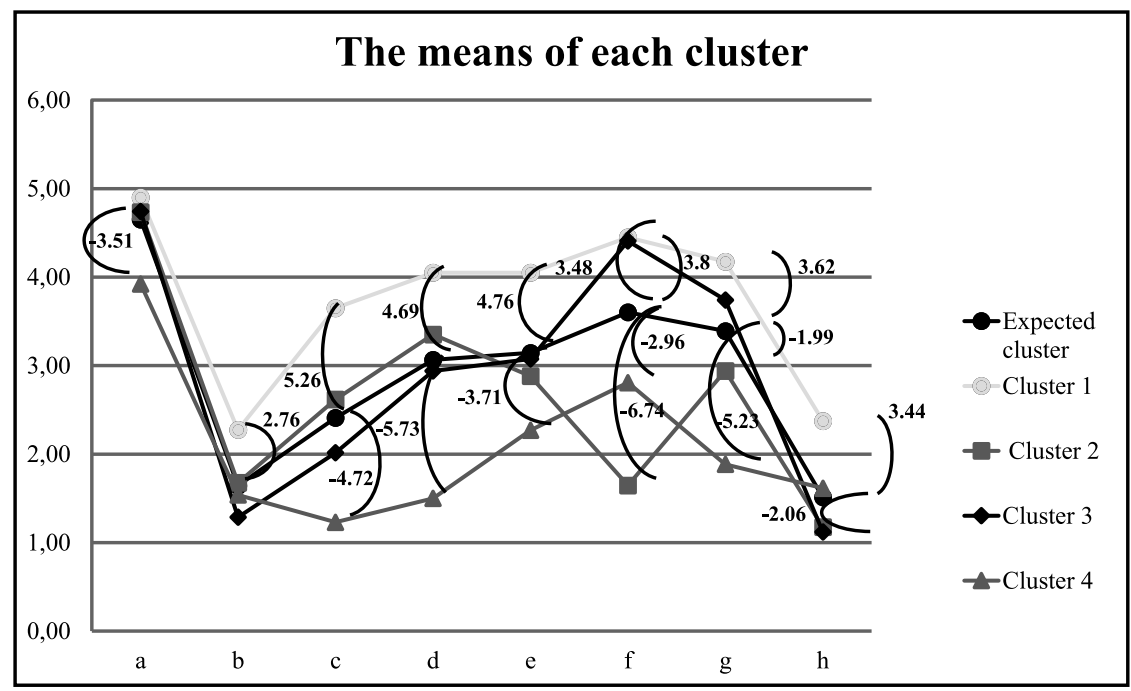

Figure 20. Czech students' profiles concerning the strength of the feeling of attachment to selected social groups based on cluster analysis. Legend: a - I feel attached to family; b - religious group; c - ethnic group; $\mathrm{d}$ - national group; $\mathrm{e}$ - academic community at my university; $\mathrm{f}$ - group sharing my interests or leisure time group; $\mathrm{g}$ - group of professionals; $\mathrm{h}$ - other people/groups. Source: authors' own research.

- evaluations of cluster 1 (comprising the declarations of $24 \%$ of the respondents) - by a substantive overestimation of the strength of the feeling of association with all the selected groups, apart from the family one;

- evaluations of cluster 2 (the declarations of $20 \%$ of the respondents) - a substantively significant underestimation in the strength of the feeling of association with the interests sharing group and/or leisure time group (MannWhitney $\mathrm{U}: \mathrm{Z}=-6.74 ; \mathrm{p}=0.00)$ and the group of professionals $(\mathrm{Z}=-1.99$; $\mathrm{p}=0.047)$; 
- evaluations of cluster 3 (the declarations of $40 \%$ of the respondents) - a substantive underestimation in the strength of the feeling of association with the interests sharing group and/or leisure time group (Mann-Whitney $U$ test: $Z=3.80 ; p=0.0002)$ and an underestimation of the strength of the feeling of association with the group of professionals $(Z=-2.06 ; p=0.04)$;

- evaluations of cluster 4 (the declarations of $16 \%$ of the respondents) - a substantive underestimation in the strength of the feeling of association with all the selected social groups apart from the religious one.

The percentage distribution of the respondents' declarations in particular clusters is more homogeneous than in the case of students from Poland. Cluster 3 ( $40 \%$ of indications) is the closest to the expected clustering. What draws attention is less significance attributed by the academic youth from the Czech Republic to the group of professionals and an obvious overestimation of the significance of interests sharing and leisure time groups. The respondents shed some light on this in their individual statements. On the one hand, they justified their lesser interest in professional work with their studying period, in which they postponed the thoughts about professional career till the following years. On the other hand, it was their age with which they explained the need for active and interesting ways of spending leisure time with their partners, friends, and acquaintances - with related social groups. The existing studies in this field point to similar attitudes of young adults. The type of higher education school and of undertaken studies has determined the contents of the expectations from the future, the breadth of the temporal horizon, and the time location of developmental tasks. Socio-economic factors have influenced the youth's temporal perspective and attitude to time as well (Czerwińska-Jasiewicz, 2003, pp. 149-162; Mądry, 2010, pp. 87-107).

The analysed issues are completed with the respondents' declarations concerning the factors which determine the choice of acquaintances, friends and life partners (cf. Figure 21).

The image of the declared determinants is relatively homogeneous. However, the youth from the University of Silesia attributes much less significance to (cf. Figure 22):

- economic status (Mann-Whitney $U$ test: $Z=-3.18 ; p=0.002$ );

- other factors $(Z=-3.99 ; p=0.00007)$.

Among other factors determining the choice of acquaintances, friends or partners, the following were indicated: individual personality traits (similar personal qualities, temperament, similar character, patience), appearance (piercing, tattoos, healthy teeth), worldview, high personal culture, interests (common hob- 
bies, topics of discussion), and social culture (attitudes to other people and to animals).

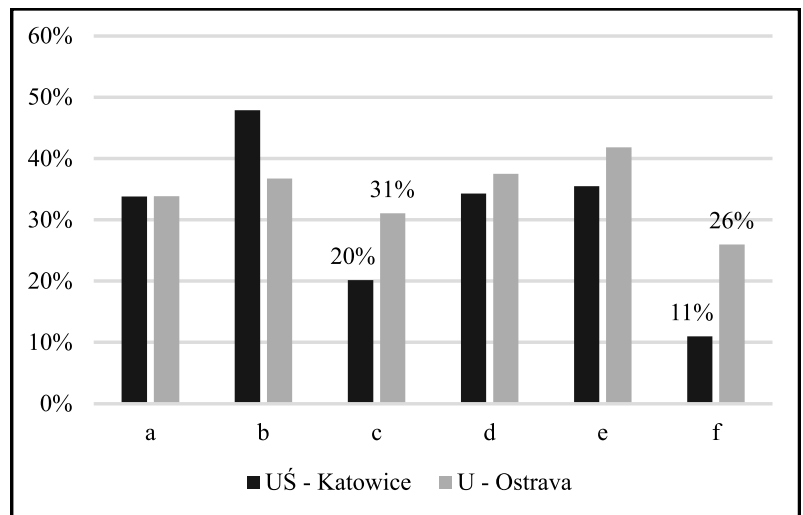

Figure 21. Factors which determine Polish and Czech students' choice of acquaintances and friends (percentages). Legend: $\mathrm{a}$ - nationality; $\mathrm{b}$ - religion; $\mathrm{c}$ - economic status; $\mathrm{d}$ - social status; e - education; f - others. Source: authors' own research.

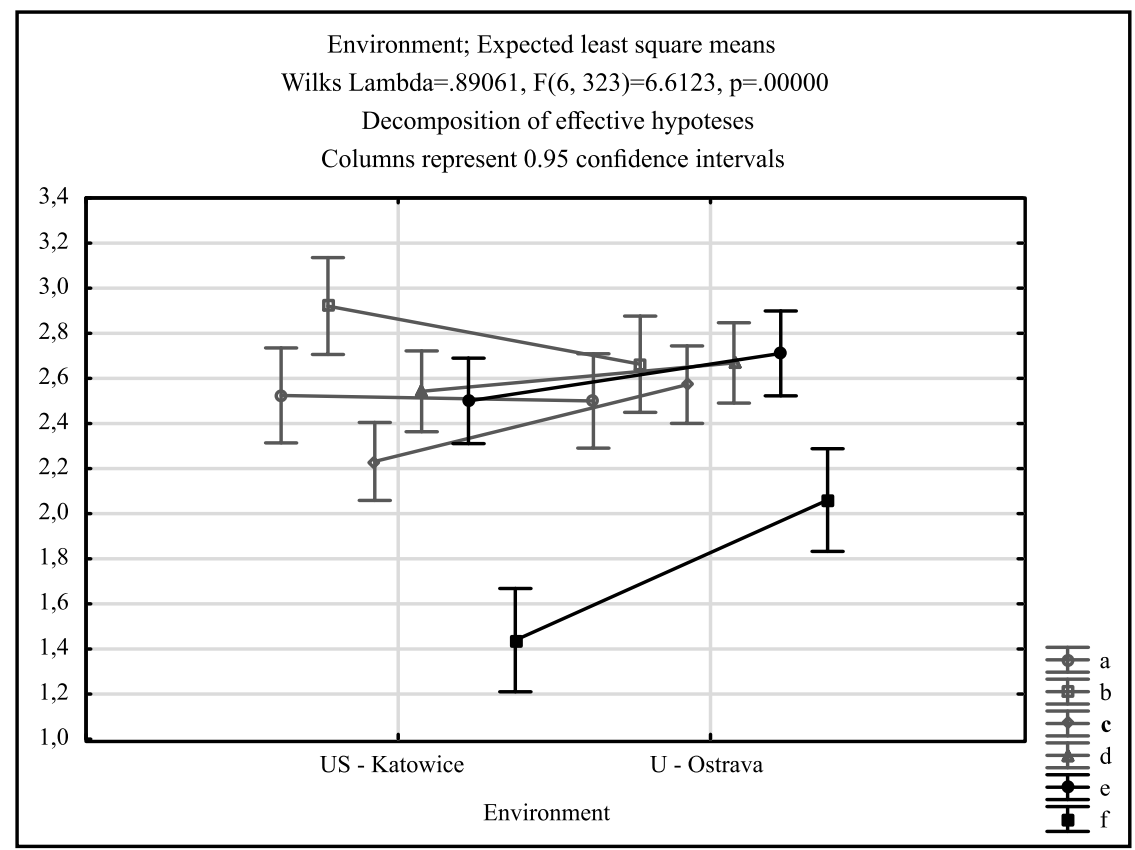

Figure 22. Factors which determine Polish and Czech students' choice of acquaintances and friends (one factor analysis ANOVA). Legend: $\mathrm{a}$ - nationality; $\mathrm{b}$ - religion; $\mathrm{c}$ - economic status; $\mathrm{d}$ - social status; e - education; $\mathrm{f}$ - others. Source: authors' own research. 
Czech students distinguished the so-called other attributes much more often, which can be also categorized as: individual personality traits (similar personal qualities, similar character, intelligence, truthfulness, honesty, carefulness, similar life values, communicativeness, sense of humour), appearance (nice looks, colour of the partner's eyes), interests (common passions, topics of discussion), family environment and education, and social culture (attitude to other people, providing help in problem situations).

The analysis of the individual statements of academic youth from both surveyed environments obtained during interviews and their interpretation confirm that students treat friendship and friends as a specific type of comradeship, which mostly means trust, bonds, honesty, fraternity, attachment, kindness, selflessness, responsibility, loyalty, and help. These attributes of friendship are an element of the broader cultural knowledge acquired in various social environments which allows not only for solving moral and social conflicts, manifesting an ability to compromise and agree within the socially negotiated moral judgements accepted in the peer group, but also for formulating particular valuing orientations concerning friendship, depending on cultural influences and the experienced socio-economic transformations. In the respondents' opinion, the sociocultural knowledge pertaining to friendship comprises such elements as: (1) the scientific component (including the historical context), (2) media component (derived from TV, advertisments, press and the Internet), (3) literary component (referring to generally known stories about true and false friendship), (4) societal one (social - associated with attitudes, especially with their emotional component and activities).

The judgements formulated by the respondents about friendship and its significance in the feeling of association with related social groups contain various types of valuing:

- the criterion of the sources of knowledge (cognitive aspect), enables one to distinguish:

- direct valuing - referring to individual experiences (individual situations and events, taking place in the family, academic or peer environment) and attributing significance (sense, importance) to friendship and/or its lack for oneself or the closest people;

- indirect valuing - determined by the acquired scientific and popular knowledge of the cultural reality and referred (in the form of statements that friendship is an objective good) to particular other people, their needs, interests, and situations;

- the criterion of emotional attitude (emotional-evaluative aspect) makes it possible to indicate:

- positive valuing - expressed in applying one's own positively marked attitude to friendship and friends; 
- negative valuing - consisting in the specification of one's own axiologically negative attitude to friendship and, at the same time, in the showing of the critically evaluated attitude to oneself and to other people;

- the criterion of behaviour (aspect of acting) enables the distinction of:

- individual valuing - in which judgements (formulated independently from the beliefs of others) result in one's own, internally justified (without any ambivalence) acting which enhances the implementation of friendship;

- social valuing - determined (sometimes induced) by external factors in the form of evaluatively heterogeneous beliefs taken over from other significant people and/or mass media.

\subsubsection{One's own life situation and satisfaction from it versus the feeling of identity}

Young adults' assessment of their own life situation is related to such cognitive categories as satisfaction, happiness, feeling of mental welfare, satisfaction with life or with its quality. As many psychologists and researchers into this subject emphasize, these terms are not identical, yet - they all refer to the individual's general attitude to life, owing to which a person actively struggles against adversities and consistently aims at fulfilling important values (Reber, 2000; Czapiński, 2004; Kanasz, 2015). It should also be stressed that the evaluation of one's own life situation may be treated as a cognitive-affective process which comprises the analysis of one's own situation and its assessment according to the fulfilment of internalized standards or as the process entailing the assessment of life as a global project stretching in the time perspective (Şimşek, 2009, Suchodolska, 2017).

The surveyed academic youth expressed their opinions on a 1-7 scale - from extreme, severe and moderate dissatisfaction, through moderate, severe and extreme satisfaction, to the answer "this does not concern me". The declarations composed four characteristic subsystems (cf. Figure 23).

What is located in the first subsystem are the indications concerning the fields of life with which the academic youth is satisfied - family life (PL - 96 \%, CZ $87 \%$ ), the environment of friends (PL - 91\%, CZ - $95 \%$ ) and the own health (PL $88 \%, \mathrm{CZ}-80 \%)$. The respondents express lesser satisfaction at life and educational achievements (PL - 86\%, CZ - 72\%), ways of spending leisure time (PL $85 \%, \mathrm{CZ}-83 \%$ ), studies (PL - 84\%, CZ - $88 \%$ ) and emotional life (PL - 82 \%, CZ $-80 \%)$. They are much less satisfied also with their current financial situation (PL $-76 \%, C Z-70 \%)$ and professional prospects after their studies (PL - $70 \%$, $\mathrm{CZ}-76 \%)$. The fourth subsystem is composed of the fields with which the 
respondents are the least satisfied - the economic (PL - $50 \%, \mathrm{CZ}-41 \%)$ and political (PL - 36\%, CZ - $31 \%$ ) situation in their countries.

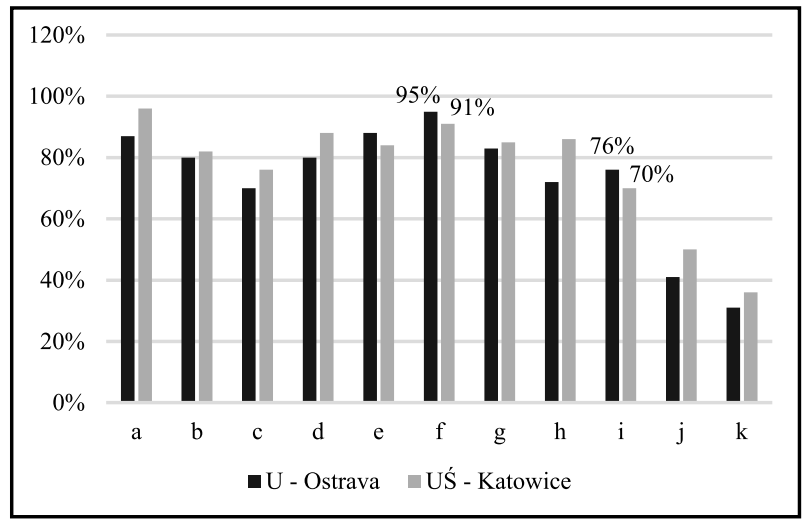

Figure 23. Polish and Czech students' feeling of satisfaction at their own life situation (percentages). Legend: $\mathrm{a}$ - family life; $\mathrm{b}$ - emotional life; $\mathrm{c}$ - financial situation; $\mathrm{d}$ - health condition; $\mathrm{e}$ studies; $\mathrm{f}$ - friends; $\mathrm{g}$ - way of spending free time; $\mathrm{h}$ - own life and educational achievements; $\mathrm{i}$ - professional prospects after studies; $\mathrm{j}$ - participation in culture, artistic activity, creativity; $\mathrm{k}$ life full of changes, adventures, attractions. Source: authors' own research.

The image of the declared feeling of satisfaction at the students' own life situation in both environments is relatively homogeneous. Still, the academic youth from the University of Silesia significantly more often than their peers from the University of Ostrava express lower evaluations in reference to (cf. Figure 24):

- friends (Mann-Whitney U test: $Z=2.62 ; \mathrm{p}=0.009$ );

- professional prospects after their studies $(Z=2.02 ; \mathrm{p}=0.044)$.

The subjective evaluation of their own life situation and satisfaction with it, as outlined by students from the Polish-Czech borderland, is determined by the individual system of their values and it indicates the way of students' perceiving the surrounding reality. As the analyses carried out so far show, young adult learners give the highest rank in their life to family values and to the peer environment (including friends and acquaintances). They are also satisfied with their health condition and they undertake various activities (e.g. regular sport exercises, healthy nutrition, healthy lifestyle) which confirm their pro-health attitudes. It does not seem to be a surprise that the respondents are not satisfied with the economic and political situation in their countries, which in fact determines their financial status, educational possibilities and professional prospects after their studies. On the basis of the data collected in the $6^{\text {th }}$ edition of the international studies Eurostudent (2018, pp. 57-59), it can be claimed that students' financial situation mostly depends on their families (PL - $46 \%, \mathrm{CZ}-50 \%$ ) and 
their own work incomes (PL - $40 \%, \mathrm{CZ}-43 \%)$, and - to the smallest extent - on the public support guaranteed by the state (PL $-3 \%, \mathrm{CZ}-2 \%)$. What is worth mentioning here are the countries in which students getting support from public sources constitute the large majority of their population (more than $60 \%$ ) - these are: Turkey, France, Sweden, Malta, Norway, Holland and Denmark. In the last of them, $91 \%$ of students obtain public financing and it constitutes $66 \%$ of their total budget (ibid, p. 75). In several countries, also in Poland, almost two fifths of students (38\%) admitted that they currently experienced severe or very severe financial difficulties - it is one of the highest numbers in Europe (ibid., pp. 8589).

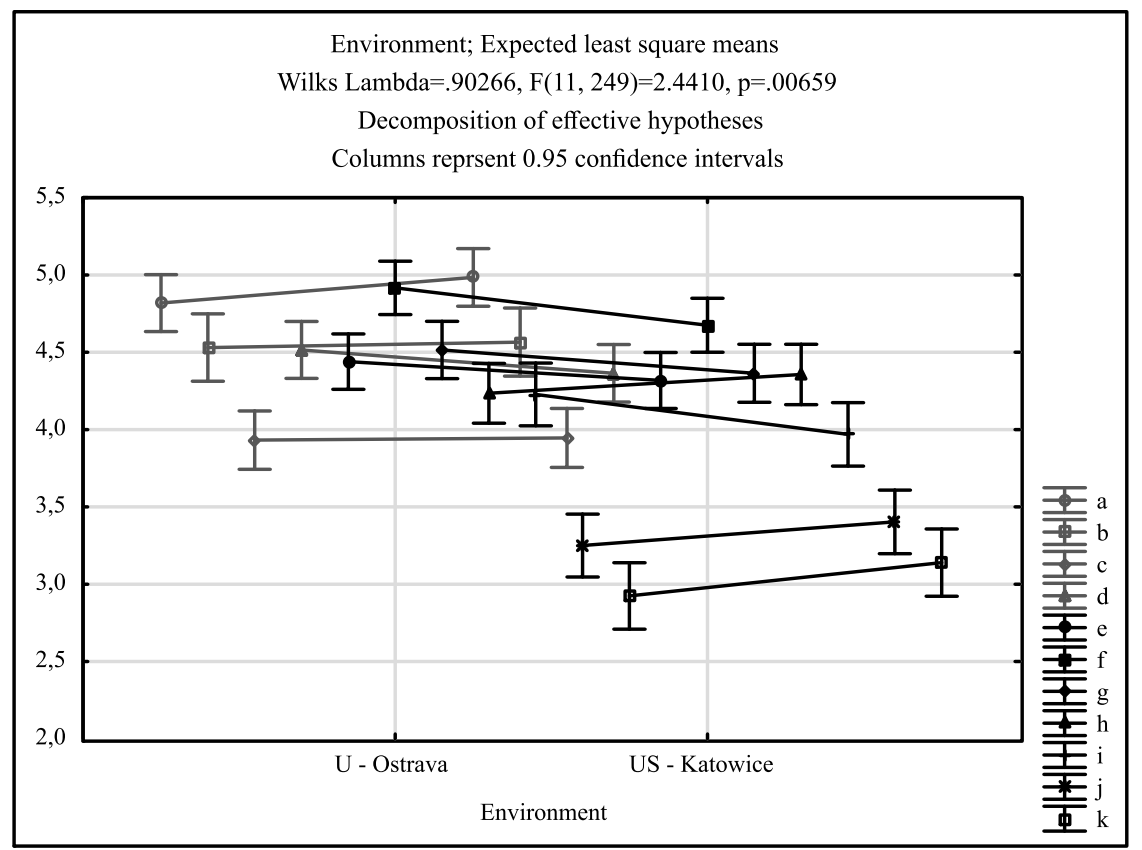

Figure 24. Polish and Czech students' feeling of satisfaction with their own life situation (one factor analysis ANOVA). Legend: $a$ - family life; $b$ - emotional life; $c$ - financial situation; $d$ health condition; e - studies; $\mathrm{f}$ - friends; $\mathrm{g}$ - way of spending free time; $\mathrm{h}$ - own life and educational achievements; $\mathrm{i}$ - professional prospects after studies; $\mathrm{j}$ - participation in culture, artistic activity, creativity; $\mathrm{k}$ - life full of changes, adventures, attractions. Source: authors' own research.

In the authorial studies, an attempt was also made to specify the relationship between Polish and Czech students' life satisfaction and their feeling of identity in the local, regional, national, European and supra-European dimension. The detailed data concerning the statistically significant relationships are presented in Table 3. 
Table 3. Evaluation of Polish and Czech students' satisfaction versus their feeling of identity (statistically significant data)

\begin{tabular}{|c|c|c|c|c|c|c|c|c|c|c|c|}
\hline \multicolumn{2}{|l|}{ Categories } & \multicolumn{2}{|c|}{$\begin{array}{c}\text { I feel } \\
\text { a resident } \\
\text { of my } \\
\text { town / vil- } \\
\text { lage }\end{array}$} & \multicolumn{2}{|c|}{$\begin{array}{c}\text { I feel } \\
\text { a resident } \\
\text { of the re- } \\
\text { gion }\end{array}$} & \multicolumn{2}{|c|}{$\begin{array}{c}\text { I feel a } \\
\text { citizen of } \\
\text { Poland/ } \\
\text { Czech Re- } \\
\text { public }\end{array}$} & \multicolumn{2}{|c|}{$\begin{array}{l}\text { I feel } \\
\text { a Euro- } \\
\text { pean }\end{array}$} & \multicolumn{2}{|c|}{$\begin{array}{l}\text { I feel a } \\
\text { citizen of } \\
\text { the world }\end{array}$} \\
\hline & & PL & $\mathrm{CZ}$ & PL & $\mathrm{CZ}$ & PL & $\mathrm{CZ}$ & PL & $\mathrm{CZ}$ & PL & $\mathrm{CZ}$ \\
\hline \multirow[t]{2}{*}{ Family life } & $S$ & $\mathrm{H}$ & & $\mathrm{H}$ & & $\mathrm{H}$ & & $\mathrm{H}$ & & $\mathrm{H}$ & \\
\hline & NS & & & & & & & & & & \\
\hline \multirow[t]{2}{*}{ Emotional life } & S & & & & & & & $\mathrm{H}$ & $\mathrm{H}$ & $\mathrm{H}$ & \\
\hline & NS & & & & & $\mathrm{L}$ & & & & & \\
\hline \multirow{2}{*}{$\begin{array}{l}\text { Financial sit- } \\
\text { uation }\end{array}$} & S & & & & & & $\mathrm{H}$ & & $\mathrm{H}$ & & $\mathrm{H}$ \\
\hline & NS & & $\mathrm{L}$ & & $\mathrm{L}$ & & $\mathrm{L}$ & & $\mathrm{L}$ & & $\mathrm{L}$ \\
\hline \multirow[t]{2}{*}{ Health condition } & S & & & & & & & & $\mathrm{H}$ & & \\
\hline & NS & $\mathrm{L}$ & & $\mathrm{L}$ & & & & & $\mathrm{L}$ & & \\
\hline \multirow[t]{2}{*}{ Studies } & $S$ & $\mathrm{H}$ & & $\mathrm{H}$ & & & & & $\mathrm{H}$ & & \\
\hline & NS & & & $\mathrm{L}$ & & & & & & & $\mathrm{L}$ \\
\hline \multirow[t]{2}{*}{ Friends } & S & $\mathrm{H}$ & $\mathrm{H}$ & $\mathrm{H}$ & & & & $\mathrm{H}$ & & & \\
\hline & NS & & & $\mathrm{H}$ & & & & & & & \\
\hline \multirow{2}{*}{$\begin{array}{l}\text { Ways of spending } \\
\text { free time }\end{array}$} & $S$ & $\mathrm{~L}$ & $\mathrm{H}$ & & $\mathrm{L}$ & & & & $\mathrm{L} / \mathrm{H}$ & & $\mathrm{L}$ \\
\hline & NS & & & & & & & & $\mathrm{L}$ & & \\
\hline \multirow{2}{*}{$\begin{array}{l}\text { Students' own life } \\
\text { and educational } \\
\text { achievements }\end{array}$} & $S$ & & $\mathrm{H}$ & & $\mathrm{H}$ & & $\mathrm{H}$ & & $\mathrm{H}$ & & $\mathrm{L} / \mathrm{H}$ \\
\hline & NS & & & & & & & & $\mathrm{L}$ & & $\mathrm{L}$ \\
\hline \multirow{2}{*}{$\begin{array}{l}\text { Professional } \\
\text { prospects after } \\
\text { studies }\end{array}$} & $S$ & & $\mathrm{H}$ & $\mathrm{H}$ & & & $\mathrm{L} / \mathrm{H}$ & $\mathrm{H}$ & $\mathrm{H}$ & $\mathrm{H}$ & \\
\hline & NS & $\mathrm{L}$ & & & & $\mathrm{L}$ & & & & & \\
\hline \multirow{2}{*}{$\begin{array}{l}\text { Economic sit- } \\
\text { uation of the state }\end{array}$} & $S$ & $\mathrm{H}$ & & & $\mathrm{H}$ & & & & $\mathrm{H}$ & & $\mathrm{H}$ \\
\hline & NS & $\mathrm{L}$ & $\mathrm{L}$ & & $\mathrm{L}$ & $\mathrm{L}$ & & & $\mathrm{L}$ & & $\mathrm{L}$ \\
\hline \multirow{2}{*}{$\begin{array}{l}\text { Political situation } \\
\text { of the state }\end{array}$} & S & $\mathrm{H}$ & & & $\mathrm{H}$ & & & & & & \\
\hline & NS & $\mathrm{L}$ & & & & & & & & & \\
\hline
\end{tabular}

Legend: S - satisfaction; NS - no satisfaction; H - high significant evaluation; L - low significant evaluation; PL - Poland; CZ - Czech Republic. Source: authors' own research.

In the environment of Polish students, the people who feel significantly more strongly associated with their living place are simultaneously very satisfied with their studies (Mann-Whitney $U$ test: $Z=2.65 ; p=0.008$ ), family life $(Z=2.35$; $p=0.02)$ and friends $(Z=2.20 ; p=0.03)$. Yet, they critically evaluate their town or village as regards the economic and political situation of the country $(Z=-2.45$; $\mathrm{p}=0.04)$, professional prospects after their studies $(Z=-2.19 ; \mathrm{p}=0.029)$, the 
possibilities of spending leisure time $(Z=-2.03 ; p=0.042)$ and their own health condition $(Z=-2.01 ; \mathrm{p}=0.044)$.

The significantly strong association with the region is related to students' satisfaction with friends $(Z=2.97 ; p=0.003)$, studies $(Z=2.76 ; p=0.006)$, professional prospects after studies $(\mathrm{Z}=2.54 ; \mathrm{p}=0.011)$ and family life $(\mathrm{Z}=2.22$; $\mathrm{p}=0.03)$.

Young adults assess their feeling of being a citizen of Poland through negative experiences and dissatisfaction at the economic situation of the state $(Z=-2.34$; $\mathrm{p}=0.019)$, professional prospects after their studies $(Z=-2.40 ; \mathrm{p}=0.017)$ and their own emotional life $(Z=-2.03 ; p=0.04)$. Only the students who are satisfied with their family life are at the same time more strongly emotionally attached to their homeland $(Z=2.03 ; p=0.04)$.

Two dimensions of the feeling of identity - the European and supra-European one - are determined by significantly positive evaluations resulting from students' satisfaction at their professional prospects after their studies $(Z=2.67$; $\mathrm{p}=0.008)$, friends $(\mathrm{Z}=2.32 ; \mathrm{p}=0.02)$, emotional life $(\mathrm{Z}=2.21 ; \mathrm{p}=0.03)$ and family life $(\mathrm{Z}=2.01 ; \mathrm{p}=0.04)$.

Satisfaction (or its lack) due to the financial situation and their own life and educational achievements does not significantly differentiate the evaluations of all the surveyed students' feeling of identity. What draws attention in the general image of the respondents' assessment of their own life situation and satisfaction at it is the low evaluation of the feeling of being a citizen of Poland. It can be assumed that the contemporary phenomena (associated with globalization, integration or immigration) taking place worldwide are changing the way of thinking about oneself and Others. The choice of the place/country of everyday life, work or education verifies the perception of oneself and of Others and contributes to the change of the feeling of identity and the related behaviour patterns. The surveyed academic youth living in the cultural borderland shape their awareness in complex sociocultural arrangements, which in turn verify their view on and evaluation of the present reality. Therefore, their identity problems, confirmed by the results of other studies (Zagórski and Strzeszewski, 2005; Rembierz, 2008b, pp. 47-60; Nikitorowicz, 2013, pp. 29-49), are not surprising.

The community of Czech students is more diversified in their declarations pertaining to their satisfaction with life and its relation to the feeling of identity. Only family life does not significantly differentiate the evaluations of all the respondents' feeling of identity. In the remaining cases, both positive and negative evaluations occur. The number of the latter particularly increases in regard to the dimension of the feeling of being a European and a citizen of the world.

Young learning adults in the Czech part of the borderland feel significantly more associated with their town/village, being at the same time satisfied with the way of spending free lime there $(Z=2.55 ; p=0.011)$, their own life and educa- 
tional achievements $(Z=2.24 ; p=0.025)$, friends $(Z=2.22 ; p=0.0265)$ and professional prospects after their studies $(Z=1.99 ; \mathrm{p}=0.047)$. Yet, they critically evaluate their place of residence as regards the economic situation of the country $(Z=-3.07 ; p=0.002)$, which determines their own financial situation $(Z=-2.12$; $\mathrm{p}=0.034)$.

The strong feeling of identity in the regional dimension is determined by both moderate and strong satisfaction at the economic and political situation of the state $(Z=2.44 ; p=0.015)$, the respondents' own life and educational achievements $(Z=2.25 ; p=0.025)$, and by extreme dissatisfaction at the economic situation of the state $(Z=-2.45 ; p=0.015)$, at their own financial situation $(Z=$ -2.29; $\mathrm{p}=0.022)$ and their way of spending leisure time $(Z=-2.06 ; \mathrm{p}=0.039)$.

In the national dimension - the feeling of being a citizen of the Czech Republic - students also declare extreme evaluations. They are both extremely satisfied and dissatisfied with their professional prospects after their studies $(\mathrm{Z}=2.71 ; \mathrm{p}=0.0067 ; \mathrm{Z}=-2.35 ; \mathrm{p}=0.019)$ and their own financial situation $(Z=2.41 ; p=0.016 ; Z=-2.33 ; p=0.02)$. Only their strong satisfaction with life and educational achievements is positively related to the feeling of identity in this field $(\mathrm{Z}=2.47 ; \mathrm{p}=0.014)$.

A similar phenomenon takes place in the case of the feeling of being a European. University students in the Czech environment, satisfied with their professional prospects after their studies $(Z=3.38 ; \mathrm{p}=0.0007)$, with their studies $(Z=2.77 ; p=0.006)$ and their emotional life $(Z=2.64 ; p=0.008)$, significantly feel the strongest associations with Europe. However, they also formulate extreme assessments of both satisfaction and dissatisfaction at their way of spending leisure time $(Z=4.13 ; p=0.00004 ; Z=-2.04 ; p=0.042)$, their own life and educational achievements $(Z=4.65 ; p=0.00003 ; Z=-2.76 ; p=0.0057)$, financial situation $(Z=3.82 ; p=0.0001 ; Z=-2.41 ; p=0.016)$, health condition $(Z=2.74$; $\mathrm{p}=0.006 ; \mathrm{Z}=-2.78 ; \mathrm{p}=0.005)$ and the economic situation of the state $(Z=2.08$; $\mathrm{p}=0.038 ; \mathrm{Z}=-2.03 ; \mathrm{p}=0.043)$.

The respondents express the weakest intensity of the feeling of being a citizen of the world, which is mostly manifested in their dissatisfaction with many aspects of their own life, mostly at the economic situation of the state $(Z=-2.75$; $\mathrm{p}=0.006)$, their way of spending free time $(Z=-2.25 ; \mathrm{p}=0.024)$, their studies $(Z=$ $-2.13 ; p=0.033)$, their life and educational achievements $(Z=-2.07 ; p=0.038)$ or their own financial situation $(Z=-2.00 ; p=0.047)$.

The obtained research results seem to confirm that the academic youth in the Polish-Czech borderland present two clearly different approaches - on the one hand - to the evaluation of the feeling of satisfaction at one's own life situation, and - on the other - to the feeling of identity, especially in the European and supra-European dimension, which is determined by the former. Although both these neighbouring countries have undergone political transformations, they 
belong to the European Union and they collaborate in many fields, it turns out that the conditions of life, particularly the influences in the educational sphere, models and socially recognized values or lifestyles are significantly different.

\section{Conclusions}

At the end of the second decade of the $21^{\text {st }}$ century, young adults are a new generation, being markedly different from earlier generations. Their specificity and unlikeness is derived from the sociocultural, political and economic situation of both investigated countries, Europe and the world, which - at the same time - is an important reference point.

The surveyed students from the Polish-Czech borderland are aware of their own subjectivity, of their individual distinctiveness and self-identity, which appear in particular social interactions. The characteristic features of these students are the following: specific optimism (a mindset towards positive events and success), self-confidence (the belief in one's own powers, preferences and potentialities), selectiveness (firmly determined valuing, selective reception and processing of information), and searching for causality (aiming at finding out cause-effect relationships between phenomena and, first of all, between their own behaviour and the possible consequences of undertaken activities). Therefore, it can be stated that university students fulfil their own life aspirations in three basic perspectives of self-perception and the perception of the surrounding culturally diversified environment:

- in the perspective indicated by the category of "time" - which orientates academic youth in their choices towards the present and future time, determined by the own group's traditions;

- in the perspective indicated by the category of "identity structure";

- in the perspective pertaining to the category of "social role" (Urbański-Korż, 1998, pp. 19-21).

What can be distinguished in the image of values preferred by Polish students and their peers from the University of Ostrava are the dominating sets of family life values and those concerning a comfortable, attractive life. Family values are still highly ranked by the respondents (especially in the Polish part of the borderland), which points to a preserved cross-generation continuity. Family is still the most appreciated value, the fundamental educational environment and the place where values are passed down. Yet, the majority of young adults are interested neither in participating in culture nor in their engagement in social matters and undertaking civil activity. A very low feeling of influence on social matters is manifested not only by the young from the Polish-Czech borderland 
but also by the whole young generation in Poland and the Czech Republic. The young attribute a lot of significance to the value of work and the acquisition of high professional qualifications, as well as to the moral aspects of their life. However, the general image of respondents' axiological preferences is characterized by a decreasing level of the total system of values, the growing tendency to focus on life for oneself, the increasing significance of individual-private values (in contrast to social ones), and aiming at self-fulfilment, understood as the conduct compliant with one's own potentialities and needs but, simultaneously, rejecting all ideologies, including the religious one.

The differences occurring in the feeling of identity and national identifications declared by particular groups of students indicate the currently observed tendency to the young generation's identification with various communities - national, local, regional, or more broadly - European and supraEuropean ones. Young learning adults' construction of their own identity means drifting apart from its homogeneous dimension in favour of discovering and a conscious choice of the enriched, multidimensional identity, most frequently determined by the processes of the democratization of social life, which take place at various paces and in various scopes. Yet, Czech students manifest the feeling of being a European or a citizen of the world to a much smaller extent. They associate their life, educational and professional plans mostly with the nearest region and the resident country.

Another important dimension of the respondents' cultural identity is their declaration concerning the strength of attachment to selected social groups in the life of which they regularly participate. The obtained research results show that young learning adults feel the strongest bonds with the family environment, the peer groups with which they share their interests and passions and spend their leisure time, as well as with the groups of professionals with whom they work. Thus, these choices confirm students' axiological preferences, in which family and profession-related values gained the biggest number of indications in both surveyed environments.

In the context of Boski's theory of cultural identity based on values and practices in the conditions of bi- and multicultural socialization, the cultural identity of the surveyed university students has a relational character. Therefore, in this context - cultural transmission is possible during the intentional learning process (e.g. in family, university, peer groups or the local environment) as well as due to the experience in the social discourse of a particular country (Boski, 2009, pp. 542-547).

What also seems to be confirmed is Arnett's standpoint, formulated in his theory of emerging adulthood. According to it, the stage of emerging adulthood occurs in the countries in which the knowledge-based economy dominates and people - to achieve a satisfying social position - have to devote many years to 
education and collecting experience, so they postpone the tasks of adulthood to the moment of achieving an appropriate social and professional position (Arnett, 2000, pp. 470-479). Both the Polish and Czech respondents confirm their decreasing motivation to engage in adult social roles and their tendency to put them off. As a result, they get married or plan this later and they decide to have children much later.

The discussion presented in this chapter does not reflect the full image of the formation of the cultural identity and behaviour of young learning adults living in the Polish-Czech environment. It only constitutes an attempt to capture, describe and interpret the characteristic features and the tendencies within the discussed issues. However, this is of substantial significance for undertaking educational activities in culturally diversified communities. 
Chapter 2.

A difficult history - what about the present day? Borderland relationships in the declarations of surveyed university students

A familiarization with other cultures is often related to travelling, which may have different characters and ranges in the contemporary world. Ryszard Kapuściński states that the biggest advantage of travelling is: "Kindness. The kindness to the Different, to the Other, the kindness that tames evil and creates a climate in which all the best and the most important becomes possible" (2008, p. 58). However, what is actually drawn from a trip is an individual matter. As the author writes: "We live closed in our cultures and geographies. They are enough for us" (p. 58), but - for other people - the goal of a trip can be the wish to experience dissimilarity (p. 102). Borderland residents do not have to travel far to learn about another culture - their Other neighbours live next to them. The location in a borderland zone is favourable due to the possibility of implementing joint activities (resulting from cross-border agreements, for example) and of participation in projects addressed to the residents of the countries which are divided/ joined by the border. This gives a chance for meeting and getting acquainted with each other. However, a possibility does not mean that all the borderland residents consider these chances as attractive and worth using.

In the territorial approach, the borderland is an area, a common space in which two or more ethnic-cultural groups function. This is an area located between two state (or regional) territories, characterized by moving around (which has an ethnic or national character) as a result of spatial closeness (Kłoskowska 1996, p. 125). The forms of coexistence are shaped through being side by side - in contacts with each other. This permeating and melting of cultures makes the borderland a very specific territory. It is a space where the norms determining a life close to each other (despite the visible differences) can be worked out in a natural way. In the perception of neighbours, there is a danger of treating what is close as evident and familiar (though in fact never familiarized), which in turn results in no need for deepening this knowledge. Another problem is the only seemingly easy way of establishing contacts (especially in the situation of linguistic closeness). 
Borderland relationships depend on many factors. They are partially associated with individual undertakings and partially initiated, promoted and implemented by various institutions, organizations, associations and societies. In the Polish-Czech borderland, the trans-border collaboration is developing intensively. This brings about both the so-called hard projects (building bridges which join both countries, common roads, etc.) and soft ones, which strengthen e.g. social or intercultural competences and are aimed at enhancing the collaboration. Yet, being a neighbour also means the burden brought about by a common (to both nations) history. In the case of the Polish-Czech borderland, there seem to be fewer difficult experiences - at least in the opinion of people living outside the borderland. In fact, this is a difficult neighbourhood which has been influenced by many conflicts, territorial and ideological arguments, as well as by mutual stigmatization.

What has been observed in Poland for several years is a lot of interest in Czechs and the Czech Republic as well as the movement of "Czechophiles". Specifically, the past few years have brought about a particular interest in Poland's southern neighbours. Classical Czech literature is extremely popular, which is confirmed by numerous re-editions of the works of such classics as Bohumil Hrabal, Milan Kundera or Karel Čapek, but also of less famous writers, such as Ota Pavel and Evžen Boček. The knowledge of Czechs and the Czech Republic is also popularized by Aleksander Kaczorowski (2007, 2012, 2018), Leszek Mazan (2007), Mariusz Szczygieł (2006, 2010, 2012) or Mariusz Surosz (2010). Their publications, especially the works of M. Szczygieł, have quickly become unavailable on the book market in spite of their many re-editions. Many blogs ${ }^{17}$ or websites in well-known social networks ${ }^{18}$ are very popular, too. More formalized activities are conducted by some associations, gathering enthusiasts of the Czech culture, art and daily life, such as Czuli Barbarzyńcy [Sensitive Barbarians], which organize festivals of Czech culture, conferences, lectures with invited experts on the Czech Republic (Czuli barbarzyńcy...). Statistical studies confirm that Czechs are one of the most liked nationalities in the world. In 2011, $51 \%$ of the respondents declared a liking of Czechs (Stosunek Polaków do... No. 13/2011), three years later - a slight decrease to $50 \%$ was noted (Stosunek Polaków do innych... No. 20/2014), and after another three years later - a record increase to $59 \%$ took place (Stosunek Polaków do innych... No. 21/2017). Although the year 2018 brought in a general decrease in Poles' liking of other nationalities, Czechs are still the most liked - with $44 \%$ of declarations (Stosunek Polaków do innych... No. 37/2018) favoring Czechs. This enhances the building of a positive image of

17 https://czechofil.com (access: 18.01.2017) Czechy-okiem Czechofila; Czechofil; Český sen. 18 A website which achieved 7556 likes on Facebook on the 14 ${ }^{\text {th }}$ February 2019: https://web. facebook.com/czechofile/?_rdr (access: 14.02.2019). 
Poland's southern neighbours. Such an interest in the neighbour and a positive attitude are favourable for establishing contacts and a wish for a closer relationship. This can also be seen in the search for attractive places for recreation, which may sometimes have a mass form that the hosts are not prepared for (Skalne miasto oblegane przez Polaków...).

Yet, does geographical closeness enhance real mutual familiarization by those who are situated the closest? Does a small geographical distance measured in kilometres imply actually getting acquainted with each other? What can be observed while conducting my studies in the Polish-Czech borderland for many years is that the tendency to be interested in the Czech Republic, which is present in other regions, is not as strong in the borderland (Lewowicki, 2017; Szafrańska, $2017 \mathrm{a}, \mathrm{b} ; 2018 \mathrm{a}, \mathrm{b})$. The easy access to information and to establishing formal and informal contacts does not increase the interest. We stand near each other, but do we not stand there with our backs turned? The research conducted among students learning in two universities at a distance of less than $40 \mathrm{~km}$ but situated in two countries is aimed at providing answers also to these questions.

\subsection{A neighbour as the other or our own? The relationship between Poles and Czechs in the region}

Due to the changing conditions of the individual functioning of future teachers the issue of preparing them for life in a culturally diversified environment gains growing significance. The global nature of changes in the modern world necessitates a confrontation with the differences between cultural traditions and patterns. This does not always take place in direct contacts of individuals and groups but often occurs through social media messages. These processes result in many social attitudes to the unknown and untamed values which are carried by the (linguistically, religiously, ethnically, nationally, culturally) Others. The issue of students' intercultural competences has been analysed in our earlier studies (Ogrodzka-Mazur, Szafrańska, Malach, Chmura, 2015). Here, our focus is on how the respondents assess their level of intercultural competences acquired during their university studies.

Competences have a multidimensional, dynamic and multisided character. In the situation of intensive intercultural contacts, the space for the exchange of values between groups and individuals has become a specific laboratory for investigating the attitudes towards Others. Intercultural competences constitute a capital of multicultural communities, which dominate the contemporary world, specifically in the West. They comprise: 
- knowledge of and attitude towards Others (relationships with the Other);

- perception of oneself and one's own identity in the multicultural world;

- familiarization with and attitude to the spiritual culture of Others (to their world of ideas);

- values (the wealth of intellectual culture);

- knowledge of and attitude to the material culture (and wildlife) of Others (Lewowicki, 2011, p. 34).

The surveyed university students were asked how they assess the intercultural competences acquired in the course of their studies. The biggest group of respondents (128 people) said that they were unable to do this. Similarly sized groups evaluated their acquired competences as high (82 people) and low (78 people). The extreme assessment was attributed in the case of 29 students who declared a very low level and 13 who declared a very high level (cf. Figure 25).

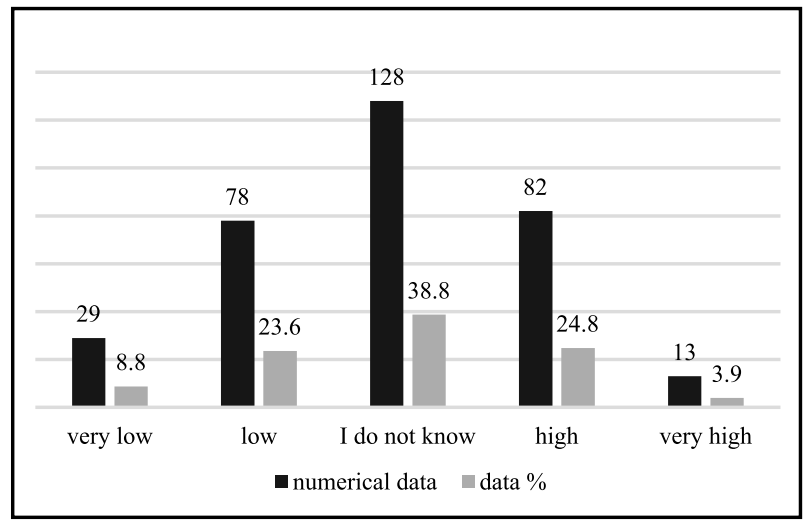

Figure 25. Surveyed students' assessment of intercultural competences acquired in the course of university studies. Source: authors' own research. $\mathrm{N}=333$.

Having analysed the differences in the answers of students of the University of Silesia (Poland) and the University of Ostrava (Czech Republic), it can be stated that these are statistically significant data of low strength of an association for $\mathrm{p}=0.002<0.05$ Cramer's $\mathrm{V}=0.23$. The students of the University of Silesia more frequently assessed their competences as high (56 respondents), yet in the group declaring very low assessment students from Poland prevailed as well (16 people). Among the respondents studying at the University of Ostrava, the largest group (77 people) declared that they were unable to assess their competences. There was also a large group (43 people) who evaluated their competences as low. The detailed data are presented in Table 4. 
Table 4. Surveyed students' assessment of intercultural competences acquired in the course of university studies in regard to their place of studies

\begin{tabular}{rcccc}
\hline Assessment of intercultural competences & $\begin{array}{c}\text { Students from } \\
\text { US }\end{array}$ & $\begin{array}{c}\text { Students from } \\
\text { UO }\end{array}$ & Total \\
& & 16 & 13 & 29 \\
very low & Number & $55.2 \%$ & $44.8 \%$ & $100.0 \%$ \\
& $\%$ & 35 & 43 & 78 \\
low & Number & $44.9 \%$ & $55.1 \%$ & $100,0 \%$ \\
I do not & Number & 51 & 77 & 128 \\
know & $\%$ & $39.8 \%$ & $60.2 \%$ & $100.0 \%$ \\
high & Number & 56 & 26 & 82 \\
& $\%$ & $68.3 \%$ & $31.7 \%$ & $100.0 \%$ \\
very high & Number & 6 & 7 & 13 \\
& $\%$ & $46.2 \%$ & $53.8 \%$ & $100.0 \%$ \\
Total & Number & 164 & 166 & 330 \\
& $\%$ & $49.7 \%$ & $50.3 \%$ & $100.0 \%$ \\
\hline
\end{tabular}

$\chi^{2}=17.453$; $\mathrm{df}=4$; for $\mathrm{p}=0.002<0.05$; Cramer's $\mathrm{V}=0.23$. Source: authors' own research.

What seems surprising in the obtained results is the large number of respondents who could not assess their intercultural competences - especially while studying and most often living in the borderland, almost every day they have contacts with representatives of other nationalities, religions/denominations or cultures. Both cities - Cieszyn and Ostrava - are culturally diversified. There are foreign students at both universities as well. Thus, the respondents have opportunities to verify their knowledge and skills in daily contacts.

Another question for students concerned the relations between Poles and Czechs living in their region. The respondents were to choose one out of 6 provided answers or write their own. The largest group - 130 (39\%) people - stated that they were aware of diversification but they lived in such a way that national divisions were not visible. The second largest group - $51(15.3 \%)$ declared that although divisions were visible, the attitudes of mutual interest and friendliness could be observed. A similarly sized group - 48 people $(14.4 \%)$ - chose the answer which emphasized creating one common community without national partitions. For 40 students $(12 \%)$ the divisions were visible but, generally, they did not cause problems or conflicts. 27 respondents $(8.4 \%)$ declared that the representatives of both nations lived their daily lives separately. The smallest group - 17 (5.2\%) - declared that they noticed national divisions and sometimes this triggered misunderstandings or even conflicts. The students who chose the answer "other" most often wrote "I do not know, I do not have such experience, because where I live, there are no Poles / Czechs" - cf. Figure 26.

What can be noticed in the analysis (after taking into account the role of the students' studies) is the statistically significant dependence with low association strength for $\mathrm{p}=0.02<0.05$, Cramer's $\mathrm{V}=0.214$. 


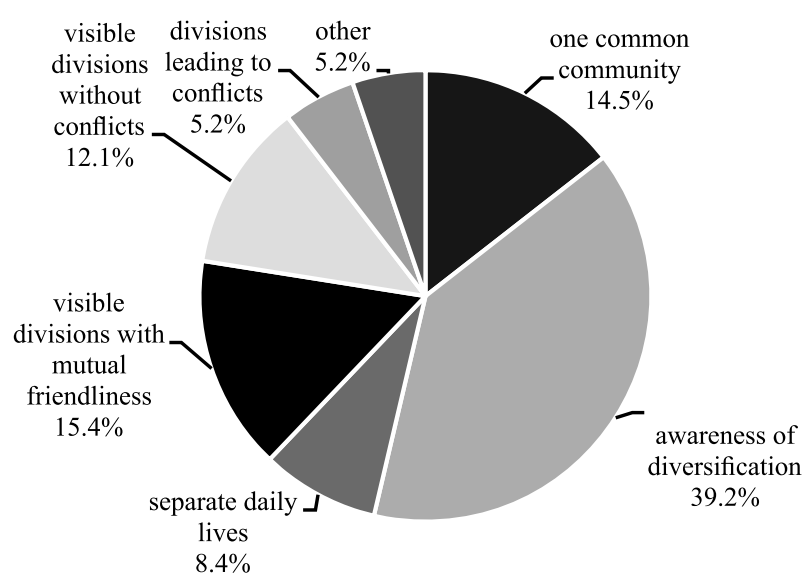

Figure 26. Surveyed students' opinions on the type of relationships between Poles and Czechs living in their region. Source: authors' own research.

Much more frequently than their Czech peers, Polish students claim that they create a common community in which national divisions have no significance. Yet, Czech students are more often of the opinion that divisions are visible - this tendency can be observed in each of the three groups of answers. The biggest difference occurs in the extreme group, which pertains to misunderstandings or conflicts of national background. Moreover, Czech students more often claim that nationality-based divisions are visible in the region, but they do not trigger tension or problems. The detailed data are presented in Table 5 .

The respondents were also asked how they evaluate their attitude to Czechs/ Poles. They were to choose one answer out of five provided. The biggest number - 125 people $(37.5 \%)$ - claim that they do not notice any substantial differences between Poles and Czechs. 93 people (27.9\%) emphasized their indifferent attitude to their neighbours. A similarly sized group of 88 respondents (26.4\%) notice differences between Poles and Czechs but the other nationality seems close to them and evokes their friendliness. Among the surveyed students, only a small group chose answers which suggested a friendly attitude to Poles/Czechs. 17 people $(5.1 \%)$ state that they notice the differences and do not feel friendliness towards their neighbours. 5 respondents firmly confirmed a significant difference. The detailed data are shown in Figure 27.

There is a statistically significant dependence with very low association strength between students' place of studies (PL/CR) and their answers - with clustering of answers into 3 groups $^{19}-$ for $\mathrm{p}=0.04<0.05$ Cramer's $\mathrm{V}=0.141$. The

19 The first group consists of the following answers: there are no serious differences between us and I notice differences between us, but they are close to me, I like them (in the Table: "no or 


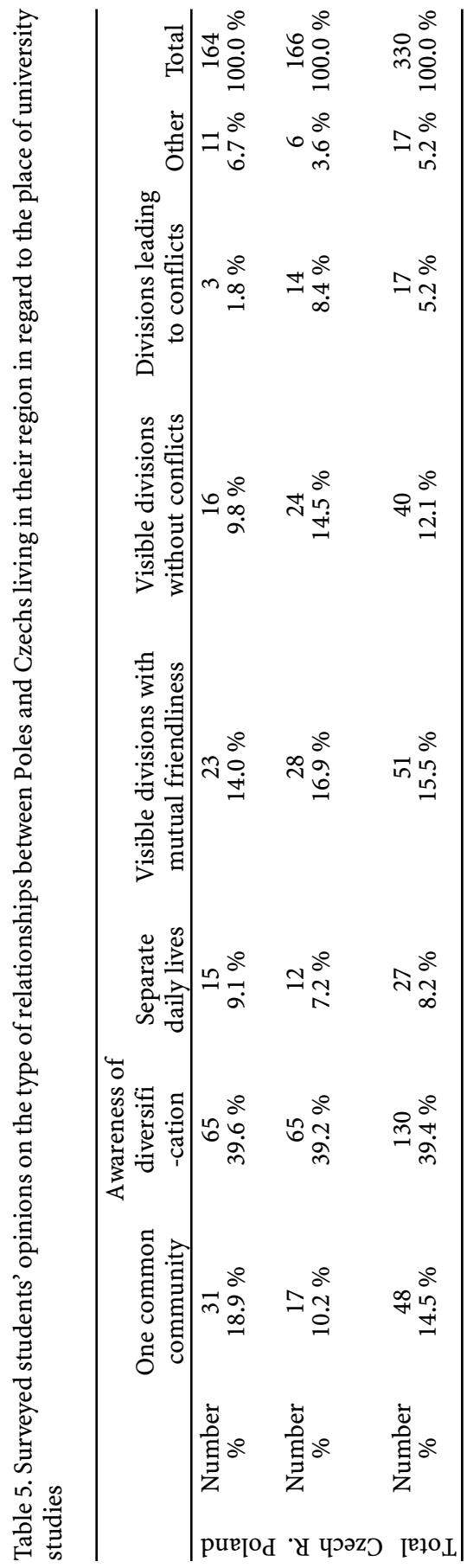




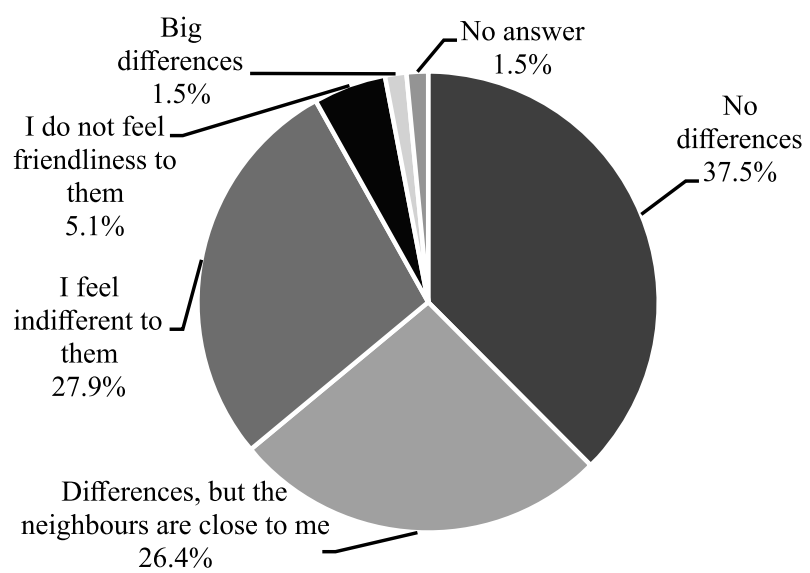

Figure 27. Surveyed students' assessment of their attitude to Poles/Czechs. Source: authors' own research.

students from Ostrava more often chose answers from the extreme groups than those from Cieszyn - the answer "I feel indifferent to them". The detailed data are comprised in Table 6.

Table 6. Surveyed students' assessment of their attitude to Poles/Czechs in regard to their place of studies

\begin{tabular}{|c|c|c|c|c|c|}
\hline $\begin{array}{l}\text { Students } \\
\text { from: }\end{array}$ & Declarations & $\begin{array}{c}\text { No or rather } \\
\text { no }\end{array}$ & $\begin{array}{l}\text { I feel indifferent to } \\
\text { them }\end{array}$ & $\begin{array}{c}\text { Rather yes or } \\
\text { yes }\end{array}$ & Total \\
\hline PL & $\begin{array}{c}\text { Number } \\
\%\end{array}$ & $\begin{array}{c}102 \\
64.2 \%\end{array}$ & $\begin{array}{c}52 \\
32.7 \%\end{array}$ & $\begin{array}{c}5 \\
3.1 \%\end{array}$ & $\begin{array}{c}159 \\
100.0 \%\end{array}$ \\
\hline $\mathrm{CZ}$ & $\underset{\%}{\text { Number }}$ & $\begin{array}{c}110 \\
66.3 \%\end{array}$ & $\begin{array}{c}41 \\
24.7 \%\end{array}$ & $\begin{array}{c}15 \\
9.0 \%\end{array}$ & $\begin{array}{c}166 \\
100.0 \%\end{array}$ \\
\hline Total & $\begin{array}{c}\text { Number } \\
\%\end{array}$ & $\begin{array}{c}212 \\
65.2 \%\end{array}$ & $\begin{array}{c}93 \\
28.6 \%\end{array}$ & $\begin{array}{c}20 \\
6.2 \%\end{array}$ & $\begin{array}{c}325 \\
100.0 \%\end{array}$ \\
\hline PL & Number & 102 & 52 & 5 & 159 \\
\hline
\end{tabular}

$\chi 2=6.455 ; \mathrm{df}=2$ for $\mathrm{p}=0.04<0.05$; Cramer's $\mathrm{V}=0.141$. Source: authors' own research.

The respondents were asked whether they had ever met in a direct way any symptoms of unwillingness or discrimination because of being a different nationality. Although the questions concerned discrimination based on nationality, students' answers went much beyond this issue.

In total, 93 respondents gave positive answers - 54 from the Czech Republic and 39 from Poland (cf. Figure 28).

In the group of Czech students, 54 provided broader answers, containing a description of the symptoms of aggression towards people of a different nation-

rather no"). The second group: they are indifferent to me, and the third: I notice differences between us and I do not like them, we are very different (in the table: "rather yes or yes"). 


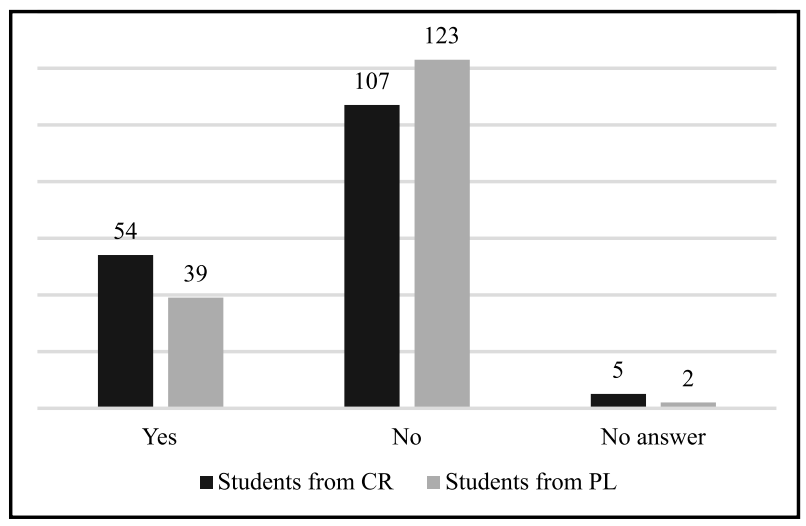

Figure 28. Declarations of Czech and Polish students concerning directly observed acts of unwillingness or discrimination towards people of a different nationality. Source: authors' own research.

ality, race or religion. Most frequently, the descriptions concerned situations which the respondents had witnessed. They can be divided into two groups: aggression directed to such people (40 descriptions) and situations in which people of a different nationality, race, ethnicity or religion provoked some other people or triggered conflicts which posed a threat to the participants' feeling of safety (14 descriptions). Some of the descriptions in the second group pertained to the "guests" who could not behave well, such as - for instance - Spanish students at the University of Ostrava, participating in the Erasmus programme: "Their behaviour out of school (at parties, in the streets) was inappropriate. Some students ended up at the police station. People in their surroundings were right to have fears". Some of these descriptions concern the improper behaviour of Poles: "I work in a pub in Krnov. Poles visit it and think they are better than us. When they get drunk, they are very aggressive to Czechs". Some similar descriptions indicate that Poles have claims and improperly behave towards Czechs who have problems with understanding them. Another image appears from several other descriptions - of Poles who do not treat Czechs as equal partners. A few respondents have experienced such symptoms of intolerance from Slovaks, who - for example - did not want to sell them some goods and told them to go to the Czech Republic, where their place was. Others draw attention to aggressive attacks from the Roma minority: "I have experienced this personally, a Roma woman wanted to steal the wallet from my bag and when I made a comment on what she was doing, she started to shout that I had discriminated against her and that I had something against her".

In total, 26 descriptions concerned symptoms of intolerance of people of other nationalities. Among them, the biggest number was associated with Poles (7), Slovaks (5) and Vietnamese (2). The described situations pertained not only to 
adults but also to children, who - for instance - did not want to play at school with a girl only because she was Vietnamese. The reason of intolerant behaviour is foreigners' insufficient knowledge of the Czech language as well as cultural differences and the related misunderstandings. In the descriptions concerning Poles, there were statements which indicated that many Czechs do not tolerate Poles only because of the nationality: "In internet discussions, many people negatively wrote about Poles without a clear reason. Frequently - only due to their nationality".

A separate group of answers (10) concerned the ethnic minority of Roma. Some statements comprised the descriptions of situations in which representatives of the Roma minority had experienced unjustified symptoms of stereotypical treatment, aggression or discrimination. One respondent described this as follows: "We had a boy in our class who was Roma and all mates at once gave him the label of stupid and bad-mannered". Even the similarity of skin colouring leads to similar behaviour of peers: "I had a classmate, who due to his complexion was insulted with the name of a Gypsy. He was not Roma, he just had a darker complection, which was a reason to tease him". There were also some descriptions of aggressive behaviour of Roma - thefts, dirty language.

10 descriptions had a general character. Their authors mentioned cases of intolerant behaviour which they had observed (verbal insults, swearing, aggression). They wrote that when many people see a different individual, they $a$ priori assume this person is bad. One female student wrote about the experiences associated with her home: "Yes, I do come from a racist family, for me - such divisions are not important, but I would be afraid to bring home a person of other nationality". Others wrote about restrictions experienced by "non-Czechs" - employment problems or some other difficulties, and about inappropriate treatment in state institutions.

Among Poles, 39 respondents gave positive answers, 7 of them did not provide any description and only confirmed the fact that they had experienced some symptoms of unwillingness or discrimination. The responses of Polish students are less comprehensive. In total, 12 answers pertained to the symptoms of intolerance associated with national dissimilarity. All answers indicating particular nationalities concerned Poland's neighbours. The situations pertaining to Ukrainians ( 3 indications) were associated with their being treated worse by Poles. One description concerned common studying: "Yes, Ukrainian students from our group are treated worse by their friends in the group". There was also a description of intolerant behaviour associated with the historical background: "Yes. Not long ago, a Ukrainian came to my home to clean the gas stove. A very nice man, who perfectly knew how to do his work. When later I talked about that man to my brother-in-law and I said that I felt pity that he had had to leave his family and look for work here in Poland, I heard those words: 'You felt pity for him?? Haven't they killed enough Poles??'. I was shocked that people living in the 
$21^{\text {st }}$ century still think in such a hopeless way. A real failure". 2 answers referred to Germans and 2 to Czechs. In the case of Germans, the described situations were associated with the stereotypical attitude to Germans presented by children and youth: "Yes, during the exchange with Germans, Poles - students from my school - threw verbal insults at Germans". Even the fact itself of being born in this country could become a reason of stigmatization: "A person close to me, a Polish woman, brought up by Polish parents in Poland since her infancy, who had been only born in Germany, had many problems among peers in primary and secondary school due to her birthplace" Only two responses described situations in which Poles had been discriminated against and they both referred to contacts with Czechs. One female respondent was physically attacked: "I was attacked by 5 girls of the Czech nationality". The other described a situation in Zaolzie: "Yes, for instance Czechs behind the border often do not tolerate Poles living in 'their' territory and often laugh at them. I live in the Czech Republic and such opposition takes place mostly in the case of younger children".

Among the provided answers, 7 concerned racial discrimination. Some forms of it used by persecutors were mentioned - from jokes, through deriding and mocking texts, invectives, insults, to throwing small objects at such people. Polish students also described situations associated with the Roma (4 respondents).

Out of all the responses, 7 indications are just descriptions of the places where such situations happened. The respondents wrote about incidents in a bus, in pubs, restaurants, travel agencies (while choosing holidays), and one person generally indicated Great Britain. One respondent cited a form of verbal provocation, another described themselves as an intolerant person.

\subsection{Learning from the neighbour in the declarations of Polish and Czech students}

The perception of others is very frequently based on stereotypes. They are a simplification mechanism which enables one to handle the description of a complex social environment. The concept of stereotypes and prejudices as cognitive categories is analysed by many sciences, e.g. philosophy, psychology, sociology, anthropology of culture, ethnography, philology, linguistics, political studies, history, and pedagogy as well. In the applied interdisciplinary theoretical and methodological approaches, two basic but also complementary orientations are indicated to specify the origin, functions and relationships between stereotypes or prejudices and other social phenomena - the psychological and sociocultural perspective. Associations, stereotypes and prejudices largely determine 
the attitude to other nations and influence the way in which activities are undertaken.

The research focus was on the following questions: Do students living in the borderland have knowledge of their neighbours? What does this knowledge concern? How do they evaluate each other; which qualities, skills or activities do they regard as beneficial and worth implementing in their own country? Is their perception of the neighbours dominated by stereotypes? Is this individual perception associated with contact with and knowledge of the Other?

An open question was directed to the respondents in which they were to write what Poles and Czechs can learn from each other.

The first surveyed group consisted of Czech students writing about what Poles might learn from Czechs. A large group of respondents (36) did not answer the question. 16 students stated that they did not know the answer, 8 wrote that they did not want to generalize and, therefore, they were unable to provide an answer. One female student described this in the following way: "No Czech or Polish quality comes to my mind that would be common to the whole nation. I would have to make use of a stereotype, which I aim to avoid ${ }^{20}$ ". Another emphasized: "There is a Pole and a Pole. It depends on the social group. Surely, football fans who go to Ostrava to drink at the weekends should behave better, but Czech football fans behave in the same way". 6 respondents wrote that Poles have nothing to learn from Czechs.

Many surveyed students indicated more than one quality, skill or manner of acting - 49 types of them were mentioned. Generally, they have been classified into four groups. Most frequently, students' responses concerned particular skills (70 indications) which Poles could acquire by learning from their neighbours. The second largest group comprised indications pertaining to social behaviour (31 indications), particular values (25), the knowledge of the neighbour (8) and general changes in the state (7). A few answers could not be classified in any group, therefore the category Others was distinguished as well (cf. Figure 29).

In the field of skills, a large group (23 respondents) indicated the need of learning the Czech language by Poles - as one student stressed: "To talk and read in Czech. I don't think Poles cannot do what Czechs can and vice versa". Others highlight that both nations have similar languages and that it is valuable to learn from each other or at least try to understand each other.

According to the respondents, Poles should learn diligence from their southern neighbours (13 indications in general), in particular - better quality of work, for instance in the service sector (5 indications within this group). Driving cars and behaviour on the road is a problem indicated by 10 students - it is necessary to have "responsibility for obeying road regulations", which Poles can

20 A student of the last year of I degree studies. 


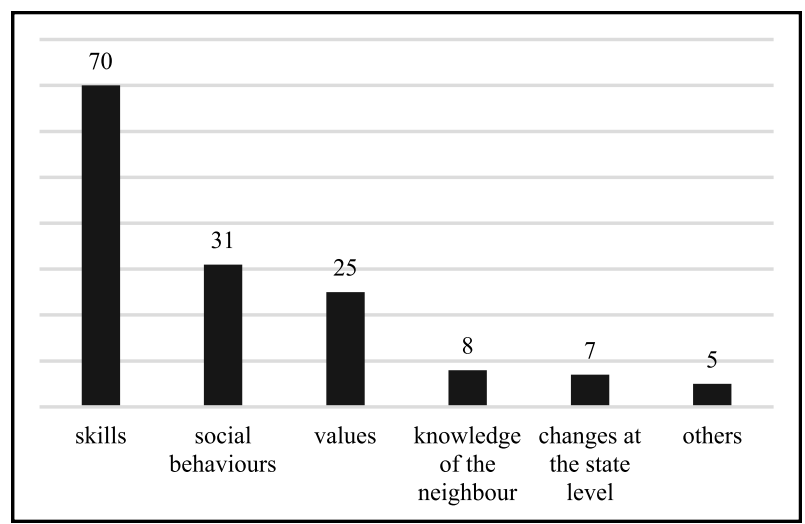

Figure 29. Czech students' answers to the question about what Poles might learn from Czechs with a division into categories. Source: authors' own research.

learn from Czechs. 8 respondents wrote that it would be valuable to learn to cook in compliance with Czech traditions. 6 students pointed to the need of learning sport issues from them - hockey and skiing was mentioned (cross-country skiing is very popular in the Czech Republic, whereas in Poland it is rather rarely practiced). Among other indicated skills, there were: making beer (and the skill of drinking it), practical and purposeful acting, learning foreign languages and trading.

The group of social behaviours comprised the indications pertaining to general changes in Poles' behaviour, suggested by 11 respondents. What was particularly emphasized was the noisiness of Poles and the lack of respect for other people and others' property (indicated by 4 students). This was exemplified by an experience of being in the same space with a group of Polish tourists who were unable to treat the visited place properly and with respect. 8 people pointed to the issues of tolerance. In this case, some answers were more extensive. Students wrote about tolerance to atheists, other religions or representatives of other sexual orientations. The following was also mentioned: better communicativeness, helpfulness, assertiveness and obeying the principles of Czech society.

In the category of values, the answers were comprised in which the respondents restricted themselves to mentioning a particular valuing notion that - in their opinion - should be improved by Poles. Among the people who are often in the company of Czechs, the love of " $k l i d$ [in Czech: calmness]" is widely known. Such functioning, keeping calmness and patience was indicated by 6 respondents. 3 respondents emphasized that it seemed valuable for Poles to have more liking for order and cleanness. The same number pointed to honesty. Most frequently, however, single indications were made, such as: humbleness, concern, understanding, reliability, responsibility, decency, or agreeability. 
8 respondents stressed the need of learning by Poles of Czech customs and traditions - the statement "familiarization with local customs, a bit of tradition" was classified in the category of the knowledge of the neighbour.

7 people focused in their responses on changes of a general nature, noticing that Poland should follow the Czech health care system, public transport, approach to education, as well as their anti-abortion policy.

The most frequent answers of Czech students are presented in Figure 30.

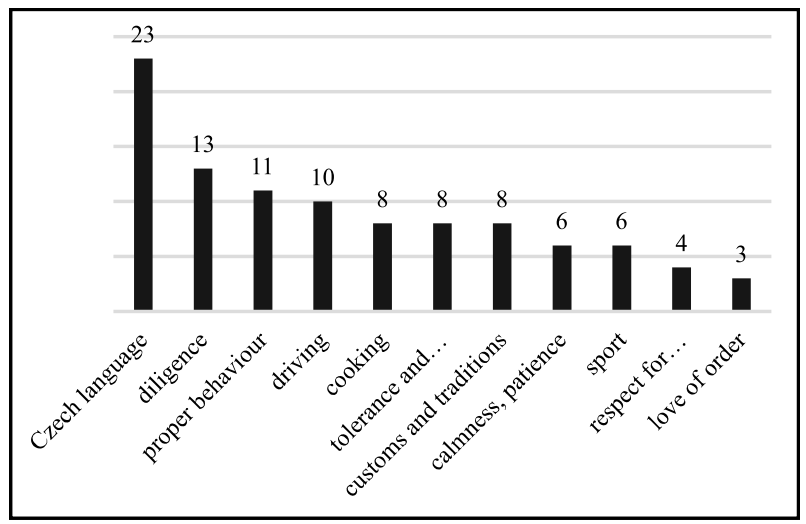

Figure 30. Most frequent answers of Czech students to the question about what Poles might learn from Czechs. Source: authors' own research.

The Czech students were also asked what - in their opinion - Czechs might learn from Poles. In this case as well, many respondents did not provide answers 28 students did not answer the question, 25 wrote that they did not know (some gave a similar justification as in the previous question), and 8 did not write anything. The answers have been qualified to the same categories, however their composition differs significantly. The indications concerning skills and social behaviours dominate (both with 55 answers), the next are the suggested changes concerning the binding principles of the state and those of a general national character (34 answers), only 6 respondents suggested references to particular values and 5 referred to the need for acquiring knowledge about the neighbour (especially the issues of traditions and customs). In the category Others, there were 3 answers which could not be classified in any category - cf. Figure 31.

Among the skills which Czechs should learn from Poles, the most frequent indications concerned the skills related to trade and business (16 respondents) the particular spirit of trade, typical of Poles ${ }^{21}$. The same number of people

21 A Polish fraud dealing with junk goods targeted skiers and wanted them to buy a faulty phone - this was an advert of one of the Czech mobile networks. The Polish embassy in Prague protested against the advert as it created a negative image of Poles (16.09.2019). 


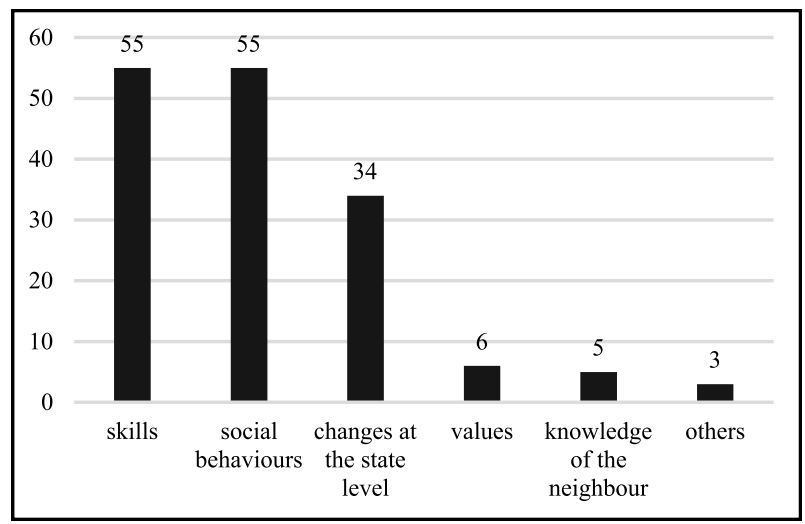

Figure 31. Czech students' answers to the question about what Czechs might learn from Poles with the division into categories. Source: authors' own research.

indicated the skill of using the Polish language. Diligence and the skill of hard work was indicated by 7 respondents. 5 students emphasized that Czechs should follow Poles' clothing style and taste in general. Only 2 respondents mentioned cooking. The other indications were single and pertained to Poles' skill of conducting negotiations, growing plants, travelling, foreign language learning, playing football, communicativeness, shouting and conducting a "slow life".

As regards social behaviour patterns which are worth copying from Poles, the most frequent were those referring to faith and religiousness (22 indications). However, it was often supplemented that this did not concern the attitude to religion itself. The following response reflects this the best: "To have an attitude to religious faith. I don't mean that we must be a Catholic country but it causes no harm to believe in something. Mostly, there should be better principles and models to lead the contemporary youth". Moreover, the respondents thought that the community behaviour presented by Poles was also important (10 answers). One respondent wrote the following: "In my opinion, they may learn commonality and bigger solidarity, which is not so common in us". In some answers (5), the issue of helping other people was emphasized. The other answers in this category had much fewer indications. Among them, are the following qualities attributed to Poles: generosity (3); friendliness to others, also to the stranger (3); easiness in establishing relationships (3); hospitality (2); as well as emphatic behaviour, optimism (a positive attitude to life), sense of humour, and the way of addressing women (1 indication each).

While answering this question, many more respondents paid attention to the issues of norms or principles and to some activities in the general national dimension which would be worth implanting in the Czech Republic. Most of the answers in this category (13) concerned the building of the feeling of national 
pride. One respondent reflected this in a broader statement: "National feeling, belonging, pride; civil engagement; the self-esteem based on the identification and life in compliance with historically significant values". The other answers were provided by smaller numbers of students. The respondents drew attention to more affordable prices in Poland (4 answers) - both in shops and in street markets. One of these respondents made a comment that it would be worth following Polish prices provided that did not bring about a lowered quality of goods and services (which in fact takes place in Poland). The same number of people (4) indicated economic principles, which were - in their opinion - better in Poland and therefore, Poland had a more stable economy. For 3 respondents, the Polish textile industry was worth implanting. The Polish educational system (according to the respondents - was at a higher level than the Czech one), the promotion of national cultural wealth and not working on Sundays and holidays gained 2 indications each. The remaining answers obtained single indications. Among other things, they pertained to building better roads, street order and neatness, as well as the approach to home products.

As was earlier mentioned, while answering this question, fewer respondents pointed to particular values. 4 types of terms appeared: courage ( 2 indications), family (2), patience, and stamina.

The most frequent answers of Czech students concerning what Czechs might learn from Poles are presented in Figure 32.

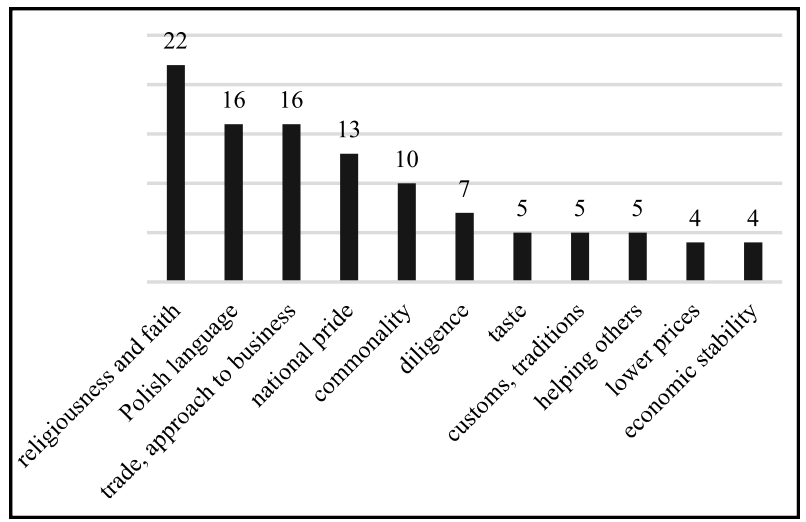

Figure 32. Most frequent answers of Czech students to the question about what Czechs might learn from Poles. Source: authors' own research.

The question for Polish students was formulated in the same way. They were asked to write what Poles might learn from Czechs. Only 2 respondents did not provide a response, but 34 answered that they did not know. There were also rather lengthy statements providing justification for the respondents' answers - 
insufficient knowledge and their unwillingness to generalize or use stereotypes. Several respondents wrote that they did not want to answer the question because they did not know Czechs enough to provide any opinion. 2 respondents wrote: nothing.

Among the answers, there were many indications concerning the need of imitating Czechs' lifestyle - therefore, a separate additional category was distinguished. The biggest number of responses concerned social behaviour (67 indications), lifestyle (36), skills (29) and much fewer concerned changes at the state level (16), the knowledge of the neighbour (10) and values (5). The category Others comprised 3 answers (cf. Figure 33).

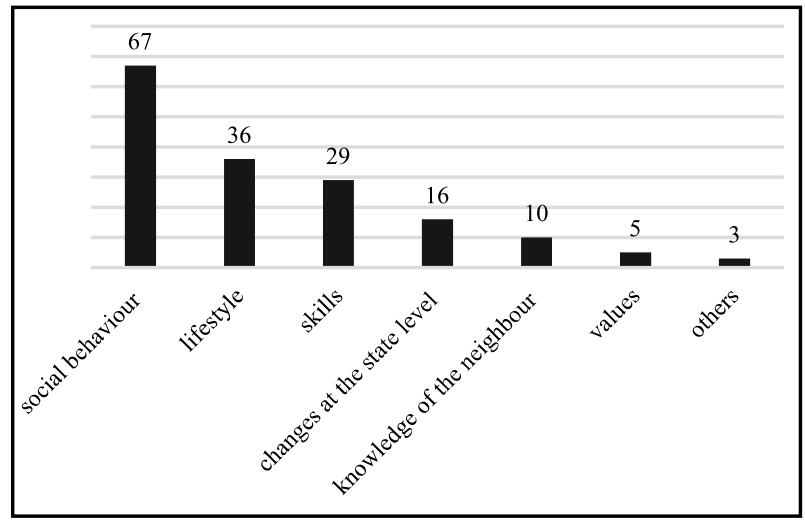

Figure 33. Polish students' answers to the question about what Poles might learn from Czechs with a division into categories. Source: authors' own research.

The largest group of answers pertained to social behaviours, which in the opinion of Polish students Poles might learn from Czechs. The biggest number of respondents (13) wrote about behaviours associated with tolerance and acceptance of other people. One respondent wrote: "Tolerance to the Other. A change in the way of thinking from 'alien' to 'such as me/the own'”. Others emphasized that it would be important to separate state and church matters in the way this had been done in the Czech Republic: "More tolerance. Not the $100 \%$ engagement in the church life. The separation of the ruling power from the church". The second largest group of students (11) highlighted the issues of distance: "The distance to oneself and to life problems”. Cheerfulness, a sense of humour and good manners were considered worth copying from their southern neighbours by 6 respondents per each. 4 students indicated optimism and 3 - the feeling of commonality and kindness. Among the remaining answers, there were: conformist behaviour, friendliness and collaboration ( 2 indications each), solidarity, helping others and punctuality (1 indication). 
Particular lifestyles were indicated by 12 respondents. One dozen focused on the need for openness to people and more freedom of behaviour, another dozen on Czechs' calmer behaviour and approach to life. Also 12 people concentrated on the issue of being open and satisfied in life.

As regards skills, the largest group wrote about learning languages (21 respondents). The remaining answers referred to cooking and cuisine (4), pragmatism (2), obeying road traffic regulations, and free time celebration (1 indication each).

Among the indications concerning changes at the level of the state, students mentioned the Czech social policy as worth imitating and drew attention to good social care for families, women in particular. The separation of state authority from the church and respecting public places were both mentioned by 3 respondents. 2 students indicated the organization of offices and institutions, because - as one of them wrote - what seemed worth learning from Czechs was "more order and better organization in offices and institutions". Also 2 respondents emphasized the necessity to make law in a similar way. The issues of economy and the system of education were both indicated by 1 person.

The knowledge concerning their neighbours, especially their traditions and customs, was indicated by 10 respondents. Among the indicated values, were: responsibility, understanding, patience, honesty and reliability (all single indications). Only 3 answers were included in the category "others".

The most frequent answers of Polish students pertaining to what Poles might learn from Czechs are presented in Figure 34.

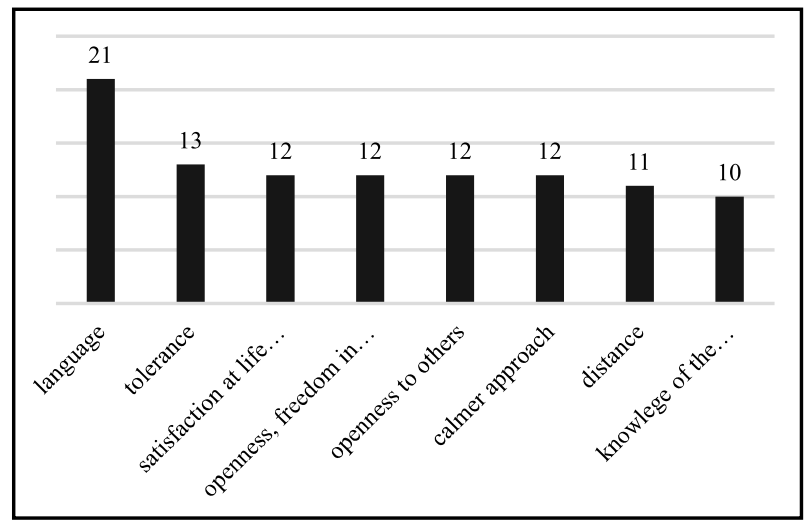

Figure 34. Most frequent answers of Polish students to the question about what Poles might learn from Czechs. Source: authors' own research.

Most frequently, the Polish students who were asked what Czechs might learn from Poles provided answers concerning skills (77 indications), smaller groups of 
answers pertained to social behaviours (40), values (11), knowledge of the neighbour (7), and changes at the state level (3) - cf. Figure 35. There were 3 answers in the category "others". 4 people did not provide answers, 2 wrote "nothing", and 20 were unable to answer the question.

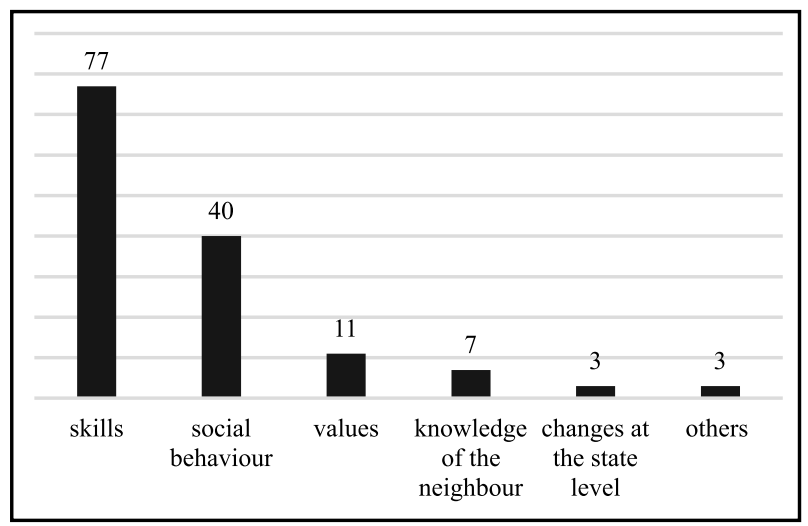

Figure 35. Polish students' answers to the question about what Czechs might learn from Poles with a division into categories. Source: authors' own research.

As regards skills, the necessity to be competent in the Polish language was indicated most often (19). Diligence was indicated by 16 respondents and the skills associated with performing particular jobs (such as the skill of planning and management, effective time management, entrepreneurship or accuracy) - by 13 respondents. Other answers were much less frequent: business and trade skills (4 indications), cooking (4), drinking (3), keeping order (2), appropriate clothing style, taste (2), resourcefulness (2). Among the 7 answers which occurred only once, there were - for instance - better driving skills and thriftiness.

In the sphere of social behaviour, the respondents most often wrote about hospitality (8). Religious issues were given an important rank as well - some respondents emphasized the respect for religion and sacred places (6) and some (5) focused on religiousness itself. Also, 5 students stressed the need for tolerance (in one response this referred to tolerance towards Poles). The remaining answers were significantly less frequent. The respondents indicated openness (3), respect for tradition (2), cultural engagement or behaviour (2), and collaboration.

Among the answers concerning values, 8 terms were used: responsibility was indicated 3 times, conscientiousness - 2, others (bravery, courage, kindness, modesty, reliability, family) - only once.

Knowledge of the neighbour was indicated by 7 students and changes at the state level only by 3 - building Biedronka shops (Jeronimo Martens supermarket chain) by 2 respondents and shaping patriotic attitudes in the Polish way by 1 . 
In the Figure 36, the most frequent answers are presented of Polish students to the question concerning what Czechs might learn from Poles.

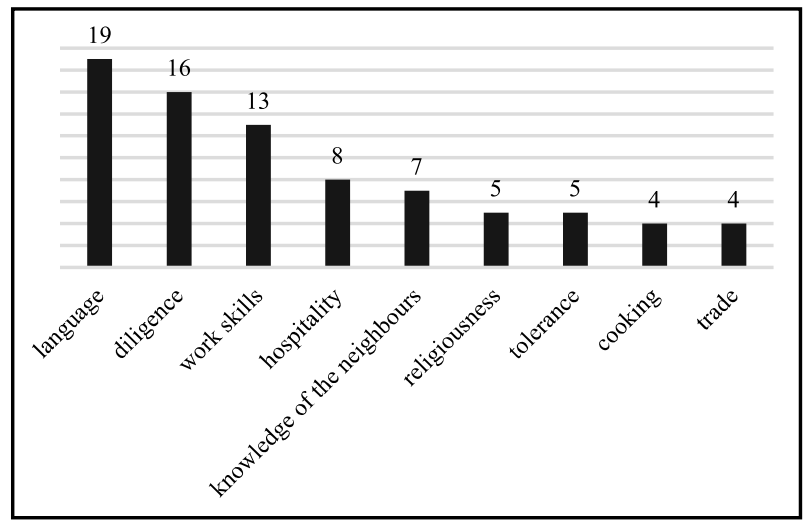

Figure 36. Most frequent answers of Polish students to the question about what Czechs might learn from Poles. Source: authors' own research.

\subsection{The perception of mixed marriages}

Another research interest in our study was to find out how the respondents view the issue of mixed marriages. The question was asked how mixed marriages were perceived in their environment (cf. Figure 37). In general, most of the answers (over $52 \%$ ) indicated that the perception of such marriages was good. The most frequent answer was "positively" - 132 respondents (39.6\%). The second largest group indicated "indifferently" - 112 people (33.6 \%). The answer "very positively" was chosen by 41 students $(12.3 \%)$. A slightly smaller group of 35 respondents $(10.5 \%)$ claimed that mixed marriages were perceived negatively and 7 respondents $(2.1 \%)$ - very negatively.

There are slight differences in the way mixed marriages are perceived by Polish and Czech students. The largest group of respondents declared positive perception of such marriages in their environment. Yet, much more frequently, these were Czech students (72; Poles - 59). A neutral attitude to mixed marriages was more often declared by Poles (60; Czechs - 51). "Very positively" was indicated more frequently by students from the Czech Republic (22) as well as the answer "negatively" (19; 15 - Poles). The answer "very negatively" was declared by 5 Polish students and 2 Czech ones (Figure 38).

The respondents were asked what problems and difficulties mixed marriages might face. The most frequent answer was intolerance of native residents $(33.3 \%)$ - the people from the same nationality group. The second largest group of 


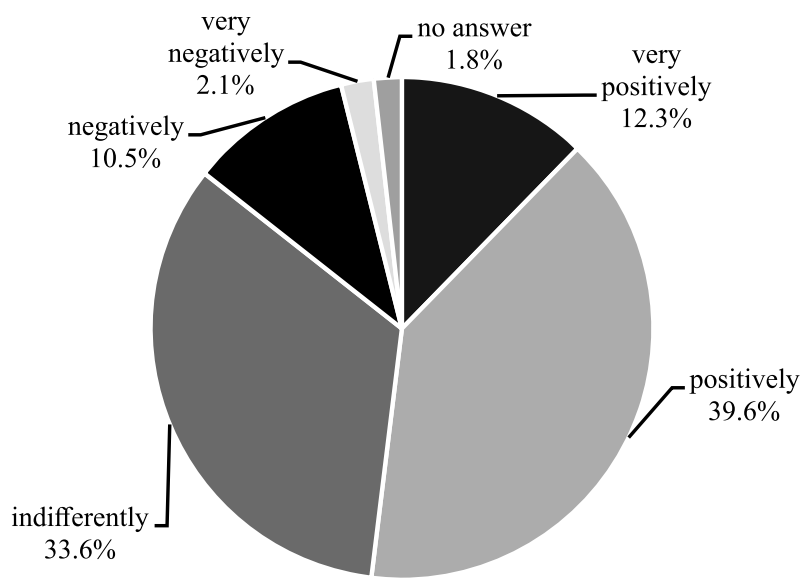

Figure 37. The perception of mixed marriages in the respondents' environment. Source: authors' own research.

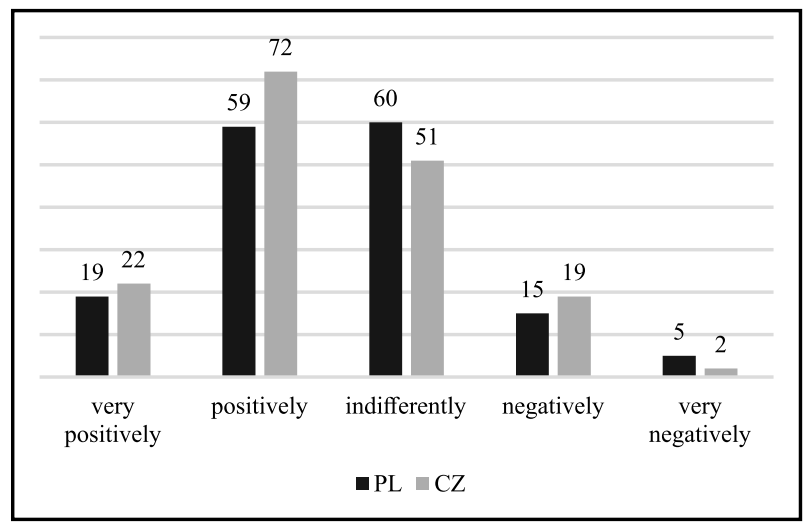

Figure 38. The perception of mixed marriages in the respondents' environment with a distinction between students learning in Poland and the Czech Republic. Source: authors' own research.

respondents $(25.8 \%)$ indicated assimilation problems in the residence place and social isolation. For $17.4 \%$ of students, the most important problems were those related to language communication. The other answers were much less frequent. The difficulties associated with finding a job were indicated by $6.9 \%, 6 \%$ of the respondents pointed to the lack of acceptance by the married couple's family/ families. Problems with raising children were indicated by $4.2 \%$. The same number of students indicated "others", which involved such answers as "none" (students from the Czech Republic) and general answers like "religious and cultural differences" (students from Poland). The detailed data are presented in Figure 39. 


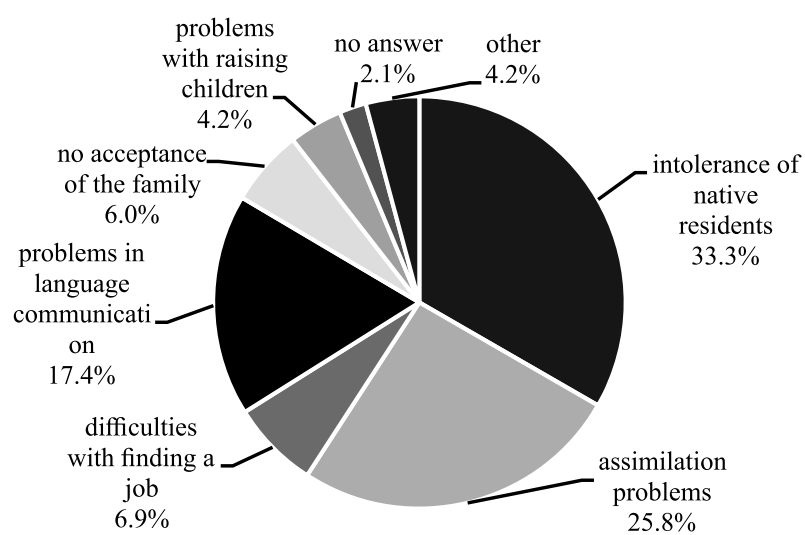

Figure 39. The difficulties which mixed marriages can face as indicated by university students from Poland and the Czech Republic. Source: authors' own research.

There is a statistically significant dependence with low association strength between the place of studying (PL/CR) and students' answers for $\mathrm{p}=0.004<0.05$ Cramer's V $=0.242$. The students from Ostrava more often claimed that mixed marriages had assimilation difficulties in their place of residence due to social isolation and communication problems. The students from Poland more often stated that mixed marriages face intolerance from native residents. The detailed data are comprised in Table 7.

Age turned out to be a factor which also statistically differentiated the respondents' answers. There is a statistically significant dependence with very low association strength between students' age and the indicated (by them) difficulties which mixed marriages might encounter for $\mathrm{p}=0.042<0.05$; Cramer's V= 0.183 . The youngest group of students (aged 19-22) most often drew attention to intolerance from native residents. The most frequent answer in this age group concerned the lack of acceptance of the married couple's family/families. The respondents aged 23-26 most frequently indicated communication problems, whereas the oldest students most often pointed to assimilation problems in the place of residence/social isolation. The detailed data are presented in Table 8. 


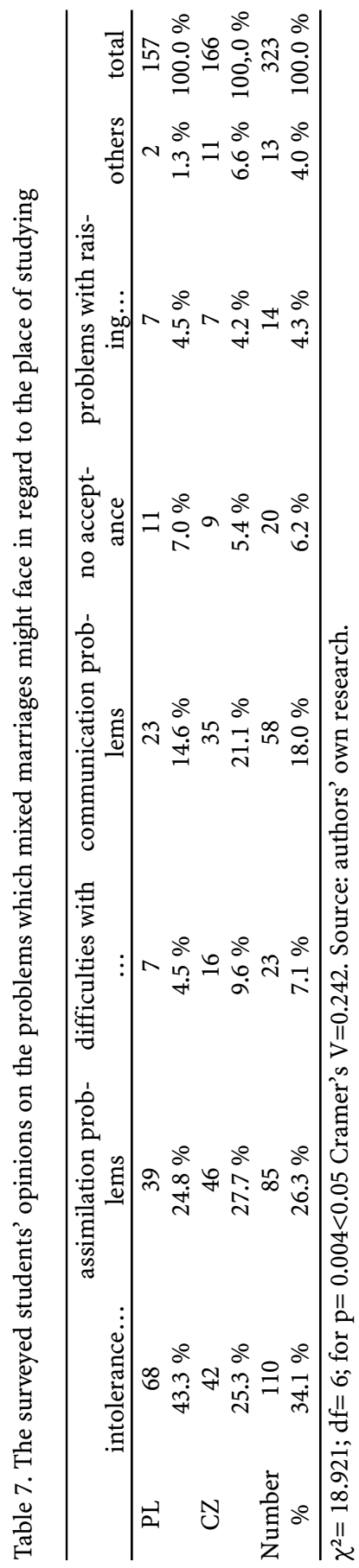




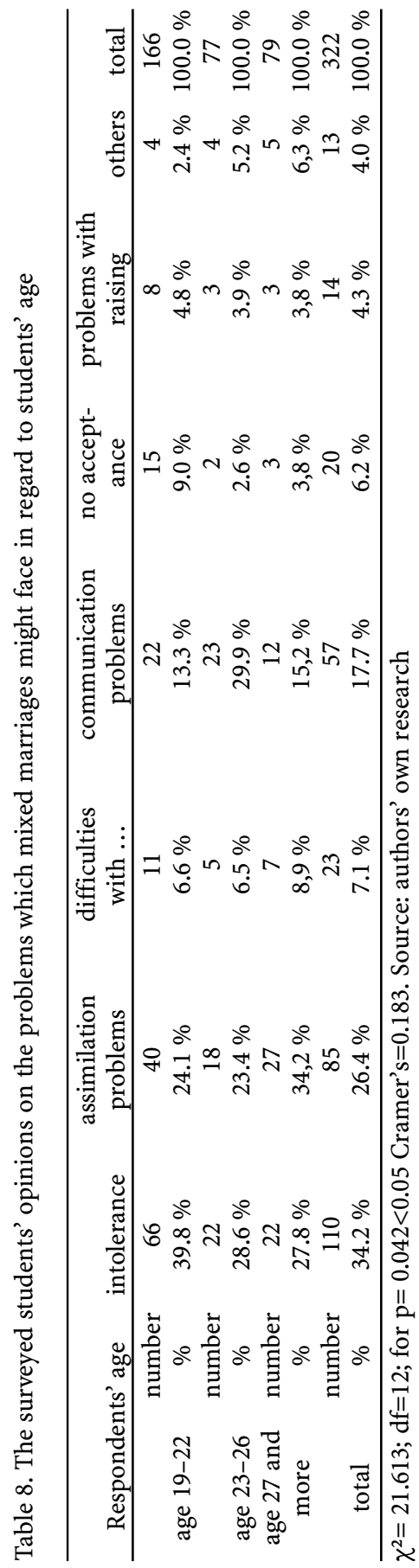




\section{Conclusions}

Geographical closeness does not always mean a willingness to learn about or become interested in who and what is near. The analyses of the obtained research results seem to confirm this. Most of the university students learning in the borderland are unable to assess their intercultural competences. Nearly daily contacts with Others in the culturally diversified environment do not stimulate them to reflect upon their skills that could enhance establishing contacts with people representing different cultural or religious models. At the same time, the respondents are aware of the diversification in their environment. They notice this, but - as $39 \%$ emphasize - national divisions are not visible. Only the smallest group of respondents $(5.2 \%)$ notice that national divisions lead to conflicts. It seems worth stressing that Polish students more often than Czech ones are of the opinion that they all constitute a joint community without visible national divisions (statistically significant dependence with a rather low association strength for $\mathrm{p}=0.02<0.05$, Cramer's $\mathrm{V}=0.214$ ). Asked about their own attitude to the neighbour, the respondents most often wrote that they did not notice national differences and they treated Poles/Czechs as their own (37.5\%). Those who noticed the differences also emphasized that their neighbours were close people to them and that they were not prejudiced against them (26.4\%). In total, slightly fewer than $7 \%$ of students indicated answers which suggested a negative attitude towards their neighbours.

The respondents were asked whether they had experienced signs of unwillingness to help or discrimination of someone only because of a different nationality. Almost 100 students gave confirming answers, which often concerned broader problems - racial, ethnic or religious ones. These extensive answers enabled the researchers to learn the details of such situations. They largely reflect sociocultural determinants - therefore, there were many descriptions of situations pertaining to the Roma among Czech respondents.

Another question was aimed at finding out how the surveyed students perceive their own and their neighbour's attractiveness. The respondents were asked what in their homeland in their opinion was worth imitating or implanting in their neighbours' state and what might be worth learning from their neighbours. The answers were divided into 5 groups. Both Polish and Czech students most often wrote that their neighbours should learn various skills from them, but less frequently, they noticed such a need in themselves (cf. Figure 40 and 41). A similar observation took place regarding social behaviour and values. What deserves attention are the areas in which the respondents notice the biggest shortages and want to implant particular qualities, behaviour patterns, or changes in their homeland. In the case of Czechs, these are the changes at the state level associated with the Polish way of shaping the feeling of national pride, as well as with the 
Polish system of prices or economic stabilization. Poles as well would like to introduce some changes modelled on their neighbours, especially in the field of social policy, the separation of the state authority from religion, or the organization of state offices and institutions. Among Polish respondents, there was an additional group of answers associated with the need for implanting the Czech lifestyle in Poland.

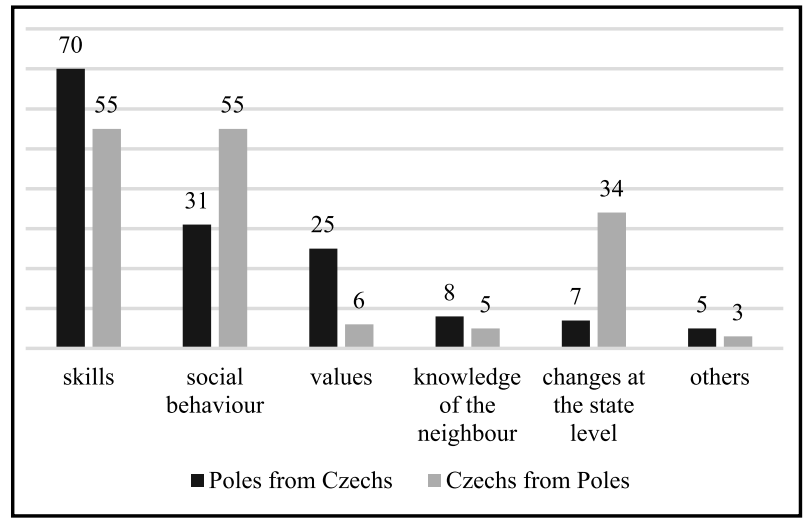

Figure 40. A comparison of Czech students' answers to the question of what Poles might learn from Czechs and Czechs from Poles with a division into categories. Source: authors' own research.

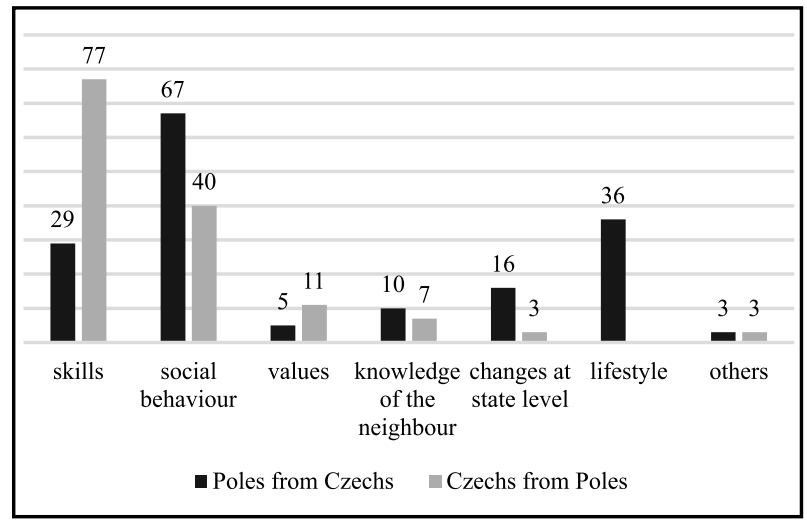

Figure 41. A comparison of Polish students' answers to the question of what Poles might learn from Czechs and Czechs from Poles with a division into categories. Source: authors' own research.

In the group of Czech respondents, there were 2 students with a particularly critical attitude to Poles. Their answers were more comprehensive and with a negative appeal in the context of both questions - what Poles might learn from 
Czechs and what Czechs might learn from Poles. While describing what Poles might learn from Czechs, they wrote: "to offer high QUALITY services, to learn the Czech language, to be more communicative and kind; decent behaviour, in speaking, respect for our culture, tradition and treating us as equal partners!". When asked what Czechs might learn from Poles, the same students wrote: "Czechs should not wonder and care for what Poles think about them". The second person emphasized: “From my experience with Poles, I don't think we can learn anything good from them". These statements might indicate bad experiences in earlier contacts with Poles or deeply rooted prejudices which block the chance for the students to familiarize themselves with their neighbours.

The study also focused on the issue of the respondents' perception of mixed marriages in their environment. There are slight differences in this respect between Polish and Czech students. Much more frequently, Czech respondents declared a very positive attitude to such relationships, while Poles more often declared a neutral attitude to such marriages. Among the problems which mixed marriages might face, the most frequent answer was "intolerance from native residents" - the people from the same nationality group. There is a statistically significant dependence with low association strength between the place of studying PL/CR and students' answers for $\mathrm{p}=0.004<0.05$ Cramer's $\mathrm{V}=0.242$. Czech students more often claimed that mixed marriages have assimilation problems in their place of residence due to social isolation and communication difficulties. Poles more frequently stated that people in such marriages face intolerance from their native residents. 
Open-Access-Publikation im Sinne der CC-Lizenz BY 4.0

(c) 2021, Vandenhoeck \& Ruprecht GmbH \& Co. KG, Göttingen ISBN Print: 9783847112549 - ISBN E-Lib: 9783737012546 


\section{Chapter 3. \\ Pathways to higher education and its value}

University studies have been a cultural and historical phenomenon with a tradition spanning more than a thousand years. Its development in the Czech Republic and Poland started early in the High Middle Ages with the foundation of the Charles University in Prague in 1348 and the Jagiellonian University in $\mathrm{Cracow}^{22}$ in 1364 as milestones. The modern history of the universities differed considerably after World War I (1914-1918). In the former Czechoslovak Republic, some other universities were established with centres in Brno and Bratislava $^{23}$. The transfer of the Technical University from Prribram to Ostrava ${ }^{24}$, induced by the presidential decree, in 1945 marked the birth of higher education in North Moravia and Silesia. Another higher educational institution in the region was established in 1953. It was the Pedagogical Institute in Opava, which started to train qualified primary education teachers after the teacher education reform. After several changes of its name and status ${ }^{25}$, the Institute became a basis of the University of Ostrava, established in 1991 by the Czech National Council Act. The University of Ostrava currently houses six faculties with almost ten thousand students. Its Pedagogical Faculty provides training to pre-primary, primary and secondary education teachers, social and special educators and kinanthropologists. The Pedagogical Institute in Katowice was established in the southern part of Poland near the Moravian-Silesian region in 1928 and trained primary and secondary school teachers. After several changes, it was transformed into the University of Silesia in 1968 as the ninth university in Poland. It currently houses 12 faculties and has about 28 thousand students.

22 The university was known as the Royal Academy for most of its history and was renamed the Jagiellonian University in the $19^{\text {th }}$ century after the Polish royal dynasty.

23 In 1919, the Masaryk University was established in Brno and the Komensky University in Bratislava.

24 The history of the institution goes back to 1716 when the Mining Academy was established in Jachymov. In 1849, the Mining-Metallurgical Academy was established in Př́bram and transferred to Ostrava in 1945. It is currently known as the Technical University of Ostrava.

25 See: Krejčí a Malach (eds.), 2008. 
Higher educational institutions are a crucial part of educational systems and fulfil educational, research and engagement functions with lesser or greater balance (OECD, 2017). The activities of the universities within each of the three main functions of higher education across the stages of performance are shown in Figure 42. Complex and long-term interactions of inputs and activities result in the formulation of evaluable outputs and intermediate outcomes as well as problematically identifiable outcomes. Because of their importance to the wellfunctioning of the university, the chosen activities, outputs and outcomes are investigated in this chapter.

The performed or expected activities of universities are also understood as their roles. Holten-Andersen (2015) enriched four "classical" roles with the fifth role the university plays in modern society. He introduced them in the following order: 1) Repository of the Knowledge of Mankind: universities as "knowledge vaults", maintaining and securing the crucial knowledge for present and future generations, 2) Generation of New Knowledge: undertaking the research activity, 3) Transferring Knowledge to the Next Generation: i.e. education, 4) Transferring Knowledge to Society: i.e. dissemination and, 5) Generating Economic Growth: playing an integral role in enhancing economic growth and thereby pursuing socio-economic goals.

\begin{tabular}{|c|c|c|c|}
\hline $\begin{array}{l}\text { Stages of } \\
\text { preformance }\end{array}$ & Education & Research & Engagement \\
\hline Input & $\begin{array}{l}\text { Access an participation } \\
\text { rates }\end{array}$ & $\begin{array}{l}\text { Research active } \\
\text { staff } \\
\text { Staff supporting } \\
\text { research }\end{array}$ & $\begin{array}{l}\text { Engagement active staff } \\
\text { Staff supporting engage- } \\
\text { ment } \\
\text { Staff involved in volunteer- } \\
\text { ing }\end{array}$ \\
\hline Activity & $\begin{array}{l}\text { Student experience of } \\
\text { teaching and learning } \\
\text { The use of technology } \\
\text { Student support } \\
\text { Staff development } \\
\text { International education } \\
\text { activities and mobility }\end{array}$ & $\begin{array}{l}\text { Doctoral and } \\
\text { postdoctoral re- } \\
\text { search } \\
\text { Earned income for } \\
\text { research projects }\end{array}$ & $\begin{array}{l}\text { Consultancy contracts } \\
\text { Licensing of HEI patents to } \\
\text { companies } \\
\text { Postgraduate students/ } \\
\text { postdoctoral researchers } \\
\text { directly funded or co-fund- } \\
\text { ed by industry/ NGOs }\end{array}$ \\
\hline Output & $\begin{array}{l}\text { Progression rates } \\
\text { Attainment rates } \\
\text { Completion rates }\end{array}$ & Publications & $\begin{array}{l}\text { Spin-off companies } \\
\text { Start-up companies } \\
\text { Joint publications with } \\
\text { non-academic authors }\end{array}$ \\
\hline $\begin{array}{l}\text { Outcome } \\
\text { (intermediate) }\end{array}$ & Skills & Scientific impact & Total earned royalty income \\
\hline $\begin{array}{l}\text { Outcome } \\
\text { (final) }\end{array}$ & $\begin{array}{l}\text { Social outcomes } \\
\text { Labour market out- } \\
\text { comes }\end{array}$ & $\begin{array}{l}\text { Social impact } \\
\text { Economic impact } \\
\text { Innovation }\end{array}$ & $\begin{array}{l}\text { Social impact } \\
\text { Economic impact } \\
\text { Innovation }\end{array}$ \\
\hline
\end{tabular}

Figure 42. Examples of performance dimensions. Source: OECD, 2017, p. 77. 
The tertiary sector of education has undergone a dynamic transformation over the last 20 years (Klemenčič, 2018). The change can be characterised by massification, internationalisation and globalisation. The expansion of tertiary education (occasionally labelled as massification) as a consequence of the increasing demand for higher education and the policy assuring access to it, led to an unprecedented increase in the number of students and of private universities in the Czech Republic and Poland. ${ }^{26}$ The number of university students in the Czech Republic has been slightly decreasing in the last five years. ${ }^{27} \mathrm{~A}$ significant number of students in the EU countries studying in other member states within the Erasmus+ Programme is the result of internationalisation. Several thousands of university students leave the Czech Republic, become familiar with the system of studies abroad and - by using their personal experience - can critically compare courses at different universities with the system prevailing in their alma mater. ${ }^{28}$ Slightly more students from other countries come to study in the Czech Republic. $^{29}$ In the last four academic years (from 2014/2015 to 2017/2018), 1019 Czech students studied in Poland, and 2920 students from Poland studied in the Czech Republic. Poland is the ninth most favourite destination for Czech students, while the Czech Republic hosts one fifth of Polish students leaving their home country to study abroad.

The priority for research and other creative activities is a problematic issue weakening the interest and activities of universities in the educational field. International university rankings most often evaluate only results in science and research. The scientometric scope is similarly reflected in the assessment of candidates' quality within habilitation and professor appointment procedures in the Czech Republic. As a reaction to the significant imbalance between education and research along with other creative activities, 16 recommendations for the European Commission concerning the improvement of the quality of learning and teaching at universities were formulated by the High Level Group on the Modernization of Higher Education in 2013 (European Commission, 2013). The

2662 universities, of which 26 were public, two state and 34 private ones, offered their services in 2018, while 21 private schools were dissolved or integrated into other universities in the period in which the law allowed their establishment after 1998. (Source http://www.msmt.cz/vzdela vani/vysoke-skolstvi/prehled-vysokych-skol-v-cr-3).

27 In 2014, 346,895 students were in the three-level system of education in the Czech Republic, while in 2018 the number was 290,099. (Annual Report on the State and Development of Education in the Czech Republic in 2018. MŠMT: Praha, 2019).

28 In the academic year 2017/2018, 7116 Czech students went abroad. Over the past four years, most have visited Germany, Spain, France and the United Kingdom. (Source: https://www.nae rasmusplus.cz/cz/mobilita-osob-vysokoskolske-vzdelavani/statistiky).

29 In the academic year 2017/2018, 10,559 students came to study from abroad. In the last four years, most of them were from Spain, France, Slovakia, Turkey, Germany and Poland. (ibid.) 
recommendations are a vital matter of this research and are logically connected with the educational process, as illustrated by the following two points:

Recommendation 2: "Every institution should develop and implement a strategy for the support and on-going improvement of the quality of teaching and learning, devoting the necessary level of human and financial resources to the task, and integrating this priority in its overall mission, giving teaching due parity with research.” (p. 27).

Recommendation 3: "Higher educational institutions should encourage, welcome, and take into account student feedback which could detect problems in the teaching and learning environment early on and lead to faster, more effective improvements." (p. 29).

The underestimating of the educational function of higher educational institutions is also manifested by the fact that the creation of university textbooks, scripts, study materials and other (currently electronic learning materials and sources) is not (at least in the Czech Republic) a matter of assessment or grading, as it should be. Unlike the vast possibilities of registration of scientific outputs in RIV or artistic outputs in RUV ${ }^{30}$, the academic staff is not motivated to create educational materials. Students frequently select straightforwardly accessible and non-verified (from the Internet) or obsolete (notes or exam questions formulated by their predecessors) sources (Sikorová, Malach, 2014).

In March 2015, Ralph Wolff, the president and the CEO of WASC World Future Society, presented ten trends influencing the development of higher education in the USA. Apart from the specifically American trends and close connections between private enterprise and universities, more general trends were specified: technology-supported and distant learning, internationalisation, globalisation (international recognition of higher education, application of the Bologne process, building and development of international branch campuses, partnership formation, joint degree or dual degree study programmes), quality and responsibility assurance (issues of graduation, learning results assurance, costs of education, indebtedness, cost compensations, school management responsibility) (Wolff, 2015). According to Wolf, the new forms of higher education institutions represent some essential trends as well: the formulation of the socalled cloud programmes across institutions, webs of partner universities and supra-national universities and the acquisition of skills for the $21^{\text {st }}$ century ${ }^{31}$, including their acquisition in the sphere of "deinstitutionalised learning". The following skills are mentioned: the skill of identifying and expressing problems; ability to identify new behaviour patterns or new combinations of activities; integration of knowledge from various fields; ability to formulate new ideas;

30 RIV (Registr Informací ve Vědě, engl. Register of scientific information), RUV (Registr Uměleckých Výsledků [Register of Art Results]).

$3121^{\text {st }}$-century skills available on: http://edglossary.org/21st-century-skills. 
ability to adequately address situations lacking a correct answer; deep, genuine curiosity; originality and inventiveness in the work environment; and problemsolving skills.

The trends in the development of modern technology applications in higher education and learning were published annually in the New Media Consortium Horizon Report. ${ }^{32}$ In 2019, the Key Trends Accelerating Higher Education Technology Adoption were introduced: a) Short-Term for the Next Year to Two Years: Redesigning Learning Spaces and Blended Learning Designs, b) Mid-Term for the Next Three to Five Years: Advancing Cultures of Innovation and Growing Focus on Measuring Learning and c) Long-Term Education for Five or More Years: Rethinking How Institutions Work and Modularized \& Disaggregated Degrees (Alexander at al., 2019). The authors of the publication explored the applications of modern digital technologies in the academic field through the implementation of the research project of the $7^{\text {th }}$ frame programme of European Union IRNet in years 2014-2017 ${ }^{33}$ (e.g. Gajdzica, Ogrodzka-Mazur, Chmura \& Malach, 2015; Ogrodzka-Mazur, Gajdzica, Malach \& Chmura, 2017, 2018a, 201b; Malach, Kostolányová, Chmura, Szafrańska-Gajdzica \& Ogrodzka-Mazur 2015, 2016.)

The presented results of the empirical research into the conditions, processes and outcomes of the university studies are divided into four subchapters introducing evaluative judgments and the opinions of students on the structure of the studied programmes' curriculum. The focus was mainly on the integration of theory and practice, the value of higher education in different countries, interpersonal relationships in the academic environment and the key processes taking place in the sphere of the educational role of the university.

\subsection{Theory and practice for a future career}

The integration of theory and practice, or the delivery of fresh valid theoretical concepts and opportunities to verify them in practice during the course of university studies, is one of more significant and controversial problems emerging mainly due to the different views of higher educational institutions on the one hand and the companies employing their graduates in the contemporary globalised market on the other. The fact that scientific outcomes are crucial for

32 Since 2019, EDUCAUSE is charged with the publication of reports.

33 IRNet - International research network for study and development of new tools and methods for advanced pedagogical science in the field of ICT instruments, e-learning and intercultural competences- project, funding from the People Programme (Marie Curie Actions) of the European Union's Seventh Framework Programme FP7/2007-2013/ under REA, grant agreement No: PIRSES-GA-2013-612536. 
university rankings may contribute both to the theoretical composition of the education, especially in the introductory subjects, and to a certain underestimation of the transfer of acquired knowledge to the professional practice. The novelisation of the Higher Education Act, which introduced academically and practically focused study programmes, represents a reaction to this natural tension deriving from the disharmony of the three functions of universities mentioned before. ${ }^{34}$ Practically focused university curricula are more oriented towards students' practice and they aim at preparing them for future careers. Government regulation ${ }^{35}$ which implements the Higher Education Act defines different criteria, mainly regarding practical training during the course of students' studies. A practically oriented Bachelor study programme takes into account some specific features linked to the need for cooperation with the professional sphere and the staff recognizes the contribution of professionals. The plans of practically oriented study programmes should include practical training, 12 weeks for Bachelor's programmes, at least six weeks for Master's programmes and at least 18 weeks for (undivided) Master's programmes (Weidnerová, 2017). The participants in the studies - students from the University of Ostrava studied under the former Act, which did not distinguish between academic and practical study programmes. Since pedagogical professions are still regarded as semiprofessions, and the Act or its implementing acts did not define the status of university programmes, and the organisation of their research activities, funding and staffing, Bachelor's and (subsequent) Master' studies will be done within the newly submitted and accredited academic programmes. The need for the practical training will be fulfilled mainly through a more significant portion of reflective practices over the course of the studies and by the demand to focus output qualification theses on the topics related to the teaching profession. With certain simplifications, it is possible to consider most of programmes organised so far as academic programmes since their graduates and educators were frequently criticised for inadequate attention paid to the needs of the practice and their insufficient practical skills.

The theory of the university curriculum approaches the question of students' development theoretically. In compliance with it, their acquisition of practical skills and interdependence in university teaching (not only in practice) is understood as a matter of the curriculum design process which includes six essential components: the programme's educational philosophy, curriculum models, programme aims and outcomes, programme organisation and structure, programme teaching and assessment strategies and module design, executed in a

34 Higher Education Act, 11/1998 as amended.

35 Government Regulation No. 274/2016 Coll., of $24^{\text {th }}$ August 2016 on standards for accreditation in higher education. 
specific context, supporting students and staff, and the use of a particular evaluation strategy (O’Neill, 2015). The curriculum is highly influenced by the social, physical, economic and cultural environment. Stark (2000) identified nine critical contextual filters that influence staff decisions in curriculum design: student characteristics, student goals, external influences, programme goals, college goals and further pragmatic factors, pedagogical literature, advice available on campus and facilities and opportunities. These and other contextual filters can be divided into the international, national, institutional, programme/discipline contexts influencing the curriculum planning process. Thus, the creation of study programmes requires professional and pedagogical competencies of academic staff. The financially motivated function of the study programme guarantor, ${ }^{36}$ who should lead the curriculum design process, was defined for this purpose. O'Neill (2015) states that the product and process models of curriculum development can be distinguished, but the elements of both are present in most programmes. However, a particular curriculum may emphasise one model more than the other. The product model based on a technical-scientific approach will offer the traditional or discipline-based curriculum and will succeed in constructive adjustment, graduates' attributes and a competency-based design. The process model is a non-technical, interpretative model, built upon conversational approaches that will highlight the negotiation of the curriculum and its processbased model. It is more focused on the learner, on approaching learning as a holistic experience and accepting students as participants.

The respondents participated in programmes which can be assessed as product models. The Ministry of Education's newly introduced principles for the accreditation of the pedagogy study programme supported by formerly defined spheres of education contribute to it as well. ${ }^{37}$ This is manifested in the decreasing number of optional subjects, a requirement of precise graduate profile or in the application of the learning outcomes approach in parts by formulating the subject matter in Bloom's goal domains.

Laksov (2018) refers to the difficulties with the integration of theory and practice by introducing three levels of integration - intrapersonal, interpersonal

36 An academic staff member, who was appointed as a professor or appointed as an associate professor or has the academic degree "Candidate of Science" (abbreviated as "CSc.") or has education acquired by graduating from the doctoral degree programme or acted in a field related to the study programme can become a guarantor of the programme according to the Government Regulation No. 274/2016 Coll. No requirements for pedagogical qualifications or experience are stated.

37 The Ministry of Education, Youth and Sports released (as the recognition authority for teaching professions according to the Act 111/1998 Coll) the General Requirements for Study Programmes. The graduates acquire professional qualifications for the regulated teaching professions and they contribute to the process of the evaluation of university study programmes. 
and organisational. Three dimensions of tension arise (together with explorative questions within their framework): obtaining legitimacy from practice (How is theory useful for practice?), balancing the degree of engagement (How do the values of the target practice match the professional values of academic development practice?) and taking into account the adjustment and level of individuality (What might the positive or negative consequences of targeting individuals be when compared to targeting groups or teams in academic development? It is essential to seek answers to these questions during the creation and implementation of the curriculum in higher educational institutions.

The problem of the proportions or balance of theoretical and practical studies has emerged as a recurrent topic discussed and examined by students. The research was carried out by students of the Pedagogical Faculty of the University of Ostrava ${ }^{38}$ with the use of the focus group method and it confirmed that the insufficient link between theory and practice is one of the most significant problems perceived by students. Insufficient possibilities to apply the constantly repeating theory in practice leads students to concerns and doubts about the benefit of their training for their future profession. The question emerges whether the university prepares students for their future professions sufficiently and whether it would not be advisable to introduce them to the practical reality sooner in their studies. Universities should consider if the students' concerns about the strong emphasis on theory at the expense of practice are justified or not (Malach, Kristová \& Valachová, 2018). A possible solution is offered by Bovill and Woolmer (2019) in the shape of student-staff co-creation in and of the curriculum. They suggest that paying more attention to curriculum theories and their assumptions about the learner offers an enhanced understanding of curricular intentions and a larger extent, to which collaboration is possible within any particular context. The idea is already implemented on the curriculum design level in the Czech Republic by two legally recognised ways: the representation of at least one student in the programme board of the study programme and the students' representation in the National Accreditation Bureau for Higher Education and in ad hoc commissions created by it to prepare evaluative materials for the purpose of accreditation. As the procedures have been in effect for a short time, it is not possible to evaluate the benefits of the collaboration.

Three items of the survey were analyzed, namely: the evaluation of the benefits of theoretical knowledge, the possibilities of practical skills development in the course of the studies and the interrelationship between theory and practice.

38 University students' beliefs about their teaching and assessment (2018). 


\subsubsection{The thoretical knowledge students acquire during their studies}

In both countries, the dominant opinion of the students is that their studies provide them with high or very high possibilities to acquire theoretical knowledge related to the field of their studies.

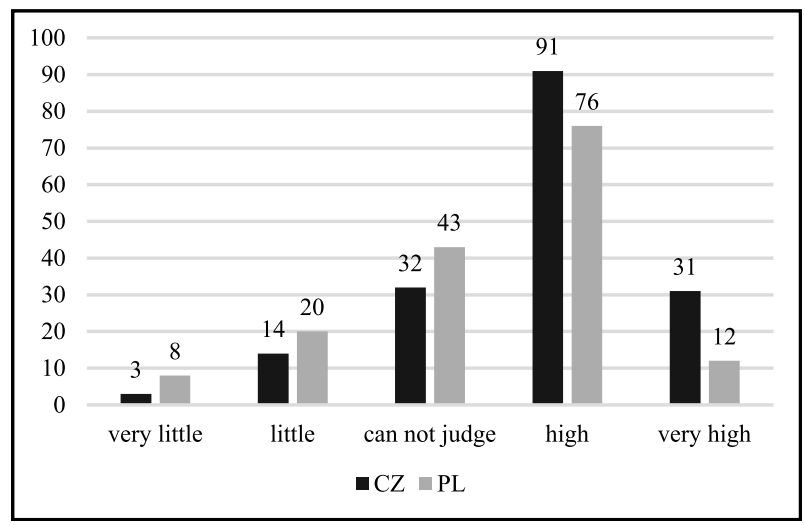

Figure 43. Distribution of responses in the evaluation of university studies in terms of acquiring theoretical knowledge for CZ and PL. Source: the authors' own research.

Figure 43 confirms that Czech students evaluated this parameter more positively. $71.3 \%$ of Czech students chose answers "high" and "very high" in contrast to $55.3 \%$ of Polish students. $18.7 \%$ of Czech students decided not to evaluate the parameter in contrast to $27 \%$ of Polish students. Only one tenth of Czech students chose the answers "little" or "very little" as well as $17.7 \%$ of Polish students.

The following hypotheses were further tested:

$1 H$ : Students from different countries assess the acquisition of theoretical knowledge differently.

$2 \mathrm{H}$ : Students of different genders assess the acquisition of theoretical knowledge differently.

$3 H$ : Students of different years of study assess the acquisition of theoretical knowledge differently. 
Table 9. Evaluation of university studies in terms of the acquistion of theoretical knowledge - frequency analysis and testing dependences between question $17 \mathrm{~b}$ and the considered categories

\begin{tabular}{|c|c|c|c|c|c|c|c|c|c|}
\hline Answer & $\mathrm{CZ}$ & PL & Male & Female & $\begin{array}{l}1^{\text {st }} \text { Year } \\
\text { of Study }\end{array}$ & $\begin{array}{l}2^{\text {nd }} \text { Year } \\
\text { of Study }\end{array}$ & $\begin{array}{l}3^{\text {rd }} \text { Year } \\
\text { of Study }\end{array}$ & \multicolumn{2}{|c|}{ Total } \\
\hline 1 & 3 & 8 & 2 & 9 & 4 & 5 & 2 & 11 & \\
\hline 2 & 14 & 20 & 5 & 29 & 18 & 12 & 4 & 34 & \\
\hline 3 & 32 & 43 & 14 & 61 & 35 & 33 & 7 & 75 & 330 \\
\hline 4 & 91 & 76 & 21 & 146 & 102 & 47 & 18 & 167 & \\
\hline 5 & 31 & 12 & 9 & 34 & 19 & 17 & 7 & 43 & \\
\hline avg & 3.7771 & 3.4146 & 3.5882 & 3.5986 & 3.6384 & 3.5179 & 3.6316 & 3.5969 & \\
\hline$p$ & \multicolumn{2}{|c|}{$0.000^{* * *}$} & \multicolumn{2}{|c|}{0.879} & & 0.794 & & & \\
\hline
\end{tabular}

$p=$ significance value; ${ }^{*} p \leq 0.05^{* *} p \leq 0.01{ }^{* * *} p \leq 0.001$. Question 17 b: Evaluate university studies in terms of the acquisition of theoretical knowledge. Answer: $1=$ very little or low, $2=$ little or low, $3=$ cannot judge, $4=$ high, $5=$ very high. Source: authors' own research.

The average value of the evaluation of university studies in terms of the acquisition of theoretical knowledge reached 3.77 in the case of Czech students and 3.41 in the case of Polish students. The difference is statistically significant and allows us to confirm the hypothesis of $1 \mathrm{H}$. The evaluation of the university studies in terms of the acquisition of theoretical knowledge differs in regard to the country.

The average value of the evaluation of university studies in terms of the acquisition of theoretical knowledge reached 3.58 in the case of men and 3.59 in the case of women. The minimum difference in the evaluation of university studies as regards the acquisition of theoretical knowledge is not dependent on students' gender.

The average value of the evaluation of university studies in terms of the acquisition of theoretical knowledge reached quite similar values of 3.63, 3.51 and 3.63 in each year of study. It thus does not allow us to confirm the hypothesis $3 \mathrm{H}$ on the existence of the dependency of evaluation of university studies in terms of theoretical knowledge acquisition on the year of study (Table 9).

The relationships were also analysed between the evaluation of the theoretical knowledge students can acquire over the course of their studies and students' answers to the question concerning a sense of belonging to the academic community (item 2e), studies (question 10) and working (question 11) abroad or an intention to study (question 12) or work abroad (questions 13) (Table 10).

Table 10 confirms that the evaluation of theoretical knowledge acquired by students from both countries weakly correlates with the level of the declared sense of belonging to the academic community of the university; in the case of Polish students, the correlation is moderate $(r=0.368)$. The evaluation of the theoretical training in the university does not depend on whether the student has worked or studied abroad or is planning to do this in the future. 
Table 10. The relation between theoretical knowledge and selected variables - correlation analysis of the relation between questions $2 \mathrm{e}, 10-13$ and questions $17 \mathrm{~b}$ for all respondents $(\mathrm{CZ}+\mathrm{PL})$

\begin{tabular}{lllllllllll}
\hline CZ+PL & Q2e $\mid r$ & Q2e $\mid p$ & $\mathrm{Q} 10 \mid r$ & $\mathrm{Q} 10 \mid p$ & $\mathrm{Q} 11 \mid r$ & $\mathrm{Q} 11 \mid p$ & $\mathrm{Q} 12 \mid r$ & $\mathrm{Q} 12 \mid p$ & $\mathrm{Q} 13 \mid r$ & $\mathrm{Q} 13 \mid p$ \\
\hline $\mathrm{Q} 17-\mathrm{b}$ & $\mathbf{0 . 1 4 2}$ & $\mathbf{0 . 0 1 0 ^ { * }}$ & -0.060 & 0.280 & -0.019 & 0.730 & -0.005 & 0.928 & 0.048 & 0.387 \\
\hline
\end{tabular}

$r ; r \in\langle-1 ; 1\rangle$ correlation coefficient. $p$ - significance value for testing hypotheses $H_{0}: r=0$; $H_{1}: r \neq 0,{ }^{\star} p \leq 0.05^{* \star} p \leq 0.01{ }^{* *} p \leq 0.001$. Q 2 e How strong are your ties with the academic community of your university? Q 10 Have you studied abroad? Q 11 Have you worked abroad? Q 12 Would you like to study abroad? Q 13 Would you like to work abroad? Source: authors' own research.

\subsubsection{Practical skills acquired by students during their university studies}

Although the prevailing opinion of the students from both countries is that their studies provide them with high or very high possibilities to acquire practical skills, many of them could not evaluate this parameter, or expressed their negative view. $47.4 \%$ of Czech students and only $28.3 \%$ of Polish students assess practical preparation 'highly' or 'very highly'; 'very little' and 'little' preparation was provided by $28.6 \%$ of Czech students and $42.7 \%$ of Polish students (Figure 44).

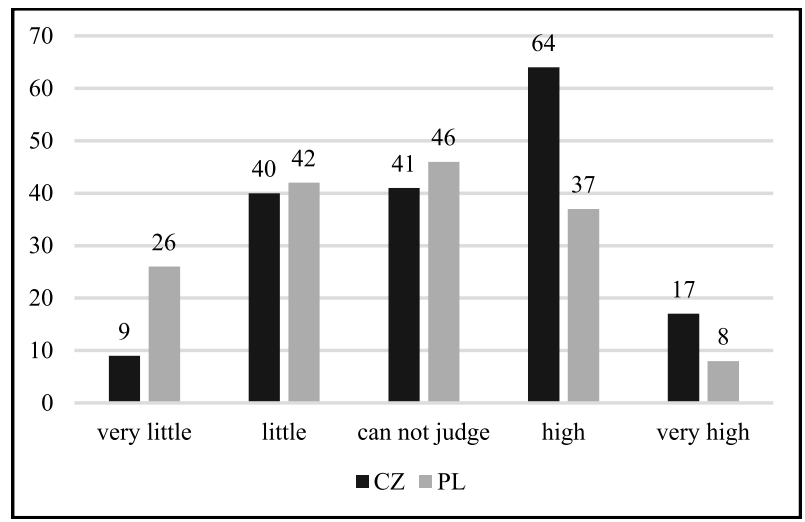

Figure 44. Distribution of answers in the evaluation of university studies in terms of the acquisition of practical skills for CZ and PL. Source: authors' own research.

The following hypotheses were tested:

$4 \mathrm{H}$ : Students from different countries assess the acquisition of practical skills differently.

$5 \mathrm{H}$ : Students of different genders assess the acquisition of practical skills differently. 
$6 \mathrm{H}$ : Students of different years of study assess the acquisition of practical skills differently.

Table 11. Evaluation of practical skills acquisition - frequency analysis and testing dependences between question $17 \mathrm{c}$ and the considered categories

\begin{tabular}{|c|c|c|c|c|c|c|c|c|c|}
\hline Answer & $\mathrm{CZ}$ & PL & Male & Female & $\begin{array}{c}1^{\text {st }} \text { Year } \\
\text { of Study }\end{array}$ & $\begin{array}{l}2^{\text {nd }} \text { Year } \\
\text { of Study }\end{array}$ & $\begin{array}{l}3^{\text {rd }} \text { Year } \\
\text { of Study }\end{array}$ & \multicolumn{2}{|c|}{ Total } \\
\hline 1 & 9 & 26 & 1 & 34 & 11 & 20 & 4 & 35 & \\
\hline 2 & 40 & 42 & 7 & 75 & 33 & 37 & 12 & 82 & \\
\hline 3 & 41 & 46 & 11 & 76 & 50 & 29 & 8 & 87 & 330 \\
\hline 4 & 64 & 37 & 26 & 75 & 72 & 20 & 9 & 101 & \\
\hline 5 & 17 & 8 & 6 & 19 & 12 & 8 & 5 & 25 & \\
\hline avg & 3.2349 & 2.7561 & 3.5686 & 2.8925 & 3.2260 & 2.6518 & 2.9737 & 2.9969 & \\
\hline$p$ & 0.00 & & & 56 & & $0.000^{* * *}$ & & & \\
\hline
\end{tabular}

$p=$ significance value; ${ }^{*} p \leq 0.05{ }^{* *} p \leq 0.01{ }^{* *} p \leq 0.001$. Question $17 c$ evaluation of university studies in terms of the practical skills acquisition. Answer: $1=$ very little or low, 2 = little or low, 3 = cannot judge, $4=$ high, $5=$ very high. Source: authors' own research.

The average evaluation of practical skills acquisition in the course of university studies reached 3.23 in the case of Czech students and 2.75 in the case of Polish students. The result is statistically significant and allows to confirm the hypothesis $4 H$. The evaluation of the university studies in terms of the acquisition of practical skills differs in regard to the country (Table 11).

The average evaluation of practical skills acquisition in the course of university studies reached 3.56 in the case of men and 2.89 in the case of women. The apparent difference in the evaluation is not statistically significant and thus does not allow to confirm the hypothesis $5 \mathrm{H}$. The evaluation of practical skills acquisition in the course of the university studies is not related to the students' gender.

The average evaluation of practical skills acquisition in the course of university studies reached close values of 3.22, 2.65 and 2.97 in individual years of study and may mirror the construction of university curricula. Propedeutical subjects (introductory subjects, pedagogical communication and interaction, use of ICT in teaching, etc.) are taught in the first years of study; basic theoretical disciplines forming theoretical frames of the graduates' profiles are used in the following years as these years are orientated towards professional practice - towards the standard school practice in the case of students of teaching courses. Hypothesis $6 \mathrm{H}$ on the dependency of the evaluation of practical skills acquisition over the course of university studies can be accepted.

The relationship between the evaluation of practical skills students can acquire in the course of studies and students' answers on the question linked to a sense of belonging to the academic community (item 2e), studies (questions 10) and 
working (question 11) abroad or an intent to study (question 12) or work abroad (questions 13) was analysed as well (Table 12).

Table 12. The relationship between practical skills acquisition and selected variables correlation analysis of the relationship between questions $2 e, 10-13$ and questions $17 c$ for all respondents $(\mathrm{CZ}+\mathrm{PL})$

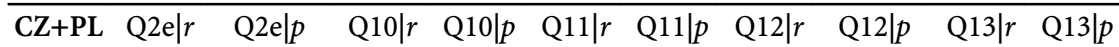

\begin{tabular}{llllllllllll}
\hline $\mathrm{Q} 17-\mathrm{C}$ & $\mathbf{0 . 2 0 4}$ & $\mathbf{0 . 0 0 0 * * *}$ & -0.067 & 0.228 & -0.046 & 0.406 & $\mathbf{- 0 . 1 6 1}$ & $\mathbf{0 . 0 0 3 * *}$ & -0.058 & 0.297 \\
\hline
\end{tabular}

$r ; r \in\langle-1 ; 1\rangle$ correlation coefficient. $p$ - significance value for testing hypotheses $H_{0}: r=0$; $H_{1}: r \neq 0,{ }^{*} p \leq 0.05^{* *} p \leq 0.01{ }^{* *} p \leq 0.001$. Q 2 e How strong are your ties with the academic community of your university? Q 10 Have you studied abroad? Q 11 Have you worked abroad? Q 12 Would you like to study abroad? Q 13 Would you like to work abroad? Source: authors' own research.

The evaluation of practical skills acquisition during the studies slightly correlates with the level of the declared feeling of belonging to the academic community of the university and with the student's aspirations towards studying abroad. The negative value of the correlative coefficient proves that students who are more critical to the level of practical skills acquisition consider studying abroad more frequently. Czech students tend to consider it more frequently (little negative correlation, $r=-0.172)$ than Polish ones $(r=-0.073)$. The evaluation does not depend on whether the students studied or worked abroad or considered working abroad.

\subsubsection{The interrelations of theory and practice in individual subjects}

The most frequent opinion of Czech students is that the interrelation of theory and practice is present to a high degree in the individual subjects. This opinion is shared by $34.5 \%$ of Czech students and $27.7 \%$ of Polish students. The most frequent opinion of Polish students $(30.8 \%)$ and the second most frequent opinion of Czech ones $(27.5 \%)$ is that the students are unable to assess the connection, which may be understood that they are not confronted with the didactic method or teaching principle, they do not understand how it works in reality and thus are not ready to consider its appearance or progress. The 'high' and 'very high' (values 4 and 5) ranking is given to the interrelation of theory and practice by $46.8 \%$ of Czech students and only by $30.8 \%$ of Polish students. Only a little more than one tenth $(12.2 \%)$ of Czech students and only every $30^{\text {th }}(3.1 \%)$ Polish student consider the interrelation of theory and practice as "very high". On the other hand, one quarter of Czech and more than one third of Polish students consider the interrelation as "very little" or "little" (Figure 45). 


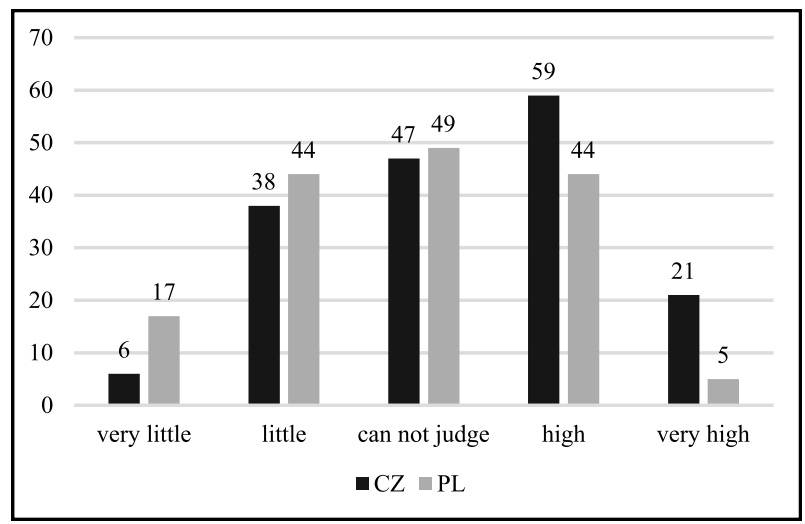

Figure 45. Distribution of answers in the evaluation of the interrelation of theory and practice in individual subjects for CZ and PL. Source: authors' own research.

The following hypotheses were tested for the topic of the interrelation of theory and practice in individual subjects:

$7 H$ : Students from different countries assess the interrelation of theory and practice differently.

$8 H$ : Students of different genders assess the interrelation of theory and practice differently.

$9 H$ : Students of different years of study assess the interrelation of theory and practice differently.

Table 13. Evaluation of the connection of theory and practice in individual subjects frequency analysis and testing dependences between question $17 \mathrm{~d}$ and the considered categories

\begin{tabular}{|c|c|c|c|c|c|c|c|c|c|}
\hline Answer & $\mathrm{CZ}$ & PL & Male & Female & $\begin{array}{l}1^{\text {st }} \text { Year } \\
\text { of Study }\end{array}$ & $\begin{array}{l}2^{\text {nd }} \text { Year } \\
\text { of Study }\end{array}$ & $\begin{array}{l}3^{\text {rd }} \text { Year } \\
\text { of Study }\end{array}$ & \multicolumn{2}{|c|}{ Total } \\
\hline 1 & 6 & 17 & 3 & 20 & 6 & 14 & 3 & 23 & \\
\hline 2 & 38 & 44 & 9 & 73 & 32 & 35 & 15 & 82 & \\
\hline 3 & 47 & 49 & 11 & 85 & 62 & 28 & 6 & 96 & 330 \\
\hline 4 & 59 & 44 & 17 & 86 & 60 & 32 & 11 & 103 & \\
\hline 5 & 21 & 5 & 11 & 15 & 18 & 5 & 3 & 26 & \\
\hline Avg & 3.3012 & 2.8598 & 3.4706 & 3.0108 & 3.2881 & 2.8214 & 2.8947 & 3.0818 & \\
\hline$P$ & 0.00 & $* * *$ & & 526 & & $0.005^{\star *}$ & & & \\
\hline
\end{tabular}

$p=$ significance value; ${ }^{\star} p \leq 0.05{ }^{\star *} p \leq 0.01{ }^{\star * *} p \leq 0.001$. Question $17 \mathrm{~d}$ : Evaluate the interrelation of theory and practice in individual subjects. Answer: $1=$ very little or low, $2=$ little or low, 3 = cannot judge, $4=$ high, 5 very high. Source: authors' own research.

The average evaluation of the interrelation of theory and practice in individual subjects reached 3.30 in the case of Czech and 2.85 in the case of Polish students. The result is statistically significant and confirms hypothesis $7 H$. The evaluation 
of the university studies in terms of the interrelation of theory and practice differs in regard to the country.

The average evaluation of the interrelation of theory and practice in individual subjects reached 3.478 in the case of men and 3.01 in the case of women. Men assess the interrelation more positively than women; however, they make only $15.45 \%$ of the sample and can evaluate the interrelation less sensitively. The results are not statistically significant and do not confirm the hypothesis $8 H$. The evaluation of the interrelation of theory and practice in the course of university studies does not depend on students' gender.

The average evaluation of the interrelation of theory and practice in individual subjects reached quite similar values in the second and third years of study, i.e. $3.28,2.82$ and 2.89 and thus allows for confirming the hypothesis $9 H$. The evaluation of the university studies in terms of the interrelation of theory and practice does depend on the year of study (Table 13).

The relationship was analysed as well between the evaluation of the interrelation of theory and practice and students' answers to the question concerning the sense of belonging to the academic community (item 2e), studies (questions 10) and working abroad (question 11) or an intention to study (question 12) or work abroad (questions 13).

Table 14. The relationship between the connection of theory and practice in individual subjects and selected variables - correlation analysis of the relationship between questions $2 \mathrm{e}, 10-13$ and questions $17 \mathrm{~d}$ for all respondents $(\mathrm{CZ}+\mathrm{PL})$

\begin{tabular}{ccccccccccc}
\hline CZ+PL & Q2e $\mid r$ & Q2e $\mid p$ & Q10 $\mid r$ & Q10 $\mid p$ & Q11 $\mid r$ & Q11 $\mid p$ & Q12 $\mid r$ & Q12 $\mid p$ & Q13 $\mid r$ & Q13 $\mid p$ \\
\hline Q17-d & $\mathbf{0 . 1 9 5}$ & $\mathbf{0 . 0 0 0}^{* * *}$ & -0.050 & 0.369 & -0.031 & 0.577 & $\mathbf{- 0 . 1 4 3}$ & $\mathbf{0 . 0 0 9 * *}$ & -0.065 & 0.238 \\
\hline
\end{tabular}

$r ; r \in\langle-1 ; 1\rangle$ correlation coefficient. $p$ - significance value for testing hypotheses $H_{0}: r=0$; $H_{1}: r \neq 0 .{ }^{\star} p \leq 0.05^{* *} p \leq 0.01{ }^{* *} p \leq 0.001$. Q 2 e How strong are your ties with the academic community of your university? Q 10 Have you studied abroad? Q 11 Have you worked abroad? Q 12 Would you like to study abroad? Q 13 Would you like to work abroad? Source: authors' own research.

The evaluation of the interrelationship of theory and practice in individual subjects weakly correlates with the declared level of feeling of belonging to the academic community of the university and the intention to study abroad (Table 14). A negative value of the correlation coefficient $(r=-0.143)$ means that students who evaluate the level of the interrelationship of theory and practice in individual subjects more negatively are more likely to consider studying abroad. Czech students tend to consider it more frequently $(r=0.122)$ than Polish $(r=-0.091)$. The evaluation does not depend on whether the students studied or worked abroad or consider working abroad. 


\section{Summary}

The overall average evaluation of theoretical knowledge students can acquire in the course of studies reached 3.59 for both universities. The overall average evaluation of practical skills students can acquire during their studies reached 2.99 for both universities. Overall, the average evaluation of the interrelationship of theory and practice in individual subjects reached 3.08 for both universities.

With regard to the five-steps rating scale, it can be stated that the level of theoretical training for the teaching profession is evaluated higher than practical training and the interrelation of theory and practice in individual subjects.

Significant differences between the evaluations of Czech and Polish students were discovered in all fundamental indicators of the curriculum. Polish students assessed their university with higher criticism than Czech students in all three parameters.

No statistically significant difference was discovered in the evaluation of men and women.

Statistically significant differences were not discovered among the students of different years of study in their evaluation of the level of theoretical knowledge they can acquire during their studies. Statistically significant results were discovered among the students of different years of study in their evaluation of their acquisition of practical skills, as well as in their evaluation of the interrelationship of theory and practice in individual subjects.

A higher percentage of Polish students chose the "cannot judge" answer than Czech students in all three indicators with the difference ranging from 3.3 to $8.3 \%$.

The evaluation of theoretical and practical training and their interrelationship in university education slightly correlates with students' feeling of belonging to the academic community of the university $(r=0.142,0.204$ and 0.195$)$ in all three cases. Getting students involved in the academic life and environment of the university or increasing the level of their engagement can be a determinant of the subjective assessment of the essential indicators of the quality of their studies and thus, of the level of theoretical and practical professional preparation. Students declaring an interest in studying abroad in the future are more critical towards the level of their practical training and the connection between theory and practice in academic subjects. 


\subsection{Value of higher education}

The interest of the young adult generation in university studies is probably influenced by their gradual acceptation of the idea of lifelong learning, prospects for better employment and a higher quality of life after graduation. In compliance with the average basis of the current patterns of graduation - $49 \%$ of today's young people across OECD countries are expected to graduate from tertiary education at least once in their lifetime (OECD, 2018, p. 208). First-time tertiary graduation rates are significantly lower for men than for women in all countries with available data. On average, across OECD countries, $43 \%$ of women are expected to obtain a tertiary degree before the age of 30 , compared to only $29 \%$ of men. Only $5 \%$ of male graduates obtain a degree in education, compared to $14 \%$ of female graduates (p. 209).

A considerable interest of the young population in higher education confirms that they treat education as a significant value. A value as "a subjective amount of importance that one attributes to certain things, phenomena, symbols, other people, etc.” (Průcha, Walterová \& Mareš, 2008, p74) is integrated with other values to the value orientation which expresses the existing set of values of the individual and also informs researchers about their inclination towards specific values. The knowledge of the individual or group value orientation allows researchers to anticipate their behaviour. Since values have both individual and social functions, it is possible to evaluate higher education as an acquired value from the perspective of individual benefits for the graduate and benefits for the society. There are individual attempts to measure and express this evaluation. The value of a university degree can be measured in several ways: increased lifetime earnings potentialities, the network of classmates and fellow alumni, subject-matter expertise, a signal of perseverance, potentially a marker of class or the capacity to move across social classes. There are also some less tangible benefits, like becoming a more multidimensional individual and part of a wellinformed public. (Cole, 2018).

The value of higher education may be highly individual and can vary in time and space. Its determination or measurement has been the object of great interest for economists, sociologists, politicians, educators and students themselves as there are attempt to express it in some measurable indicators or units. One possible objectivization is comprised in expressing the value of education in the income of graduates. Parker (2018) led to three conclusions after the analysis of the Australian data: 1) Those with tertiary education qualifications earn more than those whose highest qualification is the Year 12 Certificate; 2) Men with tertiary education earn more than women with this education. This is true even when the focus is on the hourly wage (which neutralises the fact that men are more likely to be involved in full-time work than women); 3) The earning rate in 
the case of an average Higher Education (HE) qualification remains strong. In this context, however, it may be interesting to note that: "recent Australian graduates are earning less than their previous counterparts, and these effects are strongly age-related". (Black \& Walsh, 2019 citing Norton \& Cherastidtham, 2018). Recent research in the Czech Republic has proven that there is currently no inflation of the tertiary education in the Czech labour market, even though the number of graduates have grown significantly in the last 15 years (Doseděl \& Katrňák, 2018).

The personal benefits of higher education may be essential incentives for its acquisition. "There are large incentives for people to attend higher education. Educational attainment has a strong positive relationship to skill proficiency. Adults with tertiary-level qualifications have more advanced knowledge and skills than non-graduates. This can be expected, as adults who have completed higher education have spent a longer time in education and received higher levels of instruction than their less qualified peers. Besides, completing higher levels of education often provides access to jobs that involve higher levels of further learning and information processing tasks. People with higher education are more likely to be employed, remain employed, and have more opportunities to gain experience on the job. Moreover, higher education is associated with higher earnings during a person's working life." (OECD, 2017, p. 14).

Higher education has an economical, social, cultural and environmental impact on the community at the local, regional, national and global level (OECD, 2013). The importance of the social benefits of higher education is proven by the fact that in many countries, including the Czech Republic and Poland, state universities are free of charge and the tuition in private tertiary education institutions is acceptable and ranges from 17,500 to 95,000 CZK for one semester. Many years of discussions on the tuition of state universities in the Czech Republic led to the preparation of a relevant bill in 2002. However, the political situation was not favourable for its adoption even though one of the many arguments was that education is a private estate and thus, requires the full or partial participation of the student. Tuition was designed to become one of the quality assurance tools by discouraging individuals with insufficient motivation or prerequisites from applying.

Since the respondents of our research are studying at the faculties focused on the training of future teachers, it is crucial to approach the issue of teaching professions in both their general features and peculiarities in the Czech Republic and Poland. According to the TALIS 2018 research (OECD, 2019), $90 \%$ of teachers comment that the chance to contribute to society and influence children's development was an important reason for them to become a teacher. Teaching was the first-choice career for two out of three teachers in OECD countries, but this is true for only $59 \%$ of male, compared to $70 \%$ of female 
teachers. Throughout their education and training, teachers were instructed first and foremost on subject content, pedagogy and classroom practice. Student behaviour and classroom management were included in the training of $72 \%$ of teachers. Only $38 \%$ of them participate in formal or informal induction in their school, despite the positive impact of induction processes on novice teachers' transition to the school environment and their efficacy.

The teaching workforce in the Czech Republic is ageing, and the profession is less attractive to the younger generation, partially due to low salaries. Teachers in the Czech Republic have relatively low salaries, especially in comparison to other tertiary-educated workers, even though the state increased teachers' salaries by $15 \%$ in 2018. The didactic duties of Czech teachers are below the average of OECD countries and decreased in the last ten years, in contrast to the other countries of the OECD where they slightly increased. The qualification requirement for Czech teachers is a Master's degree (OECD, 2018b; Shewbridge et al., 2016).

In Poland, some considerable dissatisfaction of teachers with their salaries prevails as the strike which took place in spring 2019 did not help to improve the situation. Teaching professions occupy high positions in the prestige hierarchy. Teachers agree that people in professions of higher social impact deserve a higher social prestige. The prestige of teachers, according to them, is influenced mainly by the following factors: personal features (openness, empathy, ability to listen); the style of work with students (based on very good relationships with students, communication with students and parents and the ability to evoke an interest in the subject and cognition); autonomy (manifested by higher powers and participation in the school management); a change in the role of the school (school with a responsible commitment to the local life). A low economic status, low quality of education and schoolwork, the role of the media, the perception of teachers by parents and students, as well as teachers' self-presentation negatively affect the prestige of the teaching profession (Smak \& Walczak, 2015).

In our research, the opinion of respondents on the social recognition and value of higher education was surveyed by an entry in which they expressed their opinion as people with the status of tertiary educated individuals in their respective country.

The slightly prevalent opinion of both Czech and Polish students is that the status of a person with a tertiary education is high or very high. Czech students evaluated the social status of a tertiary educated person more positively $(5.2 \%$ higher $-56.1 \%$ ) than Polish students (50.9\%). More than a quarter of Czech (26.3\%) and Polish (28.3\%) students chose the neutral opinion "cannot judge". About one fifth of Czech (17.6\%) or Polish (20.8\%) students believe that the status of a person with higher education is "little" or "very little" (Figure 46). 


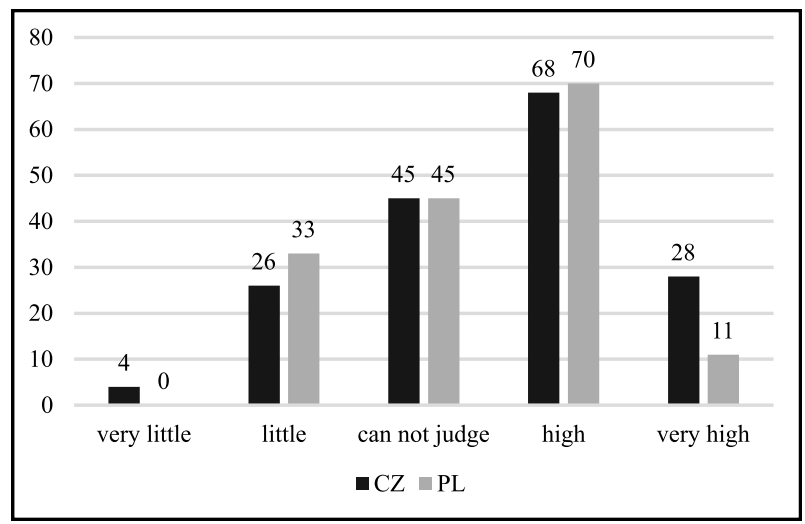

Figure 46. Distribution of answers concerning the evaluation of the value of higher education for CZ and PL. Source: authors' own research.

The hypotheses were formulated about the possible influence of students' region, gender and year of study on their assessment of the status of a person with tertiary education:

$10 H$ : Students from different countries assess the value of higher education differently.

$11 \mathrm{H}$ : Students of different genders assess the value of higher education differently.

$12 \mathrm{H}$ : Students of different years of study assess the value of higher education differently.

Table 15. Evaluation of the value of higher education - frequency analysis and testing dependences between question $17 i$ and the considered categories

\begin{tabular}{cccccccccc}
\hline \multirow{2}{*}{ Answer } & CZ & PL & Male & Female & $\begin{array}{c}1^{\text {st }} \text { Year } \\
\text { of Study }\end{array}$ & $\begin{array}{c}2^{\text {nd }} \text { Year } \\
\text { of Study }\end{array}$ & $\begin{array}{c}3^{\text {rd }} \text { Year } \\
\text { of Study }\end{array}$ & Total \\
\hline 1 & 4 & 0 & 1 & 3 & 2 & 1 & 1 & 4 & \\
2 & 26 & 33 & 9 & 50 & 29 & 23 & 7 & 59 & \\
3 & 45 & 45 & 11 & 79 & 52 & 26 & 12 & 90 & 330 \\
4 & 68 & 70 & 19 & 119 & 73 & 52 & 13 & 138 & \\
5 & 28 & 11 & 11 & 28 & 22 & 12 & 5 & 39 \\
avg & 3.5181 & 3.3841 & 3.5882 & 3.4265 & 3.4633 & 3.4375 & 3.3684 & 3.4515 \\
$p$ & 0.164 & \multicolumn{2}{c}{0.989} & & 0.451 & & \\
\hline
\end{tabular}

$p=$ significance value; ${ }^{\star} p \leq 0.05^{\star *} p \leq 0.01{ }^{\star * \star} p \leq 0.001$. Question 17 i: Evaluate the status of a person with higher education in your country. Answer: $1=$ very little or low, 2 = little or low, 3 = cannot judge, $4=$ high, $5=$ very high. Source: authors' own research.

The average evaluation of the status of a person with higher education was 3.51 for Czech students and 3.38 for Polish students. Although Czech students evaluate the status higher than Polish students, the difference is not statistically 
significant. Students in the evaluated countries do not differ in the subjectively perceived status of a person with tertiary education.

The average evaluation of the status of a person with tertiary education was 3.58 for men and 3.42 for women. Interestingly, men evaluate this educational status higher than women, but the difference is not statistically significant. The assumption in hypothesis $11 H 3.4 .2$. that there are differences in the evaluation of the status of a person with higher education due to gender has not been proven.

The finding that the average evaluation of the status of a person with tertiary education, 3.46, 3.43 and 3.36 decreases with the consecutive years of study may explain the overall influence of university as well as students' participation in professional practices in the higher years of study. The ideas of beginning students about their social and economic status after graduation are refined and rationalised along with the impact of their direct experience in the professional arena. The differences are not statistically significant and it is thus not possible to draw a conclusion confirming the hypothesis $12 \mathrm{H3} .3 .3$ that the assessment of the status of a person with higher education differs in particular years of study (Table 15).

The relationship between the evaluation of the interrelation of theory and practice and students' answers to the question about a sense of belonging to the academic community (item 2e), studies (questions 10) and working (question 11) abroad or an intention to study (question 12) or work abroad (questions 13) was analysed as well.

Table 16. Relationship between the evaluation of the value of higher education and selected variables - correlation analysis of the relationship between questions $2 \mathrm{e}, 10-13$ and questions $17 \mathrm{i}$ for all respondents $(\mathrm{CZ}+\mathrm{PL})$

\begin{tabular}{rllllllllll}
\hline CZ+PL & Q2e $\mid r$ & Q2e $\mid p$ & $\mathrm{Q} 10 \mid r$ & $\mathrm{Q} 10 \mid p$ & $\mathrm{Q} 11 \mid r$ & $\mathrm{Q} 11 \mid p$ & $\mathrm{Q} 12 \mid r$ & $\mathrm{Q} 12 \mid p$ & $\mathrm{Q} 13 \mid r$ & $\mathrm{Q} 13 \mid p$ \\
\hline 0.096 & 0.081 & $\mathbf{- 0 . 1 4 5}$ & $\mathbf{0 . 0 0 8}^{* *}$ & -0.127 & 0.021 & -0.080 & 0.149 & -0.035 & 0.523 \\
\hline
\end{tabular}

$r ; r \in\langle-1 ; 1\rangle$ correlation coefficient. $p$ - significance value for testing hypotheses $H_{0}: r=0$; $H_{1}: r \neq 0,{ }^{*} p \leq 0.05^{* *} p \leq 0.01{ }^{* *} p \leq 0.001$. Q 2 e How strong are your ties with the academic community of your university? Q 10 Have you studied abroad? Q 11 Have you worked abroad? Q 12 Would you like to study abroad? Q 13 Would you like to work abroad? Source: authors' own research.

The data concerning the evaluation of the status of a person with higher education do not correlate with the data on the declared feeling of belonging to the academic community. They are, however, slightly related to the students' experience of studying abroad. Students who spent part of their studies in different countries will probably consider the status of a person with tertiary education in their country as less important than students without any foreign experience ( $\mathrm{r}=$ - 0.145). The assumption is slightly more justified in the sample of Czech students $(r=-0.172)$ than in the case of Polish students $(r=0.102)$. The evaluation is 
not influenced by the experience of working abroad or the intention to study or work abroad. (Table 16).

\section{Summary}

The overall average evaluation of the status of a person with tertiary education for both universities was 3.45. The differences in the evaluation of the status of a person with higher education between Czech and Polish students, between men and women and among the students of particular years of study were not statistically significant. The number of students who were not able to choose either a positive or negative assessment reached more than one quarter and was slightly higher in the group of Polish students. The evaluation is slightly negatively influenced by students' past foreign experience; the influence is more significant in the case of Czech students.

\subsection{People at university}

Education and partial scientific goals are achieved by direct cooperation of the members of an academic community - university teachers (academics) and university students (students). Higher education acts in each country define the professional category of university teachers, their tasks, roles and conditions for fulfilling academic positions. The Higher Education Act in the Czech Republic says that academics are professors, associate professors, assistant professors, assistants, lecturers and scientific, research and development staff, employees of the university performing both pedagogical and creative work. Academic staff are required to ensure the excellent reputation of their university.

The professional career of an academic in the Czech Republic is possible to commence at each of the stated qualification levels. The career of an academic most frequently starts after finishing the Master's programme and the special practice or after completing the doctoral studies in the case of the qualification level of assistant or assistant professor. For the positions of associate professor and professor, a certain academic rank is required, since the Higher Education Act specifies the conditions for nominations for associate professorship and full professorship.

Academic staff conduct activity in the educational, research and engagement dimensions. Three generic functions should enrich the dimensions they should fulfil in their supporting role: the personal, academic and professional (PerezPoch, Domingo, Sanz \& López, 2018). The functions are ensured by several supportive activities (Figure 47). 


\begin{tabular}{|c|c|c|}
\hline Personal & Academic & Professional \\
\hline $\begin{array}{l}\text { Ensures the student's } \\
\text { proper integration into } \\
\text { the university. } \\
\text { - Orients the student with } \\
\text { respect to specific uni- } \\
\text { versity processes and his/ } \\
\text { her educational pathway. } \\
\text { - If a tutor identifies a non- } \\
\text { academic problem that } \\
\text { falls outside his/her } \\
\text { remit, the student may be } \\
\text { referred to other specific } \\
\text { services. }\end{array}$ & $\begin{array}{l}\text { - Advises and guides the } \\
\text { student with respect to } \\
\text { subject-related content. } \\
\text { - The teacher has a specific } \\
\text { time slot in his/her } \\
\text { schedule for this work }\end{array}$ & $\begin{array}{l}\text { - Provides information on } \\
\text { the reality of the business } \\
\text { world. } \\
\text { - Orients the student con- } \\
\text { cerning degree-related ca- } \\
\text { reer opportunities. } \\
\text { - Provides information on } \\
\text { options for further study } \\
\text { (master's and post- } \\
\text { graduate courses). }\end{array}$ \\
\hline
\end{tabular}

Figure 47. Generic functions of university professors in a supporting role. Source: PerezPoch, Domingo, Sanz \& López, 2018.

The European Commission (2018, p. 15) emphasizes the importance of academic staff in the process of improving teaching and learning by stating that "Higher education teachers are the key players in enabling students' learning, and appropriate training in teaching skills both before being employed and throughout careers is an essential pre-requisite for a high-quality system. Nevertheless, regulations rarely require academics to hold a teaching qualification, and the development of teaching skills is often left to ad hoc measures." European university communities have agreed on a similar evaluation of the importance of higher education teachers and prepared the Standards and Guidelines for Quality Assurance in the European Higher Education Area (2015). Standard 1.5 for the teaching staff says: "Institutions should assure themselves of the competence of their teachers. They should apply a fair and transparent process for the recruitment and development of the staff. (p. 13). The thesis: 'The teacher's role is essential in creating a high-quality student experience and in enabling the acquisition of knowledge, competences and skills' is comprised in the relevant guidelines. Higher educational institutions should support their teachers and their professional development and encourage innovation in teaching methods and the use of new technologies. The European Commission links the problem with the construction and implementation of study programmes in a different document (2017, p. 5): 'Designing, building and delivering good study programmes is not easy. Good teachers are crucial. Too many higher education teachers have received little, or no pedagogical training and systematic investment in teachers' continuous professional development remains the exception. National and institutional strategies to improve career opportunities and rewards for good teachers are becoming more common but are far from standard."”

In 2018, the European University Association (Gaebel, Zhang, Bunescu \& Stoeber, 2018) performed the research Trends 2018 Survey, which included 303 
higher education institutions. Twenty-five universities from Poland and eight from the Czech Republic took part in it. The main aim was to discover the problems and experiences with the implementation of the Bologna process. Some interesting data were collected in the sphere of teaching staff. "At most higher education institutions, responsibilities for teaching are shared among staff with different profiles. Depending on the system and type of institution, researchers, experts, and practitioners, as well as students, contribute to teaching, though with different levels of responsibility regarding teaching content and concepts. For example, $60 \%$ of institutions indicate that a substantial contribution comes from teaching support staff. An appointment at a higher education institution that includes teaching responsibilities may require four different elements: an academic degree, teaching experience, evaluation of teaching performance, and participation in teaching enhancement. However, these elements are not always necessary in all systems and institutions and are interpreted in very different ways. The most common requirement is an academic degree, usually a doctorate. Many institutions confirm the need to emphasise teaching experience and teacher training as elements of doctoral education. Besides, it is often not mandatory and subject to exceptions. Only half of the institutions have set formal requirements regarding teaching experience and the regular evaluation of teaching, and about one third requires participation in teaching enhancement (pedagogical development). However, these usually address only professors, lecturers, and associate professors, leaving out other types of staff that contribute to teaching. Teaching performance of teaching staff is commonly evaluated, but evaluation instruments are still being explored. Results from teaching performance evaluation have little or no impact on career progression. Institutions identify the lack of recognition for teaching in career progression as one of the top obstacles for improving learning and teaching". (Gaebel, Zhang, Bunescu \& Stoeber 2018, p9).

The preparation of academic staff for the educational function is still unsystematic, frequently random and is not always required as a qualification criterium for the commencement or development of the academic career. Chmura (2016) formulated several conclusions in his comparative research. University teachers usually capitalize on their Master's or doctoral studies, which included pedagogical practice. Universities offer courses in pedagogical skills as a supportive service for academic staff, or there are offers of similar courses from several public or private institutions such as educational organisations, foundations and associations. They are not compulsory for the academic staff and the academics are not required to participate.

Szplit (2017) critically evaluates Polish universities and their educational dimension. He states that "our academic institutions do not seem to be very interested in developing didactics. One reason for such a state of affairs is probably 
our system of financing higher education institutions, which depends on scientific development and the number of students being educated, no matter the quality of teaching and didactic work of academic staff. Despite this broader situation in Poland, studying one's practice is an effective approach that supports the professional development of an academic teacher. Considerable benefits are derivied from researching academic practice, both for educators and students" (p. 191).

No mid-term or long-term central strategy of human resources planning in higher education (data from the academic year 2015/16) (Crosier, 2018, p. 7) exists in the Czech Republic or Poland. Contrary to most European countries, academic staff do not have the status of national employees in the Czech Republic and Poland; thus, they do not have the benefits. Numerous academics in the Czech Republic have fixed-term employment contracts, and their possible renewal may be solved by announcing a selection procedure for their vacant post or by the (complex) evaluation of their work. Since 2012, universities have followed the currently valid Labour Act which states that the length of the fixed-term contract cannot exceed three years since the beginning of the employment and can be repeated only twice. After the six-year-long period, every university, if it aims to prolong the employment of the academic, is required to conclude an indefinite time contract of employment. While central rules for the remuneration of academic staff exist in Poland, in the Czech Republic the salaries are stated by internal (wage) regulations.

The 2017 Annual Report of the Ministry of Education, Youth and Sports ${ }^{39}$ states that about 40,000 employees worked in Czech public universities, 17,600 of those were academic staff (36\% women) and 3,900 research personnel (34\% women). The average monthly gross salary of the public universities' academic staff was 48,412 CZK. More than half of academic staff were assistants (9.2 thousand), more than one fifth were associate professors (3.9 thousand), more than one tenth (2.0 thousand) were professors, less than one tenth (1.2 thousand) were assistants, and less than $5 \%$ (700) were lecturers. The study of Koucký (2017) states that the insufficient salaries of higher education teachers not only result from the direct comparison of their nominal value but also from the comparison of salary levels of different university professions in the context of each country. The salary of the Czech university teachers can hardly be compared to other developed countries and this sharply limits the possibilities of a real competency in the international and national competition among good quality academic staff. It is true not only for the acquisition of significant foreign personalities for Czech universities but also for the admission or retention of the best

39 http://www.msmt.cz/uploads/Statistika_skolstvi/vyrocni_zpravy/vyrocni_zprava_vzdelavan i_2017_public.pdf. 
Czech professionals. International studies repeatedly confirm that high quality teachers are the critical factor for the high quality of education. In this situation and under current conditions it is not possible to expect or even demand results comparable with the best universities in developed countries.

From 2014 to 2016, the Institute of Psychology of the Academy of Sciences of the Czech Republic in Prague conducted a study on the sample of 2,229 academics from Czech universities and colleges (Keményová, 2017). The study revealed several interesting findings. Almost $84 \%$ of Czech scientists and academics are satisfied with their job and working conditions. If there is anything they do not like about their employment, it is their salary and dissatisfaction with their direct supervisors, e. g. heads of their department. Overall, the satisfaction of the Czech scientists prevails over negative feelings. The satisfaction of the Czech scientists is high even when compared to the world. In several similar foreign studies, the level of satisfaction was around 52-69\%. The Czech scientists are satisfied mainly because of the high degree of freedom. They can freely select the field of their work, topics and may independently plan grant applications, foreign research trips, etc. $54 \%$ of the respondents are not satisfied with their salary. The second most significant dissatisfaction is with the quality of faculty management. The low quality of management is indicated by $33 \%$ of respondents, and $41 \%$ of dissatisfied academics regard it as one of the most significant problems in their workplace. Many scientists admitted that their managers do not want to resolve conflicts in the workplace. One of the recommendations for the management of the faculties is to assist the academic staff with reconciling their work and personal life. Bothwell (2018) conducted an international study on the balance between work and personal life of university employees. The results proved that the academic staff feel stressed and insufficiently rewarded and hardly balance their personal relationships and family with the ever increasing workflow. Most of the university employees feel that they are overworked, insufficiently rewarded and that their career negatively influences their relationships with friends, family and life partners. The findings also point to significant disproportions among the answers of the academic and nonacademic staff (professional and supportive professions) and between the experience of men and women.

The Australian study on key risk findings in Australia's higher education sector (Tertiary Education Quality and Standard Agency, 2019) presents academic staffing as a critical factor of educational quality. TEQSA ${ }^{40}$ considers low teaching staff levels and high levels of academic casualisation to pose a risk to the quality of higher education and to support student growth, experience, and outcomes adequately. Moreover, low ratios of senior academic leaders for each

40 TEQSA (Tertiary Education Quality and Standards Agency). 
broad field of education also pose risks to the quality of higher education and could have a negative impact on learning outcomes for students.

During an examination of the academic staff and students' opinions on the relevance of their 14 professional competencies incorporated into three professional profiles (professional, social-personal, and academic) ${ }^{41}$ based on the sample of Czech academics (Malach \& Chmura, 2018, it was discovered that the social-personal profile received the highest relevance for both groups. The members of the academic community highly value: the culture of manners, academics' respect towards students, academics' abilities to suppress a bad mood, high academic responsibility for their professional activities, commitment to solving difficult situations and ability to make decisions and take responsibility for success and failure in professional work. What is more, the support of students by the academics, providing students with the possibilities of development and self-management, the ability to participate in dialogue and expressions of the academic's motivation to perform work duties and tasks possess high value as well. The professional profile ranked as second. The findings are a positive message in the situation when the parametrised data on the outputs of scientific research (frequently presented in a shape of criticised rankings) possess bigger importance than the fulfilment of pedagogical tasks and responsibilities and students' learning outcomes. The academic (scientific) profile ranks as third. It is not a surprise that its relevance is even on a lower level in the case of students than of academics. Among the academics of all four countries, there is full agreement on the preference of academic impeccability, integrity, and competence (Malach \& Chmura, 2019). Students are more diverse in their opinions, but both in the Czech Republic and Poland, they agree with the preference of professional and social competence. The most preferred competencies by the academics of all countries are different from the most preferred competencies of students. Academics agree to academic impeccability and integrity while students prefer professional and social responsibility. The most preferred professional profile is the social-personal one, both for academics and students from all countries. The least preferred is the academic (scientific) profile - the claim is valid for academics from all countries except Poland, for students from all countries except Poland, and both subgroups in the entire sample - for all academics and all students.

41 The research was carried out within the framework of the grant project of the Visegrad Fund entitled "High School Teacher Competence in Change" No. ID 21720008 at the University of Ostrava and the University of Silesia in 2017 to 2018. The project was further supported by universities from Ukraine and Slovakia. The authors of this book actively participated in it. See: Khoruzha L. (ed.) (2019), High School Teacher Competence in Change, Borys Grichenko Kyiv University, Kyiv. 
The opinions of the academic staff and students on the importance of professional competencies and professional profiles of the academics are very similar. This fact creates a favourable condition for their mutual communication and cooperation while fulfilling the objectives of higher education.

The opinions of the students on the staff of higher education institutions were examined by Kandiko and Mawer (2013). Students praised the enthusiastic, experienced and engaged staff, but wanted some mechanisms to develop staff and to manage "bad" teachers. Students wanted staff to be qualified and trained, and students expressed a desire for procedures to manage "bad teaching", described as lecturers not knowing the course material, reading the ready-made slides and failing to offer any support to students. Despite having a consumerist approach to higher education, students complained about academics who - in a demonstrative way - took the attitude of "just doing their job". Students wanted lecturers who were passionate and knowledgeable about their subject, with sufficient content knowledge and teaching capability. It also seems a bit surprising in an age of the unprecedented development of digital technologies and changes in communication tools that students desired more interaction with staff, both within the classroom and beyond it (p. 12). Students wanted opportunities to meet and interact with other students, engage in their lessons and participate in extra-curricular activities, both social and academic. A significant proportion of students had minimal contact with the Students' Union, particularly some groups such as part-time students, students of intensive pre-professional courses, and students who were not interested in the sporting or drinking culture.

University students are a specific social group. They are age-bounded - the vast majority belongs to one age category. An individual starts university studies usually around the age of 20 (Minksová, 2010.). The studentship is recently understood as a phase of the human life cycle. University studies may be characterised as a period of "a temporary affiliation to an internally highly variable group, representing an increasing number of young people" (Linhart et al., 1996, p. 44). The specific so-called "college socialisation" through the influence of the subculture of university students and their way of life takes place during this period (Ondrejkovič, 2004, pp. 154-155.) Despite the different social conditions of university students, their various ambitions, family backgrounds, different studying-related decisions, as well as diverse life experiences, the systemic features of university students are highly homogenized.

University students interact with their teachers and other students during their studies. The quality and quantity of the interactions may influence the course of study, retention of the results, and students' satisfaction in studies. (Halverson \& Graham 2019). The interactions are an essential factor of students' engagement in the academic culture and lifelong learning, citizenship and personal growth. This engagement, from the psychological standpoint, is examined 
as a relationship between university teaching staff (support, workload) and the student (motivation, skills, identity and self-efficacy) (Kahu, 2013).

The interaction between university teachers and adult students may be understood as a part of the process of the formation of students' professional identification and development of their professional identity. The development of their professional identity begins in the course of their studies. The student identifies themselves in the context of a particular future profession or professional field. The knowledge and skills acquired during their studies are a premise of the internal identification with the profession (Žydžiūnaite \& Crisafulli, 2013). The research has proven that the structure of curriculum influences the interaction of students and their teachers in the process of professional identity development, as well as students' characteristics (how they know themselves, what their experience in the professional field is, etc.) and the characteristics of their teachers (mainly on the level of their didactic, pedagogical and social competencies, work, and practical experience in the subject) (p. 15).

Students' expectations and demands to be a part of the community and to maintain the feeling of belonging are the main aspects of the university environment, as was discovered by Widdowson, Dixon, Peterson et al. (2015) in the sample of students from New Zealand. These expectations result from a wish to strengthen the overall positive study experience of the student. Students wanted an opportunity to communicate with other students through students' unions and clubs, institutional activities and other social possibilities; students talked about activities they want to focus on, interaction with the academic staff in the classroom and outside of it.

The involvement of students in university life also depends on the conceptualization of the student identity. Lau (2014) suggests applying Freeman's stakeholder theory ${ }^{42}$ which may be a basis of the triple understanding of the student identity. Lau distinguishes three identities (p. 764): university student as a "customer", student (together with teachers) as a member of a "community of scholars", and student as an "active partner".

University students have a different status than learners at lower levels of education. In 1989, they received the right to vote and to be elected to the academic senate of a faculty or university. Senates in the Czech Republic comprise one third of students, who maintain a certain amount of self-governing functions, for example voting for a candidate for the dean and rector and confirming the distribution of the state funds. Students also participate in the quality management of universities by participating in the Student Chamber of the Council of Universities. In 2017, they also gained the possibility to act as members of the Councils for the Internal Evaluation of Universities, members of the

42 Freeman R. (1984), Strategic management: A Stakeholder Approach. Ballinge, Boston. 
Board of the National Accreditation Office and evaluation committees, and as members of the programme boards of all newly accredited degree programmes.

The European Students Union created a report which is based on an online questionnaire survey involving 44 national student associations from 38 EHEA (European Higher Education Area) countries to better understand the students' opinions on the results of the Bologna process (Sundberg, Heerens \& Koppel (eds.), 2018). From the questions about student participation, it was inferred that "The Bologna Process no longer has any felt impact on student representation in the EHEA countries. Most countries have laws that regulate student participation by setting minimum standards. However, the required minimum is rarely surpassed. How and where students are involved and participating differs a lot. Some countries have democratic representation in the highest decision-making bodies, whereas others limit the influence on the preparatory phase" (p. 6).

Cooperative or collaborative learning of university students is a way to achieve better study results but also to establish and maintain relationships among them. Some selected results of Eurostudent VI research for the Czech Republic (Fischer, Vltavská et al., 2016) into the quality of social interactions of studies may have certain informative value. $71.3 \%$ of the students would choose the same university again; $66.8 \%$ would choose the same field of study. More than three quarters $(77.1 \%)$ certainly or almost certainly feel like a part of their university. The same research in Poland revealed that a university student spends an average of 21 hours per week on studying, which is only $12.5 \%$ of weekly disposable time, and 18 hours on working (PBS Spólka, 2018). The influence of the academic environment on the formation of the personality of university students thus seems historically lower than in the past. However, several higher education institutions declare provisions that can positively influence the relationships between academics and students in their ethical codes of academic and professional workers. ${ }^{43}$ The outline of research into university students until 2010

43 The Code of Ethics of Academic and Professional Workers of Masaryk University, Brno, 2015, states: Article 3 Education: 1) The worker is responsible for the quality of their teaching and the education of young researchers. To this end, they also maintain a high quality of the teaching aids they provide, including adapting them to current scientific knowledge. (3) A worker selflessly transmits both well-known and [their] own knowledge to students and young researchers, while giving them a personal example of fulfilling moral principles in education, research and development. (4) In teaching, a worker explicitly demonstrates attitudes and ways of acting, enabling the teacher-student relationship to be based on mutual respect and trust. By way of conducting the teaching and communicating with students, the worker demonstrates the right relationship to academic freedom and promotes the development of independent and critical thinking of students, encourages their qualifications and career development. (5) In their teaching, assessment of teaching requirements, examinations, and any other contact with students at the university, the worker approaches the students objectively and impartially. They communicate with students openly and fairly, without underestimating, humiliating or disrespecting them. Through their dealings with 
(Minksová, 2010) had not paid attention to the evaluation of the relationship between academic staff and students or to the quality of students' life in the community of schoolmates, which was also an aspect of our research.

The evaluation of interpersonal relationships at universities was conducted in two questions focused on the relationship of academic staff towards students and the quality of student's life.

\subsubsection{The relationship of academic staff and students}

The prevailing opinion in both countries is that the strength of the relationship between academic staff and students is "high" or "very high". More Czech students $(77.8 \%)$ than Polish students (57.2\%) selected one of these answers. Almost one third of Polish students (27\%) surprisingly chose "cannot judge". Nearly $10 \%$ of Czech and $15.8 \%$ of Polish students consider the strength of relationship between academic staff and students as "little" or "very little" (Figure 48).

The author's personal experience allows interpreting the findings as an expression of higher respect of the society and students for the academic staff in Poland which conserved the communication between students and teachers on the level known as "academic communication" with all the recognized aspects of formality and the teacher's authority.

The following hypotheses were tested to gain a deeper insight into the issue of intrapersonal relationships in the academic community:

$13 \mathrm{H}$ : Students from different countries assess the relationship of academic staff and students differently.

$14 H$ : Students of different genders assess the relationship of academic staff and students differently.

$15 \mathrm{H}$ : Students of different years of study assess the relationship of academic staff and students differently.

The average evaluation of the relationship between academic staff and students was 3.91 for Czech students and 3.47 for Polish students. The result is statistically significant and allows one to confirm the hypothesis $13 H$. Students in

students, the worker supports the desired level of collegial relations at the university. Article 1 of the Code of Ethics of the University of Economics and Management states: The relationship between the academic and the student is crucial for the university's mission; both the academic worker and the student are fully aware of their rights and responsibilities. The conduct of an academic concerning students and teaching is based on the principles of tolerance, respect for humanity, respect for freedom of thought and expression, and commitment to cognition. 


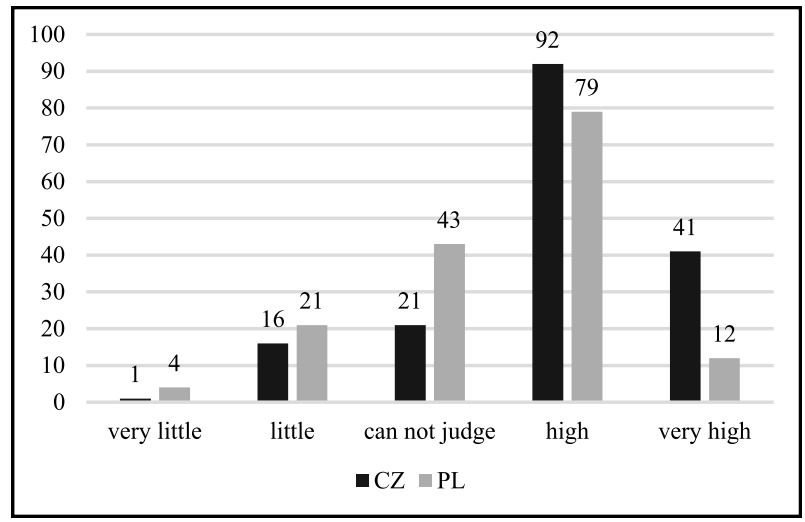

Figure 48. Frequency of answers to the question concerning the relationship of academic staff and students. Source: authors' own research.

Table 17. Evaluation of the relationship between academic staff and students - frequency analysis and testing dependences between question $17 \mathrm{p}$ and the considered categories

\begin{tabular}{|c|c|c|c|c|c|c|c|c|c|}
\hline Answer & $\mathrm{CZ}$ & PL & Male & Female & $\begin{array}{l}1^{\text {st }} \text { Year } \\
\text { of Study }\end{array}$ & $\begin{array}{l}2^{\text {nd }} \text { Year } \\
\text { of Study }\end{array}$ & $\begin{array}{l}3^{\text {rd }} \text { Year } \\
\text { of Study }\end{array}$ & Tota & \\
\hline 1 & 1 & 4 & 0 & 5 & 1 & 3 & 1 & 5 & \\
\hline 2 & 16 & 21 & 7 & 30 & 17 & 13 & 7 & 37 & \\
\hline 3 & 21 & 43 & 8 & 56 & 29 & 28 & 7 & 64 & 330 \\
\hline 4 & 92 & 79 & 22 & 149 & 104 & 52 & 15 & 171 & \\
\hline 5 & 41 & 12 & 14 & 39 & 27 & 18 & 8 & 53 & \\
\hline avg & 3.9157 & 3.4756 & 3.8431 & 3.6703 & 3.7910 & 3.6161 & 3.5789 & 3.6969 & \\
\hline$p$ & \multicolumn{2}{|c|}{$0.000^{* * *}$} & \multicolumn{2}{|c|}{0.986} & & 0.121 & & & \\
\hline
\end{tabular}

$p=$ significance value; ${ }^{*} p \leq 0.05{ }^{* *} p \leq 0.01^{\star * *} p \leq 0.001$. Question $17 \mathrm{p}$ : Evaluate relationship of academic staff and students. Answer: $1=$ very little or low, $2=$ little or low, $3=$ cannot judge, $4=$ high, $5=$ very high. Source: authors' own research.

the investigated countries differ in the evaluation of relationship of academic staff and students.

The average evaluation of the relationship of academic staff and students was 3.84 for men and 3.67 for women. The distinct difference in the results is not statistically significant and thus, does not allow to confirm the hypothesis $14 \mathrm{H}$. The evaluation of the relationship of academic staff and students is not influenced by gender.

The average evaluation of the relationship of academic staff and students in particular years of study was 3.79, 3.57 and 3.69 and is not statistically significant. Hypothesis $15 \mathrm{H}$ was not confirmed (Table 17).

The dependence between the evaluation of the relationship between academic staff and students and students' answers to the question concerning a sense of belonging to the academic community (item 2e), studies (questions 10) and 
working abroad (question 11) or an intent to study (question 12) or work abroad (questions 13) was analysed as well.

Table 18. Relations between the evaluation of the relationship between academic staff and students and selected variables -correlation analysis of the relation between questions $2 \mathrm{e}, 10-13$ and question $17 \mathrm{p}$ for all respondents $(\mathrm{CZ}+\mathrm{PL})$

\begin{tabular}{ccccccccccc}
\hline CZ+PL & $\mathrm{Q} 2 \mathrm{e} \mid r$ & $\mathrm{Q} 2 \mathrm{e} \mid p$ & $\mathrm{Q} 10 \mid r$ & $\mathrm{Q} 10 \mid p$ & $\mathrm{Q} 11 \mid r$ & $\mathrm{Q} 11 \mid p$ & $\mathrm{Q} 12 \mid r$ & $\mathrm{Q} 12 \mid p$ & $\mathrm{Q} 13 \mid r$ & $\mathrm{Q} 13 \mid p$ \\
\hline $\mathrm{Q} 17-\mathrm{p}$ & $\mathbf{0 . 2 3 1}$ & $\mathbf{0 . 0 0 0 ^ { * * * }}$ & -0.092 & 0.095 & -0.084 & 0.128 & 0.003 & 0.963 & 0.084 & 0.127 \\
\hline
\end{tabular}

$r ; r \in\langle-1 ; 1\rangle$ correlation coefficient. $p$ - significance value for testing hypotheses $H_{0}: r=0$; $H_{1}: r \neq 0,{ }^{*} p \leq 0.05^{* *} p \leq 0.01^{* * *} p \leq 0.001$. Q 2 e How strong are your ties with the academic community of your university? Q 10 Have you studied abroad? Q 11 Have you worked abroad? Q 12 Would you like to study abroad? Q 13 Would you like to work abroad? Source: authors' own research.

The evaluation of the relationship between academic staff and students weakly correlates with the level of the declared feeling of belonging to the academic community $(r=0.231)$. It is not related to students' earlier work or studies abroad or their current intention to undertake them (Table 18).

\subsubsection{Quality of the student's life}

The most frequent opinion of students in both countries is that the quality of a student's life is high, as $59.7 \%$ of Czech and $47.1 \%$ of Polish students expressed such opinions with the difference reaching $12.6 \%$. Surprisingly, almost one third of Polish students (35.9\%) chose the "cannot judge" option. $14.6 \%$ of Czech and $17.0 \%$ of Polish students regard the quality of student's life as "little" or "very little". Almost one half of Czech students and more than one half of Polish students do not have a firm opinion on their social life with their classmates, do not want to share it or evaluate it, treating it as a minimally influential factor in their students' lives. The findings may be explained by a higher degree of "distancing" in their studies and fewer chances to meet during the learning process. The range of social contacts and communication among university students is enlarging with the contribution of digitalisation and social websites and is overcoming the borders of university campuses, places of study and countries. A considerable number of students in the so-called "combined form of studies" at both universities may be an essential factor as well, even though the form of studies was not ascertained (Figure 49).

The following hypotheses were tested:

$16 \mathrm{H}$ : Students from different countries assess the quality of a student's life differently. 


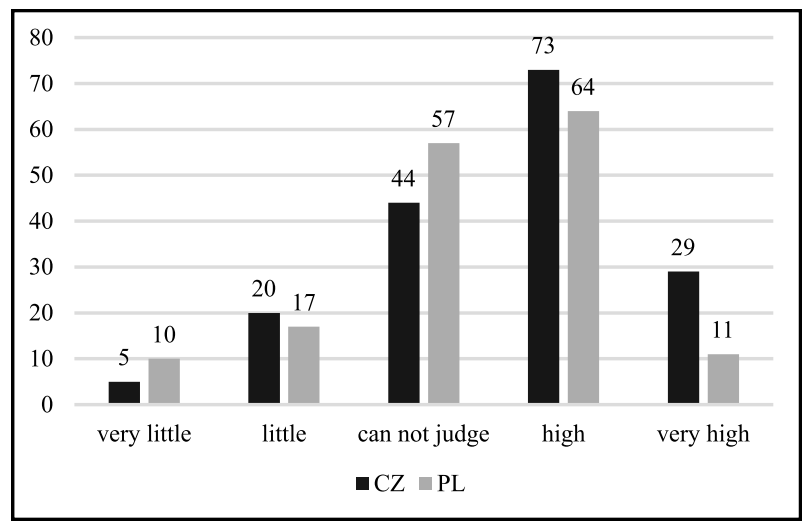

Figure 49. Frequency of answers to the question concerning the quality of a student's life with schoolmates. Source: authors' own research.

17H: Students of different genders assess the quality of a student's life differently.

$18 \mathrm{H}$ : Students of different years of study assess the quality of a student's life differently.

Table 19. Evaluation of the quality of student's life in the community of students frequency analysis and testing dependences between question $17 \mathrm{n}$ and the considered categories

\begin{tabular}{|c|c|c|c|c|c|c|c|c|c|}
\hline Answer & $\mathrm{CZ}$ & PL & Male & Female & $\begin{array}{c}1^{\text {st }} \text { Year } \\
\text { of Study }\end{array}$ & $\begin{array}{l}2^{\text {nd }} \text { Year } \\
\text { of Study }\end{array}$ & $\begin{array}{l}3^{\text {rd }} \text { Year } \\
\text { of Study }\end{array}$ & \multicolumn{2}{|c|}{ Total } \\
\hline 1 & 5 & 10 & 1 & 14 & 8 & 5 & 2 & 15 & \\
\hline 2 & 20 & 17 & 8 & 29 & 23 & 13 & 1 & 37 & \\
\hline 3 & 44 & 57 & 12 & 89 & 51 & 33 & 17 & 101 & 330 \\
\hline 4 & 73 & 64 & 23 & 114 & 76 & 49 & 12 & 137 & \\
\hline 5 & 29 & 11 & 7 & 33 & 20 & 14 & 6 & 40 & \\
\hline avg & 3.6145 & 3.2927 & 3.5294 & 3.4409 & 3.4294 & 3.4732 & 3.5000 & 3.4545 & \\
\hline$p$ & $0.002^{\star \star}$ & 0.960 & 0.969 & & & $p$ & $0.002^{\star *}$ & 0.96 & \\
\hline
\end{tabular}

$p=$ significance value; ${ }^{\star} p \leq 0.05^{* *} p \leq 0.01{ }^{* *} p \leq 0.001$. Question $17 \mathrm{n}$ : Evaluate quality of a student's life with colleagues. Answer: $1=$ very little or low, $2=$ little or low, $3=$ cannot judge, 4 = high, 5 = very high. Source: authors' own research.

The average evaluation of the quality of a student's life was 3.61 for Czech students and 3.29 for Polish students. The result is statistically significant and allows one to confirm the hypothesis $16 \mathrm{H}$. Students in the evaluated countries differ in the evaluation of the quality of student's life. The average evaluation of the quality of a student's life was 3.52 for men and 3.44 for women. This small difference in the results is not statistically significant and thus, does not allow one to confirm the hypothesis $17 \mathrm{H}$. The evaluation of the quality of student's life is not influenced by gender. The average assessment of the quality of a student's life 
in particular years of study was 3.42, 3.47 and 3.50 and is not statistically significant. Hypothesis $18 \mathrm{H}$ was not confirmed (Table 19).

The relationship between the evaluation of the quality of student's life and students' answers to the question concerning a sense of belonging to the academic community (item 2e), studies (questions 10) and working abroad (question 11) or an intention to study (question 12) or work abroad (questions 13) was analysed as well.

Table 20. Relations between the evaluation of the quality of a student's life in the student community and selected variables - correlation analysis of the relation between questions $2 \mathrm{e}, 10-13$ and question $17 \mathrm{n}$ for all respondents $(\mathrm{CZ}+\mathrm{PL})$

\begin{tabular}{|c|c|c|c|c|c|c|c|c|c|c|}
\hline $\mathrm{CZ}+\mathrm{PL}$ & $\mathrm{Q} 2 \mathrm{e} \mid r$ & $\mathrm{Q} 2 \mathrm{e} \mid p$ & Q10|r $r$ & $\mathrm{Q} 10 \mid p$ & Q11 $\mid r$ & $\mathrm{Q} 11 \mid p$ & Q12 $\mid r$ & $\mathrm{Q} 12 \mid p$ & Q13|r & $\mathrm{Q} 13 \mid p$ \\
\hline Q17-n & 0.220 & $0.000^{* * *}$ & -0.045 & 0.415 & -0.036 & 0.511 & 0.016 & 0.774 & 0.057 & 0.302 \\
\hline
\end{tabular}

$r ; r \in\langle-1 ; 1\rangle$ correlation coefficient. $p$ - significance value for testing hypotheses $H_{0}: r=0$; $H_{1}: r \neq 0,{ }^{*} p \leq 0.05^{* *} p \leq 0.01{ }^{* *} p \leq 0.001$. Q 2 e How strong are your ties with the academic community of your university? Q 10 Have you studied abroad? Q 11 Have you worked abroad? Q 12 Would you like to study abroad? Q 13 Would you like to work abroad? Source: authors' own research.

The students' assessment of the quality of a student's life in the community weakly correlates with the level of the declared feeling of belonging to the academic community of the university. It is not related to students' earlier work or studies abroad or their intention to do this (Table 20).

\section{Summary}

The overall average evaluation of the relationship between academic staff and students was 3.6969 for both universities. The overall average evaluation of the quality of a student's life reached 3.4545 for both universities.

Owing to the five-step rating scale, it is possible to state that the relationship of the academic staff and students is assessed higher by the students than the quality of a student's life.

Some significant differences were discovered in both evaluations between Czech and Polish students as Polish students evaluated their university with a higher degree of criticism than Czech students.

No statistically significant difference was discovered in the evaluation of both aspects by men and women. No statistically significant difference was discovered in the evaluation of both aspects by students of different years of study. A larger share of Polish students than Czech students chose "cannot judge" answer with the difference of $10.2 \%$ and $14.7 \%$.

The opinions of the respondents on the relationship of the academic staff and students and the quality of a student's life slightly correlate with the feeling of 
belonging to the academic community of the university $(r=0.231$ and 0.220$)$. In the case of Polish students, the correlations are moderate $(r=0.285$ and 0.315$)$. Polish students are probably more sensitive to the relationship problems in the academic community. The students with stronger feeling of belonging to the academic life at the university generally regard the relationship between the members of the academic community as healthier.

\subsection{The conditions and process of university studies}

Besides the fact that students actively participate in the self-governing and administrative proceedings of universities, they are given the possibility of regular (once a semester) expressions of their opinion on the learning process in the system of the so-called "student evaluation of learning". The evaluation is an integral part of the university quality assurance system.

Evaluative questionnaires are undergoing some specific changes and are a subject of discussions among students or between students and academics. Some specific rules of their construction are formulated in a positive format - as a scope of learning which students should express opinions about, or in a negative format - as a scope on which it is not appropriate to focus the questionnaires. The positive format includes questions concerning the cognitive and affective aspects of learning, evaluation and feedback, student learning outcomes (what I have learnt in the course), students' self-reflection (how I have contributed to the quality of the subject) and overall satisfaction with the subject. The expressions pertaining to the content of the course, the suitability of some selected lectures, professional competence of teachers or comparison of one teacher with another should not be a part of the questionnaires.

A study concerning the opinions of students on their expectations from their university was conducted in 2010 at the University of Warsaw. Students were asked to say what they considered as essential and to provide reasons why they had applied to that university. The most frequent answers were: a high level of teaching, a proper position of the university in rankings, finding suitable work after graduation, the possibility to learn from well-known scientists, taking part in the student's life, the possibility to go abroad with scholarship or the possibility to participate in research projects (Wroczyńska, 2013).

Using the focus group method with over 150 students (primarily years 1 and 2) at 16 institutions, Kandiko and Mawer (2013) acquired masses of interesting empirical data about students' expectations and perception of higher education. A significant finding of their study was that across all student year groups, institutional types and subjects, students mostly present a consumerist ethos to higher education, wanting "value-for-money". Students expected their learning 
environment to meet clear benchmarks across four areas: instrumental (computers and physical spaces); organisational (timetabling and course structure); interpersonal (staff support and engagement); and academic (lecturers' knowledge and attitude towards students). Students negatively reflected the failure to meet their expectations. Students required transparent, on-going and open processes for evaluation and the feedback opportunities that could improve their own experience, not only by providing commentary on what could help future students. An analysis of students' concept maps led to the formulation of 20 main topics students formulated to describe their expectations (in rank of order): study, social life, support, career, accommodation, teaching, clubs, facilities, resources, students' union, finances, self-development, feedback, exams, location, organisation, independence, placements, work, a year abroad (p. 69).

The students from the New Zealand university stated that they attended the institution mainly to develop their knowledge, life and social skills, to increase their prospects for further employment and economic welfare and to optimise life possibilities and its quality (Widdowson, Dixon, Peterson et al., 2015). The students shared their view of an ideal learning environment. They mainly demanded the university to offer the optimal instrumental environment (appropriate physical equipment in classroom - a stimulating environment and functional and modern IT), they further required an appropriate layout of the subjects (structure and adequate and sufficient time allocation of the subject). However, they pointed out that institutions should be cautious in the use of digital technology as a substitute for face-to-face interaction. They thus required not to use modern technology instead of an active cooperating environment of students and teachers. Students required a fair offer of subjects that would lead to deepening and testing practical matters which would help them to get by in future practice and would improve their career prospects. They also expected adequate information concerning their possible employment in the labour market provided by the counselling services.

Malach, Kristová, and Valachová (2018) used the focus group method to identify several factors that students of the University of Ostrava consider as essential to attain a quality learning environment. These are: the quality of teachers (both personal and professional), the offer of appropriate subjects for the students' area of interest and their needs, a logical timetable (which includes subjects that would prepare students not only theoretically but would also help to acquire practical skills) as well as the quality of material equipment, which would create a stimulating environment for studying. Finally, it is crucial not only to offer students the possibility to express their opinions on the quality of learning (e.g. via students' evaluation of learning) but also to reflect upon their comments and requirements. 
In the sphere of assessment, students require formative assessment and feedback in all subjects that would help them to assess the quality of their studies. However, the frustration resulting from the inadequate formulation of comments by the teacher towards the student appeared as well (Widdowson, Dixon, Peterson et al., 2015). The students from the University of Ostrava who formed the research sample confirmed the missing feedback, both formative and final. The classification level itself is not sufficiently informative. They would like to have a verbal assessment to provide them with information, e.g. how they could improve, how good their performance was in comparison to other students, which literature they should study, etc. The negative finding was that students experienced a lack of compliance with both the criteria and the principles of evaluation, as well as a violation of ethical standards. Besides, most students also do not have access to their corrected works, which again indicates insufficient feedback. They critically evaluated the issue of the defence of their final theses - they noticed an unjustified huge difference between the evaluation of the thesis by the supervisor and the reviewer (Malach, Havelková \& Gorčicová, 2018). The opinion was also expressed and positively acclaimed by others that if a more significant emphasis was put on the admission, and thus, on the quality of admitted applicants, the evaluation would not have to serve the selection of students but would mainly provide feedback.

The research carried out by The European Students' Union (Sundberg, Heerens \& Koppel (eds.), 2018) confirmed that the accepted approach to university teaching had not been reached yet. The initiatives and efforts to implement student-centred teaching seem to be very sporadic and unevenly distributed across higher educational systems. As a result, the teaching process in European higher education is still far from being student-centred while progress is scarce, if present at all. The problems with the implementation of student-centred teaching might stem from all the preconditions that such a shift demands, like, for example, proper implementation of the necessary Bologna tools that, sadly, is still missing. Furthermore, study programmes are usually still rigid and do not allow sufficient flexibility for making individualised learning a reality. In the field of quality assurance, national students unions claim that student-centred teaching is very often not treated as an equally important standard of quality. (p. 9).

Four items of the questionnaire detected students' opinions on the conditions and processes of university studies. The first was focused on the evaluation of the overall study environment at the universities. Two items were focused on the assessment of learning quality and students. The last question was aimed at the evaluation of the university's influence on the general development of a student. 


\subsubsection{The study environment created by the university}

The study environment created by the university is determined by the financial, legal, or political conditions shaped at the national or international level of management.

The prevailing opinion in both countries is that the study environment is at a high or very high level. $20.3 \%$ more of Czech students $(71.9 \%)$ than Polish students (51.6\%) evaluated their study environment assessing its level as high or very high. Almost one third of Polish students (31.4\%) surprisingly chose "cannot judge" similarly to the previously analysed items. Only $8.8 \%$ of Czech and $17.0 \%$ of Polish students consider the level of conditions as "little" or "very little" (Figure 50).

The differences between the Czech and Polish students may result from the fact that Czech students mostly learn in a newly reconstructed campus with modern equipment of classrooms and study rooms.

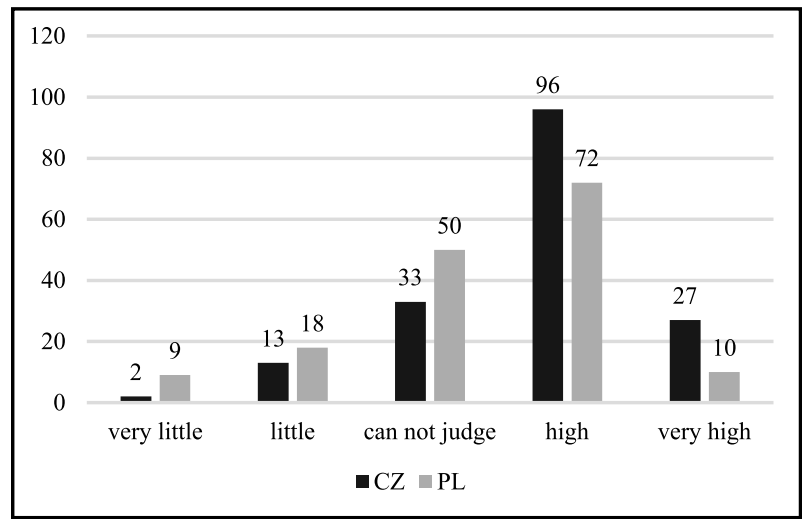

Figure 50. Frequency of answers to the question concerning the study environment created by university. Source: authors' own research.

The following hypotheses were tested for deeper insight into the problem of the study environment of the university:

19H: Students from different countries assess the study environment differently.

$20 \mathrm{H}$ : Students of different genders assess the study environment differently.

$21 \mathrm{H}$ : Students of different years of study assess the study environment differently.

The average evaluation of the study environment was 3.77 for Czech and 3.36 for Polish students. The result is statistically significant and allows for con- 
Table 21. Evaluation of the study environment created by university - frequency analysis and testing dependences between question $17 \mathrm{o}$ and the considered categories

\begin{tabular}{|c|c|c|c|c|c|c|c|c|c|}
\hline Answer & $\mathrm{CZ}$ & PL & Male & Female & $\begin{array}{l}1^{\text {st }} \text { Year } \\
\text { of Study }\end{array}$ & $\begin{array}{l}2^{\text {nd }} \text { Year } \\
\text { of Study }\end{array}$ & $\begin{array}{l}3^{\text {rd }} \text { Year } \\
\text { of Study }\end{array}$ & \multicolumn{2}{|c|}{ Total } \\
\hline 1 & 2 & 9 & 0 & 11 & 5 & 6 & 0 & 11 & \\
\hline 2 & 13 & 18 & 3 & 28 & 15 & 11 & 5 & 31 & \\
\hline 3 & 33 & 50 & 13 & 70 & 40 & 32 & 11 & 83 & 330 \\
\hline 4 & 96 & 72 & 27 & 141 & 95 & 55 & 18 & 168 & \\
\hline 5 & 27 & 10 & 8 & 29 & 23 & 10 & 4 & 37 & \\
\hline avg & 3.7771 & 3.3659 & 3.7843 & 3.5341 & 3.6497 & 3.4643 & 3.5526 & 3.5727 & \\
\hline $\mathrm{p}$ & 0.00 & & & 05 & & & & & \\
\hline
\end{tabular}

$p=$ significance value; ${ }^{\star} p \leq 0.05^{* *} p \leq 0.01{ }^{* * *} p \leq 0.001$. Question $17 \mathrm{o}$ : Study environment created by my university. Answer: $1=$ very little or low, $2=$ little or low, $3=$ cannot judge, $4=$ high, $5=$ very high. Source: authors' own research.

firming the hypothesis $19 H$. Students in the investigated countries differ in the evaluation of the study environment created by their universities.

The average evaluation of the study environment was 3.78 for men and 3.53 for women. Men assess the conditions more positively than women. The difference in the results is not statistically significant and thus does not allow one to confirm the hypothesis $20 \mathrm{H}$. The evaluation of the study environment is not influenced by gender.

The average evaluation of the study environment in particular years of study was 3.64, 3.46 and 3.55, which does not prove any tendency and is not statistically significant. The hypothesis $21 \mathrm{H}$ : "Students of different years of study assess the study environment differently" was not confirmed (Table 21).

The relationship between the study environment created by university and students' answers to the question concerning a sense of belonging to the academic community (item 2e), studies (questions 10) and working abroad (question 11) or an intention to study (question 12) or work abroad (questions 13) was analysed as well.

Table 22. Relationships between the evaluation of the study environment created by university and selected variables - correlation analysis of the relation between questions $2 \mathrm{e}$, $10-13$ and question $17 \mathrm{o}$ for all respondents $(\mathrm{CZ}+\mathrm{PL})$

\begin{tabular}{ccccccccccc}
\hline CZ+PL & Q2e $\mid \mathrm{r}$ & $\mathrm{Q} 2 \mathrm{e} \mid \mathrm{p}$ & $\mathrm{Q} 10 \mid \mathrm{r}$ & $\mathrm{Q} 10 \mid \mathrm{p}$ & $\mathrm{Q} 11 \mid \mathrm{r}$ & $\mathrm{Q} 11 \mid \mathrm{p}$ & $\mathrm{Q} 12 \mid \mathrm{r}$ & $\mathrm{Q} 12 \mid \mathrm{p}$ & $\mathrm{Q} 13 \mid \mathrm{r}$ & $\mathrm{Q} 13 \mid$ \\
\hline $\mathrm{Q} 17-\mathrm{o}$ & $\mathbf{0 . 2 8 8}$ & $\mathbf{0 . 0 0 0 ^ { * * * }}$ & -0.031 & 0.575 & -0.012 & 0.822 & -0.086 & 0.118 & 0.009 & 0.873 \\
\hline
\end{tabular}

$r ; r \in\langle-1 ; 1\rangle$ correlation coefficient. $p$ - significance value for testing hypotheses $H_{0}: r=0$; $H_{1}: r \neq 0,{ }^{*} p \leq 0.05^{* *} p \leq 0.01{ }^{* *} p \leq 0.001$. Question $17 \mathrm{o}$ : Study environment created by my university. Q 2e How strong are your ties with the academic community of your university? Q 10 Have you studied abroad? Q 11 Have you worked abroad? Q 12 Would you like to study abroad? Q 13 Would you like to work abroad? Source: authors' own research. 
The students' evaluation of the study environment created by the university weakly correlates with the level of the declared feeling of belonging to the academic community at their university. It is not related to students' previous work or studies abroad or their intention to do this (Table 22).

\subsubsection{Quality of education}

The prevailing opinion in both countries is that the quality of education is on a high or very high level. $20.4 \%$ more of Czech $(71.9 \%)$ than Polish students $(51.5 \%)$ appraised the quality of education assessing its level as high or very high. Almost one third of Polish students (28.3 \%) surprisingly chose "cannot judge", similarly to the previously analysed items while only $18.7 \%$ of Czech students chose the same option. Only $9.4 \%$ of Czech and $20.1 \%$ of Polish students consider the quality of education as "little" or "very little" (Figure 51).

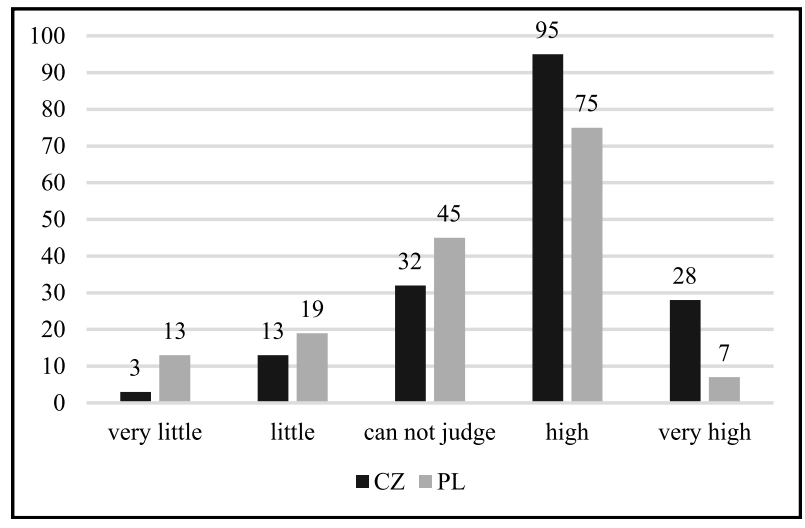

Figure 51. Frequency of answers to the question about the quality of education. Source: authors' own research.

The following hypotheses were tested for deeper insight into the problem of quality of education:

$22 \mathrm{H}$ : Students from different countries assess the quality of education differently.

$23 \mathrm{H}$ : Students of different genders assess the quality of education differently.

$24 \mathrm{H}$ : Students of different years of study assess the quality of education differently. 
Table 23. Evaluation of the quality of education - frequency analysis and testing dependences between question $17 \mathrm{q}$ and the considered categories

\begin{tabular}{|c|c|c|c|c|c|c|c|c|c|}
\hline Answer & $\mathrm{CZ}$ & PL & Male & Female & $\begin{array}{c}1^{\text {st }} \text { Year } \\
\text { of Study }\end{array}$ & $\begin{array}{l}2^{\text {nd }} \text { Year } \\
\text { of Study }\end{array}$ & $\begin{array}{l}3^{\text {rd }} \text { Year } \\
\text { of Study }\end{array}$ & \multicolumn{2}{|c|}{ Total } \\
\hline 1 & 3 & 13 & 0 & 16 & 7 & 6 & 3 & 16 & \\
\hline 2 & 13 & 19 & 3 & 29 & 13 & 15 & 4 & 32 & \\
\hline 3 & 32 & 45 & 11 & 66 & 40 & 26 & 11 & 77 & 330 \\
\hline 4 & 95 & 75 & 29 & 141 & 100 & 56 & 14 & 170 & \\
\hline 5 & 28 & 7 & 8 & 27 & 18 & 11 & 6 & 35 & \\
\hline avg & 3.7711 & 3.2927 & 3.8235 & 3.4803 & 3.6158 & 3.4554 & 3.4211 & 3.5333 & \\
\hline$p$ & \multicolumn{2}{|c|}{$0.000^{\star * *}$} & \multicolumn{2}{|c|}{0.133} & & 0.340 & & & \\
\hline
\end{tabular}

$p=$ significance value; ${ }^{*} p \leq 0.05^{* *} p \leq 0.01{ }^{* * *} p \leq 0.001$. Question $17 \mathrm{q}:$ Study environment created by my university. Answer: $1=$ very little or low, $2=$ little or low, $3=$ cannot judge, $4=$ high, $5=$ very high. Source: authors' own research.

The average evaluation of the quality of education was 3.77 for Czech and 3.29 for Polish students. The result is statistically significant and confirms the hypothesis $22 \mathrm{H}$. Students in the examined countries differ in the evaluation of the quality of education.

The average evaluation of the quality of education was 3.82 for men and 3.48 for women. Men thus assess the quality of education more positively than women. The difference in the results is not statistically significant and thus, does not allow for confirming the hypothesis $23 \mathrm{H}$. The evaluation of the quality of education is not influenced by gender.

The average evaluation of the quality of education in particular years of study was 3.61, 3.45 and 3.42, which proves a downward tendency. The results are not statistically significant. The hypothesis $24 H$ "The assessment of the quality of education differs in the years of study" was not confirmed (Table 23).

The relationship between the evaluation of the quality of education and students' answers to the question pertaining to a sense of belonging to the academic community (item 2e), studies (questions 10) and working abroad (question 11) an intention to study (question 12) or work there (questions 13) was analysed as well.

Table 24. Relations between the evaluation of quality of education and selected variables correlation analysis of the relation between questions $2 \mathrm{e}, 10-13$ and question $17 \mathrm{q}$ for all respondents $(\mathrm{CZ}+\mathrm{PL})$

\begin{tabular}{ccccccccccc}
\hline $\mathrm{CZ}+\mathrm{PL}$ & $\mathrm{Q} 2 \mathrm{e} \mid r$ & $\mathrm{Q} 2 \mathrm{e} \mid p$ & $\mathrm{Q} 10 \mid r$ & $\mathrm{Q} 10 \mid p$ & $\mathrm{Q} 11 \mid r$ & $\mathrm{Q} 11 \mid p$ & $\mathrm{Q} 12 \mid r$ & $\mathrm{Q} 12 \mid p$ & $\mathrm{Q} 13 \mid r$ & $\mathrm{Q} 13 \mid$ \\
\hline $\mathrm{Q} 17-\mathrm{q}$ & $\mathbf{0 . 2 0 9}$ & $\mathbf{0 . 0 0 0} 0^{* * *}$ & -0.035 & 0.526 & -0.020 & 0.714 & -0.051 & 0.352 & 0.003 & 0.950
\end{tabular}

$r ; r \in\langle-1 ; 1\rangle$ correlation coefficient. $p$ - Significance Value for Testing Hypotheses $H_{0}: r=$ $0 ; H_{1}: r \neq 0,{ }^{\star} p \leq 0.05{ }^{*} p \leq 0.01{ }^{* *} p \leq 0.001$. Q 2 e How strong are your ties with the academic community of your university? Q 10 Have you studied abroad? Q 11 Have you worked abroad? Q 12 Would you like to study abroad? Q 13 Would you like to work abroad? Source: authors' own research. 
The students' assessment of the quality of education weakly correlates with the level of the declared feeling of belonging to the academic community at their university. It is not related to students' earlier work or studies abroad or their intention to do this (Table 24).

\subsubsection{The approaches and methods used by teachers in the course of examination and evaluation of students}

Universities possess internal norms in the form of Study and Examination Regulations approved by the academic senate and suggested by the university authorities. They come into force after registration by the Ministry of Education, Youth and Sports and become effective upon their publication in the official notice board, usually on the public website of the university. The Regulations state the rules of studying in accredited programmes, including the rules for obtaining credits, and organisation of partial or final exams in all three levels of study. Without being explicitly stated, it is assumed that examination and other approaches in evaluation would respect the principles of academic evaluation culture, objectivity, fairness, openness, ethics or uniformity. Examination and evaluation are difficult tasks of the academic staff and they will require even more effort with the currently promoted tendency to the wider use of formative assessment.

Students in the Czech Republic and Poland mostly evaluated the quality of approaches and methods used by teachers during the examination and evaluation of students as high or very high. Almost $20 \%$ (precisely 19.6) more of Czech $(61.4 \%)$ than Polish students $(41.5 \%)$ evaluated the level of teachers' methods positively. More than one third of Polish students (37.5\%) surprisingly chose "cannot judge" similarly to the previously analysed items. However, $13.8 \%$ of Czech and up to $20.8 \%$ of Polish students consider the quality of approaches and methods used by teachers during examination and evaluation as "little" or "very little". If one adds the evasive (37.7\%) and negative (20.8\%) evaluation of Polish students, the result is that $58.5 \%$ of the respondents express certain reservations towards the approaches and methods used by teachers in examination and evaluation. The percentage of the answers in the case of Czech students is $38.6 \%$, which also signals the need to deal with the approaches and methods in students' semester evaluations. The students' opinion regading examinations and evaluation is normally not surveyed in evaluative questionnaires (Figure 52).

The assumptions pertaining to the influence of the country, gender and year of study on the students' opinions on the approaches and methods used by teachers during examination and evaluation were formulated in the following hypotheses: 


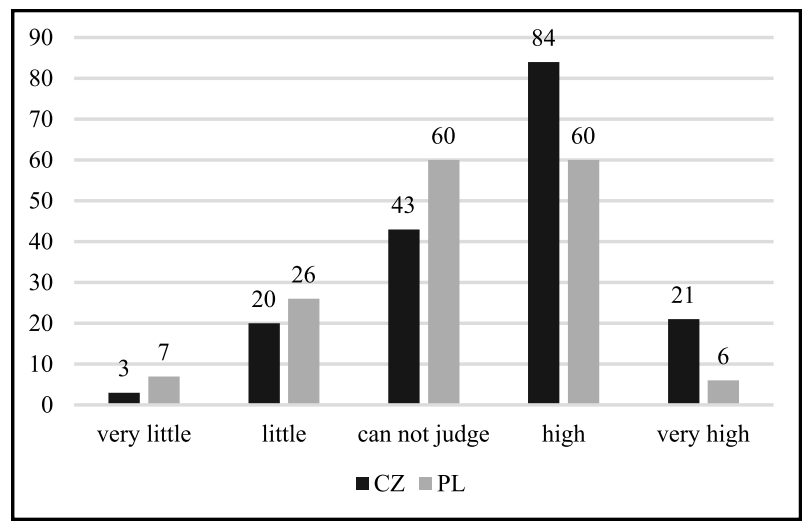

Figure 52. Frequency of answers to the question concerning the aproaches and methods used by teachers in the course of examination and evaluation of students. Source: authors' own research.

Table 25. Evaluation of the approaches and methods used by teachers in the course of examination and evaluation of students - frequency analysis and testing dependences between question $17 \mathrm{r}$ and the considered categories

\begin{tabular}{|c|c|c|c|c|c|c|c|c|c|}
\hline Answer & $\mathrm{CZ}$ & PL & Male & Female & $\begin{array}{l}1^{\text {st }} \text { Year } \\
\text { of Study }\end{array}$ & $\begin{array}{l}2^{\text {nd }} \text { Year } \\
\text { of Study }\end{array}$ & $\begin{array}{l}3^{\text {rd }} \text { Year } \\
\text { of Study }\end{array}$ & \multicolumn{2}{|c|}{ Total } \\
\hline 1 & 3 & 7 & 0 & 10 & 5 & 4 & 1 & 10 & \\
\hline 2 & 20 & 26 & 9 & 37 & 21 & 16 & 9 & 46 & \\
\hline 3 & 43 & 60 & 9 & 94 & 55 & 37 & 11 & 103 & 330 \\
\hline 4 & 84 & 60 & 29 & 115 & 84 & 48 & 12 & 144 & \\
\hline 5 & 21 & 6 & 4 & 23 & 13 & 9 & 5 & 27 & \\
\hline avg & 3.5904 & 3.2073 & 3.5490 & 3.3728 & 3.4463 & 3.3750 & 3.2895 & 3.4000 & \\
\hline$p$ & \multicolumn{2}{|c|}{$0.000^{* * *}$} & \multicolumn{2}{|c|}{0.472} & \multicolumn{2}{|c|}{0.664} & & & \\
\hline
\end{tabular}

$p=$ significance value; ${ }^{\star} p \leq 0.05{ }^{* *} p \leq 0.01{ }^{* * *} p \leq 0.001$. Question $17 \mathrm{r}$ : Evaluate the approaches and methods used by teachers during the examination and evaluation. Answer: 1 = very little or low, 2 = little or low, 3 = cannot judge, $4=$ high, $5=$ very high. Source: authors' own research.

25H: Students from different countries assess the approaches and methods used by teachers during examination and evaluation differently.

$26 \mathrm{H}$ : Students of different genders assess the approaches and methods used by teachers during examination and evaluation differently.

$27 \mathrm{H}$ : Students of different years of study assess the approaches and methods used by teachers during examination and evaluation differently.

The average assessment of the approaches and methods used by teachers during examination and evaluation is 3.59 for Czech students and 3.20 for Polish students. The result is statistically significant and allows one to confirm the hypothesis $25 \mathrm{H}$. Students in the evaluated countries differ in the assessment of approaches and methods used by teachers during examination and evaluation. 
The average assessment of the approaches and methods used by teachers during examination and evaluation was 3.54 for men and 3.37 for women. Men thus assess these approaches and methods more positively than women. The difference in the results is not statistically significant and therefore does not allow one to confirm the hypothesis $26 \mathrm{H}$. The evaluation of the approaches and methods used by teachers during examination and evaluation is not influenced by gender.

The average assessment of the approaches and methods used by teachers during examination and evaluation in particular years of study was 3.44, 3.37 and 3.26, and proves a downward tendency. More experienced students are thus more critical than the students of the first year. The results are not statistically significant - the hypothesis $27 \mathrm{H}$ "Students of different years of study assess the approaches and methods used by teachers during examination and evaluation differently" was not confirmed (Table 25).

The relationship between the evaluation of the approaches and methods used by teachers during examination and evaluation and students' answers to the question concerning a sense of belonging to the academic community (item 2e), studies (questions 10) and working abroad (question 11) or an intention to study (question 12) or work abroad (questions 13) was analysed as well.

Table 26. Relations between the evaluation of the approaches and methods used by teachers in examination and evaluation of students and selected variables - correlation analysis of the relation between questions $2 \mathrm{e}, 10-13$ and question $17 \mathrm{r}$ for all respondents

\begin{tabular}{ccccccccccc}
\hline CZ+PL & $\mathrm{Q} 2 \mathrm{e} \mid r$ & $\mathrm{Q} 2 \mathrm{e} \mid p$ & $\mathrm{Q} 10 \mid r$ & $\mathrm{Q} 10 \mid p$ & $\mathrm{Q} 11 \mid r$ & $\mathrm{Q} 11 \mid p$ & $\mathrm{Q} 12 \mid r$ & $\mathrm{Q} 12 \mid p$ & $\mathrm{Q} 13 \mid r$ & $\mathrm{Q} 13 \mid$ \\
\hline $\mathrm{Q} 17-\mathrm{r}$ & $\mathbf{0 . 2 1 9}$ & $\mathbf{0 . 0 0 0 * * *}$ & -0.050 & 0.366 & -0.045 & 0.410 & -0.025 & 0.653 & 0.003 & 0.961 \\
\hline
\end{tabular}

$r ; r \in\langle-1 ; 1\rangle$ correlation coefficient. $p$ - significance value for testing hypotheses $H_{0}: r=0$; $H_{1}: r \neq 0,{ }^{*} p \leq 0.05^{* *} p \leq 0.01{ }^{* *} p \leq 0.001$. Q2e How strong are your ties with the academic community of your university? Q 10 Have you studied abroad? Q 11 Have you worked abroad? Q 12 Would you like to study abroad? Q 13 Would you like to work abroad? Source: authors' own research.

The data in Table 26 confirm that the assessment of the approaches and methods used by teachers in examination and evaluation weakly correlates with the level of the declared feeling of belonging to the academic community. It is not related to students' earlier work or studies abroad or their intention to undertake this aspect of their university studies. 


\subsubsection{The overall influence of the university on students' comprehensive development}

The comprehensive development of an individual is an established term for the formation of a holistic personality in the sense of classical educational (intellectual, moral, work, physical and aesthetic) elements or target (cognitive, psychomotor and affective, more recently also interpersonal and meta-cognitive) domains. Another way of understanding the significance of this construct is its concept as a unity of the professional and socio-personal development or as the integration of the individual's development and the development of key competencies, or more recently - of transversal skills or competencies. The respondents, mostly students of teaching professions, were undoubtedly able to consider all of the above, or at least the first two concepts while declaring the intensity of the university's impact on their comprehensive development.

The prevailing opinion in both countries is that the overall influence of the university on the comprehensive development of students is on a high or very high level. $15.3 \%$ more of Czechs (70.0 \%) than Polish students (44.7\%) positively appraised the overall influence of the university on students' comprehensive development. Almost one third of Polish students (28.3\%) surprisingly selected "cannot judge", similarly to the previously analysed items, while only $18.2 \%$ of Czech students chose the same option. $11.2 \%$ of Czech and $25.1 \%$ of Polish students consider the level of the overall influence of the university on their comprehensive development as "little" or "very little" (Figure 53).

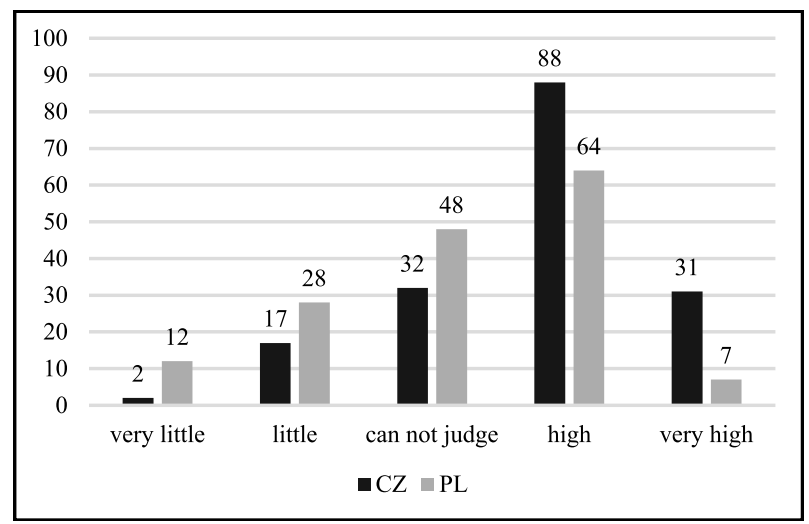

Figure 53. Frequency of answers to the question concerning the overall influence of the university on students' comprehensive development. Source: authors' own research. 
The assumptions pertaining to the influence of the study, gender and year of study on the overall influence of the university on students' comprehensive development were formulated in the following hypotheses:

$28 \mathrm{H}$ : Students from different countries assess the overall influence of the university on students' comprehensive development differently.

$29 \mathrm{H}$ : Students of different genders assess the overall influence of the university on students' comprehensive development differently.

$30 \mathrm{H}$ : Students of different years of study assess the overall influence of the university on students' comprehensive development differently.

Table 27. Evaluation of the overall influence of the university on students' comprehensive development - frequency analysis and testing dependences between question $17 \mathrm{~s}$ and the considered categories

\begin{tabular}{|c|c|c|c|c|c|c|c|c|c|}
\hline Answer & $\mathrm{CZ}$ & PL & Male & Female & $\begin{array}{l}1^{\text {st }} \text { Year } \\
\text { of Study }\end{array}$ & $\begin{array}{l}2^{\text {nd }} \text { Year } \\
\text { of Study }\end{array}$ & $\begin{array}{l}3^{\text {rd }} \text { Year } \\
\text { of Study }\end{array}$ & \multicolumn{2}{|c|}{ Total } \\
\hline 1 & 2 & 12 & 2 & 12 & 9 & 5 & 0 & 14 & \\
\hline 2 & 17 & 28 & 5 & 40 & 19 & 17 & 9 & 45 & \\
\hline 3 & 32 & 48 & 8 & 72 & 44 & 26 & 10 & 80 & 330 \\
\hline 4 & 88 & 64 & 27 & 126 & 83 & 55 & 15 & 153 & \\
\hline 5 & 31 & 7 & 9 & 29 & 23 & 11 & 4 & 38 & \\
\hline avg & 3.7590 & 3.1829 & 3.7059 & 3.4301 & 3.5198 & 3.4464 & 3.3684 & 3.4727 & \\
\hline$p$ & \multicolumn{2}{|c|}{$0.000^{\star * *}$} & \multicolumn{2}{|c|}{0.975} & & 0.573 & & & \\
\hline
\end{tabular}

$p=$ significance value; ${ }^{*} p \leq 0.05{ }^{* *} p \leq 0.01{ }^{* * *} p \leq 0.001$. Q 17 s: Evaluate the overall influence of the university on your comprehensive development. Answer: $1=$ very little or low, 2 = little or low, 3 = cannot judge, $4=$ high, $5=$ very high. Source: authors' own research.

The average evaluation of the overall influence of the university on the comprehensive development of the students is 3.75 for Czech students and 3.180 for Polish students. The result is statistically significant and allows one to confirm the hypothesis $28 \mathrm{H}$. Students in the evaluated countries differ in the assessment of the overall influence of the university on their comprehensive development.

The average evaluation of the overall influence of the university on students' comprehensive development was 3.70 for men and 3.43 for women. Men assess this overall influence as slightly better than women. The difference in the results is not statistically significant and thus does not confirm the hypothesis $29 \mathrm{H}$ that: "Students of different genders assess the overall influence of the university on students' comprehensive development differently."

The average evaluation of the overall influence of the university on students' comprehensive development in particular years of study was 3.51, 3.44 and 3.366, which proves a downward tendency. More experienced students are more critical than first year students. The results are not statistically significant. The hypothesis $30 \mathrm{H}$ : "Students of different years of study assess the overall influence of 
the university on students' comprehensive development differently" was not confirmed (Table 27).

The relationship between the evaluation of the overall influence of the university on students' comprehensive development and students' answers to the question concerning a sense of belonging to the academic community (item 2e), studies (questions 10) and working abroad (question 11) or an intention to study (question 12) or work abroad (questions 13) was analysed as well.

Table 28. Relations between the overall influence of the university on students' comprehensive development and selected variables - correlation analysis of the relation between questions $2 \mathrm{e}, 10-13$ and question 17 s for all respondents $(\mathrm{CZ}+\mathrm{PL})$

\begin{tabular}{ccccccccccc}
\hline $\mathrm{CZ}+\mathrm{PL}$ & $\mathrm{Q} 2 \mathrm{e} \mid r$ & $\mathrm{Q} 2 \mathrm{e} \mid p$ & $\mathrm{Q} 10 \mid r$ & $\mathrm{Q} 10 \mid p$ & $\mathrm{Q} 11 \mid r$ & $\mathrm{Q} 11 \mid p$ & $\mathrm{Q} 12 \mid r$ & $\mathrm{Q} 12 \mid p$ & $\mathrm{Q} 13 \mid r$ & $\mathrm{Q} 13 \mid p$ \\
\hline $\mathrm{Q} 17-\mathrm{s}$ & $\mathbf{0 . 2 3 1}$ & $\mathbf{0 . 0 0 0 ^ { * * * }}$ & -0.093 & 0.090 & -0.045 & 0.413 & -0.086 & 0.117 & 0.033 & 0.555 \\
\hline$r, r \in(-1 ; 1)$ & 0 & & & &
\end{tabular}

$r ; r \in\langle-1 ; 1\rangle$ correlation coefficient. $p$ - significance value for testing hypotheses $H_{0}: r=0$; $H_{1}: r \neq 0,{ }^{*} p \leq 0.05^{* *} p \leq 0.01{ }^{* * *} p \leq 0.001$. Q2e How strong are your ties with the academic community of your university? Q 10 Have you studied abroad? Q 11 Have you worked abroad? Q 12 Would you like to study abroad? Q 13 Would you like to work abroad? Source: authors' own research.

The data in Table 28 confirm that the assessment of the overall influence of the university on students' comprehensive development weakly correlates with the level of the declared feeling of belonging to the academic community. It is not related to students' earlier work or studies abroad or their intention to do this.

\section{Summary}

The overall average evaluation of the study environment created by the university was 3.53 for both universities. The overall average evaluation of the quality of education was 3.53 for both universities. The overall average evaluation of the approaches and methods used by teachers during examination and evaluation was 3.40 for both universities.

The overall average evaluation of the overall influence of the university on students' comprehensive development was 3.47 for both universities. Although there are no big differences among the four values, it can be perceived that the study environment created by the university and quality of education are assessed slightly better than the overall influence of the university on students' comprehensive development and the approaches and methods used by teachers in examination and evaluation. Some significant differences in all four indicators - the assessment of the studying conditions, the evaluation of the quality of education and of the approaches in evaluation, the influence of the university on students' comprehensive development - were revealed in the assessments of 
Czech and Polish students, as Polish students were more critical in all four indicators than their Czech peers.

No statistically significant difference was discovered in the evaluation of all aspects by men and women or by students in different years of study.

A higher percentage of Polish than Czech students chose the "cannot judge" answer with the difference ranging from $3.3 \%$ to $8.3 \%$.

Students as a whole evaluate (in descending order by the correlation coefficient $r$ value) more positively the studying environment $(r=0.288)$, the overall influence of the university on students' comprehensive development $(r=0.231)$, the approaches and methods used by teachers in examination and evaluation $(r=0.2019)$ and the quality of education $(r=0.209)$. The assessment shows an interrelation between the strength of the bonds with the academic community of the university. In the case of Czech students, none of the correlation coefficients reached statistical significance $(r=0.172 ; 0.091 ; 0.072$ and 0.066$)$ but in the case of Polish students they reached a moderate level of significance $(r=0,455 ; 0,437$; 0,427 and 0,401).

Previous studies and work abroad or an intention to study or work abroad after finishing the studies were not in correlation with students' opinions in any of the four observed indicators - the study environment, quality of education, approaches in examination and evaluation and overall influence on the student's development. No differences were discovered between the Czech and Polish students.

\section{Conclusions}

In nine of the ten analysed items focused on the assessment of particular parameters of university studies, statistically significant differences between Czech and Polish students were discovered. The differences are not only significant in the evaluation of the status of a person with higher education. The average assessment was lower for the Polish research sample than for the Czech one. The higher criticism of Polish students towards university studies may be explained by their answers' to the questions regarding their satisfaction with their studies and the financial status analysed in the previous parts of the book.

No statistically significant differences were identified in the opinions of men and women. Students of the second and third years of study are more critical in the evaluation of practical skills acquisition and the interrelation of theory and practice in teaching than the students of the first year. The results are statistically significant. The finding is also confirmed by the fact that the average evaluation of the acquisition of practical skills was the lowest out of all ten averages (2.9969) and the average evaluation of the interrelation of theory and practice in teaching 
was the second lowest. The empirical results are thus compliant with the opinions of future teachers in our research sample calling for more emphasis on practical professional preparation. The third lowest average evaluation (3.400) was reached in the assessment of the approaches and methods used by teachers in the course of examination and evaluation of students. The students also frequently selected the "cannot judge" answer in this item. The problem is usually ignored by the evaluative tools for the students' subject evaluation and is not an object of an independently performed assessment. Students' opinions on the evaluation are not commonly known, even though the evaluative processes in all their forms (examiner- evaluation, peer-evaluation, self-evaluation) are or should be an essential part of the study culture at universities.

The average evaluation of the relationship between the academic staff and students reached the maximum value (3.6969). The level of theoretical knowledge acquired at university (3.5969), the study environment created by the university (3.5727) and the quality of education (3.5333) reached the other top positions in the average value. Teaching conditions and the teaching itself are evaluated quite favourably by the students of borderlands of Poland and the Czech Republic. The surprisingly high percentage of students choosing rather an evasive answer (up to $37 \%$ of respondents and always more Polish than Czech) was noted as well. This fact raises the need for the formation of diagnostic and evaluation competences of the university student, especially in the case of those preparing for the teaching profession. 


\section{Chapter 4. University students studying and working abroad, their field of study and the university}

The university is a place where people of different ages, nationalities, backgrounds, experiences, opinions, expectations and ambitions meet, learn and create new values. The basis of every university is its academic community, which consists of its students and academics. Universities are open and dynamic institutions reflecting and actively driving the wider social development in the Czech Republic and abroad. Czech higher education has been governed by the Strategy for Education Policy in the Czech Republic (until 2020), which was adopted in 2014 as an overarching strategic document determining the basis for long-term plans at all levels of the educational system, including higher education, as well as other conceptual materials. Strategy 2020 sets out three fundamental goals: (1) reducing inequalities in education, (2) supporting high-quality teaching and teachers as a prerequisite for such teaching and (3) managing the system in a responsible and efficient manner (Dlouhodobý záměr vzdělávací a vědecké, výzkumné, vývojové a inovační, umělecké a další tvưrčí činnosti pro oblast vysokých škol na období 2016-2020, 2015).

Two strongly interrelated phenomena have occurred in the Czech Republic, as well as in many other European countries, in the last 20 years. The first was the democratization in education, and second, the mass character of higher education. These phenomena resulted in an increase in the number of universities, especially private and regional ones, and an increase in the number of students in lecture halls, as can be seen in Figure 54.

In the Czech Statistical Office press release, Báčová (2016) states that there were 1.3 million people with university education in the Czech Republic in 2016, which is $134 \%$ more than in 1996 . In contrast, the number of people with only a primary school education significantly decreased from 900,000 to 408,000 in the last 20 years. The number of people with secondary school education without the maturity exam (the secondary school exit exam in the Czech Republic) fell by 125,000 to 2.2 million. The number of people with secondary education with the maturity exam rose by 505,000 to 2.1 million. The total percentage of people with a university education has reached $22 \%$ in the Czech Republic, but it is still less 


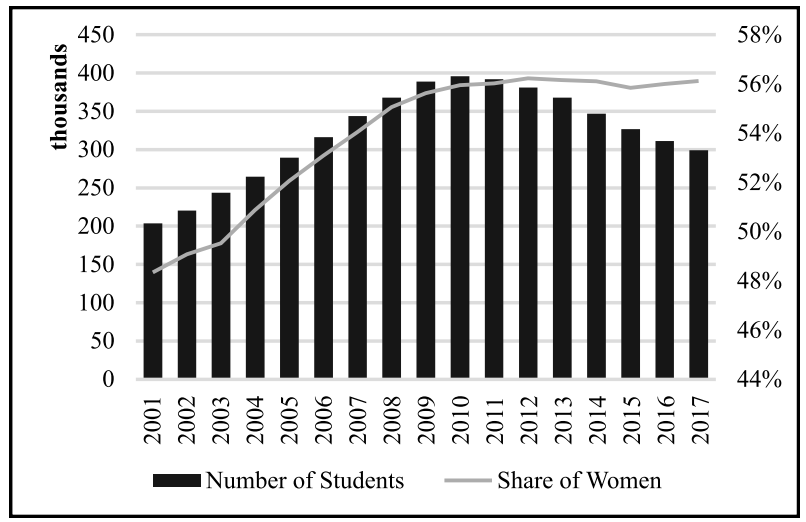

Figure 54. The development in the number of university students in the Czech Republic. Source: https://dsia.msmt.cz/vystupy/vu_vs_f 1 .html.

than in the majority of EU member countries. Since 2002, an increase in the number of women with university education has been observed in the Czech Republic and this trend is still continuing.

In contemporary Czech society, education has become an important element of the way of life, a life goal, a way of spending free time and a major value. Czechs also view education as a mechanism of social promotion. When children gain significantly higher education than their parents, they could move into the upper classes of society. This many-years-long experience of the intergenerational lift has been one of the reasons why education has such prestige in the Czech society. Education, especially a higher one, has a status providing character and is connected with a certain social prestige and position in the society. However, the relationship between the educational level and social prestige is relative. The lower the number of graduates in the population, the higher the social prestige they can enjoy. For example, the social and professional prestige of people with secondary technical education in the 1930s is incomparable with their prestige now. The value of education ranked $16^{\text {th }}$ on a scale of 23 values for the total of the population. There are groups of people who value education the most and groups which recognize the minimal importance of education. The importance of education in life and lifestyles rises with the education gained by the individual. People with an apprenticeship certificate or with secondary education without the maturity exam have the lowest potential to pursue further education. The most educated people - people with a university degree, attribute the highest importance to education. $91 \%$ of people from this group view education as a permanent and important part of their life and lifestyle (Sak \& Mareš, 2007).

The value and importance of education as a permanent and significant part of one's life and way of life strongly correlates not only with the level of education 
reached by an individual but also by their parents. The repeated studies among university students between 2003 and 2005 showed that the higher the parents' education, the higher the quality of the family and students' lifestyle. The most interesting aspect in the research is that this proportion was not so significant in relation to the income (Prudký, Pabian \& Šima, 2010).

Why do Czechs undertake education? The research brought surprising results in the sense that pragmatic reasons for education are less frequent or less important. As regards the motivation to education, "I want to be educated" ${ }^{44}$ ranked as the first and "education helps me preserve and develop intellectual qualities" as the second. The motivation to gain education for women is based more on non-pragmatic reasons. The most important reason for education of young people aged $15-18$ is the item "I want to be educated" to understand the world, society, myself and others; to be less easily manipulated; to have social prestige; to have better chance in the labour market; to be professionally better equipped (Sak \& Mareš, 2007). The level of education is viewed as one of the factors which influence people's position in the labour market (Breen, 2004) and a lot of sociological research shows that education is one of the most important ones. The main reason why population should be educated is the fact that education has an impact on the whole of society as well as on individual people. As regards the society, there are social benefits, which consist of less crime, a healthier population, higher gross domestic product or higher social cohesion. As far as individual reasons are concerned, an individual can expect certain benefits connected with higher social status thanks to a more prestigious job, the job market, higher income or lower risk of unemployment (Doseděl \& Katrňák, 2017). Both authors carried out an interesting study in which they examined whether the increasing number of people with university education in the Czech Republic devaluated education and whether the theory of educational inflation applied to the Czech labour market. They found out that the value of a university education did not decrease, rather the contrary. This was proved in the financial sphere (university graduates receive higher salaries), as well as in the non-financial sphere (university graduates are less threatened by unemployment).

According to Keller and Tvrdý (2008), people study mainly because they view education as an advantageous investment, and as regards employability, they see how they can make good use of this long-term investment financially. Nonetheless, as they state further, motivation to study can take many forms and the financial benefit does not have to be at the top of the ranking. Regardless of their education, people attribute the highest importance to their own interest in the

44 An individual wants to be viewed as educated because of their surroundings, they do not want to be viewed as an uneducated person or fool since intelligence and education are often confused. 
field. One out of ten studied without having an interest in the studied field. The factor of employability in the labour market together with the influence of family tradition ranked the second.

Even though young people are educated, they do not have enough experience, qualification or sufficient language knowledge. Therefore, they can be vulnerable in the labour market. The group most threatened with unemployment are lowqualified workers, young people without education, with an incomplete education or with only primary school education (Veteška, 2010).

\subsection{University students studying and working abroad}

Taking into account paid work during the classes-free period also shows that, on the EUROSTUDENT ${ }^{45}$ average, around $70 \%$ of students pursue paid work while enrolled in higher education. Around $20 \%$ of students take up paid jobs only in the classes-free period. Working only during the learning period is relatively uncommon; students with paid jobs during the academic year tend to be employed in the vacation period as well: on average $4 \%$ of students work only during the (entire) academic year, and $3 \%$ only work from time to time during this period. Around one third of students, on average, are engaged in paid work during the vacation period as well as during the entire academic year, and $13 \%$ of students have occasional paid jobs both in the academic year and in the vacation period. Across countries, large differences can be found. The highest shares of students who work only in the academic year can be found in Slovakia, Finland, Sweden, Croatia, and France. In these countries, around one quarter of students engage in paid work only in the vacation period. More than $80 \%$ of students pursue paid work while enrolled in higher education in Estonia, the Czech Republic, Iceland, Norway, and Slovakia. In Estonia, the Czech Republic, Iceland, and Latvia, $40 \%$ to $50 \%$ of students are employed both during the entire academic year and during the vacation period. The highest shares of students (60\% to $70 \%$ ) who never take up paid jobs, neither during the academic year nor in the vacation period, are found in Georgia, Albania, and Serbia. Students indicate working for both financial as well as non-financial reasons. On the EUROSTUDENT average, around $60 \%$ of students state that they pursue paid jobs during the academic year in order to gain experience in the labour market. This reason is particularly relevant for students in Croatia, the Czech Republic, Estonia, Finland, France, and Georgia. Indeed, the research has indicated that

45 This Synopsis of Indicators presents the findings of the $6^{\text {th }}$ round of the EUROSTUDENT project, to which 28 countries of the European Higher Education Area (EHEA) contributed between 2016 and 2018. 
working simultaneously with studies might be beneficial to students' future placement in the labour market and their employability, as it provides students with the opportunity to recognise workplace-relevant skills. About half of the students with paid jobs during the academic year across EUROSTUDENT countries shows that self-earned income is a necessity for being able to study. Particularly, large shares of students state this in Albania, Germany, Finland, Hungary, Ireland, Iceland, Malta, Norway, Poland, and Portugal. The self-earned income in Hungary, Malta, and Poland, as well as in Austria, Estonia, Latvia, Romania, and Switzerland, constitutes almost half (or more) of the working students' available total income. Across all EUROSTUDENT countries, students from less privileged backgrounds more frequently (in comparison to their peers from more well-off families) state that they could not afford to study without paid jobs during the academic year (Hauschildt, Vögtle \& Gwosć, 2018).

With the accession of the Czech Republic into the European Union, the opportunities of Czech students to work abroad rose significantly. The EU member countries usually allow foreign students to work but often only part-time or for a limited number of working hours per period of time ("Vláda České republiky", 2019).

Czech citizens can largely benefit from the services of EURES ${ }^{46}$, whose main aim is to facilitate the international mobility of the workforce. The EURES public employment services are offered by all 28 EU member countries, EEA countries (Iceland, Lichtenstein and Norway) and also Switzerland - through bilateral agreements. The main purpose of the EURES network is to provide services useful to all workers, applicants and job seekers, but also to the employers who want to use the right to free movement. EURES services are offered through two basic channels: firstly, there are databases available at the European Job Mobility Portal; secondly, there are information and advisory services offered by EURES advisors and contact officers who work at regional offices and contact points at Labour Offices of the Czech Republic ("EURES v zemích Evropské unie", 2019).

According to the CV analysis on the Profesia.cz job portal, only $8 \%$ of Czechs are interested in working abroad. According to a survey from 2013, Slovaks are more mobile. $43 \%$ of them were interested in working abroad. The greater flexibility of Slovaks is not only caused by a worse situation in their own labour market, but also by the fact that especially young Slovaks do not differentiate between working in Slovakia and going abroad. In addition, two thirds of Czechs registered at the profesia.cz job portal are not willing to commute within the Czech Republic or move for work in another country. When they do express a willingness to work outside of the Czech Republic, Czechs are most interested in working in Germany and Austria. One of frequent serious obstacles is an in-

46 European Employment Services. 
sufficient knowledge of the English and German languages ("Ministerstvo práce a sociálních věcí”, 2013).

According to a survey by Work Service from 2017, $14 \%$ of Poles intend to work abroad, which amounts to 2.8 million people. One out of four Poles only intends to work abroad short-term and one out of five Poles to move abroad with a family permanently. The main motivators to work abroad are significantly higher salaries, lack of employment opportunities at home and career prospects (Ratajczak, 2017).

It is necessary for young people who move abroad to study or work to have their education recognised. As regards higher education, there is the ECTS ${ }^{47}$, however, each higher education institution decides how many ECTS credits they give for each of their programmes. If there was no ECTS evaluation in the study programme which an applicant completed in the past, they can ask for an evaluation and recognition of the qualification. This will help both the applicant and the host university to document how their former studies relate to the university study curriculum. Depending on the practices in the given country, the evaluation of their former studies will lie within the responsibility of the educational institution, the relevant education ministry or the national academic recognition or information centre ("Evropský portál pro mládež", 2013).

As part of the internationalisation, students and academic staff from the University of Ostrava can visit partner universities in Europe and study or do a traineeship through the Erasmus+ international programme. The University of Ostrava also offers its own mobility programme called VIA, which enables students to study or do a traineeship in various countries throughout the world, with cooperation having been established with universities in the USA, South Korea, China, Mexico, Thailand, Japan, Australia, Argentina and many other countries ("Ostravská univerzita", 2018).

The data from 2011 show that only $5.5 \%$ of graduates from all public universities have at least one-month experience abroad. However, the intention of the $\mathrm{EU}$ is to have $20 \%$ of university graduates with experience collected abroad by 2020. This is also connected with opportunities to study in different foreign languages and the development of suitable services for foreign as well as Czech students and teachers ("Ministerstvo průmyslu a obchodu", 2011).

As regards entering the labour market, work or study experience from abroad is very important for students. They gain new experience as well as strengthen their work and study rhythm while fulfilling new duties in a completely new cultural and social environment. Thus, they can develop their professional competencies (Chmura, 2016).

47 European Credit Transfer and Accumulation System. 
Table 29 presents an overview of the outgoing and incoming students of the University of Ostrava within the Erasmus+ programme. At first glance, it is apparent that students from the University of Ostrava use this opportunity to a very small extent. In the last three years, there were only 65 outgoing students compared to 247 incoming ones. Students of the University of Ostrava most often go to Spain or the United Kingdom. The majority of foreign incoming students at the University of Ostrava come from Spain and then, from Poland. Only seven students from the University of Ostrava did a graduate traineeship within the Erasmus+ programme.

Table 29. Outgoing students within the Erasmus+ programme at the University of Ostrava and incoming students from partner universities at the University of Ostrava

\begin{tabular}{lcccccc}
\hline & \multicolumn{3}{c}{ Erasmus } & outgoing students & \multicolumn{3}{c}{ Incoming foreign students } \\
\hline Year & 2016 & 2017 & 2018 & 2016 & 2017 & 2018 \\
Studies & 26 & 26 & 13 & 98 & 84 & 65 \\
Graduate traineeships & 3 & 2 & 2 & & & \\
\hline
\end{tabular}

Source: https://pdf.osu.cz/dokumenty.

\subsection{University students studying and working abroad - descriptive and hypotheses testing results}

The aim of this international research was to find answers to the following questions:

1. What are the differences in the proportions of students studying abroad and students considering studying abroad between Polish and Czech students? Are these differences influenced by students' characteristics (age, year of studies and gender)? Does experience from studying abroad influence students' evaluation of selected parameters of their current university studies?

2. What are the differences between Polish and Czech students in the proportions of students with work experience from abroad or students considering working abroad after their studies? Are these differences influenced by students' characteristics (age, year of studies and gender)? Does experience from working abroad influence students' evaluation of selected parameters of their current university studies?

3. Does the students' sense of regional belonging influence the real possibility or potentiality to work or study abroad? Are these differences influenced by students' characteristics (age, year of studies and gender)?

The topic of students studying and working abroad was examined with the use of four questions in the questionnaire. The first two questions focused on experi- 
ence, in other words, on whether students have already studied or worked abroad. The two other questions examined the degree of students' willingness to study or work abroad.

Tables 30-33 show the results in descriptive statistics in the form of arithmetic means which express the attitudes of Czech and Polish students to the particular question. The degree of their attitude was expressed using the interval scale with the following values: 1 (Yes), 2 (No). At the same time, the tables present the testing of hypotheses which were formulated in this quantitative research. The hypotheses focused on testing the existence, or respectively, the non-existence, of statistically significant differences. In the hypotheses, the classification based on the country of studies, gender and year of studies was taken into consideration. Each hypothesis was linked to a particular question from the questionnaire. The significance level was declared as $5 \%$, or rather 0.05 . For each defined hypothesis, the testing of data normality was carried out using Shapiro-Wilk and AndersonDarling tests at the significance level of 0.05 . As regards the achieved results of the normality testing, the Kruskal-Wallis test had to be used for testing the formulated hypotheses. The tables comprise the descriptive frequency analysis, with regard to the required coefficient significance value $p$ in software IBM SPSS version 25. For $p>0.05$, the dependences between variables do not exist. For $\mathrm{p}<0.05$ ( $\mathrm{p}^{*}$ weak significance, $\mathrm{p}^{* * *}$ important significance), the confirmed dependences are marked in bold in the table.

\subsubsection{University students studying abroad}

The following hypotheses were provided for Question 10 "Have you studied abroad?":

$1 H_{\mathrm{A}}$ : There is a statistically significant dependence between students' experience with studying abroad and the country of studies.

$2 H_{\mathrm{A}}$ : There is a statistically significant dependence between students' experience with studying abroad and their gender.

$3 H_{\mathrm{A}}$ : There is a statistically significant dependence between students' experience with studying abroad and their year of studies.

Table 30 shows that 40 students ( $12 \%$ ) from the research sample have experience with studying abroad. The number of Czech students who had studied abroad was 27 and the number of Polish students was 13. It is also worth noting that students from the first and second years of studies study abroad most often, while there is a significant decline in interest in their third year.

If all three levels of significance value in the observed hypotheses are examined, it can be stated that in all cases, the alternative hypotheses $1-3 H_{\mathrm{A}}$ are rejected at the level of $5 \%$ in favour of the zero hypotheses $1-3 H_{0}$. Therefore, 
Table 30. Studies abroad - frequency analysis and testing of dependences between question 10 and the considered categories

\begin{tabular}{cccccccccc}
\hline Answer & CZ & PL & Male & Female & $\begin{array}{c}1^{\text {st }} \text { Year } \\
\text { of Studies }\end{array}$ & $\begin{array}{c}2^{\text {nd }} \text { Year } \\
\text { of Studies }\end{array}$ & $\begin{array}{c}3^{\text {rd }} \text { Year } \\
\text { of Studies }\end{array}$ & Total \\
\hline Yes & 27 & 13 & 6 & 34 & 19 & 18 & 3 & 40 & 330 \\
No & 144 & 146 & 45 & 245 & 159 & 96 & 35 & 290 \\
avg & 1.8614 & 1.8963 & 1.8824 & 1.8781 & 1.8927 & 1.8393 & 1.9211 & & \\
$p$ & 0.332 & \multicolumn{2}{c}{0.932} & & 0.557 & & & \\
\hline
\end{tabular}

$1=$ Yes; $2=$ No. $p=$ significance value; ${ }^{\star} p \leq 0.05{ }^{* *} p \leq 0.01{ }^{* * *} p \leq 0.001$. Source: authors' own research.

there is no statistically significant dependence between students' experience with studying abroad and their country of study, gender or year of study.

\subsubsection{University students working abroad}

The following hypotheses were provided for Question 11 "Have you worked abroad?":

$4 H_{\mathrm{A}}$ : There is a statistically significant dependence between students' experience with working abroad and the country of study.

$5 H_{\mathrm{A}}$ : There is a statistically significant dependence between students' experience with working abroad and their gender.

$6 H_{\mathrm{A}}$ : There is a statistically significant dependence between students' experience with working abroad and their year of study.

Table 31. Work abroad - frequency analysis and testing of dependences between question 11 and the considered categories

\begin{tabular}{|c|c|c|c|c|c|c|c|c|}
\hline Answer & $\mathrm{CZ}$ & PL & Male & Female & $\begin{array}{c}1^{\text {st }} \text { Year } \\
\text { of Studies }\end{array}$ & $\begin{array}{l}2^{\text {nd }} \text { Year } \\
\text { of Studies }\end{array}$ & $\begin{array}{c}3^{\text {rd }} \text { Year } \\
\text { of Studies }\end{array}$ & Total \\
\hline Yes & 28 & 22 & 10 & 40 & 32 & 12 & 6 & 50 \\
\hline No & 142 & 137 & 41 & 239 & 146 & 102 & 32 & 280 \\
\hline avg & 1.8494 & 1.8476 & 1.8039 & 1.8566 & 1.8192 & 1.8929 & 1.8421 & \\
\hline$p$ & 0.9 & & & 335 & & 0.488 & & \\
\hline
\end{tabular}

$1=$ Yes; $2=$ No. $p=$ significance value; ${ }^{\star} p \leq 0.05^{* *} p \leq 0.01{ }^{* *} p \leq 0.001$. Source: authors' own research.

The situation of students working abroad and students studying abroad is very similar. A total of 50 students ( $15 \%$ ) worked abroad, 28 of them were Czechs and 22 - Poles. The majority of students with experience of working abroad are firstyear students, then the interest declines significantly as is the case with studying abroad (Table 31). 
If all three levels of significance value in the observed hypotheses are examined, it can be stated that in all cases, the alternative hypotheses $4-6 \mathrm{H}_{\mathrm{A}}$ are rejected at the level of $5 \%$ in favour of the zero hypotheses $4-6 H_{0}$. Therefore, there is no statistically significant dependence between students' experience with working abroad and the country where they study, their gender or year of study.

\subsubsection{Students' willingness to study abroad}

The following hypotheses were provided for Question 12 "Would you like to study abroad?":

$7 H_{\mathrm{A}}$ : There is a statistically significant dependence between students' willingness to study abroad and the country of study.

$8 H_{\mathrm{A}}$ : There is a statistically significant dependence between students' willingness to study abroad and their gender.

$9 H_{\mathrm{A}}$ : There is a statistically significant dependence between students' willingness to study abroad and their year of study.

Table 32. Willingness to study abroad - frequency analysis and testing of dependences between question 12 and the considered categories

\begin{tabular}{|c|c|c|c|c|c|c|c|c|}
\hline Answer & $\mathrm{CZ}$ & PL & Male & Female & $\begin{array}{c}1^{\text {st }} \text { Year } \\
\text { of Studies }\end{array}$ & $\begin{array}{c}2^{\text {nd }} \text { Year } \\
\text { of Studies }\end{array}$ & $\begin{array}{c}3^{\text {rd }} \text { Year } \\
\text { of Studies }\end{array}$ & Total \\
\hline Yes & 75 & 36 & 22 & 89 & 67 & 33 & 11 & 111 \\
\hline No & 96 & 123 & 29 & 190 & 111 & 81 & 27 & $219^{330}$ \\
\hline avg & 1.5723 & 1.7561 & 1.5686 & 1.6810 & 1.6215 & 1.7054 & 1.7105 & \\
\hline$p$ & 0.00 & $0^{* * *}$ & & 119 & & 0.384 & & \\
\hline
\end{tabular}

$1=$ Yes; $2=$ No. $p=$ significance value; ${ }^{\star} p \leq 0.05{ }^{\star \star} p \leq 0.01{ }^{\star *} p \leq 0.001$. Source: authors' own research.

Table 32 shows students' willingness to study abroad. In total, 111 students (33.6\%) from the research sample would like to study abroad, of whom $50 \%$ more Czechs are interested in studying abroad than Poles. First-year students $(60 \%)$ are most interested in studying abroad, a significant decline in interest can be observed in the second (29.7\%) and the third year of study (9.9\%).

If all the three levels of significance value in the observed hypotheses are examined, it can be stated that $7 \mathrm{H}_{0}$ is rejected at the level of $0.1 \%$ in favour of $7 \mathrm{H}_{\mathrm{A}}$. Therefore, there is a statistically significant dependence between students' willingness to study abroad and the country in which they study. The other alternative hypotheses $8-9 H_{\mathrm{A}}$ are rejected at the level of $5 \%$ in favour of zero hypotheses $8-9 H_{0}$. Therefore, there is no statistically significant dependence between students' willingness to study abroad and their gender or year of study. 


\subsubsection{Students' willingness to work abroad}

The following hypotheses were provided for Question 13 "Would you like to work abroad?":

$10 H_{\mathrm{A}}$ : There is a statistically significant dependence between students' willingness to work abroad and the country of study.

$11 H_{\mathrm{A}}$ : There is a statistically significant dependence between students' willingness to work abroad and their gender.

$12 \mathrm{H}_{\mathrm{A}}$ : There is a statistically significant dependence between students' willingness to work abroad and their year of study.

Table 33. Willingness to work abroad - frequency analysis and testing of dependences between question 13 and the considered categories

\begin{tabular}{ccccccccc}
\hline Answer & CZ & PL & Male & Female & $\begin{array}{c}1^{\text {st }} \text { Year } \\
\text { of Studies }\end{array}$ & $\begin{array}{c}2^{\text {nd }} \text { of Studies } \\
\text { of }\end{array}$ & $\begin{array}{c}3^{\text {rd }} \text { Year } \\
\text { of Studies }\end{array}$ & Total \\
\hline Yes & 74 & 47 & 20 & 101 & 71 & 38 & 12 & 121 \\
No & 96 & 112 & 31 & 178 & 106 & 74 & 26 & 209 \\
avg & 1.5663 & 1.7012 & 1.6078 & 1.6380 & 1.5989 & 1.6607 & 1.6842 & \\
$P$ & $0.011^{*}$ & 0.682 & & 0.491 & & \\
\hline
\end{tabular}

$1=$ Yes; $2=$ No. $p=$ significance value; ${ }^{\star} p \leq 0.05^{* \star} p \leq 0.01{ }^{\star *} p \leq 0.001$. Source: authors' own research.

Table 33 shows students' willingness to work abroad. 121 students (33.6\%) from the research sample would like to study abroad, and more Czechs (74) than Poles (47) in this case as well. Similarly, first-year students are most interested in studying abroad, then the interest declines linearly.

If all three levels of significance value in the observed hypotheses are examined, it can be stated that $10 \mathrm{H}_{0}$ is rejected at the level of $5 \%$ in favour of $10 \mathrm{H}_{\mathrm{A}}$. Therefore, there is a statistically significant dependence between students' willingness to work abroad and the country in which they study. The other alternative hypotheses $11-12 \mathrm{H}_{\mathrm{A}}$ are rejected at the level of $5 \%$ in favour of the zero hypotheses $11-12 H_{0}$. Therefore, there is no statistically significant dependence between students' willingness to work abroad and their gender or year of study.

\subsection{The feeling of citizenship - correlation analysis}

The research also examined how the descriptive results collected among Czech and Polish students correlate with the first item in the questionnaire. Item 1 focuses on the feeling of citizenship: "Indicate how much you feel" a) a citizen of your town; b) a citizen of your region; c) a citizen of the Czech Republic (a citizen of Poland in the Polish version); d) a citizen of the European Union; e) a citizen of 
the world. In each answer, respondents chose from a scale of five numbers $(1=$ NO; 2 rather NO; $3=$ I cannot say; $4=$ rather YES; $5=$ YES).

In the following tables, the correlation analysis is comprised in regard to the required coefficient $r$ and the significance value $p$. Having conducted the analysis with the use of software IBM SPSS version 25, it can be stated that the acquired results are advantageous in favour of the conclusions based on the existence of statistically significant dependences between the two considered variables (questions in the questionnaire). $r$ close to 0 and $p>0.05$ do not signify dependences between variables. In the opposite case, $r$ differs from 0 and $p<0.05$; therefore, dependences between answers are confirmed (marked in bold in the table).

Table 34. Feeling of citizenship - correlation analysis of the relation between question 1 and Questions 10-13 for all respondents (CZ+PL)

\begin{tabular}{ccccccccc}
\hline CZ+PL & Q10 $\mid r$ & $\mathrm{Q} 10 \mid p$ & $\mathrm{Q} 11 \mid r$ & $\mathrm{Q} 11 \mid p$ & $\mathrm{Q} 12 \mid r$ & $\mathrm{Q} 12 \mid p$ & $\mathrm{Q} 13 \mid r$ & $\mathrm{Q} 13 \mid p$ \\
\hline Q1-a & 0.053 & 0.333 & 0.052 & 0.349 & 0.063 & 0.254 & $\mathbf{0 . 1 1 8}$ & $\mathbf{0 . 0 3 2}^{*}$ \\
$\mathrm{Q} 1-\mathrm{b}$ & 0.022 & 0.692 & -0.053 & 0.338 & 0.029 & 0.594 & 0.020 & 0.721 \\
$\mathrm{Q} 1-\mathrm{c}$ & $\mathbf{0 . 1 4 2}$ & $\mathbf{0 . 0 1 0 ^ { * * }}$ & 0.062 & 0.263 & 0.099 & 0.071 & 0.100 & 0.069 \\
$\mathrm{Q} 1-\mathrm{d}$ & -0.087 & 0.114 & $\mathbf{- 0 . 2 0 8}$ & $\mathbf{0 . 0 0 0 ^ { * * * }}$ & 0.057 & 0.298 & 0.072 & 0.191 \\
$\mathrm{Q} 1-\mathrm{e}$ & -0.079 & 0.155 & $\mathbf{- 0 . 2 2 2}$ & $\mathbf{0 . 0 0 0 ^ { * * * }}$ & -0.060 & 0.279 & -0.074 & 0.178 \\
\hline
\end{tabular}

$\mathrm{Q} 1=1^{\text {st }}$ question; $\mathrm{Q} 10=$ Have you studied abroad?; $\mathrm{Q} 11=$ Have you worked abroad?; $\mathrm{Q} 12=$ Would you like to study abroad?; Q13 = Would you like to work abroad? $r ; r \in\langle-1 ; 1\rangle$ correlation coefficient. $p$ - significance value for the testing of hypotheses $H_{0}: r=0 ; H_{1}: r \neq 0$, ${ }^{*} p \leq 0.05^{* *} p \leq 0.01{ }^{* * *} p \leq 0.001$. Source: authors' own research.

On the basis of the results provided in Table 34 which concern all the respondents, it can be observed that there was a mild correlation between Items Q1a and Q13, which expressed whether the citizen of their town is willing to work abroad. A second mild correlation was found between Items Q1-c and Q10, which expressed how the strength of students' feeling of citizenship related to their experience with studying abroad. A weak negative correlation was found in Item Q1-d concerning the feeling of citizenship of the European Union and the experience with working abroad and Item Q1-e, expressing the feeling of world citizenship and experience with working abroad. 
Table 35. Feeling of citizenship - correlation analysis of the relation between question 1 and questions 10-13 for Czech respondents (CZ)

\begin{tabular}{|c|c|c|c|c|c|c|c|c|}
\hline $\mathrm{CZ}$ & \begin{tabular}{l|r}
$\mathrm{Q} 10$ & $r$
\end{tabular} & $\mathrm{Q} 10 \mid p$ & Q11 $\mid r$ & $\mathrm{Q} 11 \mid p$ & \begin{tabular}{l|r} 
Q12 & $r$
\end{tabular} & $\mathrm{Q} 12 \mid p$ & \begin{tabular}{l|r} 
Q13 & $r$
\end{tabular} & Q13 $\mid p$ \\
\hline Q1-a & -0.021 & 0.793 & 0.011 & 0.886 & 0.030 & 0.701 & 0.098 & 0.208 \\
\hline Q1-b & -0.016 & 0.839 & -0.086 & 0.272 & -0.002 & 0.977 & -0.014 & 0.858 \\
\hline Q1-c & -0.013 & 0.867 & -0.092 & 0.237 & 0.101 & 0.193 & 0.022 & 0.774 \\
\hline Q1-d & -0.111 & 0.154 & -0.180 & $0.020^{*}$ & 0.132 & 0.090 & 0.042 & 0.594 \\
\hline Q1-e & -0.032 & 0.678 & -0.089 & 0.253 & -0.012 & 0.875 & -0.053 & 0.500 \\
\hline
\end{tabular}

$\mathrm{Q} 1=1^{\text {st }}$ question; $\mathrm{Q} 10=$ Have you studied abroad?; $\mathrm{Q} 11$ = Have you worked abroad?; $\mathrm{Q} 12=$ Would you like to study abroad?; Q13 = Would you like to work abroad? $r ; r \in\langle-1 ; 1\rangle$ correlation coefficient. $p$ - significance value for the testing of hypotheses $H_{0}: r=0 ; H_{1}: r \neq 0$, ${ }^{\star} p \leq 0.05^{* *} p \leq 0.01{ }^{* * *} p \leq 0.001$. Source: authors' own research.

Table 35 shows the data collected among the respondents from the Czech Republic. What can be observed is a negative correlation in Item Q1-d concerning the feeling of citizenship ofthe European Union and the experience with working abroad.

Table 36. Feeling of citizenship - correlation analysis of the relation between question 1 and questions 10-13 for Polish respondents (PL)

\begin{tabular}{|c|c|c|c|c|c|c|c|c|}
\hline PL & $\mathrm{Q} 10 \mid r$ & $\mathrm{Q} 10 \mid p$ & Q11 $r$ & $\mathrm{Q} 11 \mid p$ & Q12 $\mid r$ & Q12 $\mid p$ & Q13 $\mid r$ & $\mathrm{Q} 13 \mid p$ \\
\hline Q1-a & 0.140 & 0.075 & 0.096 & 0.219 & 0.084 & 0.283 & 0.129 & 0.099 \\
\hline Q1-b & 0.057 & 0.470 & -0.025 & 0.748 & 0.055 & 0.487 & 0.046 & 0.558 \\
\hline Q1-c & 0.298 & $0.000^{* * *}$ & 0.189 & $0.016^{*}$ & 0.127 & 0.104 & 0.189 & $0.015^{\star}$ \\
\hline Q1-d & -0.087 & 0.266 & -0.246 & $0.002^{\star *}$ & -0.123 & 0.118 & 0.048 & 0.539 \\
\hline Q1-e & -0.127 & 0.106 & -0.359 & $0.000^{* * *}$ & -0.095 & 0.226 & -0.084 & 0.285 \\
\hline
\end{tabular}

$\mathrm{Q} 1=1^{\text {st }}$ question; $\mathrm{Q} 10=$ Have you studied abroad; $\mathrm{Q} 11=$ Have you worked abroad?; $\mathrm{Q} 12=$ Would you like to study abroad?; Q13 = Would you like to work abroad? $r ; r \in\langle-1 ; 1\rangle$ correlation coefficient. $p$ - significance value for the testing of hypotheses $H_{0}: r=0 ; H_{1}: r \neq 0$, ${ }^{*} p \leq 0.0{ }^{* *} p \leq 0.01{ }^{* * *} p \leq 0.001$. Source: authors' own research.

Table 36 presents the results collected among Polish students. A small correlation can be observed in Q1-c, concerning the experience with studying abroad, working abroad and the willingness to work abroad. A weak negative correlation was found in Item Q1-d, expressing the feeling of citizenship of the European Union and the experience with working abroad, and Item Q1-e, expressing the feeling of world citizenship and the experience with working abroad.

\section{Summary}

Only 40 students (12\%) out of 330 have studied abroad. $50 \%$ more Czech students (27) have studied abroad than Polish (13). The first and second-year students study abroad most often. Third year students study abroad very rarely. A statistically significant dependence between students' experience with study- 
ing abroad and the country of study, their gender or year of study was not found in any case.

50 students $(15 \%)$ have experience with working abroad. 28 Czechs $(8.4 \%)$ and 22 Poles $(6.6 \%)$ worked abroad. Students who have the largest experience with working abroad are in their first year of studies (32 students - $9.6 \%$ ). There are 12 second-year students (3.6\%). The smallest number can be found in the third year -6 students $(1.8 \%)$. No statistically significant dependence between students' experience with working abroad and the country of study, their gender or the year of study was found in any case.

111 students (33.6 \%) would like to study abroad. $50 \%$ more of Czechs (75$22.7 \%$ ) are more interested in this than Poles (36-11\%). Students most interested in studying abroad are in their first year $(60 \%)$ and second year $(29.7 \%)$. Again, a significant decline can be observed in the third year ( $9.9 \%)$. A statistically significant dependence has been observed only in regard to the country of study. It has not been found in connection with their gender or year of study.

A total of 121 students (36.6\%) would like to work abroad, and again, there are more Czechs $74(22.4 \%)$ than Poles $47(14.2 \%)$. Also, in this case, first-year students are most interested in working abroad - $71(21.5 \%)$ and then the interest decreases linearly, as we can observe in the second year - $38(11.5 \%)$ and the third year - 12 (3.6\%). A statistically significant dependence has only been found between students' willingness to work abroad and the country of study. It has not been observed in connection with their gender or the year of study.

There was a slight correlation between Items Q1-a and Q13, which express whether feeling like a citizen of the student's town is an impediment to being willing to work abroad. A second slight correlation was found between Items Q1-c and Q10, which expressed how the strength of students' feeling of Czech/Polish citizenship related to their experience with studying abroad. A weak negative correlation was found in Item Q1-d, concerning the feeling of citizenship of the European Union and experience with working abroad, and Item Q1-e, concerning the feeling of world citizenship and experience with working abroad.

A weak correlation was observed in Q1-c in connection with the experience of studying abroad, working abroad and a willingness to work abroad. A weak negative correlation was found in Item Q1-d, pertaining to the feeling of citizenship of the European Union and the experience with working abroad, and Item Q1-e, concerning the feeling of world citizenship and experience with working abroad. 


\subsection{Teachers' professional qualities and prospects}

To work as a teacher, it is necessary to have professional teacher qualities, which include not only expert skills and knowledge concerning the subject but also pedagogical and psychological knowledge. People interested in teaching acquire this through higher education - as regards the Czech Republic, it is the Master's degree. The necessity to get a university degree to be qualified as a teacher is stated in the National Programme for the Development of Education in the Czech Republic (2001) and imposed by the Act on educational staff. Future teachers study at faculties of education, or at other faculties which have accredited programmes for the education of teachers. Graduates of other university programmes can also gain qualification to teach vocational subjects at secondary schools in the course of life-long learning (so-called supplementary pedagogical studies) (Vašutová, 2004).

The graduates of educational faculties who work as teachers should have professional competences to perform their profession effectively. Teacher competences vary and are characterised differently by different authors. In compliance with the professional public (Průcha \& Mareš, 2013), (Vašutová, 2007), we can generally define the following teacher competences: Subject competence within their specialisation, teachers can transform the knowledge of given subjects into the educational content of lessons. They can integrate interdisciplinary knowledge and create interdisciplinary relationships. Didactic/psychodidactic competence - they know how to use teaching and learning strategies; they can use a methodology and adapt it to learners' individual needs. Pedagogical competence - they know educational procedures and conditions, they can support the development of learners' individual qualities, they know children's rights and respect them in their work. Management competence - teachers know the conditions and procedures of how a school works, they can perform administrative tasks related to learners' documentation, they have organisational skills for extracurricular activities. Diagnostic and evaluating competence - they can use tools for pedagogical diagnostics, they can identify students with learning disabilities. Social competence - they can use tools to create a positive learning environment. Pro-social competence - they can use tools for learners' socialisation. Communicative competence - they can use the means of pedagogical communication; they can communicate and cooperate with parents and other social partners. Intervention competence - they can use intervention means to ensure discipline; they can recognise sociopathological phenomena in learners. Personal competence - mental and physical fitness and resilience, a good health condition, moral integrity. Personality-cultivating competence - teachers have broad general knowledge, they can represent their profession, they have personal 
qualities for the cooperation with colleagues, they can reflect learners' educational needs and interests.

The above-mentioned teacher professional competences are an inseparable part of the so-called "Quality Standard of the Teaching Profession", and its existence can be viewed as an important prerequisite for the professionalization of the profession and its application will have a positive impact on the quality of education in Czech schools. It was supposed to determine the teacher's career path, remuneration and changes in the preparation for this profession. Unfortunately, contrary to other countries, this standard has still not been applied in the Czech Republic and the Act on pedagogical staff is used only for the codification of the teaching profession.

Another problem in the Czech educational system is the lack of qualified teachers and this situation complicates matters especially for school head teachers who have to justify exceptions in their teaching staff. The Ministry of Education decided to solve the current situation (from January 2019 on) by reducing the requirements for teachers within the amendment to the Act on pedagogical staff. The amendment modifies the requirement for professional qualification before starting the teaching profession. This modification should enable head teachers to hire teachers to teach general subjects at lower- and upper-secondary schools. Those teachers will be obligated to have a university education, but not necessarily pedagogical education, on condition that they complete pedagogical education in an accredited university study programme or in a programme for life-long learning provided by a university. In this way, the Ministry of Education tries to at least partially deal with the problem with the lack of fully qualified teachers. This proposal has drawn the attention of the professional as well as general public. Sárközi (2019) states that such a practice is unacceptable and would undermine the teaching profession in general. In practice, when didactic requirements for teaching students at primary schools constantly increase, it means that teachers will teach without approbation for up to three years and they will have to finish a 250-hour course of supplementary pedagogical education. Paradoxically, the fact that non-teachers start teaching cannot solve the problem with a lack of teachers. It only mitigates the upward pressure on teachers' salaries for a short time. Hřebecký (2019) also agrees with the above-mentioned opinion and adds that not until salaries improve significantly will the hiring of new teachers be only an improvisation without a future. He also adds that the adequate remuneration for teachers is an expression of their pedagogical work. Furthermore, he states that only the best people and not people with the best degree should teach and he appeals to the great powers of head teachers who can choose and lead their staff.

One of the criteria for the attractiveness of this field of study is public opinion on the prestige of the teaching profession and its social status. The Public 
Opinion Research Centre, which is a research department at the Institute of Sociology of the Czech Academy of Sciences, published a report on the prestige of professions in June 2019. According to the survey, working as a teacher at primary school is one of the most respectable and prestigious professions. Since 2004, it had been ranking the fourth, and from 2011 until June 2019, it ranked the fifth out of 26 professions. The scale of professional prestige is different for each generation. The youngest generation (aged up to 24 years) attributes less prestige to the teaching profession than the generation 65+ ("Prestiž povolání 2019", 2019).

Hlaváček (2015) has an interesting viewpoint regarding the survey results. He asks whether the society really appreciates teachers and whether this profession is, in fact, so highly prestigious. The author states that teachers' work is very meaningful and one would like to appreciate it, however, teachers are very badly remunerated, and therefore, becoming a teacher is rather considered as a sign of a lack of success and, when having great ambitions, even as a personal failure. The author explains the ambivalent attitude of the Czech society to the teaching profession in this manner: "The survey, therefore, distorts the facts - it presents the highly prestigious profession of a politician, which we also morally doubt, as little socially esteemed, which is not true. Although we do not trust politicians, we view their profession as prestigious. Similarly, it is not true that we esteem the teaching profession. We do not esteem it and we also have an ambivalent attitude towards it - we support teachers but, at the same time, we have strong doubts about them in the pragmatic sense concerning money." In Germany, teachers are relatively highly respected and, contrary to Czech teachers, are also well paid. However, according to Hlaváček, this is mainly because Germans do not pay as much attention to money and success as Czechs do. According to the author, improving teachers' salaries is a way to dissolve the ambivalent attitude of Czechs to teachers.

Both beginning teachers and experienced ones have many opportunities to improve their qualifications within professional education carried out in private educational companies through educational programmes accredited by the Ministry of Education, Youth and Sports of the Czech Republic ${ }^{48}$ or in Regional Institutions for the Further Education of Pedagogical Staff, or directly at faculties of education. In 2018, the University of Ostrava carried out 132 courses within lifelong learning. Out of these, 89 courses focused on the profession. In total, these courses of lifelong learning were attended by 3232 students. In addition, the

48 The Ministry of Education, Youth and Sports is the central body of the state administration responsible for pre-schools, primary schools, secondary schools and universities, for the scientific policy, research and development, including international cooperation in this area, and for academic degrees, for the state care of children, youth, sports, tourism and sports representation of the state. 
University of Ostrava offered its students educational modules focusing on broadening special knowledge and skills ("VÝROČNÍ ZPRÁVA O ČINNOSTI 2018”, 2018).

The development of professional competence is very important for teachers. If it is supposed that new teachers want to be a part of the profession for their entire professional life, they can expect to work for 40 or even 50 years. During that time, conditions for teaching will change several times and teachers will have to adapt to a new educational reality. This is because new technologies and technical equipment appear and are constantly developed and teaching methods are constantly being created and exsiting ones are perpetually being adjusted. Students also change because they belong to different generations and teachers have to learn to understand their mentality. The topic of generations has been dealt with in the so-called "theory of generation development", which works with generations " $X$ ", "Y", "Z" and "Alpha". In the first half of the $20^{\text {th }}$ century, shortly after the Velvet Revolution, young and enterprising people set up the first private companies in the Czech Republic. They are people born roughly between 1965 and 1982, who represent the so-called generation X, also called "Husák's" ${ }^{49}$ children" in the Czech Republic. The former Czechoslovakia was governed by the communist party and this generation was brought up in very specific and different conditions in comparison to the following generations. Generation $\mathrm{X}$ people usually had both parents working, in other words, women also played the role of a worker and provider. The divorce rate was rising and many children grew up in single-parent families. Divorce in the family is viewed as one of the reasons why they are so adaptable at work, being very innovative and independent. They are the first generation to grow up with computers and they are no strangers to new technologies. In the labour market, they prefer the mentoring of the more experienced to strict rules and orders. The following generation is generation $Y$, which consists of people born between 1983 and 1995. They are often called "millennials" because they lived at the turn of the century and they define the following one. They are sometimes nicknamed the "boomerang generation" because they often return to parents or friends, they seek deeper values in life and they want to live a more peaceful life than their predecessors. This results in a renewed interest in marriage, religion and older values, in which they search for opportunities to flourish in their private life. This generation was formed by new technologies, the invasion of new knowledge, globalisation and economic changes and these factors were much stronger than in previous generations. Frequent role models are their working parents who wanted to ensure a better future for their children and to provided them with various forms of education

49 The name derives from Gustáv Husák (1913-1991), the eighth president of Czechoslovakia, in office from $29^{\text {th }}$ May 1975 to $10^{\text {th }}$ December 1989. 
and activities. Consequently, people from generation $\mathrm{Y}$ are viewed as optimists with a vision of a better future. Their self-confidence is very high and they require appreciation. They want more free time than their older counterparts, they work overtime only very unwillingly and they spend their money on leisure activities. Money is a means - not a sense of work. They highly appreciate lifelong learning and the subsequent experience from the scope of activity of the company in which they work. Changes are common in their life. They want to communicate openly and to work in an environment based on modern technologies. Money is important for them, but they put more emphasis on the so-called "work-life balance", they value their free time and want to spend it in a meaningful way (Kmošek, 2018).

As regards the labour market, Hrdličková (2017) describes generation Y as a group of people who grew up in a consumerist society and lived in plenitude. From an early age and as young adults, they had things which their parents did not have at their age. They expect to have holidays, entertainment and a generally satisfying and happy life, which the previous generations had to give up even for several years or which they even did not think about. Millennials also view freedom with the same matter-of-factness. In the labour market in the last five to seven years, experienced people have been gasping in shock when they have heard the requirements stated by people from generation $\mathrm{Y}$ and they have struggled to accede to them. They have to accept this as a fact. However, it took a long time for many companies to understand what was happening. The basis for success of many American companies was the fact that they gave people maximum freedom and comfort and they expected maximum performance for it. Not all companies in the Czech Republic understand this approach. Generation Y is followed by generation $\mathrm{Z}$ - the people born between 1995 and 2010. Chum (2013) states that their formative years will take up to 30 years. They are obsessed with experience and tend to be impatient and self-centred. They have to try everything and get hands-on experience, but at the same time, they live separately in social media. On the one hand, they are intellectually more ahead and they reach maturity faster, but on the other hand, they do not understand such terms as tradition or status quo. Yet, they feel that they can create their own future. It is a generation which grows up in a direct contact with advanced digital technologies and they want to solve their problems "with one click". The author also describes the completely new generation "Alpha", people born after 2010, who are still a mystery. The professional public which studies cultural generations regards them as a major break in human history because they not only will live in a world intertwoven with digital technologies and on the edge of economical and humanitarian crisis but their parents, teachers, classmates and role models will live in that age too. A big change which is expected from generation Alpha is a new wave of globalism and gradual decline of nationalism. 
A global viewpoint on the issue of millennials can be obtained from the Deloitte report (Deloitte, 2019), which is based on the views of 13,416 millennials questioned across 42 countries and territories, and 3009 people from generation $\mathrm{Z}$ from 10 countries. This report states that millennials and generation $\mathrm{Z}$, the youngest generations, are no less ambitious than their predecessors; more than half want to earn high salaries and be wealthy. Yet, their priorities have shifted. Travel and seeing the world was at the top of millennials' list of aspirations (57\%), while slightly fewer than half said they wanted to own a home (49\%). They also were more attracted to making a positive impact on their communities or society in general (46\%) than to having children and starting families (39\%). Generally, millennials think their ambitions are achievable. However, for many, their dreams have been delayed by financial or other constraints. They have a love/hate relationship with technology. Younger generations are enthusiastic about technology and understand its benefits; $71 \%$ of millennials feel positive about their personal use of digital devices and social media, but more than half said, as a balance, that social media does more harm than good. Nearly two thirds (64\%) of millennials said they would be physically healthier if they reduced their time on social media, and 6 in 10 said it would make them happier people. Cybersecurity concerns also loom large. Only $14 \%$ of millennials strongly agree that the benefits of technology outweigh the risks associated with sharing personal data, $79 \%$ are worried they will be victims of online fraud, and a quarter of millennials have reduced consumer relationships because of companies' inability to protect data.

In regional education ${ }^{50}$, there were approximately 246,000 employees 173,000 teaching staff and 73,000 non-teaching staff. Out of the total number of teaching staff, there were 135,000 teachers and more than 5000 teachers of vocational training. The average gross salary of all employees was $26,600 \mathrm{CZK}$. The average gross salary of teachers was $31,600 \mathrm{CZK}$ (Výroční zpráva o stavu a rozvoji vzdělávánív České republice v roce 2017, 2018).

50 Regional education includes schools and educational institutions established by the Ministry of Education, Youth and Sports of the Czech Republic, municipalities, regions, including religious private schools - kindergartens, primary schools, secondary schools, conservatories, and undergraduate schools. 


\subsection{Students' professional qualities and prospects - descriptive and hypotheses testing results}

This part of the research was aimed to answer the question: How do university studies meet Czech and Polish students' expectations in terms of their prospects and opportunities for further professional development? Are these differences influenced by students' characteristics (age, year of studies and gender)?

The issue of teachers' professional qualities and prospects was investigated using five questions focusing on the suitability of acquired education for the profession, opportunities for teachers' development after their studies, assessing their own professional qualities and prospects for getting a job in accordance with the acquired education and the status of an individual with education in this field in their respective countries.

Tables 37-41 comprise the results of the descriptive statistics in the form of absolute numbers and arithmetic means which express the attitudes of Czech and Polish students to the given question. Students were supposed to assess their university studies using a five-point scale. The scale had the following points: $1=$ very little; 2 = little; 3 = cannot say; $4=$ high; $5=$ very high.

Using the methodological approaches from the previous chapter, similar principles and methods of quantitative research were applied. The same significance level of $5 \%$ was taken into consideration.

\subsubsection{The suitability of the acquired education for the profession}

The following hypotheses were provided for Item $17 \mathrm{e}$ "The suitability of the acquired education for the profession":

$13 \mathrm{H}_{\mathrm{A}}$ : There is a statistically significant dependence between the suitability of students' acquired knowledge for the profession and the country of their studies.

$14 H_{\mathrm{A}}$ : There is a statistically significant dependence between the suitability of students' acquired knowledge for the profession and their gender.

$15 H_{\mathrm{A}}$ : There is a statistically significant dependence between the suitability of students' acquired knowledge for the profession and their year of study. 
Table 37. The suitability of the acquired education - frequency analysis and testing of dependences between question $17 \mathrm{e}$ and the considered categories

\begin{tabular}{|c|c|c|c|c|c|c|c|c|}
\hline Answer & $\mathrm{CZ}$ & PL & Male & Female & $\begin{array}{c}1^{\text {st }} \text { Year } \\
\text { of Studies }\end{array}$ & $\begin{array}{l}2^{\text {nd }} \text { Year } \\
\text { of Studies }\end{array}$ & $\begin{array}{c}3^{\text {rd }} \text { Year } \\
\text { of Studies }\end{array}$ & Total \\
\hline 1 & 4 & 10 & 0 & 14 & 5 & 7 & 2 & 14 \\
\hline 2 & 11 & 32 & 3 & 40 & 16 & 20 & 7 & 43 \\
\hline 3 & 32 & 42 & 12 & 62 & 36 & 27 & 11 & 74 \\
\hline 4 & 81 & 63 & 24 & 120 & 89 & 43 & 12 & 144 \\
\hline 5 & 43 & 12 & 12 & 43 & 32 & 17 & 6 & 55 \\
\hline avg & 3.8735 & 3.2317 & 3.8824 & 3.4946 & 3.7119 & 3.3839 & 3.3421 & \\
\hline$p$ & \multicolumn{2}{|c|}{$0.000^{\star * *}$} & \multicolumn{2}{|c|}{0.802} & & 0.054 & & \\
\hline
\end{tabular}

$1=$ very little; $2=$ little; $3=$ cannot say; $4=$ high; 5 = very high. $p=$ significance value; ${ }^{\star} p \leq 0.05{ }^{* *} p \leq 0.01{ }^{* * *} p \leq 0.001$. Source: authors' own research.

It can be observed in Table 37 that 144 respondents (43.6\%) see a high suitability of the acquired education for their future or current profession and 55 students (16.6\%) view it as very high suitability. A relatively significant number of students $74(22.4 \%)$ cannot say - there are more Polish students in this group. In general, Czech students display higher average values in this item, it means that they view their studies more positively in relation to their profession, as can be seen in Figure 55. If the differences between genders are compared, as regards average values, men evaluate this item more positively than women by 0.4 points. First-year students see the suitability of their education more positively than second and third-year students.

If all the three levels of significance values in the hypotheses are observed, it can be stated that $13 H_{0}$ is rejected at the level of $0.1 \%$ in favour of $13 H_{\mathrm{A}}$. Therefore, there is a statistically significant dependence between the suitability of students' acquired education for the profession and the country of study. Other alternative hypotheses $14-15 H_{\mathrm{A}}$ are rejected at the level of $5 \%$ in favour of zero hypotheses $14-15 H_{0}$. Therefore, there is no statistically significant dependence between the suitability of students' acquired education for the profession and their gender or year of study.

\subsubsection{Opportunities for students' development after their studies}

The following hypotheses were formulated for Item $17 \mathrm{f}$ "Opportunities for students' development after their studies":

$16 H_{A}$ : There is a statistically significant dependence between opportunities for students' development after their studies and the country of their studies.

$17 H_{A}$ : There is a statistically significant dependence between opportunities for students' development after their studies and their gender. 


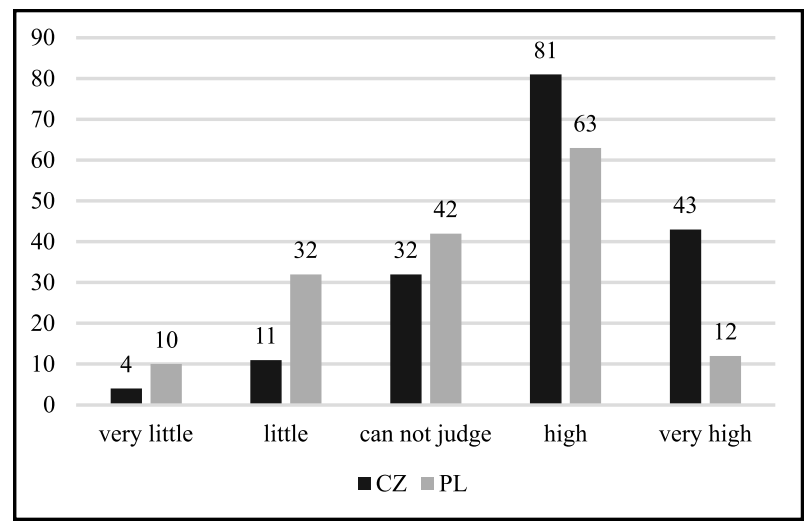

Figure 55. Absolute frequencies of item 17e. Source: authors' own research.

$18 H_{A}$ : There is a statistically significant dependence between opportunities for students' development after their studies and their year of studies.

Table 38. Opportunities development - frequency analysis and testing of dependences between question $17 \mathrm{f}$ and the considered categories

\begin{tabular}{|c|c|c|c|c|c|c|c|c|c|}
\hline Answer & $\mathrm{CZ}$ & PL & Male & Female & $\begin{array}{c}1^{\text {st }} \text { Year } \\
\text { of Studies }\end{array}$ & $\begin{array}{c}2^{\text {nd }} \text { Year } \\
\text { of Studies }\end{array}$ & $\begin{array}{c}3^{\text {rd }} \text { Year } \\
\text { of Studies }\end{array}$ & \multicolumn{2}{|c|}{ Total } \\
\hline 1 & 1 & 3 & 0 & 4 & 0 & 3 & 1 & 4 & \\
\hline 2 & 17 & 15 & 8 & 24 & 14 & 11 & 7 & 32 & \\
\hline 3 & 41 & 47 & 11 & 77 & 54 & 25 & 9 & 88 & 330 \\
\hline 4 & 75 & 83 & 22 & 136 & 84 & 61 & 13 & 158 & \\
\hline 5 & 37 & 11 & 10 & 38 & 26 & 14 & 8 & 48 & \\
\hline avg & 3.7651 & 3.5305 & 3.6667 & 3.6452 & 3.6836 & 3.6250 & 3.5263 & & \\
\hline$P$ & 0.0 & & & 863 & & 0.922 & & & \\
\hline
\end{tabular}

$1=$ very little; $2=$ little; $3=$ cannot say; $4=$ high; $5=$ very high. $p=$ significance value; ${ }^{*} p \leq 0.05{ }^{* *} p \leq 0.01{ }^{* * *} p \leq 0.001$. Source: authors' own research.

It can be observed in Table 38 that 158 students (47.8 \%) from both countries see their opportunities for the development after their studies as very high. In this case, the number of Poles is higher than the number of Czechs. The opportunities for their development after their studies are seen as very high by 48 students $(14.5 \%)$. The situation is reversed here since three times more Czechs than Poles see it this way. Only 4 students $(1.2 \%)$ think that the opportunities for their development are very little. If the average in individual categories is examined, it can be observed that Czech students see their opportunities for development after their studies as higher than Polish students. The average values in the other two categories are almost similar, in other words, men and women see their opportunities in the same way and so do students from different years of study. 
If all three levels of significance values in the hypotheses are examined, it can be stated that $16 \mathrm{H}_{0}$ is rejected at the level of $5 \%$ in favour of $16 \mathrm{H}_{\mathrm{A}}$. Therefore, there is a statistically significant dependence between opportunities for students' development after their studies and the country of study. Other alternative hypotheses $17-18 \mathrm{H}_{\mathrm{A}}$ are rejected at the level of $5 \%$ in favour of zero hypotheses $17-$ $18 \mathrm{H}_{0}$. Therefore, there is no statistically significant dependence between opportunities for students' development after their studies and their gender or year of study.

In Figure 56, the distribution of the answers of the respondents from both countries can be seen. A relatively large number of answers can be found in the middle of the scale - namely, students who cannot judge.

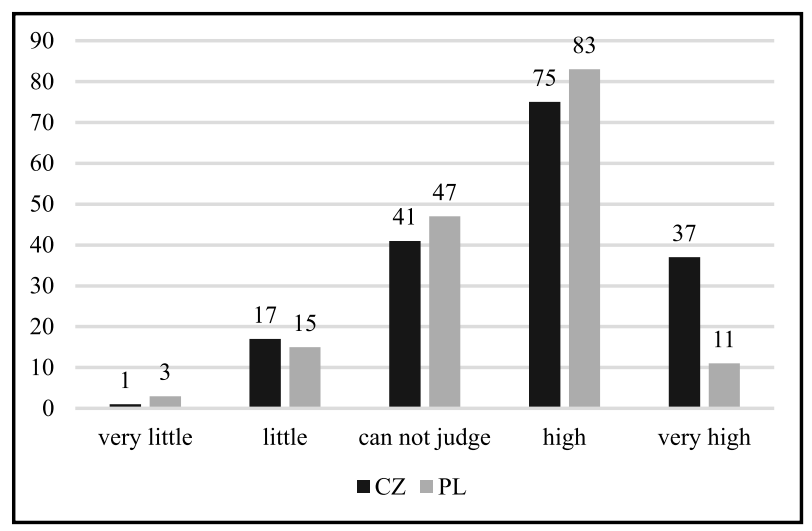

Figure 56. Absolute frequencies of item $17 \mathrm{f}$. Source: authors' own research.

\subsubsection{Assessment of the students' own professional qualities}

The following hypotheses were provided for Item $17 \mathrm{~g}$ "Assess your professional qualities":

$19 H_{A}$ : There is a statistically significant dependence between students' professional qualities and their country of study.

$20 H_{A}$ : There is a statistically significant dependence between students' professional qualities and their gender.

$21 H_{A}$ : There is a statistically significant dependence between students' professional qualities and their year of study. 
Table 39. Professional qualities - frequency analysis and testing of dependences between question $17 \mathrm{~g}$ and the considered categories

\begin{tabular}{ccccccccc}
\hline Answer & CZ & PL & Male & Female & $\begin{array}{c}1^{\text {st }} \text { Year } \\
\text { of Studies }\end{array}$ & $\begin{array}{c}2^{\text {nd }} \text { Year } \\
\text { of Studies }\end{array}$ & $\begin{array}{c}3^{\text {rd }} \text { Year } \\
\text { of Studies }\end{array}$ & Total \\
\hline 1 & 3 & 2 & 1 & 4 & 3 & 0 & 2 & 5 \\
2 & 12 & 15 & 5 & 22 & 12 & 7 & 8 & 27 \\
3 & 51 & 43 & 11 & 83 & 52 & 32 & 10 & 943 \\
4 & 84 & 80 & 28 & 136 & 92 & 60 & 12 & 164 \\
5 & 21 & 19 & 6 & 34 & 19 & 15 & 6 & 40 \\
avg & 3.6205 & 3.6341 & 3.6471 & 3.6237 & 3.6271 & 3.7321 & 3.3158 & \\
$p$ & 0.813 & 0.076 & & 0.313 & & \\
\hline
\end{tabular}

$1=$ very little; $2=$ little; $3=$ cannot say; $4=$ high; 5 = very high. $p=$ significance value; ${ }^{\star} p \leq 0.05{ }^{* *} p \leq 0.01{ }^{* * *} p \leq 0.001$. Source: authors' own research.

Table 39 shows that 164 respondents (49.6\%) see their professional qualities for the profession as very high. As seen in Figure 57, the number of Czechs is slightly higher than of Poles. The same is true for those who rated their professional qualities as very high - 40 students (12\%). In total, 94 students $(28.4 \%)$ cannot assess their professional qualities; in this case, there were more Czechs (51) than Poles (43). The averages are even across categories.

If all the three levels of significance values in the hypotheses are examined, it can be stated that all three alternative hypotheses $19-21 \mathrm{H}_{\mathrm{A}}$ are rejected at the level of $5 \%$ in favour of the zero hypotheses $19-21 \mathrm{H}_{0}$. Therefore, there is no statistically significant dependence between students' professional qualities and their country of study, their gender or year of study.

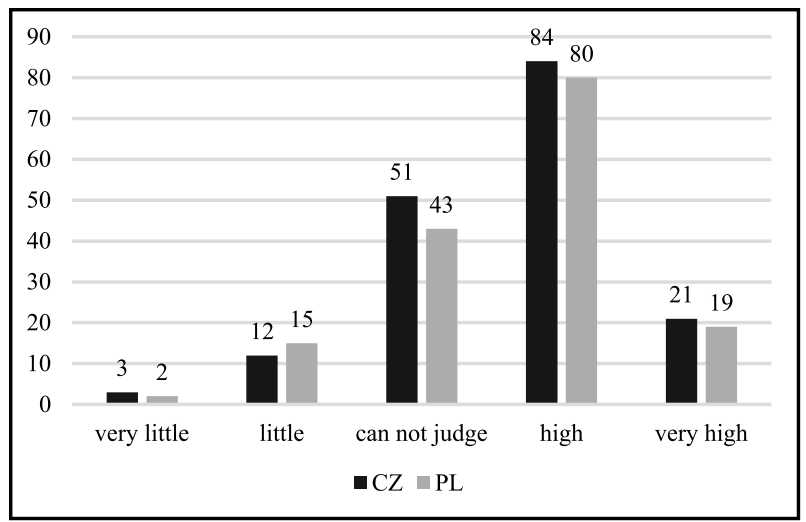

Figure 57. Absolute frequencies of item 17g. Source: authors' own research. 


\subsubsection{Prospects for getting a job in accordance with students' acquired education}

The following hypotheses were provided for Item $17 \mathrm{~h}$ "Prospects for getting a job in accordance with acquired education":

$22 \mathrm{H}_{A}$ : There is a statistically significant dependence between prospects for getting a job in accordance with students' acquired education and their country of study.

$23 \mathrm{H}_{A}$ : There is a statistically significant dependence between prospects for getting a job in accordance with students' acquired education and their gender.

$24 H_{A}$ : There is a statistically significant dependence between prospects for getting a job in accordance with students' acquired education and their year of study.

Table 40. Prospects for getting a job in accordance with acquired education - frequency analysis and testing of dependences between question $17 \mathrm{~h}$ and the considered categories

\begin{tabular}{|c|c|c|c|c|c|c|c|c|}
\hline Answer & $\mathrm{CZ}$ & PL & Male & Female & $\begin{array}{c}1^{\text {st }} \text { Year } \\
\text { of Studies }\end{array}$ & $\begin{array}{c}2^{\text {nd }} \text { Year } \\
\text { of Studies }\end{array}$ & $\begin{array}{c}3^{\text {rd }} \text { Year } \\
\text { of Studies }\end{array}$ & Total \\
\hline 1 & 4 & 9 & 0 & 13 & 4 & 5 & 4 & 13 \\
\hline 2 & 14 & 27 & 2 & 39 & 14 & 18 & 9 & 41 \\
\hline 3 & 42 & 52 & 15 & 79 & 51 & 36 & 7 & $94 \quad 330$ \\
\hline 4 & 78 & 55 & 26 & 107 & 82 & 40 & 11 & 133 \\
\hline 5 & 33 & 16 & 8 & 41 & 27 & 15 & 7 & 49 \\
\hline avg & 3.7108 & 3.2805 & 3.7843 & 3.4444 & 3.6384 & 3.3750 & 3.2105 & \\
\hline$p$ & \multicolumn{2}{|c|}{$0.000^{* * *}$} & \multicolumn{2}{|c|}{0.295} & & 0.106 & & \\
\hline
\end{tabular}

$1=$ very little; $2=$ little; $3=$ cannot say; $4=$ high; $5=$ very high. $p=$ significance value; ${ }^{*} p \leq 0.05{ }^{* *} p \leq 0.01{ }^{* * *} p \leq 0.001$. Source: authors' own research.

The data in Table 40 show that 133 students (40.3\%) see high prospects for getting a job in accordance with their acquired education. In this regard, Czech students significantly outnumber Polish students, since this answer was chosen by 78 Czech students and only 55 Polish students. These numbers are depicted in Figure 58. A relatively high percentage of students $(28.4 \%, 94$ respondents) could not say what their prospects for getting a job were. On the other hand, 49 students $(14.8 \%)$ see their prospects for getting a job as very high and again, Czech students are more positive than Polish students in this regard. This is also true when the average values are concerned. Men see their prospects more positively than women.

If all the three levels of significance values in the hypotheses are examined, it can be stated that $22 \mathrm{H}_{0}$ is rejected at the level of $0.1 \%$ in favour of $22 \mathrm{H}_{\mathrm{A}}$. Therefore, there is a statistically significant dependence between the prospects for getting a job in accordance with students' acquired education and the country of study. The other alternative hypotheses $23-24 \mathrm{H}_{\mathrm{A}}$ are rejected at the level of $5 \%$ 
in favour of zero hypotheses $23-24 \mathrm{H}_{0}$. Therefore, there is no statistically significant dependence between the prospects for getting a job in accordance with students' acquired education and their gender or year of study.

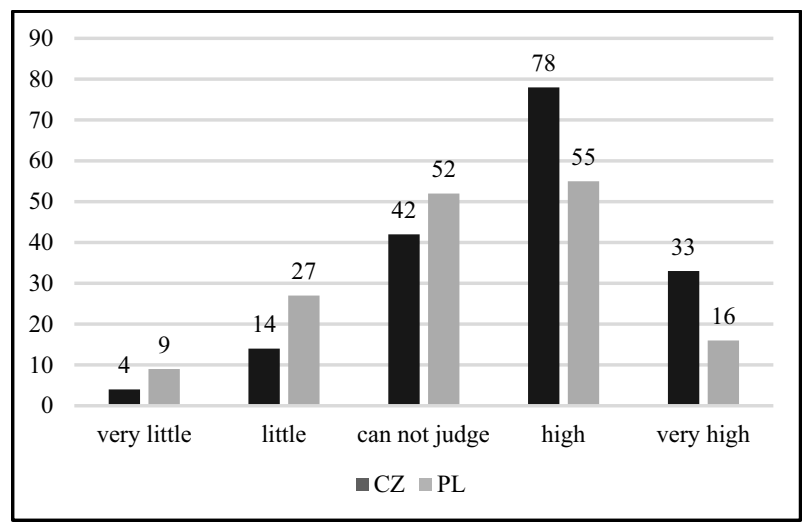

Figure 58. Absolute frequencies of item 17h. Source: authors' own research.

\subsubsection{The status of an individual with education in the studied field}

The following hypotheses were provided for Item $17 \mathrm{j}$ "The status of an individual with education in the studied field in their respective countries":

$25 \mathrm{H}_{A}$ : There is a statistically significant dependence between the status of an individual with education in the studied field and their country of study.

$26 \mathrm{H}_{A}$ : There is a statistically significant dependence between the status of an individual with education in the studied field and their gender.

$27 H_{A}$ : There is a statistically significant dependence between the status of an individual with education in the studied field and their year of study.

The data in Table 41 show that 114 students (34.5\%) cannot say what the status of an individual with education in the studied field is. Figure 59 provides an optical comparison of the individual answers. If individual countries are compared, the absolute value is almost the same, they differ by two students - 58 Czechs and 56 Poles. In total, 105 students (31.8\%) view the status of an individual with education in the studied field as high, 11 Czechs more than Poles. 32 students $(9.6 \%)$ see the status of an individual with education in this field as very high. The averages are even across categories.

If all the three levels of significance values in the hypotheses are examined, it can be stated that all three alternative hypotheses $25-27 \mathrm{H}_{\mathrm{A}}$ are rejected at the level of $5 \%$ in favour of zero hypotheses $25-27 \mathrm{H}_{0}$. Therefore, there is no statistically 
Table 41. The status of an individual with education in the studied field in their countries frequency analysis and testing of dependences between question $17 j$ and the considered categories

\begin{tabular}{|c|c|c|c|c|c|c|c|c|}
\hline Answer & $\mathrm{CZ}$ & PL & Male & Female & $\begin{array}{c}1^{\text {st }} \text { Year } \\
\text { of Studies }\end{array}$ & $\begin{array}{l}2^{\text {nd }} \text { Year } \\
\text { of Studies }\end{array}$ & $\begin{array}{l}3^{\text {rd }} \text { Year } \\
\text { of Study }\end{array}$ & Total \\
\hline 1 & 4 & 8 & 2 & 10 & 5 & 7 & 0 & 12 \\
\hline 2 & 35 & 32 & 12 & 55 & 34 & 27 & 6 & 67 \\
\hline 3 & 58 & 56 & 10 & 104 & 60 & 36 & 18 & 114330 \\
\hline 4 & 58 & 47 & 21 & 84 & 61 & 34 & 10 & 105 \\
\hline 5 & 16 & 16 & 6 & 26 & 18 & 10 & 4 & 32 \\
\hline avg & 3.2651 & 3.2073 & 3.3333 & 3.2186 & 3.2938 & 3.1071 & 3.3158 & \\
\hline$P$ & 0.6 & 57 & & 119 & & 0.534 & & \\
\hline
\end{tabular}

$1=$ very little; $2=$ little; $3=$ cannot say; $4=$ high; $5=$ very high. $p=$ significance value; ${ }^{*} p \leq 0.05{ }^{* *} p \leq 0.01{ }^{* * *} p \leq 0.001$. Source: authors' own research.

significant dependence between the status of an individual with education in the field and their country of study, their gender or year of study.

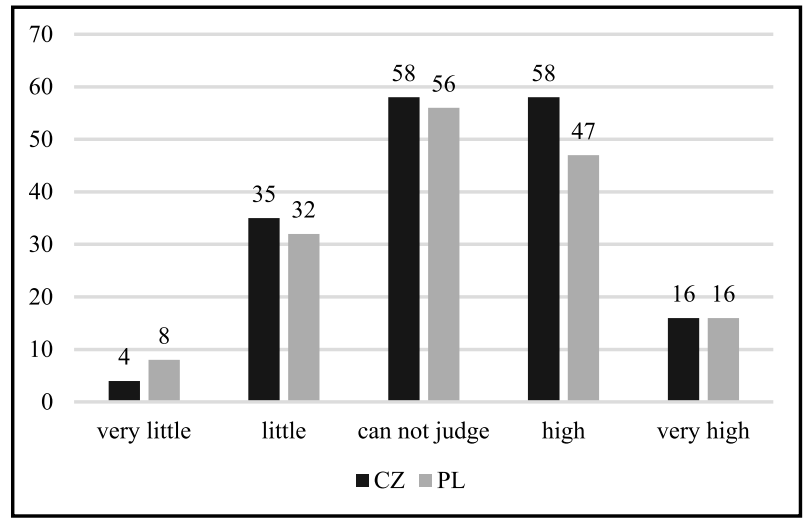

Figure 59. Absolute frequencies of item 17j. Source: authors' own research.

\subsection{Students' feeling of bonds with the academic community at their university - a correlation analysis}

In the second item of the questionnaire (Q2e), respondents were asked to assess how strongly they feel connected with the academic community at their university. Again, the respondents answered using a five-point scale ( $1=\mathrm{I}$ do not feel connected at all; 2 = I rather do not feel connected; $3=$ it is not easy to answer; $4=$ I feel rather connected; $5=$ I feel connected). Tables $42-44$ demonstrate the correlation of the five items of the questionnaire: Q17e - the suitability of acquired education for the profession, Q17f - opportunities for students' devel- 
opment after their studies, Q17g - their professional qualities, Q17h - prospects for getting a job in accordance with acquired education and $\mathrm{Q} 17 \mathrm{j}$ - the status of an individual with education in the studied field in their countries with Q2e and Q10-13.

Table 42. Correlation analysis of the relation between questions $2 \mathrm{e}, 10-13$ and questions $17 \mathrm{e}-\mathrm{j}$ for all respondents $(\mathrm{CZ}+\mathrm{PL})$

\begin{tabular}{|c|c|c|c|c|c|c|c|c|c|c|}
\hline $\mathrm{CZ}+\mathrm{PL}$ & \begin{tabular}{l|l}
$\mathrm{Q}$ & $r$
\end{tabular} & $\mathrm{Q} 2 \mathrm{e} \mid p$ & Q10 $\mid r$ & $\mathrm{Q} 10 \mid p$ & Q11 $\mid r$ & $\mathrm{Q} 11 \mid p$ & Q12 $\mid r$ & $\mathrm{Q} 12 \mid t$ & Q13 | & $\mathrm{Q} 13 \mid p$ \\
\hline Q17-e & 0.152 & $0.006^{* *}$ & -0.078 & 0.156 & -0.035 & 0.532 & -0.082 & 0.135 & 0.013 & 0.819 \\
\hline Q17-f & 0.234 & $0.000^{* * *}$ & -0.074 & 0.180 & -0.072 & 0.191 & -0.036 & 0.511 & 0.117 & $0.034^{*}$ \\
\hline Q17-g & 0.147 & $0.007^{\star *}$ & -0.097 & 0.079 & -0.075 & 0.171 & -0.070 & 0.203 & 0.036 & 0.514 \\
\hline Q17-h & 0.085 & 0.121 & -0.147 & $0.007^{\star *}$ & -0.168 & $0.002^{\star *}$ & -0.043 & 0.434 & -0.005 & 0.923 \\
\hline Q17-j & 0.100 & 0.068 & -0.079 & 0.150 & -0.069 & 0.210 & -0.108 & 0.051 & -0.103 & 0.061 \\
\hline
\end{tabular}

Q10 = Have you studied abroad?; Q11 = Have you worked abroad?; Q12 = Would you like to study abroad?; Q13 = Would you like to work abroad? $r ; r \in\langle-1 ; 1\rangle$ correlation coefficient. $p$ - significance value for the testing of hypotheses $H_{0}: r=0 ; H_{1}: r \neq 0,{ }^{*} p \leq 0.05$ ${ }^{* *} p \leq 0.01{ }^{* * *} p \leq 0.001$. Source: authors' own research.

In Table 42, a slight correlation can be noticed between the opportunities for students' development, the suitability of acquired education for the profession and their professional qualities with Q2e - the bonds with the academic community at their university. At the same time, there was a small correlation between Q17f and the willingness to work abroad.

Table 43. Correlation analysis of the relation between questions $2 \mathrm{e}, 10-13$ and questions $17 \mathrm{e}-\mathrm{j}$ for Czech respondents (CZ)

\begin{tabular}{|c|c|c|c|c|c|c|c|c|c|c|}
\hline $\mathrm{CZ}$ & \begin{tabular}{l|l} 
Q2e & $r$
\end{tabular} & Q2e $\mid p$ & Q10 & Q10 $\mid p$ & \begin{tabular}{l|l} 
Q11 & $r$
\end{tabular} & Q11 $p$ & Q12 & Q12 $p$ & Q13 $\mid r$ & Q13 $\mid p$ \\
\hline Q17-e & 0.076 & 0.329 & -0.090 & 0.249 & 0.015 & 0.850 & 0.051 & 0.511 & 0.037 & 0.637 \\
\hline Q17-f & 0.189 & 0.015 & -0.120 & 0.124 & -0.052 & 0.506 & 0.030 & 0.698 & 0.119 & 0.128 \\
\hline Q17-g & 0.059 & 0.451 & -0.136 & 0.080 & -0.049 & 0.534 & 0.015 & 0.849 & 0.038 & 0.629 \\
\hline Q17-h & 0.000 & 0.996 & -0.158 & $0.043^{\star}$ & -0.074 & 0.341 & 0.019 & 0.811 & -0.036 & 0.647 \\
\hline Q17-j & 0.032 & 0.681 & -0.141 & 0.070 & -0.041 & 0.601 & -0.090 & 0.251 & -0.198 & $0.011^{\star *}$ \\
\hline
\end{tabular}

Q10 = Have you studied abroad?; Q11 = Have you worked abroad?; Q12 = Would you like to study abroad?; Q13 = Would you like to work abroad? $r ; r \in\langle-1 ; 1\rangle$ correlation coefficient. $p$ - significance value for the testing of hypotheses $H_{0}: r=0 ; H_{1}: r \neq 0,{ }^{\star} p \leq 0.05$ ${ }^{* *} p \leq 0.01{ }^{* * *} p \leq 0.001$. Source: authors' own research.

In Table 43, only a weak negative correlation can be observed between Q17h - prospects for getting a job in accordance with acquired education and experience with studying abroad, and also a weak negative correlation between $\mathrm{Q} 17 \mathrm{j}$ the status of an individual with education in the studied field and the willingness to work abroad.

The correlation analysis in the case of Polish students is larger than in Czech students. In all five items Q17e-j, a slight correlation can be observed with the feeling of bonds with the academic community at their university (Table 44). 
Table 44. Correlation analysis of the relation between questions 2e, 10-13 and questions 17a-17 s for Polish respondents (PL)

\begin{tabular}{|c|c|c|c|c|c|c|c|c|c|c|}
\hline PL & Q2e $\mid r$ & Q2e $\mid p$ & $\mathrm{Q} 10 \mid r$ & Q10 & Q11 & $\mathrm{Q} 11 \mid p$ & \begin{tabular}{l|l} 
Q12 & 1
\end{tabular} & Q12 & Q13 & $\mathrm{Q} 13 \mid p$ \\
\hline Q17-e & 0.303 & $0.000^{* * *}$ & -0.040 & 0.614 & -0.085 & 0.279 & -0.106 & 0.178 & 0.081 & 0.300 \\
\hline Q17-f & 0.322 & $0.000^{\star * * *}$ & 0.000 & 0.995 & -0.098 & 0.213 & -0.065 & 0.406 & 0.162 & 0.038 \\
\hline Q17-g & 0.238 & $0.002^{\star *}$ & -0.052 & 0.506 & -0.103 & 0.190 & -0.178 & $0.023^{\star}$ & 0.033 & 0.679 \\
\hline Q17-h & 0.214 & $0.006^{* *}$ & -0.121 & 0.122 & -0.264 & $0.001^{\star *}$ & -0.025 & 0.754 & 0.087 & 0.266 \\
\hline Q17-j & 0.173 & $0.026^{*}$ & -0.009 & 0.906 & -0.097 & 0.218 & -0.121 & 0.122 & 0.002 & 0.979 \\
\hline
\end{tabular}

Q10 = Have you studied abroad?; Q11 = Have you worked abroad?; Q12 = Would you like to study abroad?; Q13 = Would you like to work abroad?. $r ; r \in\langle-1 ; 1\rangle$ correlation coefficient. $p$ - significance value for the testing of hypotheses $H_{0}: r=0 ; H_{1}: r \neq 0,{ }^{*} p \leq 0.05$ ${ }^{* *} p \leq 0.01{ }^{* *} p \leq 0.001$. Source: authors' own research.

\section{Summary}

The suitability of acquired education for students' future or current profession is viewed positively by two thirds of respondents - 218 (66\%). 144 of them (43.6\%) see the suitability of acquired education as high and 55 students $(16.6 \%)$ as very high. 74 respondents $(22.4 \%)$ cannot say, more Poles - 42 (12.7\%) than Czechs $32(9.6 \%) .57$ respondents $(17.2 \%)$ assess the suitability of the acquired education for their future or current profession negatively, there are more Poles -42 (12.7 \%) than Czechs - 15 (4.5\%). There are 14 students $(4.2 \%)$ who are the most pessimistic and see very little suitability in the acquired education for their future profession. Czech students and men view their studies more positively as regards their future profession. First-year students see the suitability of the acquired education more positively than second- or third-year students.

There is only a statistically significant dependence between the suitability of students' acquired education for the profession and their country of study. No statistically significant dependence of the suitability of students' acquired education for the profession and their gender or year of study has been proved.

The degree of correlation between the bonds with the academic community and items Q17e-j is higher among Polish than Czech students.

\subsection{The image of the university and the attractiveness of the study field}

In 2019, the University of Ostrava joined some of the most prestigious scientific institutions in Europe since it gained one of the most important awards for its work in the field of human resources. The university managed to meet the strict conditions of the European Commission, which awarded it the HR Excellence in 
Research Award. It joined the group of such institutions as the Swiss CERN, the University of Oxford, Mendel University in Brno, and Charles University or CEITEC in the Czech Republic. There are only 13 science and research institutes (or their subdivisions) which received this quality award in the Czech Republic and 481 institutions in the European Union ("Ostravská univerzita", 2019).

In 2018, the University of Ostrava obtained the so-called institutional accreditation in seven areas of education, which means a major change in educational activities. Thus, the University of Ostrava became entitled to approve study programmes in the following areas of education: philology (bachelor's degree, master's degree, Ph.D.), philosophy, religious studies and theology (B., M., Ph.D.), historical sciences (B., M., Ph.D.), social work (B., M.), physical education and sports, kinanthropology (B., M.), teaching (B., M.), healthcare (B., M., Ph.D.). In 2018, the University of Ostrava had 138 so-called originally accredited study programmes in all types and forms of studies, 52 bachelor's, 47 master's and 39 doctoral study programmes. The amendment of the Higher Education Act in force from $1^{\text {st }}$ September 2018 automatically prolonged the accreditation of all these study programmes until $31^{\text {st }}$ December 2024. In 2018, the University of Ostrava accredited 95 new study programmes (46 bachelor's, 25 master's and 24 doctoral study programmes), of which 78 were approved within institutional accreditation. In previous years, the University of Ostrava received the ECTS Label, which requires compliance with the requirements of the methodology for learning outcomes and new study programmes are prepared in accordance with this methodology. The university image is also influenced by the services provided to students. It includes, for instance, professional and career counselling, guidance for students with special needs, programmes for exceptionally gifted students, support for socio-economically disadvantaged students, and support for doctoral students. The university image is also shaped by its cooperation with industry in the creation and transfer of innovations and their commercialisation, as well as its membership of international associations, organisations and groups. In 2018, the University of Ostrava participated in the evaluation of the Times Higher Education where it ranked $801^{\text {st }}-1000^{\text {th }}$, and the seventh among Czech public universities ("VÝROČNÍ ZPRÁVA O ČINNOSTI 2018", 2018).

For a long time, the top universities in the Times Higher Education rankings have been the University of Oxford (UK), the University of Cambridge (UK) and Stanford University (USA). As for Czech universities, the top-ranked universities were Charles University in Prague in the $401^{\text {st }}-500^{\text {th }}$ place, Masaryk University in Brno and Palacky University in Olomouc in the $601^{\text {st }}-800^{\text {th }}$ place. The Polish bestranked university was the Jagiellonian University in the $601^{\text {st }}-800$ th place together with the University of Warsaw. The University of Silesia in Katowice ranked $1001^{\text {st }}+$ ("World University Rankings", 2019). 
4.7.1. The image of the university and the attractiveness of the study field descriptive and hypotheses testing results

The aim of the research in this aspect was to find an answer to the question: How do Polish and Czech students assess the attractiveness of their field of study and how do they assess the image of the university in which they are studying? Are these differences influenced by students' characteristics (age, year of study and gender)?

Tables 45-46 comprise the results of descriptive statistics in the form of absolute numbers and arithmetic means which express the attitudes of Czech and Polish students to the given question. Students were supposed to assess the attractiveness of their field of study and how they perceive the university image using a five-point scale. The scale had the following points: $1=$ very little; $2=$ little; 3 = cannot say; $4=$ high; $5=$ very high.

As the methodological approaches from the previous chapter were used, similar principles and methods of the quantitative research were applied. The same significance level of $5 \%$ was taken into consideration.

The following hypotheses were provided for Item 17a "The attractiveness of my field of study":

$28 H_{A}$ : There is a statistically significant dependence between students' views on the attractiveness of their field of study and their country of study.

$29 H_{A}$ : There is a statistically significant dependence between students' views on the attractiveness of their field of study and their gender.

$30 H_{A}$ : There is a statistically significant dependence between students' views on the attractiveness of their field of study and their year of study.

Table 45. The attractiveness of my field of study - frequency analysis and testing the dependences between question 17a and the considered categories

\begin{tabular}{|c|c|c|c|c|c|c|c|c|}
\hline Answer & $\mathrm{CZ}$ & PL & Male & Female & $\begin{array}{c}1^{\text {st }} \text { Year } \\
\text { of Studies }\end{array}$ & $\begin{array}{c}2^{\text {nd }} \text { Year } \\
\text { of Studies }\end{array}$ & $\begin{array}{c}3^{\text {rd }} \text { Year } \\
\text { of Studies }\end{array}$ & Total \\
\hline 1 & 5 & 8 & 1 & 12 & 4 & 5 & 4 & 13 \\
\hline 2 & 18 & 18 & 7 & 29 & 21 & 10 & 5 & 36 \\
\hline 3 & 31 & 35 & 4 & 62 & 32 & 23 & 11 & $66 \quad 330$ \\
\hline 4 & 79 & 81 & 28 & 132 & 91 & 56 & 13 & 160 \\
\hline 5 & 38 & 17 & 11 & 44 & 30 & 20 & 5 & 55 \\
\hline avg & 3.7349 & 3.5244 & 3.8039 & 3.5986 & 3.6836 & 3.6696 & 3.2632 & \\
\hline$p$ & 0.0 & & & 114 & & 0.269 & & \\
\hline
\end{tabular}

$1=$ very little; $2=$ little; $3=$ cannot say; $4=$ high; $5=$ very high. $p=$ significance value; ${ }^{*} p \leq 0.05{ }^{* *} p \leq 0.01{ }^{* * *} p \leq 0.001$. Source: authors' own research.

It can be observed in Table 45 that 160 students ( $48.4 \%$ ) see high attractiveness in the field of study they have chosen. In this regard, the difference between Czechs and Poles is minimal ( 2 students), but if the fifth point is considered, it is seen 
that 55 students $(16.6 \%)$ perceive the attractiveness of their field of study as very high and there is also a $50 \%$ difference between Czech and Polish students. In general, Czechs view the attractiveness of their field of study by 0.2 points more positively than Poles. Again, there are many students - $66(20 \%)$ - who cannot say. If average values are compared in the two other categories, it can be seen that men see the attractiveness of their field of study more positively than women and third-year students view it less positively than first and second-year students.

If all the three levels of significance values in the hypotheses are examined, it can be stated that $28 \mathrm{H}_{0}$ is rejected at the level of $5 \%$ in favour of $28 \mathrm{H}_{A}$. Therefore, there is a statistically significant dependence between students' views on the attractiveness of their field of study and their country of study. The other alternative hypotheses $29-30 H_{A}$ are rejected in favour of zero hypotheses $29-30 H_{0}$. Therefore, there is no statistically significant dependence between students' views on the attractiveness of their field of study and their gender or year of study.

In Figure 60, it can be noticed that the middle answers are quite even while there is up to a $50 \%$ difference between the extreme answers "very little" and "very high".

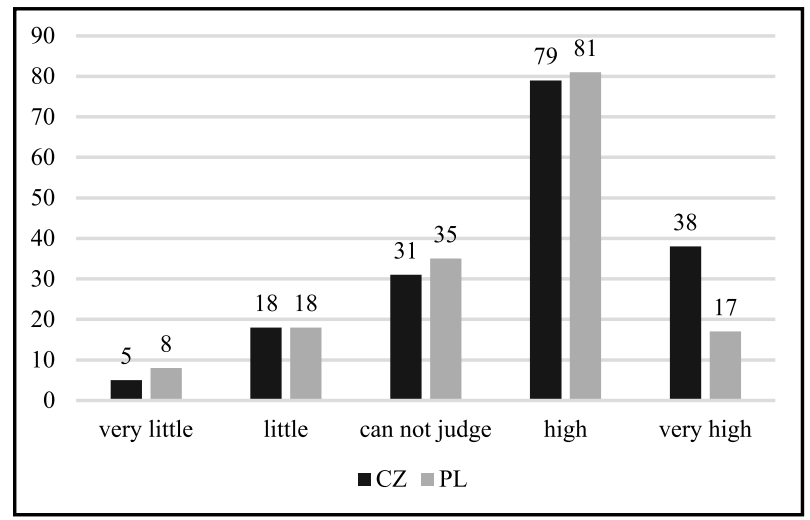

Figure 60. Absolute frequencies of item 17a. Source: authors' own research.

The following hypotheses were provided for Item $17 \mathrm{~m}$ "The image of the chosen university":

$31 H_{A}$ : There is a statistically significant dependence between students' views on the image of the university and the country of study.

$32 \mathrm{H}_{\mathrm{A}}$ : There is a statistically significant dependence between students' views on the image of the university and their gender.

$33 H_{A}$ : There is a statistically significant dependence between students' views on the image of the university and their year of study. 
Table 46. The image of the chosen university - frequency analysis and testing of dependences between question $17 \mathrm{~m}$ and the considered categories

\begin{tabular}{|c|c|c|c|c|c|c|c|c|c|}
\hline Answer & $\mathrm{CZ}$ & PL & Male & Female & $\begin{array}{c}1^{\text {st }} \text { Year } \\
\text { of Studies }\end{array}$ & $\begin{array}{c}2^{\text {nd }} \text { Year } \\
\text { of Studies }\end{array}$ & $\begin{array}{c}3^{\text {rd }} \text { Year } \\
\text { of Studies }\end{array}$ & \multicolumn{2}{|c|}{ Total } \\
\hline 1 & 2 & 8 & 2 & 8 & 4 & 4 & 2 & 10 & \\
\hline 2 & 26 & 22 & 9 & 39 & 26 & 15 & 7 & 48 & \\
\hline 3 & 37 & 41 & 11 & 67 & 43 & 29 & 6 & 78 & 330 \\
\hline 4 & 85 & 68 & 21 & 132 & 81 & 54 & 18 & 153 & \\
\hline 5 & 21 & 20 & 8 & 33 & 24 & 12 & 5 & 41 & \\
\hline avg & 3.5602 & 3.4512 & 3.4706 & 3.5125 & 3.5254 & 3.5000 & 3.4474 & & \\
\hline$p$ & 0.3 & & & 986 & & 0.276 & & & \\
\hline
\end{tabular}

$1=$ very little; $2=$ little; $3=$ cannot say; $4=$ high; $5=$ very high. $p=$ significance value; ${ }^{\star} p \leq 0.05{ }^{* *} p \leq 0.01{ }^{* * *} p \leq 0.001$. Source: authors' own research.

In Table 46, it can be observed that the majority of students, $153(46.3 \%)$ in total, perceive the image of their university as high and 41 students $(12.4 \%)$ as very high. Again, a great number of students $78(23.6 \%)$ could not say. This can be also observed in Figure 61. If the arithmetic means are compared in all three categories, it can be stated that there are no significant differences and the values are around 3.5 points.

If all the three levels of significance values in the hypotheses are examined, it can be stated that all three alternative hypotheses $31-33 H_{A}$ are rejected at the level of $5 \%$ in favour of zero hypotheses $31-33 H_{0}$. Therefore, there is no statistically significant dependence between students' views on the image of the chosen university and their country of study, their gender or year of study.

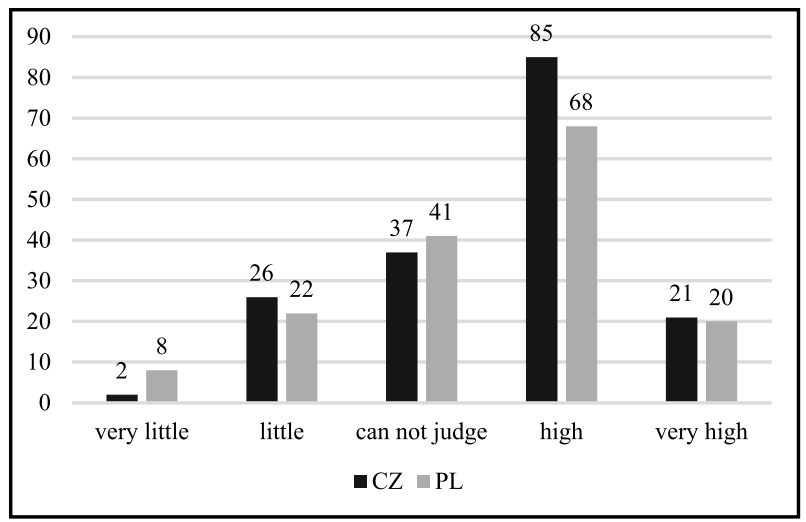

Figure 61 . Absolute frequencies of item $17 \mathrm{~m}$. Source: authors' own research. 
4.7.2. The image of the university and the attractiveness of the study field correlation analysis

In Items Q17a and Q17 m, there are correlations between the feeling of attachment to the academic community at their university Q2e and questions Q10-13.

Table 47. Correlation analysis of the relation between questions $2 \mathrm{e}, 10-13$ and questions $17 \mathrm{a}, 17 \mathrm{~m}$ for all respondents $(\mathrm{CZ}+\mathrm{PL})$

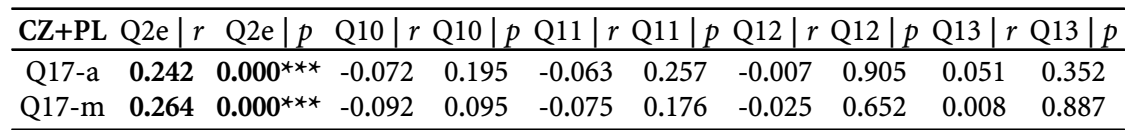

Q10 = Have you studied abroad?; Q11 = Have you worked abroad?; Q12 = Would you like to study abroad?; Q13 = Would you like to work abroad? $r ; r \in\langle-1 ; 1\rangle$ correlation coefficient. $p$ - significance value for the testing of hypotheses $H_{0}: r=0 ; H_{1}: r \neq 0,{ }^{\star} p \leq 0.05$ ${ }^{* *} p \leq 0.01{ }^{* * *} p \leq 0.001$. Source: authors' own research.

As can be observed in Table 47, there was a slight correlation between the attractiveness of the field of study and the university image and the feeling of bonds with the academic community at their university among all respondents.

Table 48 demonstrates the results collected among Czech students only, and in this case, no correlation was found.

Table 48. Correlation analysis of the relation between questions $2 \mathrm{e}, 10-13$ and questions $17 \mathrm{a}, 17 \mathrm{~m}$ for Czech respondents (CZ)

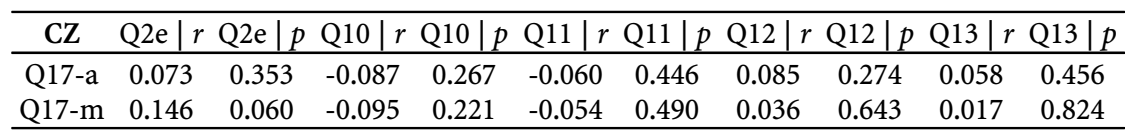

Q10 = Have you studied abroad?; Q11 = Have you worked abroad?; Q12 = Would you like to study abroad?; Q13 = Would you like to work abroad? $r ; r \in\langle-1 ; 1\rangle$ correlation coefficient. $p$ - significance value for the testing of hypotheses $H_{0}: r=0 ; H_{1}: r \neq 0,{ }^{\star} p \leq 0.05$ ${ }^{* *} p \leq 0.01{ }^{* * *} p \leq 0.001$. Source: authors' own research.

In Table 49 for Polish students, a medium correlation can be noticed between the attractiveness of the field of study and the university image and students' feeling of bonds with the academic community.

Table 49. Correlation analysis of the relation between questions $2 \mathrm{e}, 10-13$ and questions $17 \mathrm{a}, 17 \mathrm{~m}$ for Polish respondents (PL)

\begin{tabular}{ccccccccccccc}
\hline PL & $\mathrm{Q} 2 \mathrm{e} \mid r$ & $\mathrm{Q} 2 \mathrm{e}$ & $p$ & $\mathrm{Q} 10$ & $r$ & $\mathrm{Q} 10 \mid p$ & $\mathrm{Q} 11 \mid r$ & $\mathrm{Q} 11 \mid p$ & $\mathrm{Q} 12 \mid r$ & $\mathrm{Q} 12 \mid p$ & $\mathrm{Q} 13 \mid r$ & $\mathrm{Q} 13 \mid p$ \\
\hline $\mathrm{Q} 17-\mathrm{a}$ & $\mathbf{0 . 4 4 7}$ & $\mathbf{0 . 0 0 0 * * *}$ & -0.042 & 0.590 & -0.067 & 0.394 & -0.072 & 0.356 & 0.077 & 0.327 \\
$\mathrm{Q} 17-\mathrm{m}$ & $\mathbf{0 . 3 8 5}$ & $\mathbf{0 . 0 0 0 * * *}$ & -0.084 & 0.285 & -0.094 & 0.231 & -0.068 & 0.386 & 0.014 & 0.856 \\
\hline
\end{tabular}

Q10 = Have you studied abroad?; Q11 = Have you worked abroad?; Q12 = Would you like to study abroad?; Q13 = Would you like to work abroad ? $r ; r \in\langle-1 ; 1\rangle$ correlation coefficient. $p$ - significance value for the testing of hypotheses $H_{0}: r=0 ; H_{1}: r \neq 0,{ }^{\star} p \leq 0.05$ ${ }^{* *} p \leq 0.01{ }^{* * *} p \leq 0.001$. Source: authors' own research. 


\section{Summary}

A total of 215 (65\%) students view the attractiveness of their chosen field of study positively. Czech students see their choice of the field of study more positively than Poles. The same applies to men compared to women. The attractiveness of the field of study slightly decreases in higher years of study. Only 13 (3.9\%) students recognize very little attractiveness in their field of study. A total of 194 $(58.7 \%)$ students assess the image of the chosen university highly or very highly, and Czechs more positively than Poles.

The attractiveness of the field of study and the university image slightly correlates with the feeling of bonds with the academic community of all respondents. This correlation is medium in the case of Polish students and there is no correlation as regards Czech students.

\section{Conclusions}

Working and studying abroad appears to be an important experience for young people and their future personal and professional life. People are forced to adapt to new life conditions related to a new place, culture, different language and human behaviour. Young people abroad try to find their way and learn to rely on their competencies, cope with tasks and deal with sometimes emotionally difficult situations. Studying or working abroad is not easy for them and if they manage it successfully, they can profit from this success in handling such a difficult situation. This, in turn, influences their self-confidence and resilience in various difficult situations that occur later in life.

The findings in this international research have demonstrated that a small number of students, only 40 (12\%), have study experience collected abroad. The same applies to work experience abroad, there are only 50 (15\%) students who have worked abroad. In both cases, there are more Czechs than Poles. The majority of students went abroad for work or studies in their first year of studies, then the interest linearly decreases to a minimum in the third year. Respondents' gender does not influence working or studying abroad, men and women have the same experience. Polish students studied abroad half as much as Czech students, but the Polish students have the most statistically significant correlation with the feeling of being a citizen in the EU. The respondents are more willing to study $(33.6 \%)$ and work (36.6\%) abroad than the real experience has shown. There are $50 \%$ more Czechs willing to study abroad than Poles, and $37 \%$ more Czechs than Poles are willing to work abroad. First-year students are more interested in studying and working abroad and the interest decreases linearly to the minimum in higher years of studies. Women are more interested in studying and working 
abroad than men; however, the difference is minimal. There was a slight correlation between the feeling of citizenship of their country and willingness to work abroad in the case of Polish students.

The research also focused on the professional prospects of university students studying education and $60 \%$ of them can see the suitability of their education for their future profession. In this regard, Czechs are more positive than Poles and men more than women. The suitability of the acquired education is seen most favourably by first-year students, this opinion then decreases in other years of study. Up to $23 \%$ of students cannot say how suitable the acquired education is for their profession. Czechs can see more opportunities for their development than Poles; similar results were observed as regards the gender and year of study. When assessing their own professional qualifications, Czechs and Poles showed relatively identical results, the same applies to gender. Third-year students assessed them the least. Many students (28\%) could not say how they viewed their professional qualities; however, the majority (62\%) see them positively. As regards the prospects for getting a job in accordance with the acquired education, Czechs, men and first-year students view them most positively. A high percentage of respondents $(28.4 \%$ ) cannot say what their prospects are. Poles and Czechs see their social status after finishing studies similarly; men view it more positively than women and third-year students most positively. When assessing the status, the majority of students were negative, more precisely $24 \%$ of them, and $34.5 \%$ could not say. There was a slight correlation between students' feeling of bonds with the academic community at their university and the suitability of the acquired education for the profession, opportunities for their development after their studies and their own professional qualities.

Two thirds (65.5\%) of students view the attractiveness of their field of study positively; Czechs, men and third-year students being the largest groups. $23.4 \%$ of all respondents cannot assess the image of their university and $58.7 \%$ view it positively, mostly Czechs and women. Students of particular years of study see it in the same way. There was a medium correlation between the feeling of attachment to the academic community at their university and the attractiveness of the field of study and the image of the studied university in the case of Polish students.

The research demonstrated students' attitudes to individual questions and depicted the differences between students of two different nationalities, genders and different years of study. The findings of this research show that the majority of respondents see the attractiveness in their field of study, their potentialities and professional future in a positive light. In addition, the study has revealed that many students cannot say what they think about individual categories, which also raises an interesting question concerning the reasons for this attitude. 
Open-Access-Publikation im Sinne der CC-Lizenz BY 4.0

(c) 2021, Vandenhoeck \& Ruprecht GmbH \& Co. KG, Göttingen ISBN Print: 9783847112549 - ISBN E-Lib: 9783737012546 


\section{Ending}

The contemporary Polish-Czech borderland is gradually transforming into a multicultural community with an ambiguous cultural, linguistic and religious identification. This is taking place in spite of its still persisting bicultural, bilingual and bi-religious character. The assimilation-based type of interethnic coexistence, which currently functions in this borderland, is largely modifying the consolidated stereotypes and prejudices, as well as the ways in which alien ethnic groups and nations are perceived. Its characteristic features are a feeling of closeness over a feeling of cultural distance and a substantial revival of mutual relationships, which have been increasingly intensive in the new socio-economic conditions after 1989. The reevaluation that has co-occurred with this in the area of cultural patterns of perceiving "the ethnically different" has changed the existing images of the Own and the Others. At the same time, some new (qualitatively different) patterns of cultural behaviour have come into being - they are shaped to a lesser extent by accommodation processes and to a larger extent by the attitudes of openness and understanding.

The sociocultural capital and the economic condition of the borderland significantly determine the living standards of minority and majority groups in this territory, as well as their goals and life plans. This has an impact on both the diversified life conditions of the inhabitants and the possibilities of bringing up and educating children and youth. Thus, the borderland is becoming a particular cultural space, in which the current university-aged generation can broaden their knowledge of the problems and diversities of their local environment and the whole country, Europe or the world, and take an active part in the sociocultural life and, at the same time, feel a specific social integrity. This integrity firstly means the acceptance of common values and institutions, secondly - it is based on the shared recognition of socially prevailing behaviour patterns and methods of social control, thirdly - it is considered as a form of social capital based on mutual trust maintained by social relationships, and finally - it is built on the feeling of belonging to particular communities and sharing a common cultural identity. 
Both in the Polish and Czech educational science, there have been rather few studies on the social, cultural and educational functioning of university students in the conditions of cultural diversity. The existing knowledge in this field, presented mostly within comparative pedagogy, usually consists in presenting expert opinions on the current state and situation of higher education in a particular country and on the applied solutions. The scientific exploration undertaken by our team largely broadens this subject matter and is grounded in the research problems which concern the relationships between the sociocultural capital of the Polish-Czech borderland and the feeling of cultural identity and the education of university students in the following dimensions:

- the manifested identity behaviours approached from the perspective of axiological preferences, the declared feeling of identity and national identifications, the feeling of belonging to particular social groups and the relationship between the evaluation of one's own life situation and one's feeling of identity;

- the acquired intercultural competences, including the social perception of neighbours, nationally mixed marriages, and the respondents' attitude to the observed manifestations of discriminatory behaviour;

- the quality of university education in the context of the relationships between students and the academic staff, the conditions for development created by universities, the theoretical knowledge and practical skills acquired in the course of studies, as well as their impact on the students' professional career;

- students' attitudes to university studies and working abroad, including the qualifications for a teaching profession, as well as the respondents' perception of the attractiveness of their university courses, professional prospects and the factors which motivate them to go abroad.

The comparative studies have been conducted in 3 stages with the use of the quantitative-qualitative approach. Stage I comprised monographic (field) studies aimed at the familiarization with the inherited and currently created sociocultural capital of the Polish-Czech borderland. In stage II, the quantitative (questionnaire) studies were conducted, with the use of authors' standardized tools. In the final stage - III, the qualitative studies were carried out, with the use of ethnographic observation, individual interviews and document analysis, in order to deepen the obtained data in the examined fields.

The profile, outlined in this book, of the cultural identity and education of university students from the Polish-Czech borderland, allows the authors to formulate many conclusions. They were presented in detail as the conclusions in each chapter, at the end - only the major conclusions (resulting from the synthesis of the research results) were presented. 
A diversified image of the values currently appreciated by the generation of university students points to the changes in their axiological awareness, determined by a particular (at that age) social sensitivity and, at the same time, a clearly felt otherness of the economic and cultural condition of either of their residence countries. The values and life goals seem to be similar to the typical features of the image of values most highly ranked by contemporary university youth with a clear tendency to focus on a life for oneself and with an increase in the significance of individual-private values, associated with work, a professional career and self-fulfilment. The differences in the declared national identifications of particular student groups point to a visible tendency to the young generation's identification with different communities - of their homeland, local, regional, or more broadly, European or supra-European ones. The construction of their own identity by university students means drifting apart from its homogenous dimension and getting closer to discovering the conscious choice of an enriched, multidimensional identity, which is most often determined by processes of the democratization of social life, which take place at various paces and in different scopes. Contrary to their Polish peers, the identity profile of Czech students has mostly a national dimension and is characterized by a clear preference for their own ethnic (national) group in regard to identity, language and social contacts, as well as by the well-balanced level of their duties and rights.

This is also reflected in their interest in their neighbours and in their image of Poles/Czechs. Much more frequently, Polish students emphasize that - together with Czechs - they constitute one community in which nationality-based divisions are meaningless. Yet, Czech students much more often claim that the divisions are visible. The perception of nationally mixed marriages looks slightly different - in this case, Czech students treat them as a positively evaluated phenomenon. Students from Poland notice that such marriages first of all have to face their compatriots' intolerance, whereas their Czech peers stress that such couples have problems with assimilation in their country of residence due to social isolation and communication problems. Many respondents notice in their environment some phenomena associated with ethnic or nationality-based aggression and violence. More descriptions of such situations were provided by students from Ostrava. What must raise concern is the fact that the majority of respondents, who live their daily life in a culturally diversified environment, are unable to assess their intercultural competences.

"Pathways to higher education and its value", the third chapter of the book, presents the history of institutions representing higher education in Poland and the Czech Republic, particularly in the borderland between the two countries. It also comprises a list of significant external factors influencing their functioning. Some interesting findings in four areas are included here as well - Theory and practice for a future career, The value of higher education, People at university 
and The conditions and process of university studies. All of them characterise university studies in the perspective of their process, future employment of graduates and the involved people. The Czech and Polish students differed in the assessment of most of the evaluated criteria of university studies, but the Polish students expressed more critical views. No statistically significant difference between men and women was found. Students of the two higher years of study were more critical in their assessment of the practical skills acquired throughout the studies and the association of theory and practice in individual subjects. These are the most significant weaknesses of the respondents' studies. Students are also less satisfied with the assessment of their work by teachers at exams; predominantly, they have also avoided unambiguous opinions on their assessment. The respondents assessed the relationship between academic staff and students, the level of theoretical knowledge they can acquire in the course of their studies, the conditions created by their universities and the quality of education as very good. Students from Poland more often than those from the Czech Republic selected evasive answers, and - therefore - it will be necessary to consider improving the diagnostic and evaluation competencies of a university student who is preparing to undertake the teaching profession.

Some distinct differences between Czech and Polish students occur in the analysed areas of the fourth chapter, which focuses on studying and working abroad, the vocational background, the perspectives and image of the study field, as well as its attractiveness. On the basis of the research results, it can be stated that one third of the interviewed students are interested in studying and working abroad, with the number of Czechs being higher than that of Poles. Being interested is one thing, yet - only $12 \%$ of Polish and $15 \%$ of Czech students have practical experience with studying and working abroad. The evaluation of the acquired education brings considerably better results. Two thirds of all students evaluate it positively and believe that their pedagogical education constitutes a significant potential for their future teaching activities. Czech students evaluate the area slightly more positively than Polish ones. The percentage is similar for students' attitudes related to the image of their university and the attractiveness of their field of study. In the future, it will certainly be interesting to re-conduct a similar survey and to analyse the possible changes in individual categories.

The studies and their results presented in this book have enriched the knowledge of the sociocultural processes taking place in the Polish-Czech borderland and have contributed to the scientific description of the functions attributed to modern intercultural education in the European and global educational system. Moreover, the studies provided valuable pedagogical, psychological and sociological information, as well as helped one to explain and understand the changes taking place in the feeling of cultural identity and in the education of university students in selected countries of Central and Eastern 
Europe in the context of contemporary social processes. The obtained research results and the formulated conclusions have also substantial cognitive significance for educational specialists, intercultural educators, experts in cultural studies and sociologists exploring social changes and cross-generational transmission. 
Open-Access-Publikation im Sinne der CC-Lizenz BY 4.0

(c) 2021, Vandenhoeck \& Ruprecht GmbH \& Co. KG, Göttingen ISBN Print: 9783847112549 - ISBN E-Lib: 9783737012546 


\section{Bibliography}

Alexander B., Ashford-Rowe K., Barajas-Murphy N., Dobbin G., Knott J., McCormack M., Pomerantz J., Seilhamer R., Weber N. (2019), EDUCAUSE Horizon Report: 2019 Higher Education. CO:EDUCAUSE, Louisville.

Andersen A. (1997), Istota Uniwersalizmu [The Essence of Universalism]. In: J. M. Dołęga, J. Kuczyński, A. Woźnicki (eds), Szkoła przeżycia cywilizacyjnego. Wydawnictwo Naukowe "Scholar", Warszawa.

Arnett J. J.(2000), Emerging adulthood. A theory of development from the late teens through the twenties. American Psychologist, Vol. 55, No. 5.

Babiński G. (2001), Pogranicza stare i nowe. Ciągłość i zmiana procesów społecznych [Old and new borderlands. The continuity and change of social processess]. In: K. Krzysztofek, A. Sadowski (eds), Pogranicza etniczne w Europie. Harmonia i konflikty [Ethnic borderlands in Europe. The harmony and conflicts]. Uniwersytet w Białymstoku, Białystok.

Babiński G. (2002), Przemiany pograniczy narodowych i kulturowych - propozycje typologii [Transformations of national and cultural borderlands]. In: R. Stemplowski, A. Żelazo (eds), Polskie pogranicza a polityka zagraniczna u progu XXI wieku [Polish borderlands versus the Polish foreign policy at the start of the $21^{\text {st }}$ century]. Polski Instytut Spraw Międzynarodowych, Warszawa.

Báčová, P. (2016). Vysokoškoláků rapidně přibývá [The number of students is growing fast]. Český statistický úrad. Praha. Retrieved from https://www.czso.cz/csu/czso/vyso koskolaku-rapidne-pribyva.

Bajtoš J. (2013), Didaktika vysokej školy [University didactics]. Iura edition, Bratislava. Bartosiak M. (2012), Tożsamość fraktalna - wyzwanie kultury ery globalizacji [The fractal identity - a challenge for culture of the globalization era]. In: R. Mielczarek, M. Skorzycki (eds), Co za horyzontem? Spojrzenia na granice kultury [What is behind the horizon? The views on the borders of culture]. Społeczna Akademia Nauk, Łódź.

Bauman Z. (2007), Szanse etyki w zglobalizowanym świecie [Chances of ethics in the globalized world]. “Znak”, Kraków.

Bauman Z. (2007), Tożsamość [Identity]. GWP, Gdańsk.

Bauman Z. (2008), Zindywidualizowane społeczeństwo [The individualized society]. GWP, Gdańsk.

Berry J.W. (1994), Acculturative stress. In: W. J. Lonner, R. S. Malpass (eds), Psychology and culture. Allyn and Bacon, Needham Heights. 
Biggs J., Tang, C. (2011), Teaching for quality learning at university. Open University Press, Berkshire.

Bikont A. (1988), Tożsamość społeczna - teorie, hipotezy, znaki zapytania [Social identity theories, hypotheses, question marks]. In: M. Jarymowicz (ed.), Studia nad spostrzeganiem relacji "Ja - Inni": tożsamość, indywiduacja, przynależność [Studies on the perception of the relation "Me-Others": identity, individualization, belonging]. Zakład Narodowy im. Ossolińskich, Wrocław - Warszawa.

Black R., Walsh L. (2019), Imagining Youth Futures. Springer, Singapore.

Bobrownicka M. (2006), Patologie tożsamości narodowej w postkomunistycznych krajach słowiańskich: uwagi o genezie i transformacji kategorii tożsamości [The pathologies of national identity in post-communist Slavic countries: some remarks on the origin and transformation of the category of identity]. "Universitas", Kraków.

Bokszański Z. (1989), Tożsamość - Interakcja - Grupa. Tożsamość jednostki w perspektywie teorii socjologicznej [Identity - Interaction - Group. Identity of the individual from the perspective of sociological theory]. UŁ, Łódź.

Bokszański Z. (2007), Tożsamości zbiorowe [Group identities]. Wydawnictwo Naukowe PWN, Warszawa.

Boski P. (1992), W stronę modelu teoretycznego tożsamości: wymiary tożsamości narodowej [Towards the theoretical model of identity: the dimensions of national identity]. In: P. Boski, M. Jarymowicz, H. Malewska-Peyre, Tożsamość a odmienność kulturowa [Cultural identity and difference]. IP PAN, Warszawa.

Boski P. (2008a), Wielokulturowość i psychologia dwukulturowej integracji [Multiculturalism and psychology of bicultural integration]. In: H. Mamzer (ed.): Czy klęska wielokulturowości?[A failure of multiculturalism?] "Humaniora", Poznań.

Boski P. (2008b), Tożsamość kulturowa [Cultural identity]. In: P. Oleś, A. Batory (eds): Tożsamość $i$ jej przemiany a kultura [Identity and its transformations versus culture]. PAN, KUL, Warszawa - Lublin.

Boski P. (2009), Kulturowe ramy zachowań społecznych. Podręcznik psychologii międzykulturowej [The cultural framework of social behaviour. A handbook of intercultural psychology]. PWN, Warszawa.

Breen, R. (2004). Social Mobility in Europe. New York: Oxford University Press. https://doi. org/10.1093/0199258457.001.0001.

Bruner J. S. (1996), The culture of education. London Harward University Press, Cambridge.

Brzezińska A. I., Piotrowski K. (2010), Formowanie się tożsamości a poczucie dorosłości i gotowość do tworzenia bliskich związków [Identity forming versus the feeling of adulthood and readiness to create close relationships]. Czasopismo Psychologiczne, Vol. 16, No. 2.

Brzezińska A. I., Syska W. (eds) (2016), Ścieżki wkraczania w dorosłość [The pathways of stepping into adulthood]. UAM, Poznań.

PBS Spółka z o.o. (2018), Raport końcowy Społeczne i ekonomiczne warunki życia studentów w Polsce na tle innych krajów europejskich dla Ministerstwa Nauki i Szkolnictwa Wyższego [The final report Social and economic conditions of students' life in Poland against the background of other European countries for the Ministry of Science and Higher Education] Sopot, Warszawa. https://www.gov.pl/web/nauka/podsumowanieprojektu-eurostudent-vi. 
Ciechnowska D. (2009), Kultura studiowania [Culture of studying]. In: D. Ciechanowska (ed.), Proces ksztalcenia akademickiego [The proces of academic education]. Uniwersytet Szczeciński, Szczecin.

Cleaver E., Lintern M., McLinden, M. (2014), Teaching and Learning in Higher Education. Disciplinary Approaches to Educational Enquiry. SAGE, London.

Cole J. (2018), What's the Value of higher education? Yale Insights. https://insights.som. yale.edu/insights/what-s-the-value-of-higher-education.

Crosier D. (Coord.) (2017), Eurydice Brief. Modernisation of Higher Education in Europe: Academic Staff 2017. EACEA, Brussels.

Český sen [The Czech dream] http://czeski-sen.blogspot.com.

Chlebowczyk J. (1983), O prawie do bytu małych i młodych narodów: kwestia narodowa $i$ procesy narodotwórcze we wschodniej Europie środkowej w dobie kapitalizmu (od schytku XVIII do poczatków XX wieku) [On the right to existence for small and young nations: the national issue and nation-creating processes in East-Central Europe in the capitalist era (from the late $18^{\text {th }}$ to the early $20^{\text {th }}$ century)]. PWN, Warszawa - Kraków.

Chodynicka A. M., Więckowska J. (2005), Wywiad kulturowy [A cultural interview]. In: K. Stemplewska-Żakowicz, K. Krejtz (eds), Wywiad psychologiczny [A cultural interview]. Vol. 3. Wywiad $w$ różnych kontekstach praktycznych [An interview in different practical contexts]. Pracownia Testów Psychologicznych Polskiego Towarzystwa Psychologicznego, Warszawa.

Czapiński J. (ed.) (2004), Psychologia pozytywna. Nauka o szczęściu, zdrowiu, sile i cnotach człowieka [Positive psychology. Science of human happiness, health, power and virtues]. Wydawnictwo Naukowe PWN, Warszawa.

Czechofil [A Czechophile] https://czechofil.com.

Czechy-okiem Czechofila [The Czech Republic - in a Czechophile's eyes] https://czechofilgi rs.blogspot.com.

Česká republika. Dlouhodobý záměr vzdělávací a vědecké, výzkumné, vývojové a inovační, umělecké a další tvůrčí činnosti pro oblast vysokých škol na období 2016-2020 (Česká Republika 2015). Praha: MŠMT. http://www.msmt.cz/uploads/odbor_30/Jakub/D Z_2016_2020.pdf.

Czerwińska-Jasiewicz M. (2003), Nadzieje i obawy młodzieży dotyczące przyszłości w okresie przemian społecznych w Polsce a jej cele życiowe [The hopes and fears of youth concerning their future in the times of social transformations in Poland versus their life goals]. In: L. Wojciechowska (ed.), Spostrzeganie zjawisk świata społecznego przez dzieci, młodziez i młodych dorostych [Perceiving the phenomena of social world by children, youth and young adults]. UW, Warszawa.

Czuli barbarzyńcy [Sensitive barbarians] http://www.czulibarbarzyncy.net.pl.

Dąbrowska A., Kniejski A. (2012), Tożsamość jako kategoria edukacyjna [Identity as an educational ctegory]. In: K. Szmyd, E. Barnaś-Baran, E. Dolata, A. Śniegulska (eds), Myśl i praktyka edukacyjna w obliczu zmian cywilizacyjnych [The educational thought and practice in the face of civilization changes]. Vol. 1. Człowiek $i$ wychowanie $w$ perspektywie wieloetnicznej $i$ wielokulturowej [The human being and education in the multiethnic and multicultural perspective]. URZ, Rzeszów.

Deloitte, (2019). The Deloitte Global Millennial Survey 2019: Societal discord and technological transformation create a "generation disrupted". file://C:/Users/uzivatel/App 
Data/Local/Packages/Microsoft.MicrosoftEdge_8wekyb3d8bbwe/TempState/Downloa ds/Deloitte_Global_Millennial_Survey_2019.pdf.

Denzin N. K., Lincoln Y. S. (eds) (2009), Metody badań jakościowych [Strategies of qualitative inquiry], Vol. 1-2. PWN, Warszawa.

Donnellan M., Larsen-Rife D., Conger R. (2005), Personality, family, history and competence in early adult romantic relationships. Journal of Personality \& Social Psychology, Vol. 88, No. 3 .

Doseděl, T., \& Katrňák, T. (2017). Economic and Non-economic Returns to Higher Education during a Period of Educational Expansion in the Czech Republic. Czech Sociological Review, Vol. 53 (5), https://doi.org/10.13060/00380288.2017.53.5.361.

Doseděl T, Katrňák T. (2018) Finanční a nefinanční návratnost vzdělávání [A financial and non-finantial turn in education]. In: Hamplová D., Katrňák T. (eds) Na vzdělání záleží. Jak vzdělanostní rozdíly ovlivňují osudy lidí včeskéspolečnosti [It depends on education. How educational differences influence people's fate in the Czech society]. Centrum pro studium demokracie a kultury, Brno.

Dyczewski L., Jurek K. (eds), (2013), Tożsamość w wielokulturowym kontekście [Identity in the multicultural context]. Centrum Europejskie Natolin, Wydawnictwo KUL, Lublin.

EURES v zemích Evropské unie. (2019). https://portal.mpsv.cz/eures/sit.

European Commission (2013), Report to the European Commision on Improving the quality of teaching and learning in Europe's higher education institutions. Publication Office of the European Union, Luxembourg.

European Commission (2017), Communication from the Commission to the European Parliament, the Council, the European Economic and Social Committee and the Committee of the Regions on a renewed EU agenda for higher education.

European Commission/EACEA/Eurydice. (2018), The European Higher Education Area in 2018: Bologna Process Implementation Report. Publications Office of the European Union, Luxembourg.

European Students' Union (2018), Bologna with Student Eyes 2018. European Students' Union, Brussels.

European Values Study (2017), Survey 2017. https://europeanvaluesstudy.eu.

Eurostudent VI. Społeczne i ekonomiczne warunki życia studentów w Polsce na tle innych krajów europejskich [Social and economic conditions of students' life in Poland against the background of other European countries]. Final report for MNiSW (2018). Partner in Business Strategies, Sopot - Warszawa.

Evropský portál pro mládež. (2013). https://europa.eu/youth/eu/article/53/1577_cs.

Felchner A., Gal K., Jakubczak-Krawczyńska K. (2016), Wartości preferowane przez studentów Wydziału Nauk Społecznych Uniwersytetu Jana Kochanowskiego Filii w Piotrkowie Trybunalskim - w świetle badań empirycznych [The values preferred by students of the Faculty of Social Sciences of Jan Kochanowski University - Branch in Piotrków Trybunalski - in the light of empirical studies]. Lubelski Rocznik Pedagogiczny [The Lublin Pedagogical Yearbook], Vol. 35, No. 1.

Filek J. (2003), Filozofia odpowiedzialności XX wieku [The $20^{\text {th }}$ century philosophy of responsibility]. "Znak”, Kraków.

Fischer J., Vltavská K. et al. (2016), EUROSTUDENT VI. Základní výsledky šetření postojů a životních podminek studentů vysokých škol v České republice [Basic results of the study 
on the attitudes and life conditions of university students in the Czech Republic]. Ministerstvo školství, mládeže a tělovýchovy, Praha.

Fry H., Ketteridge S., Marshall S. (eds) (2009), A handbook for teaching and learning in higher education enhancing academic practice. Routledge, New York and London.

Gadacz T., Migasiński J. (eds) (2002), Lévinas i inni [Lévinas and others]. UW, Warszawa.

Gaebel M., Zhang T. Bunescu L., Stoeber H. (2018), Trends 2018: Learning and teaching in the European Higher Education Area. European University Association, Brussels.

Gajdzica A., Ogrodzka-Mazur E., Chmura M., Malach J. (2015), Research into students' ICT competences and their use in ICT at selected universities. A Polish- Czech Comparative study. Studia Edukacyjne, No. 36, p. 365-379.

Gałdowa A. (2000), Tożsamość człowieka [Human identity]. UJ, Kraków.

Giddens A. (2001), Nowoczesność $i$ tożsamość. "Ja" i społeczeństwo w epoce późnej nowoczesności [Modernity and Self-Identity. Self and Society in the Late Modern Age]. Wydawnictwo Naukowe PWN, Warszawa.

Gilarek K. (2003), Państwo narodowe a globalizacja - dynamika powstawania nowego ładu [A national state and globalization - the dynamics of the birth of a new order]. Wydawnictwo Adam Marszałek, Torun.

Gofron B. (2013), Konstruktywistyczne ujęcie procesu uczenia się [A constructivist approach to the learning proces]. Periodyk Naukowy Akademii Polonijnej [The Scientific Journal of the Academy of Polish Community Abroad], No. 1 (7).

Goodenough W. H., Harris A. (2006), Description and comparison in cultural anthropology. Aldine Transaction, New Jersey.

Grygierek M. (2001), Tożsamość człowieka a zakorzenienie w rodzimej kulturze [Human identity and the rooting in the native culture]. Rocznik Pedagogiczny [The Pedagogical Yearbook], No. 24.

Grzymała-Kazłowska A. (2013), Ku socjologii mobilnego społeczeństwa? Rozwój nowych koncepcji migracji i integracji a socjologia [Towards sociology of a mobile society? The development of new concepts of migration and integration versus sociology]. Studia Socjologiczne [Sociological Studies], No. 3 (210).

Habermas J. (1993), Obywatelstwo a tożsamość narodowa: rozważania nad przyszłościa Europy [Citizenship and national identity: reflections upon the future of Europe], IFiS PAN, Warszawa.

Halík, T., Dostatni, T. (2011), Smírená různost (rozhovor) [Co-existing diversity (an interview)]. Portál, Praha.

Halverson L.R., Graham C.R. (2019), Learner engagement in blended learning environments: A conceptual framework. Online Learning, Vol 23, No. 2. doi:10.24059/olj.v23i2. 1481.

Hauschildt, K., Vögtle, E., \& Gwosć, C. (2018). Social and Economic Conditions of Student Life in Europe: EUROSTUDENT VI 2016-2018 | Synopsis of Indicators. Bielefeld: German Centre for Higher Education Research and Science Studies (DZHW).

Hewstone M. (1999), Kontakt i kategoryzacja: zmiana stosunków międzygrupowych $\mathrm{w}$ ujęciu psychologii społecznej [Contact and categorization: a change in intergroup relations as approached by social psychology], In: C. N. Macrae, Ch. Stangor, M. Hewstone, Stereotypy i uprzedzenia. Najnowsze ujęcie [Stereotypes and prejudice. The latest approach]. GWP, Gdańsk. 
Hlaváček, K. (2015). Nakolik si vážíme profesí učitel a politik? [How much are the professions of a teacher and a politician appreciated?]. http://ceskapozice.lidovky.cz/forum /nakolik-si-vazime-profesi-ucitel-a-politik.A150802_231141_pozice-forum_lube.

Hogg M. A., Vaughan G. M. (2010), Essentials of social psychology. Frenchs Forest, N.S.W., Pearson Australia.

Holten-Andersen P. (2015), The role of universities in modern societies. CBS Copenhagen Business School. https://www.cbs.dk/en/about-cbs/organisation/senior-management/ news/the-role-of-universities-in-modern-societies.

Hrdličková, L. (2017). Střet generací má v Česku unikátní podobu [The generation clash has a unique form in the Czech Republic]. https://restart.ihned.cz/c1-65743500-stre t-generaci-ma-v-cesku-unikatni-podobu.

Hřebecký, M. (2019). K novele zákona o pedagogických pracovnících [On the ammendment of the act on teachers]. http://www.ceskaskola.cz/2019/01/miroslav-hrebecky-k -novele-zakona-o.html.

http://histecc.kubg.edu.ua/en.

http://weinoe.us.edu.pl.

http://www.irnet.us.edu.pl.

https://pdf.osu.cz.

Chmura, M. (2016). Nezaměstnanost jako ekonomický a sociální problém - edukační východiska $z$ nezaměstnanosti [Unemployment as an economic and social problem - educational ways of rising from unemployment]. Ostravská univerzita, Ostrava.

Chmura M. (2016), Pedagogické vzdělávání akademických pracovníků u nás a v zahraničí komparativní pohled [Pedagogical education of the academic staff at home and abroad - a comparative review]. In: Malach J., Sikorová Z., Sklenářová N., Kocór M. (eds) Vnitřní evaluace kvality výuky v terciárním vzdělávání [Internal evaluation of didactic quality in higher education]. Pedagogicka fakulta Ostravské univerzity, Ostrava.

Chum, S. (2013). Současné generace X, Y a Z - krátké seznámení [The contemporary generations $\mathrm{X}, \mathrm{Y}$ and $\mathrm{Z}$ - an introduction]. https://sebastianchum.blog.idnes.cz/blog .aspx?c=372981.

Jarymowicz M. (1984), Spostrzeganie własnej indywidualności [Perception of the own individuality]. Zakład Narodowy im. Ossolińskich, Wrocław - Warszawa.

Jarymowicz M. (1989), Próba operacjonalizacji pojęć "tożsamość osobista - tożsamość społeczna": odrębność schematowa Ja - My - Inni jako atrybut tożsamości [An attempt to operationalize the notions "personal identity - social identity": the scheme separateness of $\mathrm{Me}$ - Us - Others as an identity attribute]. Studia Psychologiczne [Psychological Studies], Vol. XXVII/2.

Jarymowicz M. (2008), Psychologiczne podstawy podmiotowości: szkice teoretyczne, studia empiryczne [Psychological foundations of subjectivity: theoretical outlines, empirical studies]. Wydawnictwo Naukowe PWN, Warszawa.

Jawłowska A. (ed.) (2001), Wokót problemów tożsamości [Around identity problems]. LTW, Warszawa.

Jestem Czechofilem [I am a Czechophile] https://www.facebook.com/czechofile.

Kaczorowski A. (2007), Praskie łowy [The Prague Hunt]. Świat Książki, Warszawa.

Kaczorowski A. (2012), Praski elementarz [The Prague Primer]. Wydawnictwo Czarne, Wołowiec. 
Kaczorowski, A., (2018), Ota Pavel. Pod powierzchnia [Ota Pavel. Under the Surface]. Wydawnictwo Czarne, Wołowiec.

Kahu E. R. (2013), Framing student engagement in higher education, Studies in Higher Education, Vol 38, Iss 5. DOI: 10.1080/03075079.2011.598505.

Kanasz T. (2015), Uwarunkowania szczęścia. Socjologiczna analiza wyobrażeń młodzieży akademickiej o szczęściu i udanym życiu [The determiners of happiness. A sociological analysis of academic youth's images of happiness and successful life]. APS, Warszawa.

Kandiko C. B., Mawer M. (2013), Student expectations and perceptions of higher education. A study of UK higher education. Kings College, London.

Kapuściński R. (2008), Lapidaria IV-VI. Biblioteka Gazety Wyborczej, Warszawa.

Kasíková H. (2015), Didaktika vysoké školy a teorie učitelského vzdělávání jako zdroj jejího rozvoje [Higher education didactics and the theory of academic teachers' education as a source of their development]. Aula, Vol. 23, No. 1.

Kawiecka E. (2010), Wielokulturowość i tożsamość w świetle problemów współczesnej antropologii społeczno-kulturowej [Multiculturalism and identity in the light of the problems of modern sociocultural anthropology. In: H. Mamzer (ed.), My i oni. Interdyscyplinarne obrazy wielokulturowości [We and they. Interdisciplinary images of multiculturalism]. UAM, Poznań.

Keller, J., \& Hruška Tvrdý, L. (2008). Vzdělanostní společnost?: chrám, výtah a pojištovna [An educational community?: a temple, a lift, and an insurance]. Praha: Sociologické nakladatelství.

Keményová Z. (2017), Výzkum: Jak se cítí vědci v Česku [Research: How scientists feel in the Czech Republic]. Universitas. Magazín vysokých škol, 7. června.

Kempny M. (2001), Globalizacja kultury i ulokalnienie tożsamości? Procesy kulturowe $\mathrm{w}$ teoretycznym dyskursie współczesnej socjologii [The globalization of culture and localization of identity? Cultural processes in the theoretical discourse of modern sociology]. In: A. Jawłowska (ed.), Wokót problemów tożsamości [Around identity problems]. Wydawnictwo LWT, Warszawa.

Kempny M.(2000), Czy globalizacja kulturowa współdecyduje o dynamice społeczeństw postkomunistycznych [Does cultural globalization co-determine the dynamics of postcommunist societies?]. Kultura i Społeczeństwo [Culture and Society], No. 1.

Klemenčič M. (2018), European higher education in 2018. European Journal of Higher Education, 8:4. DOI: 10.1080/21568235.2018.1542238.

Klimstra T. A., Luyckx K., Branje S., Teppers E., Goossens L., Meeus W. H. J. (2013), Personality traits, interpersonal identity and relationship stability: longitudal linkages in late adolescence and young adulthood. Youth Adolescence, Vol. 42, No. 11.

Klus-Stańska D. (2010), Dydaktyka wobec chaosu pojęć i zdarzeń [Didactics in the face of a chaos of notions and events]. Wydawnictwo Akademickie "Żak", Warszawa.

Kłoskowska A. (2002), Kultury narodowe wobec globalizacji a tożsamość jednostki [National cultures in the face of globalization versus an individual's identity]. Kultura i Społeczeństwo [Culture and Society], Vol. 46, No. 2.

Kłoskowska A. (ed) (1990), Oblicza polskości [The faces of Polishness]. UW, Warszawa.

Kłoskowska M. (1996), Kultury narodowe u korzeni [National cultures at their roots]. Wydawnictwo Naukowe PWN, Warszawa. 
Kmošek, P. (2018). Generace X Y Z. Rozumíte generacím? Čím a jak je oslovit? [Generations $\mathrm{X}$ Y Z. Do you understand generations? How to understand them?] Petr Krmošek. http s://www.kmosek.com/generace-x-y-z-rozumite-generacim-cim-a-jak-je-oslovit.

Konarzewski K. (2000), Jak uprawiać badania oświatowe. Metodologia praktyczna [How to conduct educational studies. A practical methodology]. WSiP, Warszawa.

Kolb D. A. (1984), Experiential learning. NJ: Prentice-Hall, Englewood Cliffs.

Kosowska-Rataj J., Nycz E. (eds) (2008), Edukacyjny wymiar tożsamości kulturowej. Raporty $z$ badań [The educational dimension of cultural identity. A research report]. UO, Opole.

Koucký J. (2017), Platy vysokoškolských učitelů jsou ve srovnání se zahraničím velmi nízké. Universitas. Magazin vysokých škol, 30. října.

Krejčí V., Malach, J. (2008), 55 výročí vysokoškolského vzdělávání na Severni Moravě a ve Slezsku [The $55^{\text {th }}$ anniversary of higher education in Northern Moravia and Silesia]. Ostravská Univerzita, Ostrava.

Kvale S. (2004), InterViews. Wprowadzenie do jakościowego wywiadu badawczego [An introduction to the qualitative research interview]. Wydawnictwo Uniwersyteckie "Trans Humana", Białystok.

Kwiatkowska A. (1999), Tożsamość a społeczne kategoryzacje [Identity and social categorizations]. IP PAN, Warszawa.

Kwiek M. (2014), Reformy edukacji wyższej w Republice Czeskiej w obszarze finansowania szkót wyższych [The reforms of higher education in the Czech Republic in the field of financing university-level schools]. IBE, Warszawa.

Kyuchukov H., Lewowicki T., Ogrodzka-Mazur E. (eds) (2015), Intercultural education concepts, practice, problems. LINCOM Academic Publishers, Munich.

Laird M. D., Harvey P., Lancaster J. (2015), Accountability, entitlement, tenure, and satisfaction in Generation Y. Journal of Managerial Psychology, Vol. 30, No. 1.

Laksov K. B. (2018), Lessons learned: towards a framework for integration of theory and practice in academic development. International Journal for Academic Development, Vol. 24, No. 4. DOI: 10.1080/1360144X.2018.1549046.

Langer C, Siembida M. (2018), Wartości preferowane przez studentów edukacji wczesnoszkolnej i wychowania przedszkolnego [The values preferred by students of pre- and early-school education]. Edukacja - Technika - Informatyka /Education - Technology Computer science], No. 4 (26).

Lau J.W.C. (2014), Enriching Stakeholder Theory: Student Identity of Higher Education. American Journal of Industrial and Business Management, 4. http://dx.doi.org/10.423 6/ajibm.2014.412082.

Lévinas E. (2006), Transcendencja i pojmowalność [Transcendence and legibility]. In: K. Michalski (ed.), Człowiek $w$ nauce współczesnej [The human in modern science]. Rozmowy w Castel Gandolfo. "Znak”, Kraków.

Lewowicki T. (1995a), Problemy tożsamości narodowej - w poszukiwaniu sposobów uogólnionych ujęć kwestii poczucia tożsamości i zachowań z tym poczuciem związanych [Problems of national identity - in the search for some generalized approaches to the feeling of national identity and behaviour associated with this feeling]. In: M. M. Urlińska (ed.), Edukacja a tożsamość etniczna [Education versus ethnic identity]. UMK, Toruń. 
Lewowicki T. (1995b), O badaniach społeczności pogranicza - od parcjalnych opisów ku elementom teorii zachowań tożsamościowych [On the research into borderland communities - from partial descriptions towards the elements of the theory of identity behaviours]. In: J. Nikitorowicz (ed.), Edukacja międzykulturowa - w kręgu potrzeb, oczekiwań i stereotypów [Intercultural education - in the circle of needs, expectations and stereotypes]. Wydawnictwo Uniwersyteckie "Trans Humana", Białystok.

Lewowicki T. (2009), Przemiany ustrojowe i kulturowe a poczucie tożsamości i stosunek młodzieży do wybranych kwestii społecznych - dostrzegalne skutki transformacji [Political and cultural transformations versus youth's feeling of identity and attitude to selected social issues - the visible effects of transformations]. In: T. Lewowicki, E. Ogrodzka-Mazur, A. Szczurek-Boruta A. (eds), Poczucie tożsamości $i$ stosunek młodzieży do wybranych kwestii społecznych - studium z pogranicza polsko-czeskiego [Youth's feeling of identity and attitude to selected social issues - a study from the PolishCzech borderland]. Wydział Etnologii i Nauk o Edukacji Uniwersytetu Śląskiego, WSP ZNP w Warszawie, Wydawnictwo Adam Marszałek, Cieszyn - Warszawa - Toruń.

Lewowicki T. (2011), Cztery spojrzenia na wielokulturowość i edukację międzykulturową [Four views on multiculturalism and intercultural education]. In: J. Nikitorowicz, A. Sadowski, D. Misiejuk (eds), Kompetencje do komunikacji międzykulturowej [Intercultural communication competences]. "Pogranicze. Studia Socjologiczne [Borderland. Sociological Studies]”, Vol. XXI, Wydawnictwo Uniwersytetu w Białymstoku, Białystok.

Lewowicki T. (2014), Edukacja międzykulturowa - od lokalnych sukcesów ku globalnym przesłaniom i oddziaływaniom [Intercultural education - from local successes to global messages and influences]. Edukacja Międzykulturowa [Intercultural Education], No. 3.

Lewowicki, T., Szczurek-Boruta A., Szafrańska A. (2017). Sfery życia duchowego dzieci, młodzieży i dorosłych - studium z pogranicza polsko-czeskiego. O nauczycielach, ich spostrzeganiu świata społecznego i aktywności [Spheres of the spiritual life of children, youth and adults - a study from the Polish-Czech borderland. On teachers, their perception of the social life and activities] Vol. 4. Wydział Etnologii i Nauk o Edukacji Uniwersytetu Śląskiego, Wydawnictwo Adam Marszałek, Cieszyn - Toruń.

Lewowicki T., Suchodolska J. (eds) (2000), Rodzina - Wychowanie - Wielokulturowość [Family - Education - Multiculturalism]. UŚ - Filia w Cieszynie, Wyższa Szkoła Pedagogiczna ZNP w Warszawie, Cieszyn.

Lewowicki T., Ogrodzka-Mazur E., Szczurek-Boruta A. (eds) (2009), Poczucie tożsamości i stosunek młodzieży do wybranych kwestii społecznych - studium z pogranicza polskoczeskiego [Youth's feeling of identity and their attitude to selected social issues - a study from the Polish-Czech borderland]. Wydział Etnologii i Nauk o Edukacji Uniwersytetu Śląskiego, WSP ZNP w Warszawie, Wydawnictwo Adam Marszałek, Cieszyn - Warszawa - Torun.

Lewowicki T., Ogrodzka-Mazur E., Szczurek-Boruta A. (eds) (2011), Edukacja międzykulturowa - dokonania, problemy, perspektywy [Intercultural education - accomplishments, problems, prospects]. Wydział Etnologii i Nauk o Edukacji Uniwersytetu Śląskiego, WSP ZNP w Warszawie, Wydawnictwo Adam Marszałek, Cieszyn - Warszawa - Torun.

Lewowicki T., Ogrodzka-Mazur E., Chojnacka-Synaszko B., Klajmon-Lech U. (eds) (2018), Spheres of spiritual life - a study on permanence and changeability of identity behaviours in borderland communities. LINCOM Academic Publishers, Munich. 
Linhart J., Petrusek M., Vodáková A., Maříková H. (1996), Velký sociologický slovník [The great sociological dictionary]. Karolinum, Praha.

Lompart A. (2010), Jednostka zakorzeniona? Wykorzeniona? [A rooted or uprooted individual?] UW, Warszawa.

Lunenburg F. C. (1998), Constructivism and technology: instructional designs for successful education reform. Journal of Instructional Psychology, Vol. 25, No. 2.

Luszniewicz A., Słaby T. (2008), Statystyka z pakietem komputerowym STATISTICA ${ }^{T M}$ PL. Teoria i zastosowania [Statistics with a computer suite STATISTICA ${ }^{T M}$ PL. The theory and applications]. C.H. Beck, Warszawa.

Machaj I. (2017), Walory poznawcze kategorii tożsamości społecznej jednostki. Człowiek i Społeczeństwo, Vol. 44.

Malach J., Kostolányová K., Chmura M., Szafrańska-Gajdzica, A., Ogrodzka-Mazur E. (2015), ICT-supported education at Czech and Polish universities: a comparative study. International Journal of Information and Communication Technology in Education, Vol. 4. No 4.

Malach J., Kostolánová K., Chmura M., Ogrodzka-Mazur E., Szafrańska-Gajdzica A. (2016), Social media at Czech and Polish universities: a comparative study. International Journal of Information and Communication Technologies in Education, Vol. 5, No. 1.

Malach J., Chmura M. (2017), Příprava akademických pracovníků na vzdělávací činnosti ve světle trendů ve výuce a učení na vysokých školách [Preparing academic staff for educational activities in the light of the trends in education of university students]. Slavonic Pedagogical Studies Journal, No. 6 (1).

Malach J., Chmura M. (2018), Profesní kompetence vysokoškolských učitelů z pohledu vysokoškolských učitelů a studentů [Professional competences of academic teachers from the standpoint of academic teachers and students]. In: Malach J., Vicherková D. (eds) Otázky evaluace výuky na vysokých školách [Questions about the evaluation of teaching in higher education]. Pedagogická fakulta Ostravské univerzity, Ostrava.

Malach J., Chmura M. (2019), Development of academic staff competence in the Czech Republic. In: Khoruzha L. (ed.) High School Teacher Competence in Change, Borys Grichenko Kyiv University, Kyiv.

Malach J., Havelková D., Gorčicová V. (2018), Přesvědčení a názory studentů Ostravské univerzity na kvalitu jejich hodnocení [The beliefs and opinions of students from the University of Ostrava concerning the quality of their assessment]. In: Malach J., Vicherková D. (eds) Otázky evaluace výuky na vysokých školách [Questions about the evaluation of teaching in higher education]. Ostravská univerzita Pedagogická fakulta, Ostrava.

Malach J., Kristová K., Valachová, A. (2018), Přesvědčení a názory studentů ostravské univerzity na kvalitu jejich vysokoškolského studia [The beliefs and opinions of students from the University of Ostrava concerning the quality of their studies]. In: Malach J., Vicherková D. (eds) Otázky evaluace výuky na vysokých školách [Questions about the evaluation of teaching in higher education]. Pedagogická fakulta Ostravské univerzity, Ostrava.

Malina A. (2015), Osobowość młodych dorosłych a podejmowanie zadań rozwojowych związanych $\mathrm{z}$ rodziną [Personality of young adults versus undertaking family-related 
developmental tasks]. Polskie Forum Psychologiczne [The Polish Psychological Forum], Vol. 20, No. 4.

Mamzer H. (ed.) (2007), W poszukiwaniu tożsamości. Humanistyczne rozważania interdyscyplinarne [In search for identity. Humanistic interdisciplinary considerations]. UAM, Poznań.

Mariański J. (2019), Religijność młodzieży szkolnej w procesie przemian (1988-2017) [Religiousness of school youth in the process of transformation (1988-2017)]. Edukacja Międzykulturowa [Intercultural Education], No. 1 (10).

Marody M., Giza-Poleszczuk A. (2004), Przemiany więzi społecznej [Transformations of social bonds]. Wydawnictwo Naukowe "Scholar", Warszawa.

Marshall J. (2014), Introduction to comparative and international education. Sage Publications Ltd, Los Angeles - London - New Delhi - Singapore - Washington.

Mazan, L. (2007), Polska Praga, czyli dlaczego Matejko lubit knedle [Poland Prague - or why Matejko liked dumplings]. Oficyna Wydawnicza “Anabasis”, Kraków.

Mądry M. (2010), Plany i marzenia w życiu człowieka. Teoretyczne podstawy badań [Plans and dreans in human life. The thoretical foundations of research]. SCRIPTA COMENIANA LESNENSIA, No. 8.

Melosik Z., Szkudlarek T. (1998), Kultura, tożsamość i edukacja. Migotanie znaczeń [Culture, identity and education. The shimmering of senses]. Oficyna Wydawnicza "Impuls", Kraków.

Miles M. B., Huberman A. M. (2000), Analiza danych jakościowych [An analysis of qualitative data]. Wydawnictwo Uniwersyteckie "Trans Humana", Białystok.

Miluska J. (2005), Problemy integracji europejskich krajów kolektywistycznych i indywidualistycznych: zadania dla edukacji [Problems of the integration between collectivist and individualist countries: tasks for education]. Edukacja Humanistyczna [Humanistic Education], No. 1-2.

Miluska J. (2006a), Społeczno-kulturowe podstawy procesu kształtowania tożsamości we współczesnym świecie [Sociocultural foundations of the identity shaping process in the contemporary world]. Przeglad Zachodni [The Western Review], R. 62, No. 4.

Miluska J. (2006b), Tożsamość społeczna - bariera czy pomoc w kształtowaniu pozytywnych relacji międzykulturowych? [Social identity - a barrier or aid in shaping posiyive intercultural relations?\} In: T. Lewowicki, A. Szczurek-Boruta, E. OgrodzkaMazur (eds), Teorie i modele badań międzykulturowych [Theories and models of intercultural studies]. UŚ, Wyższa Szkoła Pedagogiczna ZNP w Warszawie, Cieszyn Warszawa.

Ministerstvo práce a sociálních věcí. (2013) [Ministry of Labour and Social Affairs. (2013)]. Praha. https://www.mpsv.cz/cs/15729.

Ministerstvo průmyslu a obchodu. (2011) [Ministry of Industry and Trade. (2011)]. http s://www.businessinfo.cz/cs/clanky/smk-reforma-vysokeho-skolstvi-7304.html.

Minksová L. (2010), Vysokoškoláci - přehled hlavních sociologických výzkumů realizovaných v ČR [University students - a review of major sociological studies conducted in the Czech Republic]. Data a výzkum-SDA Info 2010, Vol. 4, No. 1.

Moustakas C. (2001), Fenomenologiczne metody badań [Phenomenological research methods]. Wydawnictwo Uniwersyteckie "Trans Humana", Białystok 2001.

Nantl J. (2014), Český rámec kvalifikací [The Czech qualification framework]. Národní ústav pro vzdělávání, Praha. 
Nikitorowicz J. (2003), Typy tożsamości człowieka w społeczeństwie zróżnicowanym kulturowo [Types of human identity in the culturally diversified society]. Chowanna, Vol. 1 (20).

Nikitorowicz J. (2005), Kreowanie tożsamości dziecka. Wyzwania edukacji międzykulturowej [Creating the child's identity. Challenges for intercultural education]. GWP, Gdańsk.

Nikitorowicz J. (2009), Edukacja regionalna i międzykulturowa [Regional and inyercultural education]. WAiP, Warszawa.

Nikitorowicz J. (2013), Tożsamość - twórczy wysiłek ku patriotyzmowi [Identity - a creative effort towards patriotism]. In: J. Nikitorowicz (ed.), Patriotyzm i nacjonalizm. Ku jakiej tożsamości kulturowej? [Patriotism and nationalism. Towards which cultural identity?] Oficyna Wydawnicza "Impuls", Kraków.

Nikitorowicz J. (2017), Etnopedagogika w kontekście wielokulturowości i ustawicznie kształtujacej się tożsamości [Ethnopedagogy in the context of multiculturalism and constantly-shaped identity] . Oficyna Wydawnicza "Impuls", Kraków.

Noah H. J., Eckstein M. A. (1988), Dependency theory in comparative education: twelve lessons from the literature. In: J. Schriewer, B. Holmes (eds), Theories and methods in comparative education. Peter Lang Publishers, Frankfurt am Main.

Nowicka E. (1992), Elementy tożsamości społecznej polskiej młodzieży [Elements of social identity of Polish youth]. Kultura i Społeczeństwo [Culture and Society], No 4.

Norton A., Cherastidtham I. (2018), Mapping Australian higher education 2018. https://úg rattan.edu.au/report/mapping-austalian-higher-education-2018/.

OECD (2019), OECD Multilingual Summaries. TALIS 2018 Results (Volume I). Teachers and School Leaders as Lifelong Learners. https://read.oecd-ilibrary.org/education/talis-201 8-results-volume-i/summary/english_0d310598-en\#page1.

OECD (2018a), Education at a Glance 2018: OECD Indicators, OECD Publishing, Paris. OECD (2018b), "Czech Republic" in Education at a Glance 2018: OECD Indicators, OECD Publishing, Paris. DOI: https://doi.org/10.1787/eag-2018-42-en.

OECD (2017), Benchmarking higher education system performance: Conceptual framework and data, Enhancing Higher Education System Performance. OECD Publishing, Paris.

OECD (2013), Assessment of Higher Education Learning Outcomes AHELO: Feasibility Study Report: Volume 2 Data Analysis and National Experiences, OECD, Paris.

Ogrodzka-Mazur E. (2001), Kategoria tożsamości w analizach zmiany społecznej. Implikacje pedagogiczne do badań edukacji międzykulturowej [Category of identity in the analyses of social change. Pedagogical implications for studies on intercultural education]. In: T. Lewowicki, E. Ogrodzka-Mazur (eds), W poszukiwaniu teorii przydatnych w badaniach międzykulturowych [In search for theories useful in intercultural studies]. UŚ - Filia w Cieszynie, Cieszyn.

Ogrodzka-Mazur E. (2007), Kompetencja aksjologiczna dzieci w młodszym wieku szkolnym. Studium porównawcze środowisk zróżnicowanych kulturowo [Axiological competence of children at early school age. A comparative study of culturally differentiated environments]. UŚ, Katowice.

Ogrodzka-Mazur E. (2011), Rodzina i dziecko w otoczeniu wielokulturowym. Relacje międzypokoleniowe i ich rola w przekazie wartości [The family and child in the multicultural envronment. Cross-generation relations and their role in the transmission of values]. In: T. Lewowicki, E. Ogrodzka-Mazur, A. Szczurek-Boruta (eds), Edukacja 
międzykulturowa - dokonania, problemy, perspektywy [Intercultural education - accomplishments, problems, prospects]. Wydział Etnologii i Nauk o Edukacji Uniwersytetu Śląskiego, Wyższa Szkoła Pedagogiczna ZNP w Warszawie, Wydawnictwo Adam Marszałek, Cieszyn - Warszawa - Toruń.

Ogrodzka-Mazur E. (2013), (Nie)obecność patriotyzmu w świadomości aksjologicznej młodego pokolenia Polaków - "przesuwanie się horyzontu aksjologicznego" czy kryzys $\mathrm{w}$ wartościowaniu? [(Non-)existence of patriotism in the axiological awareness of young Poles - a "shifting axiological horizon" or a crisis in valueing?] In: J. Nikitorowicz (ed.), Patriotyzm i nacjonalizm. Ku jakiej tożsamości kulturowej? [Patriotism and nationalism. Towards which cultural identity?] Oficyna Wydawnicza "Impuls", Kraków.

Ogrodzka-Mazur E., Szafrańska A., Chmura M., Malach J. (2015), Research into students' ICT competencies and their use in ICT at selected universities. A Polish - Czech comparative study. Studia Edukacyjne [Educational Studies], No. 36.

Ogrodzka-Mazur E., Grabowska B., Szafrańska-Gajdzica A., Kwadrans Ł. (2016), Education of children and youth in culturally diverse environments: experiences - problems prospects. Lincom Academic Publishers, Munich.

Ogrodzka-Mazur E., Szafrańska-Gajdzica A. (2016), The diagnosis of ICT and intercultural competences of pedagogy students. A Polish - Czech comparative study. In: J. Malach, I. Červenková, M. Chmura (eds), Pokroky v hodnocení klícových kompetencí [The progress in the evaluation of key competences]. Ostravská univerzita, Ostrava.

Ogrodzka-Mazur E. (2016), Wartości cenione przez uczniów z pogranicza polsko-czeskiego [Values appreciated by learners from the Polish-Czech borderland]. In: T. Lewowicki, E. Ogrodzka-Mazur, A. Minczanowska, G. Piechaczek-Ogierman: Sfery życia duchowego dzieci i młodzieży z pogranicza polsko-czeskiego [Spheres of the spiritual life of children and youth from the Polish-Czech borderland]. Vol. 1. Przemiany wartości i aspiracji zyciowych [Transformations of values and life aspirations]. Wydział Etnologii i Nauk o Edukacji Uniwersytetu Śląskiego, Wydawnictwo Adam Marszałek, Cieszyn - Toruń.

Ogrodzka-Mazur E. (2017), The realization and fulfillment of life aspirations by children and youth from the Polish-Czech borderland. The New Educational Review, Vol. 47, No. 1.

Ogrodzka-Mazur E., Szafrańska A., Malach J., Chmura M. (2018a), Stimulating the learning of Polish and Czech students with the use of e-learning resources. Studia Edukacyjne [Educational Studies], No. 48.

Ogrodzka-Mazur E., Szafrańska A., Malach J., Chmura M. (2018b), Supporting the Learning of Polish and Czech Students by Digital Tools. The New Educational Review, Vol. 51, No. 1.

Ogrodzka-Mazur E., Szafrańska A., Malach J., Chmura M. (2017), The Use of E-learning Resources by Academic Teachers - a Polish-Czech Comparative Study. The New Educational Review, Vol. 50, No 4.

Oleś P. K. (2012a), Tożsamość osobista i społeczna - płynna czy określona? [Personal and social identity - liquid or defined?] In: W. Łukaszewski, D. Doliński, A. Fila-Jankowska, T. Maruszewski, A. Niedźwieńska, P. Oleś, T. Szkudlarek, Tożsamość. Trudne pytanie kim jestem [Identity. Difficult questions on who I am]. Smak Słowa, Sopot.

Oleś P. K. (2012b), Psychologia człowieka dorosłego [Psychology of an adult]. Wydawnictwo Naukowe PWN, Warszawa. 
O'Neill G. (2015), Curriculum Design in Higher Education: Theory to Practice, Dublin: UCD Teaching \& Learning. http://www.ucd.ie/t4cms/UCDTLP0068.pdf.

Ondrejkovič P. (2004), Socializácia v sociológii výchovy [Socialization in sociology of education]. Veda, Bratislava.

Ostravská univerzita. (2019). https://www.osu.cz/23601/ostravska-univerzita-se-zaradilamezi-nejprestiznejsi-vedecke-instituce-v-evrope.

Ostravská univerzita: Studium a stáže v zahraničí. (2018) [Foreign studies and internships. (2018)]. https://www.osu.cz/studium-a-staz-v-zahranici/.

Paleczny T. (2017), Procesy asymilacji, transkulturacji i uniwersalizacji kulturowej: przegląd problematyki [Processes of assimilation, transculturation and cultural universalization: an overview]. Krakowskie Studia Międzynarodowe [Cracow International Studies], No. 3.

Panic I. (ed) (2009-2015), Dzieje Śląska Cieszyńskiego od zarania do czasów współczesnych [The history of Cieszyn Silesia from the dawn to modern times], Vol. 1-8. Starostwo Powiatowe w Cieszynie, Cieszyn.

Perez-Poch A., Domingo J., Sanz M., López, D. (2018), University teaching culture. In: Carrasco, S., de Corral, I. (eds) University teaching and innovation. Evolution and challenges through the CIDUI. Sectretaria Tècnica CIDUI- Associació Catalana d'Universitats Públiques, Barcelona.

Pietruska-Madej E. (1995), Pragmatyczne i apragmatyczne aspekty odkrycia naukowego [Pragmatic and non-pragmatic aspects of scientific discovery]. Filozofia Nauki [Philosophy of Science], No. 3-4.

Piotrowski K. (2010), Wkraczanie $w$ dorosłość. Tożsamość i poczucie dorosłości młodych osób z ograniczeniami sprawności [Stepping into adulthood. The identity and feeling of adulthood of young people with limited abilities]. Wydawnictwo Naukowe "Scholar", Warszawa.

Podlahová L. a kol. (2012), Didaktika pro vysokoškolské učitele [Didactics for academic teachers]. Grada, Praha.

Prestiž povolání 2019 [Prestige of professions 2019]. (2019) https://cvvm.soc.cas.cz/media /com_form2content/documents/c2/a4986/f9/eu190724.pdf.

Prudký, L., Pabian, P., \& Šima, K. (2010). České vysoké školství: na cestě od elitního k univerzálnímu vzděláváni 1989-2009 [Czech higher education: on the way from elite to common education 1989-2009]. Praha: Grada.

Průcha, J., \& Mareš, J. (2013). Pedagogický slovník [A pedagogical dictionary]. Portál, Praha.

Průcha J., Walterová E., Mareš J. (2008), Pedagogický slovník [A pedagogical dictionary]. Portál, Praha.

Ratajczak, M. (2017). Polacy wciąż chcą szukać szczęścia za granicą. 2,8 mln rodaków myśli o emigracji zarobkowej [Poles still want to seek happiness abroad. 2.8 million compatriots think about economic emigration] [Online].

Reber A. S. (2000), Słownik psychologii [A dictionary of psychology]. Wydawnictwo Naukowe "Scholar", Warszawa.

Rembierz M. (2008a), Refleksja moralna nad odpowiedzialnością i etosem filozofa w XX wieku [Moral reflection upon the responsibility and ethos of a philosopher in the $20^{\text {th }}$ century]. In: Z. Plašienkowá, M. Rembierz (eds), Człowiek w społeczeństwie [A human 
in the society]. Vol. 1. Społeczeństwo - kultura - moralność [Society-culture - morality]. ATH, Bielsko-Biała.

Rembierz M. (2008b), Współczesne procesy integracji a paradoksy tożsamości europejskiej [Contemporary integration processes versus paradoxes of the European identity]. Bielsko-Bialskie Studia Europejskie [Bielsko-Biała European Studies], No. 2 (6).

Report to the European Commission on New modes of learning and teaching in higher education (2014). Publications Office of the European Union, Luxembourg.

Robertson R. (1992), Globalization. Social theory and global culture. SAGE Publications, London.

Rocznik Statystyczny Rzeczypospolitej Polskiej [Statistical Yearbook of the Republic of Poland] (2018). GUS, Zakład Wydawnictw Statystycznych, Warszawa.

Rocznik Statystyki Międzynarodowej [International Statistics Yearbook] (2018). GUS, Zakład Wydawnictw Statystycznych, Warszawa.

Rohlíková L., Vejvodová J. (2012), Vyučovací metody na vysoké škole [Teaching methods in higher education]. Grada, Praha.

Rószkiewicz M., Węziak-Białowolska D. (eds) (2013), Projektowanie badań społecznoekonomicznych. Rekomendacje i praktyka badawcza [Designing socio-economic studies. Recommendations and research practice]. PWN, Warszawa.

Różańska A. (2015), Edukacja religijna młodzieży w warunkach pluralizmu religijnego w wybranych krajach Europy Środkowo-Wschodniej (Grupa Wyszehradzka: Polska, Czechy, Stowacja, Wegry) - studium porównawcze [Religious education of youth in the conditions of religious pluralism in selected countries of Central and Eastern Europe (Visegrad group: Poland, Czech Republic, Slovakia, Hungary) - a comparative study]. Wydział Etnologii i Nauk o Edukacji Uniwersytetu Śląskiego w Katowicach, Wydawnictwo Adam Marszałek, Cieszyn - Toruń.

Różańska A. (2019), (A)religijność po czesku - ateizm, analfabetyzm religijny czy coś więcej? [(Non-)religiousness in the Czech way - atheism, religious illiteracy or something more? Edukacja Międzykulturowa [Intercultural Education], No 1 (10).

Sajdak A. (2013), Paradygmaty kształcenia studentów i wspierania rozwoju nauczycieli akademickich. Teoretyczne podstawy dydaktyki akademickiej [Paradigms of teaching university students and supporting the development of academic teachers. Theoretical foundations of academic didactics]. Oficyna Wydawnicza "Impuls", Kraków.

Sak, P., \& Mareš, J. (2007). Člověk a vzdělání v informační společnosti [The human and education in the information society]. Portál, Praha.

Sárközi, R. (2019). Možná se zavřou i pedagogické fakulty [Educational faculties can be shut down as well]. http://www.ceskaskola.cz/2019/01/radek-sarkozi-k-novele-zakona -o.html.

Shewbridge, C., Herczdyński, J., Radinger, T., Sonnemann, J. (2016), OECD Reviews of School Resources: Czech Republic 2016. OECD Publishing, Paris.

Sikorová Z., Biolek M., Červenková I., Sklenářová N., Světlák M. (2007), Praktické problémy vysokoškolské výuky [Practical problems with teaching in higher education]. Vysoká škola báňská - Technická univerzita, Ostrava.

Sikorová Z:; Malach J. (2014), Užívání studijních materiálů a př́ístupy k učení u studentů učitelství [The use of learning materials and methods by students - future teachers]. In: Malach J., Sikorová Z. (eds) Pedagogická diagnostika a profese učitele [Pedagogical diagnostics and the teacher's profession]. Ostravská univerzita, Ostrava. 
Şimşek Ö.F. (2009), Happiness revisited: ontological well-being as a theory-based construct of subjective well-being. Journal of Happiness Studies, No. 10 (5).

Shapiro B. L. (1994), What children bring to light. A constructivism perspective on children's learning in science. Teachers College Press, New York.

Skalne miasto oblegane przez Polaków... [The rocky city besieged by Poles...] http://natema t.pl/237239,skalne-miasto-polacy-oblegaja-czeska-policja-zamyka-przejscie-graniczne.

Slavík, M., a kol. (2012). Vysokoškolská pedagogika [Pedagogy of higher education]. Grada, Praha.

Smak M., Walczak D. (2015), Pozycja społeczno-zawodowa nauczycieli. Raport $z$ badania jakościowego [The socio-professional position of teachers. A report from a qualitative study]. Instytut Badań Edukacyjnych, Warszawa.

Standards and Guidelines for Quality Assurance in the European Higher Education Area (ESG). (2015). European Association of Institutions for Higher Education, Brussels.

Stańczak J. (ed.) (2018), Sytuacja demograficzna Polski do 2017 r. Urodzenia i dzietność [The demographic situation of Poland until 2017. Births and having children]. GUS, Zakład Wydawnictw Statystycznych, Warszawa.

Stark J.S. (2000), Planning introductory college courses: Content, context and form. Instructional Science, Vol. 28, Iss. 5.

Staś-Romanowska M. (2004), Aksjologiczne konotacje zjawiska tożsamości Ja [Axiological connotations of Ego-identity]. In: A. Szerląg (ed.), Edukacja ku wartościom [Education to values]. Oficyna Wydawnicza "Impuls", Kraków.

Statistical Yearbook of the Czech Republic (2018), https://www.czso.cz/csu/czso/statistical -yearbook-of-the-czech-republic-2018.

Stephan W. G., Stephan C. W. (1999), Wywieranie wplywu przez grupy. Psychologia relacji [Impact of groups. Psychology of relations]. GWP, Gdańsk.

Stosunek do innych narodów [The attitude to other nations]. Komunikat $\mathrm{z}$ badań CBOS No 21/2017. https://www.cbos.pl/SPISKOM.POL/2017/K_021_17.PDF.

Stosunek do innych narodów [The attitude to other nations]. Komunikat $\mathrm{z}$ badań CBOS No 37/2018. https://www.cbos.pl/SPISKOM.POL/2018/K_037_18.PDF.

Stosunek Polaków do innych narodów [The attitude of Poles to other nations]. Komunikat $\mathrm{z}$ badań CBOS 20/2014. https://www.cbos.pl/SPISKOM.POL/2014/K_020_14.PDF.

Stosunek Polaków do innych narodów [The attitude of Poles to other nations]. . Komunikat z badań CBOS BS. 13/2011. https://www.cbos.pl/SPISKOM.POL/2011/K_013_11.PDF.

Strelau J., Doliński D. (eds) (2008), Psychologia. Podręcznik akademicki [Psychology. An academic handbook]. Vol. 2. GWP, Gdańsk.

Strózik T. (2014), System wartości a ocena jakości życia młodzieży akademickiej w świetle badań ankietowych studentów uczelni Poznania [The system of values versus the evaluation of academic youth's quality of life in the light of a questionnaire studies among students of universities in Poznań]. STUDIA OECONOMICA POSNANIENSIA, Vol. 2, No. 2 (263).

Suchodolska J. (2017), Poczucie jakości życia młodych doroslych: na przykładzie studenckiej społeczności akademickiej [Young adults' feeling of the quality of life: the case of students' academic community]. Wydawnictwo Adam Marszałek, Torun.

Sundberg C., Heerens N., Koppel K. (eds) (2018), Bologna with student eyes. The final countdown. European Students' Union, Brussels. 
Surosz, M. (2010). Pepiki. Dramatyczne stulecie Czechów [“Pepiki”. A dramatic century for Czechs]. Wydawnictwo W.A.B., Warszawa.

Szafrańska, A. (2017 a), Pogranicze polsko-czeskie jako przestrzeń budowania współpracy transgranicznej z perspektywy nauczycieli [The Polish-Czech borderland as a space for building trans-frontier collaboration from teachers' perspective]. Edukacja Międzykulturowa [Intercultural Education], No. 1 (6).

Szafrańska, A. (2017 b), Tak dalecy czy/i tak bliscy? Obraz Czechów w percepcji polskich nauczycieli [So distant or/and so close? The image of Czechs as perceived by Polish teachers]. Rocznik Lubelski [The Lublin Yearbook], No. 3.

Szafrańska, A. (2018 a), Od zaangażowanego uczestnictwa do biernego krytykanctwa. Aktywność nauczycieli mieszkających na pograniczu polsko-czeskim $\mathrm{w}$ działania transgraniczne a ich ocena polityków i organizacji podejmujących inicjatywy na rzecz współpracy $\mathrm{Pl}-\mathrm{Cz}$ [From committed participation to passive criticism. The engagement of teachers living in the Polish-Czech borderland in trans-frontier activities versus their evaluation of the politicians and organizations undertaking initiatives for PL-CZ collaboration]. Kultura i Edukacja [Culture and Education], No. 3.

Szafrańska, A. (2018 b), (Nie)Wiedza nauczycieli mieszkających na pograniczu polskoczeskim o swoich sasiadach [(Lack of) Knowledge of teachers living in the Polish-Czech borderland concerning their neighbours]. Edukacja Międzykulturowa [Intercultural Education], No. 2 (9).

Szczurek-Boruta A., Grabowska B. (2009), Dynamika kształtowania się tożsamości młodzieży - ku tożsamości wzbogaconej [The dynamics of shaping youth's identity towards the enriched identity]. In: T. Lewowicki, E. Ogrodzka-Mazur, A. SzczurekBoruta A. (eds), Poczucie tożsamości i stosunek młodzieży do wybranych kwestii społecznych - studium z pogranicza polsko-czeskiego [Youth's feeling of identity and their attitude to selected social issues - a study from the Polish-Czech borderland]. Wydział Etnologii i Nauk o Edukacji Uniwersytetu Śląskiego, WSP ZNP w Warszawie, Wydawnictwo Adam Marszałek, Cieszyn - Warszawa - Toruń.

Szczygieł M. (2006), Gottland. Wydawnictwo Czarne, Wołowiec.

Szczygieł M. (2010), Zrób sobie raj [Make a paradise yourself]. Wydawnictwo Czarne, Wołowiec.

Szczygieł M. (2012), Láska nebeská [Love actually]. Wydawnictwo Agora S.A., Warszawa.

Szkołut T. (2003), Paradoksy globalizacji a tożsamość kulturalna narodu [Paradoxes of globalization and the nation's cultural identity]. In: A. L. Zachariasz (ed.), Narody słowianskie wobec globalizacji [Slavic nationalities in the face of globalization]. URz, Rzeszów.

Szplit A. (2017), Inquiry-based Continuing Professional Development for University Teachers: Polish Initiatives and Concerns. In: Boyd, P., Szplit A. (eds). Teachers and teacher educators learning through inquiry: international perspectives. Wydawnictwo Attyka, Kraków.

Szymański M. J. (2016), Kim jestem? Tożsamość jako zadanie w czasach gwałtownej zmiany społecznej [Who am I? Identity as a task in the times of rapid social change]. Lubelski Rocznik Pedagogiczny [Lublin Pedagogical Yearbook], Vol. 35, No. 1.

Śliwerski B. (2008), Uniwersalizm jako metanarracja alternatywnego myślenia w/o edukacji (na przykładzie wybranych współczesnych koncepcji pedagogicznych) [Universalism as meta-narration of alternative thinking in/of education (the cases of selected modern 
pedagogical theories)]. In: E. Dubas, H. M. Griese, M. Dzięgielewska (eds), Uniwersalia $w$ międzykulturowym porównaniu. Studium polsko-niemieckie [Universalia in an intercultural comparison. A Polish-German study]. UŁ, Łódź.

Tertiary Education Quality and Standards Agency (2019), Key risk findings on Australia's higher educaction sector. TEQSA, Melbourne.

Universities UK (2018), Universities staff prioritized in EU settlement scheme. 11 October 2018. https://www.universitiesuk.ac.uk/news/Pages/University-staff-prioritised-in-EUsettlement-scheme.aspx.

Urbański-Korż R. (1998), Wartości wychowawcze w perspektywie recentywistycznej [Educational values in the recentivistic perspective]. Teraźniejszość - Człowiek - Edukacja [Present time - Humanity - Education], No. 3.

Vasta E. (2007), Accommodating diversity: why current critiques of multi-culturalism miss the point. University of Oxford, Oxford.

Vašutová, J. (2004). Profese učitele v českém vzdělávacím kontextu [The teacher's profession in the Czech educational context]. Paido, Brno.

Vašutová, J. (2007). Být učitelem: co by měl učitel vědèt o své profesi [To be a teacher: what a teacher should know about their profession]. Univerzita Karlova v Praze, Pedagogická fakulta, Praha.

Weidnerová S. (2017), Tvorba profesně orientovaných studijních programů ve spolupráci s průmyslovou praxí [Designing vocationally oriented university curricula in collaboration with industrial practice]. Veletrh Véda Výzkum Inovace dne 1.3.2017. http://vvvi. cz/konference/prezentace/Simona_Weidnerova.pdf.

Welsch W. (2004), Tożsamość w epoce globalizacji - perspektywa transkulturowa [Identity in the globalization era - a transcultural perspective]. In: K. Wilkoszewska (ed.), Estetyka transkulturowa [Transcultural aesthetics]. "Universitas”, Kraków.

Węziak-Białowolska D. (2013), Model kapitału intelektualnego regionu. Koncepcja pomiaru $i$ jej zastosowanie [A model of the intellectual capital of the region. A concept of measurement and its applications]. Szkoła Główna Handlowa w Warszawie, Warszawa.

Veteška, J. (2010). Kompetence ve vzdělávání dospělých: pedagogické, andragogické a sociálni aspekty. [Competences in adults' education: the pedagogical, andragogical and social aspects]. Univerzita Jana Amose Komenského, Praha.

Vláda České republiky. (2019). Euroskop. [Euroskop Portal] Praha: Vláda České republiky. Retrieved from https://www.euroskop.cz/609/sekce/prace-pri-studiu-v-zahranici.

Výroční zpráva o činnosti 2018: [Annual activity report 2018] Ostravská univerzita. (2018). Ostrava. https://dokumenty.osu.cz/rektorat/vz/zprava2018.pdf.

Výroční zpráva o stavu a rozvoji vzdělávánív České republice v roce 2017: Vzdělávání v roce $2017 v$ datech. [Annual report on the condition and development of education in the Czech Republic in 2017: Education in 2017 in data] (2018). Praha: Ministerstvo školství, mládeže a tělovýchovy České republiky.

Widdowson D. A.; Dixon R. S.; Peterson E. R.; Rubie-Davies Ch. M.; Irving, S. E. (2015), Why Go to School? Student, Parent and Teacher Beliefs about the Purposes of Schooling. Asia Pacific Journal of Education, Vol. 3, No. 4.

Witkowski L. (1988), Tożsamość i zmiana [Identity and change]. UMK, Torun.

Wojnar I. (1998), Światowa dekada rozwoju kulturalnego - nowe propozycje dla edukacji [The world decade of cultural development - new suggestions for education]. In: 
I. Wojnar, J. Kubin (eds), Edukacja wobec wyzwañ XXI wieku [Education in the face of the $21^{\text {st }}$ century challenges]. Dom Wydawniczy "Elipsa", Warszawa.

Wolff R. (2015), World future society. [on-line], http://documentslide.com/document $\mathrm{s} / 10$-trends-affecting-the-future-of-highereducation-ralph-wolff-president-and-execut ive-director-senior-college-commissionwasc-world-future-society.html.

Wroczyńska, A. (2013) Oczekiwania współczesnych studentów wobec uczelni wyższych prezentacja wyników prowadzonych badań [Expectations of contemporary students from universities - a presentation of the conducted research]. Studia BAS, No. 3(35).

World University Rankings. (2019). https://www.timeshighereducation.com/world-unive rsity-rankings/2019/world-ranking\#!/page/0/length/25/locations/PL/sort_by/rank/sor t_order/asc/cols/stats.

Wysocka E. (2003), Akulturacja [Acculturation]. In: T. Pilch (ed.), Encyklopedia pedagogiczna XXI wieku [Pedagogical Encyclopaedia of the $21^{\text {st }}$ century], Vol. 1. Wydawnictwo Akademickie "Żak”, Warszawa.

Wysocka E. (2013), Wschodząca dorosłość a tożsamość młodego pokolenia - współczesne zagrożenia dla kształtowania tożsamości. Analiza teoretyczna i empiryczne egzemplifikacje [Emerging adulthood versus the identity of the young generation - contemporary threats to identity forming. A theoretical analysis and empirical exemplifications]. Colloquium Wydziału Nauk Humanistycznych i Społecznych [A Colloquium of the Faculty of Humanistic and Social Sciences], No. 1.

Zagórski K., Strzeszewski M. (eds) (2005), Polska, Europa, Świat. Opinia publiczna $w$ okresie integracji [Poland, Europe, World. The public opinion in the period of integration]. Wydawnictwo Naukowe "Scholar" - CBOS, Warszawa.

Ziółkowska B. (2005), Okres wczesnej dorosłości. Jak rozpoznać potencjał młodych dorosłych? [The period of early adulthood. How to recognize the potentialities of young adults?] In: A. I. Brzezińska (ed.), Psychologiczne portrety człowieka. Praktyczna psychologia rozwojowa [Psychological portraits of a human. Practical developmental psychology]. GWP, Gdańsk.

Żardecka-Nowak M., Nowak W. M. (eds) (2004), Tożsamość indywidualna i zbiorowa. Szkice filozoficzne [Individual and group identity. Philosophical outlines]. URz, Rzeszów.

Žydžiūnaitė V., Crisafulli S. (2013), Interakce mezi vysokoškolskými studenty a vyučujícími jako nástroj rozvoje profesní identity studentů [The interaction between students and academic teachers as a tool for developing students' professional identity]. AULA, Vol 21, No 1. 
Open-Access-Publikation im Sinne der CC-Lizenz BY 4.0

(c) 2021, Vandenhoeck \& Ruprecht GmbH \& Co. KG, Göttingen ISBN Print: 9783847112549 - ISBN E-Lib: 9783737012546 


\section{Summary}

The issues of the communities living in borderlands, mostly in the Polish-Czech borderland, have been explored in many studies prepared by the Social Team for the Research into Borderland Culture and Education, functioning at the Faculty of Ethnology and Education of the University of Silesia (located in Cieszyn), as well as the Pedagogical Faculty of the University of Ostrava. All of them constitute a recording of the important political, social, economic, and cultural changes which have taken place in Poland and the Czech Republic since 1989. The multisided transformation occurring over the last three decades has also resulted in some changes in the thinking about the role and function of culture and education. The reforms undertaken in both countries, also in the field of higher education, are reflected in the current social and cultural condition of the younger generation and they affect the aims, values and life aspirations of the young.

The contemporary generation of university-aged Poles and Czechs is a new generation, different from the earlier generations of their peers. University students do not share a common world view, axiology, or communication code (as did, for example, their predecessors who lived in the post-war or immediate postcommunist years). It is a generation of growing diversity in their attitudes and value assessments - they appear to be slightly lost, reflective, and often focused on their own existence.

The observed processes of change and their relative dynamics made the authors of this book undertake - in 2018 - some comparative studies on the cultural identity and education of university students. The research comprised 330 university students - 164 in Poland (Cieszyn) and 166 in the Czech Republic (Ostrava). The research sample is representative for students of pedagogy, educated in the University of Silesia and the University of Ostrava.

The first chapter, entitled The cultural identity of university students - individual and community resources in building the borderland capital, contains an outline of the major determinants of identity formed in the period of early adulthood, as well as the results of authors' own studies on identity behaviours 
manifested by students from the Polish-Czech borderland. They were approached from the perspective of axiological preferences, the declared feeling of identity and national identification, the feeling of attachment to some selected social groups, and the relationship between the assessment of one's own life situation and one's feeling of identity.

Geographical closeness does not always mean a willingness to familiarize or even to be interested in who or what is near. This seems to be confirmed by the analyses of the obtained research results, which are presented in the second chapter A difficult history - what about the present day? Borderland relationships in the declarations of the surveyed students. Students living in the borderland, in a culturally diversified environment, are very often unable to assess their intercultural competences. Yet, they are aware of the differentiation of the environment in which they function. In this chapter, the data are presented concerning the way in which the neighbours and nationally mixed marriages are perceived. The manifestations of discriminating behaviour observed by the respondents have been also described.

In the third chapter, entitled Pathways to higher education and its value, the university is dealt with as an institution consisting of people and the research results are presented, concerning the relationship between university students and academic teachers, the quality of life of young adults studying at university, and the developmental conditions offered by universities. The research results are presented which pertain to students' opinion on the development of the theoretical knowledge and practical skills acquired by students during their university studies, and their influence on the students' future professional career. Furthermore, the results of the studies on the quality of education in universities - an interesting and often discussed issue is also shown and analyzed.

The last chapter University students studying and working abroad, their field of study and the university comprises the analyses of the data concerning the attitudes of students from the investigated countries to studying and working abroad. The factors which motivate the respondents have been described and the barriers or limits in this field have also been indicated. Moreover, students' opinions concerning teaching qualifications and the respondents' view on the attractiveness of their academic course (also the ranking of universities) and their professional prospects have also been considered.

The research results presented in the book broaden the existing pedagogical knowledge and may be used by the organisers of education in their reflection upon the functioning of the institutions which educate university-aged students. They can be also applied in designing the developmental plans of such institutions in the context of adjusting them to the social needs of all participants of education (respecting the right to the preservation of one's own culture and identity). In the practical dimension, the obtained results can become an im- 
portant reference point for social and educational politicians who search for new solutions in the organization of higher educational institutions in many countries. 
Open-Access-Publikation im Sinne der CC-Lizenz BY 4.0

(c) 2021, Vandenhoeck \& Ruprecht GmbH \& Co. KG, Göttingen ISBN Print: 9783847112549 - ISBN E-Lib: 9783737012546 


\section{Streszczenie}

Sprawom społeczności żyjących w regionach pogranicznych, a przede wszystkim pogranicza polsko-czeskiego, poświęcono wiele prac przygotowanych zarówno przez Społeczny Zespół Badań Kultury i Oświaty Pogranicza, funkcjonujący na Wydziale Sztuki i Nauk o Edukacji Uniwersytetu Śląskiego w Cieszynie, jak i pracowników Wydziału Pedagogicznego Uniwersytetu Ostrawskiego. Są one zapisem ważnych zmian politycznych, społeczno-gospodarczych i kulturowych zachodzących w Polsce i Republice Czeskiej po 1989 roku. Dokonująca się $\mathrm{w}$ ciaggu ostatnich trzydziestu lat wielopłaszczyznowa transformacja spowodowała również zmiany w myśleniu o roli i funkcji kultury i edukacji. Podjęte $\mathrm{w}$ obu krajach reformy m.in. w zakresie szkolnictwa wyższego znajdują odzwierciedlenie w aktualnej kondycji społecznej i kulturowej młodego pokolenia, jak również przekładają się na jego cele, wartości i aspiracje życiowe.

Współczesne młode pokolenie dorosłych Polaków i Czechów jest nową generacją, inną od wcześniejszych pokoleń swoich rówieśników. Młodzież akademicką nie łączy już ( jak to miało miejsce w latach np. powojennych czy pokomunistycznych) wspólny światopogląd, aksjologia i kod komunikacyjny - jest ona generacją o rosnącym zróżnicowaniu postaw i ocen wartościujących, swoiście zagubioną, refleksyjną, skupioną często wokół własnej egzystencji.

Zauważane procesy zmian i ich względna dynamika - skłoniły autorów książki do podjęcia w 2018 roku zespołowych badań porównawczych, dotyczących tożsamości kulturowej i edukacji młodych uczących się. Objęto nimi łącznie 330 studentów, w tym 164 w Polsce (Cieszyn) i 166 w Republice Czeskiej (Ostrawa). Badana grupa jest reprezentatywna dla studentów kierunku pedagogika, kształcących się w Uniwersytecie Śląskim i Uniwersytecie Ostrawskim.

W rozdziale pierwszym, zatytułowanym Tożsamość kulturowa młodych uczacych się - zasoby indywidualne i wspólnotowe w budowaniu kapitału Pogranicza, nakreślono najważniejsze wyznaczniki formowania (się) tożsamości w okresie wczesnej dorosłości, jak również przedstawiono wyniki badań własnych dotyczących zachowań tożsamościowych przejawianych przez studentów z pogranicza polsko-czeskiego. Ujęto je z perspektywy preferencji aksjologicznych, de- 
klarowanego poczucia tożsamości i identyfikacji narodowych, poczucia związku $\mathrm{z}$ wybranymi grupami społecznymi oraz związku, jaki zachodzi między oceną własnej sytuacji życiowej a poczuciem tożsamości.

Bliskość geograficzna nie zawsze oznacza chęć poznania czy nawet zainteresowanie tym kto/co obok. Potwierdzają to analizy uzyskanych wyników badań zaprezentowane $\mathrm{w}$ rozdziale drugim: Trudna historia - jaka teraźniejszość? Relacje na pograniczu $w$ deklaracjach badanych studentów. Studenci mieszkający na pograniczu, w środowisku zróżnicowanym kulturowo, bardzo często nie potrafią ocenić swoich kompetencji międzykulturowych. Są jednocześnie świadomi zróżnicowania środowiska, w którym funkcjonują. W rozdziale przedstawiliśmy dane dotyczące spostrzegania sąsiadów oraz małżeństw mieszanych narodowościowo. Opisane zostały też przejawy zachowań dyskryminacyjnych obserwowane przez badanych.

W trzecim rozdziale zatytułowanym Drogi do szkoły wyższej $i$ ich wartość zajmujemy się uniwersytetem jako instytucją złożoną z ludzi i prezentujemy wyniki badań dotyczące relacji miedzy studentami a nauczycielami akademickimi, analizą jakości życia młodych dorosłych będących na studiach wyższych oraz warunkami do rozwoju tworzonymi przez uniwersytety. Prezentujemy wyniki badań dotyczące opinii studentów na temat rozwoju wiedzy teoretycznej i umiejętności praktycznych nabywanych przez studentów podczas studiów na uniwersytecie oraz ich wpływu na karierę zawodową. Przedstawiamy również wyniki badań dotyczących istotnej i będącej często przedmiotem dyskusji kwestię jakości kształcenia na uniwersytetach.

Ostatni rozdział Studia i praca studentów za granica oraz ich kierunek studiów $i$ uniwersytet zawiera analizy danych dotyczących postaw studentów z badanych krajów do studiowania i pracy za granicą. Opisane zostały zarówno czynniki motywujące respondentów do wyjazdu za granicę, ale również wskazane bariery i ograniczenia w tym zakresie. Rozpatrywane są opinie studentów dotyczące zagadnienia kwalifikacji zawodowych do zawodu nauczyciela, a także spostrzegania przez badanych atrakcyjności swojego kierunku studiów (również ranking uczelni) i perspektyw zawodowych.

Przedstawione w książce rezultaty badań wzbogacają dotychczasową wiedzę pedagogiczną i mogą posłużyć organizatorom oświaty, w refleksji nad funkcjonowaniem placówek kształcenia młodych dorosłych oraz tworzeniem planów rozwoju tych instytucji w kontekście dostosowania ich do potrzeb społecznych wszystkich uczestników edukacji (z poszanowaniem prawa do zachowania własnej kultury i tożsamości). W wymiarze praktycznym mogą również stanowić istotny punkt odniesienia dla polityków społecznych i oświatowych wielu krajów, poszukujących nowych rozwiązań w zakresie organizacji szkolnictwa wyższego. 


\section{Shrnutí}

Problematice komunit žijících v příhraničních oblastech, zejména u polskočeských hranic, byla již dříve věnována velká pozornost. Mnoho výzkumů o kultuře a vzdělávání v pohraničí realizovaly týmy působící na Fakultě etnologie a pedagogických věd Slezské univerzity v Cieszyně a zaměstnanci Pedagogické fakulty Ostravské univerzity. Jsou to záznamy o důležitých politických, sociálněekonomických a kulturních změnách, které se odehrávali v Polsku a České republice po roce 1989. Mnohostranná transformace, která proběhla za posledních třicet let, také způsobila změny v myšlení o roli a funkci kultury a vzdělávání. Reformy provedené v obou zemích zasahují i do oblasti vysokoškolského vzdělávání, čímž se odrážejí v současném sociálním a kulturním stavu mladé generace a promítají se do jejích cílů, hodnot a životních ambicí.

Současná mladá generace dospělých Poláků a Čechů je nová generace, která se liší od předchozích generací svých vrstevníků. Akademická mládež již není propojena (jako tomu bylo $\mathrm{v}$ poválečných nebo postkomunistických letech) se společným světonázorem, axiologií a komunikačním kódem, ale jde o generaci s rostoucí paletou postojů a hodnocení, často soustředěných kolem své vlastní existence.

Pozorované procesy změn a jejich relativní dynamika, přiměly autory knihy, aby v roce 2018 provedli týmovou srovnávací studii kulturní identity a vzdělávání mladých studentů. Do šetření bylo celkem zahrnuto 330 studentů, z toho $164 \mathrm{v}$ Polsku (Slezská univerzita Cieszyn) a 166 v České republice (Ostravská univerzita).

V první kapitole nazvané Kulturní identita mladých studentů-individuálních a komunitních zdroju prì budováni kapitálu Borderlandu, byly nastíněny nejdůležitější determinanty utváření identity v ranné dospělosti. Výsledky vlastního výzkumu chování a identity studentů z polsko-českého pohraničí byly převzaty z pohledu axiologických preferencí, deklarovaného pocitu identity a národních identifikací, pocitu vztahu s vybranými sociálními skupinami a vztahu mezi hodnocením vlastní životní situace a pocitu identity. 
Zeměpisná blízkost neznamená vždy touhu vědět nebo dokonce zájem o to, co bude dál. Potvrzuje to analýza získaných výsledků výzkumu uvedených $\mathrm{v}$ druhé kapitole: Obtižná historie - jaká je prítomnost? Vztahy na hranici $v$ prohlášeních dotázaných studentů. Studenti žijící v pohraničí, v kulturně rozmanitém prostředí, nemohou často posoudit své interkulturní kompetence. Jsou si rovněž vědomi rozmanitosti prostředí, ve kterém působí. V kapitole prezentujeme údaje o vnímání sousedů a manželství smíšených národností. Popsány byly také projevy diskriminačního chování pozorované respondenty.

Ve třetí kapitole nazvané Cesty $k$ vysokoškolskému vzděláváni a jeho hodnota se zabýváme univerzitou jako institucí složenou z lidí a prezentujeme výsledky výzkumu vztahů mezi studenty a akademickými učiteli, analýzu kvality života mladých dospělých ve vysokoškolském vzdělávání a podmínek rozvoje vytvořených univerzitami. Prezentujeme názory studentů na rozvoj teoretických znalostí a praktických dovedností získaných během jejich studia na univerzitě a dopad na jejich kariéru. Prezentujeme také výsledky výzkumu důležité a často diskutované problématiky kvality vzdělávání na vysokých školách.

Poslední kapitola, Studium a práce vysokoškoláků v zahraniči a jejich obor a univerzita, obsahuje analýzu dat o postojích studentů ze studovaných zemí ke studiu a práci v zahraničí. Byly popsány faktory motivující respondenty k odchodu do zahraničí a v tomto ohledu byly uvedeny bariéry a omezení. Zvažují se názory studentů na problematiku odborné kvalifikace pro učitelskou profesi, na atraktivitu svého studijního oboru a profesní perspektivy.

Výsledky výzkumu, které jsou uvedené v této knize, přispívají k bližšímu poznání pedagogických jevů a takto obohacují současné pedagogické vědění. Závěry mohou využít instituce odpovědné za vzdělávání mladých dospělých a mohou posloužit $\mathrm{k}$ vytvoření plánů rozvoje těchto institucí v souvislosti s jejich přizpůsobením společenským potřebám všech účastníků vzdělávání (při respektování práva na zachování vlastní kultury a identity). Z praktického hlediska mohou být také důležitým referenčním bodem pro sociální a vzdělávací politiky $\mathrm{v}$ mnoha zemích hledající nová řešení v oblasti organizace vysokoškolského vzdělávání. 


\section{Biographical notes}

\section{Ewa Ogrodzka-Mazur}

a full professor in the Institute of Education at the Faculty of Arts and Educational Science in Cieszyn (University of Silesia in Katowice, Poland). Since 2012, the Head of the Department of General Pedagogy and Research Methodology. Her scientific and research interests include: early school pedagogy, multi- and intercultural education, social and educational policy, the quality of academic training in the acquisition of intercultural competence and theories and models of intercultural studies. The author, co-author and scientific co-editor of 76 monographs and over 200 articles, including: $W$ poszukiwaniu teorii przydatnych w badaniach międzykulturowych (2001); Świat wartości i edukacja międzykulturowa (2003); Kompetencja aksjologiczna dzieci w młodszym wieku szkolnym. Studium porównawcze środowisk zróżnicowanych kulturowo (2007); Dziecko $w$ świecie literatury i życiu wspótczesnym (2013); Tożsamość kulturowa, religijność i edukacja religijna postrzegana z perspektywy społeczności szkół z polskim językiem nauczania w wybranych krajach europejskich (2014); Intercultural education - concepts, practice, problems (2015); Sfery życia duchowego dzieci i młodzieży z pogranicza polsko-czeskiego czeskiego. Vol. 1. Przemiany wartości $i$ aspiracji życiowych (2016); Education of children and youth in culturally diverse environments: experiences - problems - prospects (2016); Spheres of spiritual life a study on permanence and changeability of identity behaviours in borderland communities (2018). Since 1989, she has been a member of the Social Team for Research into Borderland Culture and Education, supervised by Professor Tadeusz Lewowicki. A participant in research placements, e. g. to El Camino College (Los Angeles, the USA, 2005), Curtin University (Perth, Australia, 2014, 2016 and 2017), Twente University (Enschede, the Netherlands, 2015), Herzen State Pedagogical University of Russia (St. Petersburg, Russia, 2014 and 2015), Borys Grinchenko Kiev University (Kiev, Ukraine, 2015, 2016 and 2017), Lusiada Lisbon University (Portugal, 2015). A member of: the Team for Pedagogy of Culture and Intercultural Education and the Team of Social Pedagogy at the Committee of 
Pedagogical Sciences of the Polish Academy of Sciences, the Polish-Czech Scientific Society, the Commission for Polish-Czech and Polish-Slovak Relations of the Polish Academy of Sciences (Katowice branch), the Association for Supporting Intercultural Education, the Polish Philosophical Society, the Ukrainian Academy of Acmeology, the National Academy of Educational Sciences of Ukraine. She is also the Editor-in-Chief of the academic journal "Edukacja Międzykulturowa [Intercultural Education]".

ewa.ogrodzka-mazur@us.edu.pl; eom1@wp.eu

ORCID: https://orcid.org/0000-0001-9990-6176

\section{Anna Szafrańska}

Ph.D. hab., assistant professor in the Department of General Pedagogy and Research Methodology of the Faculty of Arts and Educational Science in Cieszyn (University of Silesia in Katowice, Poland). Her scientific and research interests include: early school pedagogy, pedeutology, multi- and intercultural education. The author, co-author and scientific co-editor of 16 monographs and over 120 articles, including: Reforma oświaty a praktyka edukacji wczesnoszkolnej [Educational reforming and early school practice] (2006); Portret zbiorowy nauczycieli aktywnych - między zaangażowaniem a oporem wobec zmian [A group portrait of active teachers - between engagement and resistance to change] (2013); Pedagogická diagnostika $v$ teórii a aplikáciách [Educational diagnostics in the theory and applications] (2013); Edukacja na obczyźnie postrzegana z perspektywy dzieci, nauczycieli i rodziców ze szkół z polskim językiem nauczania [Education abroad viewed from the perspective of children, teachers and parents from schools with Polish as the teaching language] (2014), Education of children and youth in culturally diverse environments: experiences - problems - prospects (2016), Sfery $\dot{z} y$ cia duchowego dzieci, młodzieży $i$ dorosłych - studium z pogranicza polskoczeskiego. O nauczycielach, ich spostrzeganiu świata społecznego i aktywności [Spheres of spiritual life of children and youth - a study from the Polish-Czech borderland] (2017), Selected problems of teachers' functioning in Central and Eastern Europe. A Polish-Czech-Slovak study (2017). A participant in 145 (over 40 foreign) conferences and in 18 research and didactic projects - in 7 as the coordinator. Since 1999, she has been a member of the Social Team for Research into Borderland Culture and Education, supervised by Professor Tadeusz Lewowicki. A participant in research placements, e.g. to Curtin University (Perth, Australia, 2014, 2016 and 2017), Twente University (Enschede, the Netherlands, 2015), Herzen State Pedagogical University of Russia (St. Petersburg, Russia, 2014 and 2015), Borys Grinchenko Kiev University (Kiev, Ukraine, 2015, 2016 and 2017), Lusiada Lisbon University (Portugal, 2016), Extramadura University 
(Badajoz, Spain, 2017). She is also a member of the Team for Pedagogy of Culture and Intercultural Education, the Team for Social Pedagogy, and the Team for School Pedagogy at the Committee of Pedagogical Sciences of the Polish Academy of Sciences; the Polish-Czech Scientific Society; the Association for Supporting Intercultural Education, the Ukrainian Academy of Acmeology. Finally, she is an Assistant Editor of the academic journal "Edukacja Międzykulturowa [Intercultural Education]".

anna.gajdzica@us.edu.pl; annaszafranska@interia.eu

ORCID: https://orcid.org/0000-0001-9797-2591

\section{Josef Malach}

Ph.D., associate professor, the head of the Department of Pedagogy and Adult Education at the Faculty of Education at the University of Ostrava; the author of three scientific monographs and more than 80 scientific articles. His main teaching and research interests include: university and adult education, application of ICT in education, educational assessment and entrepreneurship education. A member of the Czech team and the coordinator of WP 6 in the project IRNet (International Research Network for the study and development of new tools and methods for advanced pedagogical science in the field of ICT instruments, e-learning and intercultural competences) of the 7th Framework Programme, within the Marie Curie Actions International Research Staff Exchange Scheme, Grant Agreement No: PIRSES-GA-2013-612536:2014-2017. The Czech national coordinator of the Visegrad found project High school teacher competence in change, ID 21720008. He is also a member of academic councils of Ph.D. study programmes and a member of scientific boards of several faculties and universities in the Czech Republic, Poland and Slovakia. A coeditor of the academic journal "The New Educational Review", a member of editorial boards of the academic journals "Kwartalnik Pedagogiczny [Pedagogical Quarterly]" and "Edukacja Humanistyczna [Humanities Education]" in Poland and since 1993 - a guarantor of the international conferences Educational diagnostics and evaluation.

josef.malach@osu.cz

ORCID: https://orcid.org/0000-0002-3960-486X 


\section{Milan Chmura}

Ph.D., assistant professor at the Department of Education and Adult Education at the Faculty of Education of the University of Ostrava. His scientific and research interests include: adult education and ICT applications, professional development of the teacher and lecturer, higher education, self-education. He is the author and co-author of several monographs and articles, including: Professional Pedagogical Competences of University Teachers from the Perspective of Students and Academics (2019), International Grant Cooperation as a Tool for Development of Professional Competencies of University Teachers 2016) and others. He has been a participant in research internships, e.g. Curtin University (Perth, Australia, 2016 and 2017), Herzen State Pedagogical University in Russia (St. Petersburg, Russia, 2015 and 2016), Borys Grinchenko University in Kiev (Kiev, Ukraine, 2015, 2016 and 2017). He is also a member of the Expert Board of Jan Amos Comenius University in Prague for adult education, a corresponding member of the Ukrainian Academy of Akmeology, a participant in national and international scientific research projects. He has also participated as a member of the Czech team in the IRNet project (International Research Network for the Study and Development of New Tools and Methods for Advanced Educational Sciences in ICT, e-Learning and Intercultural Competences) of the 7th Framework Program under the Marie Curie Program, Grant Agreement No: PIRSES-GA2013-612536: 2014-2017. Finally, he was a member of the Czech team in the international Visegrad project High school teacher competence in change ID 21720008 (2017-2018).

milan.chmura@osu.cz

ORCID: https://orcid.org/0000-0002-5767-698X 


\section{Index of names}

Alexander 111

Andersen 47

Arnett $41,77,78$

Babiński 14

Báčová 157

Bajtoš 30, 31

Bartosiak 46

Bauman 46, 50

Berry 26

Biggs 30

Bikont 38

Black 52, 124

Blaško 31

Blašková 31

Bobrownicka 37

Bokszański 37, 39

Boski 26, 37, 40, 77

Bothwell 32

Bovill 114

Branje 41

Breen 159

Bruner 28

Brzezińska 41

Bunescu 129, 130

Ciechanowska 30

Cleaver 30

Cole 123

Conger 62

Crisafulli 135

Crosier 131

Czapiński 70

Czerwińska-Jasiewicz 67
Dąbrowska 49

Denzin 34

Dixon 135, 143, 144

Doliński 37

Domingo 128, 129

Donnellan 62

Doseděl 124,159

Dostatni 63

Dyczewski 47

Eckstein 28

Felchner 54

Filek 49

Fischer 136

Fry 30, 31

Gadacz 49

Gaebel 129, 130

Gajdzica 111

Gal 54

Gałdowa 37

Giddens 37

Gilarek 45

Giza-Poleszczuk 16

Gofron 28

Goodenough 25

Goossens 41

Gorčicová 144

Grabowska 50, 60

Graham 134

Grygierek 47, 48

Grzymała-Kazłowska 16

Gwosć 161 


Habermas 37
Halík 63
Halverson 134
Harris 25
Harvey 53
Hauschildt 161
Havelková 144
Heerens 144
Hewstone 27
Hilton 31
Hlaváček 173
Hogg 39
Hrdličková 175
Hřebecký 172
Huberman 34
Cherastidtham 124
Chlebowczyk 14
Chmura 28, $30,31,81,111,130,133,162$
Chodynicka 35
Chojnacka-Synaszko 15
Chum 175

Jakubczak-Krawczyńska 54

Jarymowicz 38, 39

Jawłowska 37

Jurek 47

Kaczorowski 80

Kahu 135

Kanasz 70

Kandiko 134, 142

Kapuściński 79

Kariková 30

Kasíková 30

Katrňák 124, 159

Kawiecka 45

Keller 159

Keményová 132

Kempny 45, 50

Ketteridge 30

Klajmon-Lech 15

Klemenčič 109

Klimstra 41

Kłoskowska 39, 47, 60, 79

Klus-Stańska 28
Kmošek 175

Kniejski 49

Kolb 31

Konarzewski 35

Koppel 136, 144

Kostolánová 28

Koucký 131

Kristová 114, 143

Kucharčíková 31

Kvale 34

Kwadrans 50

Kwiatkowska 37

Kwiek 43

Kyuchukov 15

Laird 53

Laksov 113

Lancaster 53

Langer 54

Larsen-Rife 62

Lau 135

Lévinas 49

Lewowicki $13,15,26,27,50,51,56,58,61$, 81,82

Lincoln 34

Linhart 134

Lintern 30

Lompart 16

López 128, 129

Lunenburg 28

Luszniewicz 35

Luyckx 41

Mądry 67

Machaj 38

Malach 28, 30, 31, 81, 107, 110, 111, 114, $133,143,144$

Malina 62

Mamzer 37

Mareš $123,158,159,171$

Mariański 64

Marody 16

Marshall 28, 30, 31

Mawer 134, 142

Mazan 80

McLinden 30 
Meeus 41

Melosik 37

Mezirow 31

Migasiński 49

Miles 34

Miluska 38, 48

Minksová 134, 137

Moustakas 34

Nikitorowicz $40,44,45,50,74$

Noah 28

Norton 124

Nowak 37

Nowicka 38

O’Neill 113

Ogrodzka-Mazur 15, 16, 25, 28, 30, 31, 37, $50,51,81,111$

Oleś 38,41

Ondrejkovič 134

Pabian 159

Paleczny 46

Panic 14

Parker 123

Pellegrino 31

Perez-Poch 128

Peterson 135, 143, 144

Pietruska-Madej 34

Piotrowski 41, 42, 43

Podlahová 30

Prudký 159

Průcha 123, 171

Prusáková 30

Ratajczak 162

Reber 70

Rembierz 49, 74

Report 28

Robertson 45

Rohlíková 30

Różańska 63

Sajdak 30

Sak 158, 159

Sanz 128
Sárközi 172

Shapiro 28

Shewbridge 125

Siembida 54

Sikorová 30, 110

Şimşek 70

Słaby 35

Slavík 30

Śliwerski 48

Smak 125

Stark 113

Staś-Romanowska 40, 55

Stefani 29

Stephan 27, 28

Stoeber 129, 130

Strelau 37

Strózik 54

Strzeszewski 74

Suchodolska 51, 70

Summan 31

Sundberg 136, 144

Surosz 80

Syska 41

Szafrańska 30, 31, 81

Szafrańska-Gajdzica 28, 50, 51, 111

Szczurek-Boruta 15, 60

Szczygieł 80

Szkołut 46

Szkudlarek 37

Szplit 130

Szymański 46

Šima 159

Tang 30

Teppers 41

Turek 31

Tvrdý 159

Urbański-Korż 76

Valachová 114, 143

Vasta 16

Vašutová 171

Vaughan 39

Vejvodová 30

Veteška 160 
Vltavská 136

Wojnar 39

Vögtle 161

Wolff 31,110

Woolmer 114

Walczak 125

Wroczyńska 142

Walsh 124

Wysocka 26, 44

Walterová 123

Weidnerová 112

Zagórski 74

Welsch 46

Żardecka-Nowak 37

Węziak-Białowolska 19

Zhang 129, 130

Widdowson 135, 143, 144

Ziółkowska 41, 42

Więckowska 35

Witkowski 37, 38

Zitouni 31

Žydžiūnaitè 135 


\section{Index of subjects}

academic community $62,63,116,121,127$

academic staff $31,108,110,128,129,131$

activities of universities 108, 109

approaches and methods used by

teachers 149

axiological preferences 51

borderland capital 221

broadening the range of sociocultural integration with 48

building the feeling of multidimensional cultural and intercultural identity 48

central strategy of human resources 131 collaborative learning 136

competency-based 113

consolidation of identity 42

constructing the global identity 46

cultural identity $37,44,51,58,77,78$

dilemmas of constructing individual cultural identity 44

discrimination $32,86,88,89,103$

dispersed (multicultural) identity 45

economic status $67,68,125,127$

educational function of higher educational 110

educational inflation 159

emerging adulthood 41

ethical codes 136

ethnic group 59, 62

ethnocentric (inherited) identity 44
EURES 161

family environment $52,61,69,77$

feeling of association with selected social groups 32, 61, 64

feeling of identity $15,32,44,47,50,55,70$, 74,75

globalization and multiculturalism 45

higher education $10,14,107,114,123,124$, 128

identity behaviours $23,26,32,50,60$

ideological context 27

individual identity 37,46

integrated (intercultural) identity 45

intercultural communication and dia-

logue 48

intercultural competences $32,80,81$

internationalisation $31,109,110,162$

intolerant 88,89

knowledge of the neighbour 90, 92, 95, 97

learning young adults 25

level of education 158,159

mass character of higher education 157

mixed marriages $98,100,105$

model of identity 39

motivation to education 159

move abroad to study 162 
national group 62,63

national identifications $32,55,56,60,77$, 196

outgoing and incoming students 163

own life situation $32,70,222$

people at university 128

position in society 158

position in labour market 15

practical skills 94

practical skills students 117

professional competences 31, 171, 172

professional teacher qualities 171

promoting the paradigms of "educating for

development" and "coexistence" 49

quality of a student's life 139

quality of education 147,148

quality of teachers 143

relationship of academic staff towards students 137

religious group 62,63

sensitization to the Other and noticing the dissimilarity of people from other cultures 48 social identity $15,38,39,50,60$

social prestige $125,158,159$

social status $68,125,159,172,193$

structure of values 51

students during their studies 134

students' willingness to study abroad 166

study environment created by the univer-

sity $145,147,154$

symbolic interactionism 39

teaching workforce 125

tertiary education $29,109,123,124,125$, 127

theoretical knowledge students 116,122

theory and practice for a future career 111

university students studying abroad 164

university students studying and working abroad 163

university students working abroad 165

value and importance of education 158

value of higher education 111,123

virtual (culturally disoriented) identity 45

working abroad $10,33,119,121,139,141$

workplace-relevant skills 161 